ROMANIAN ACADEMY

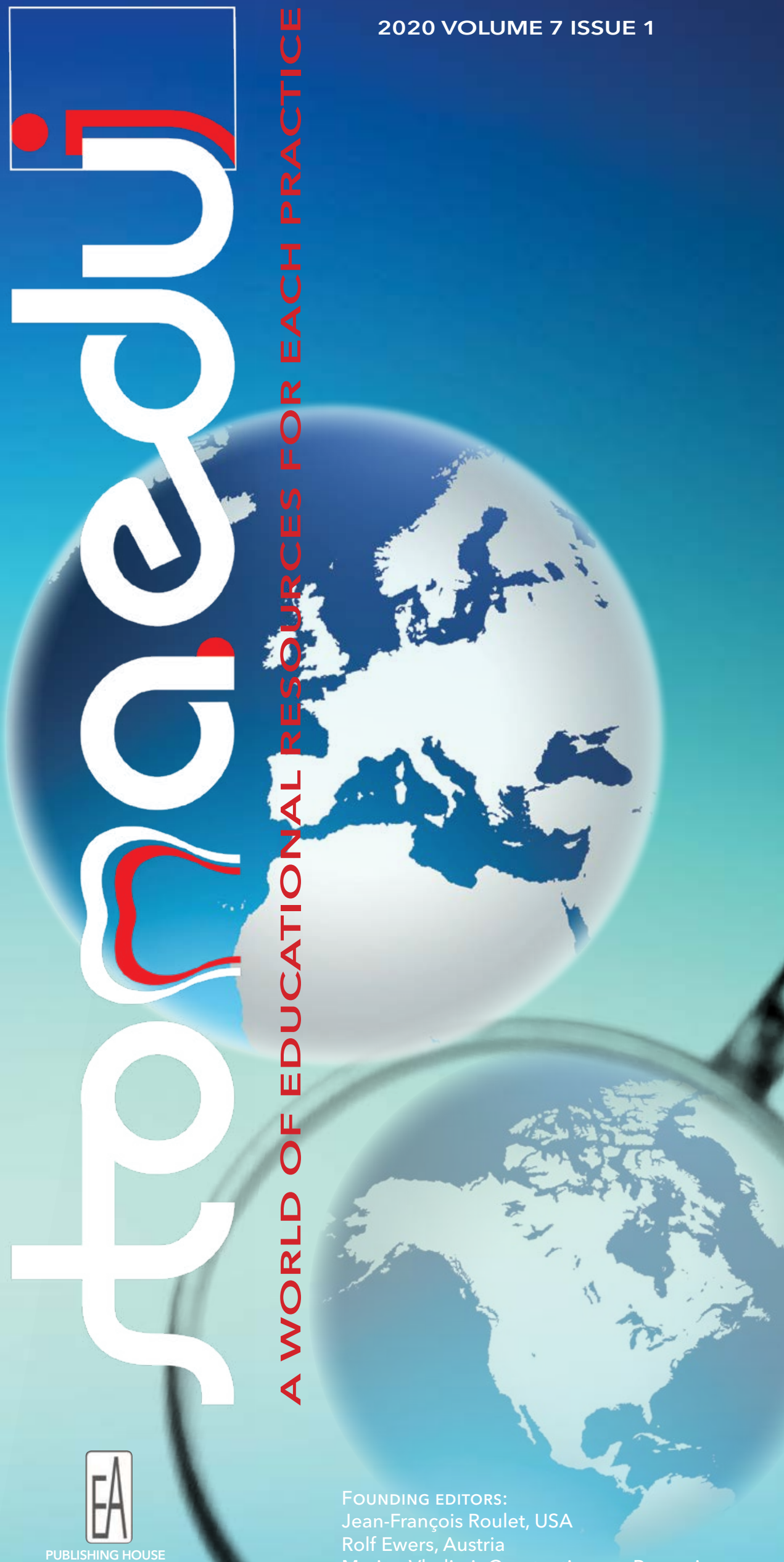

Marian-Vladimir Constantinescu, Romania

2020 VOLUME 7 ISSUE 1

\title{
STOMATOLOGY EDU JOURNAL
}

since 2014 


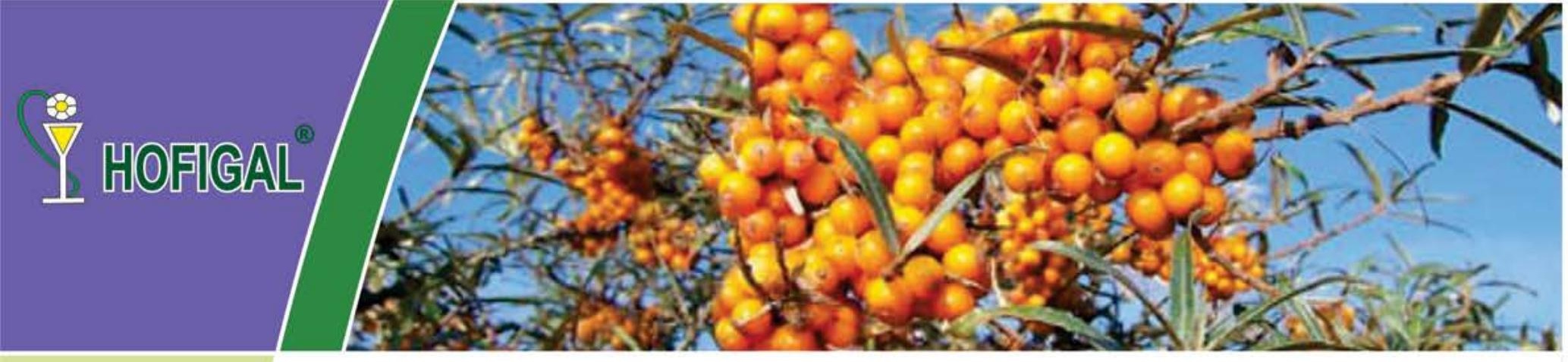

\section{Hofident $Q_{10}$}

Product presentation: Solution for oral hygiene.

Composition (INCI): aqua/water, alcohol, Capsella Bursa Pastoris extract, Plantago Lanceolata extract, Chamomilla Recutita extract, Achillea Millefolium extract, Aesculus Hippocastanum extract, Mentha Piperita extract, Ubiquinone.

Action: The product has antiseptic, healing, hemostatic, anti-inflammatory aєtion, it acts as a antioxidant, detoxifier, deodorant. It is strongly recommended in gingivitis, stomatitis, thrush, compression pain causedby dental prostheses, after tooth extraction, in case of nipple lesion, bleeding gums, mouth and gum ulcers.

Recommendations: It delays dental plaque formation, it prevents bad odour and provides daily mouth hygiene.

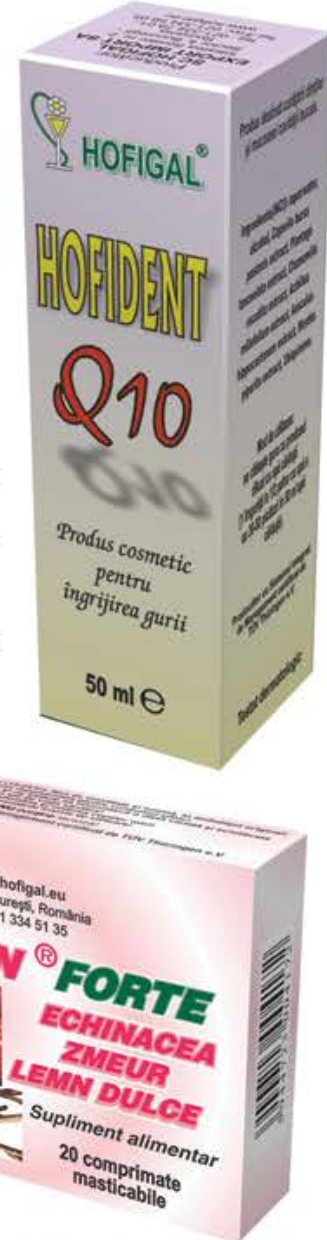

\section{Hoflmun ${ }^{\oplus}$ FORTE}

Product presentation:

Chewable tablets to stimulate the immune system

Composition: Each chewable tablet contains raspberry fruit extract (Rubii idaei fructus), Echinacea extract (Echinacea purpurea), concentrated extract of licorice root (Glycyrrhiza radix), magnesium ascorbate and excipients.

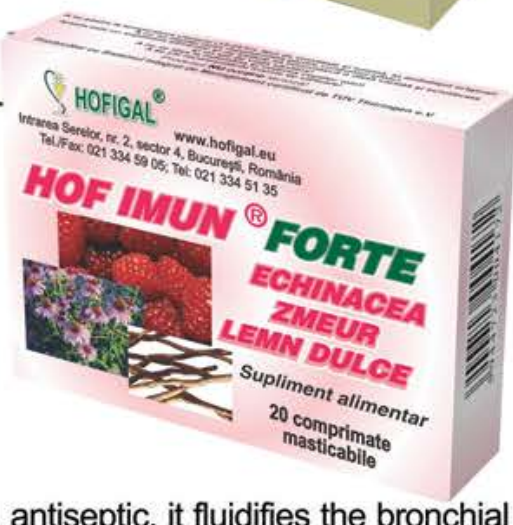

Action:It stimulates the immune system, it is antiinflammatory, antiviral, antiseptic, it fluidifies the bronchial and pharyngeal secretions, antioxidant, cardioprotective, vasoprotective, it has antineoplastic antileukimic action, (due to the ellagic acid), it contributes to wound healing, fortifies and remineralizes (it regulates the potassium balance), it has antiulcer effects and is an overall body tonic.

Recommendations: to supplement the diet with nutrients and bioactive substances in: acute and chronic infections of the upper airways (angina, pharyngitis, laryngitis, bronchitis), prophylactic during periods with increased risk of infection with influenza viruses, it has sweating effects in fever, in recurrent herpes episodes of mucocutaneous rash, frequent urinary tract infections, inflammatory urogenital processes; immunodepression after radiotherapy or chemotherapy, bacterial skin infections, psoriasis, neurodermitis, chronic cardiovascular diseases associated with hypercholesterolemia, adjuvant in the diet indicated in the treatment of gastroduodenal ulcers, tonic during periods of physical and mental strain, exhaustion.

\section{Bucoprotect gel}

\section{Product presentation: Gel for oral hygiene.}

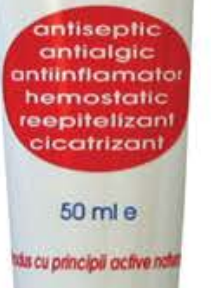

Composition (INCI): aqua, capsella bursa pastoris, calendula officinalis, achillea milefolium, hippophae rhamnoides, olea europea, hypericum perforatum, carbomer triethanolamine, collagen, foeniculum vulgare, mentha piperita, citrus amara.

Action: Antiseptic, anti-inflammatory, healing, stimulates the inside lining of the mouth and gums trophicity, reduces pain caused by specific oral diseases (gingivitis, stomatitis, lesions of the prosthesis, thrush, periodontitis). 


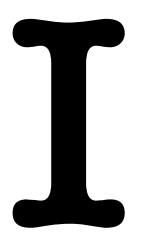

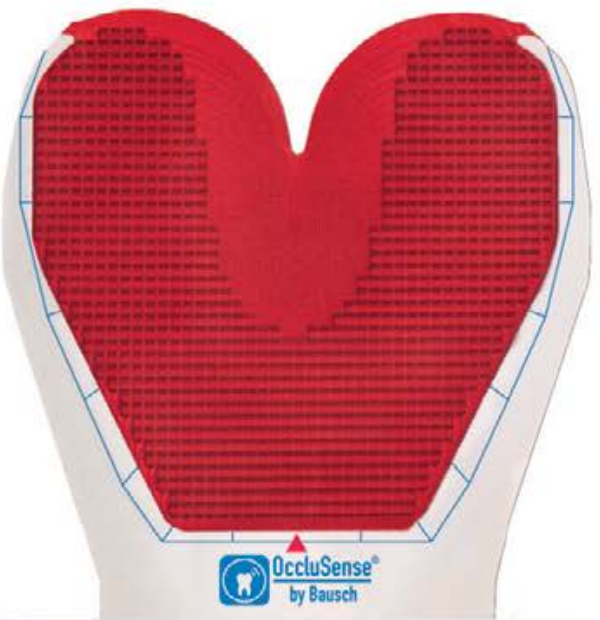

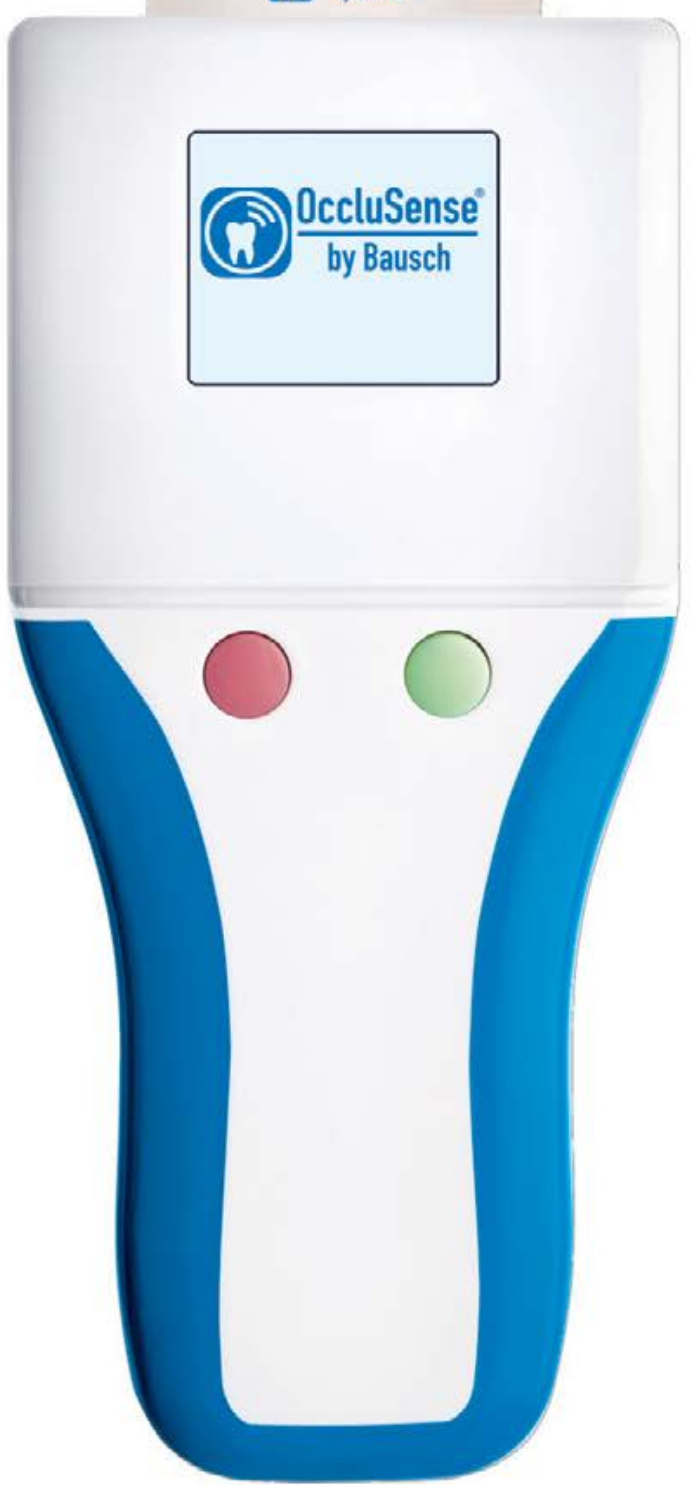

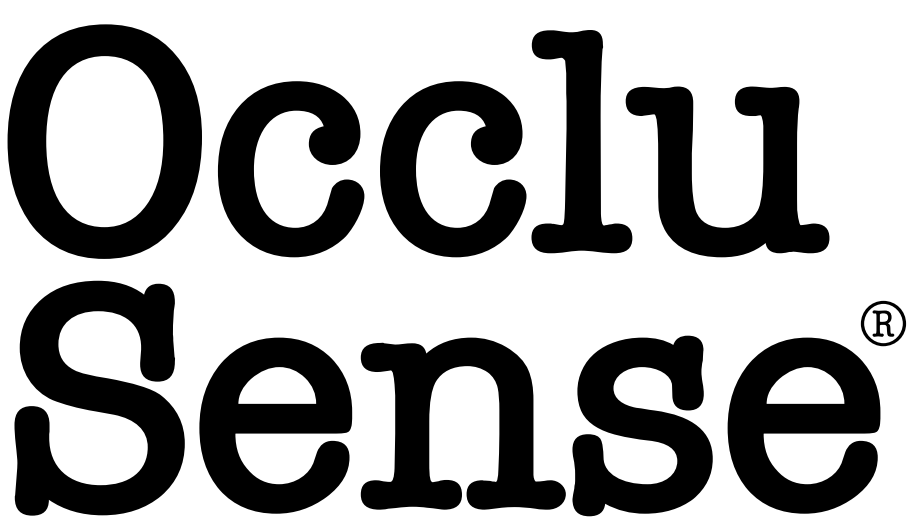

\section{Innovative device for digital occlusion control.}

Take advantage of the award-winning OccluSense ${ }^{\circledR}$ system:

- 60 microns thin, flexible pressure sensors record both static and dynamic occlusion

- Data transfer to OccluSense ${ }^{\circledR}$-iPad-App via wireless network

- Ergonomic design for intuitive handling

- Additionally, red colour coating marks the occlusal contacts on the patient's teeth

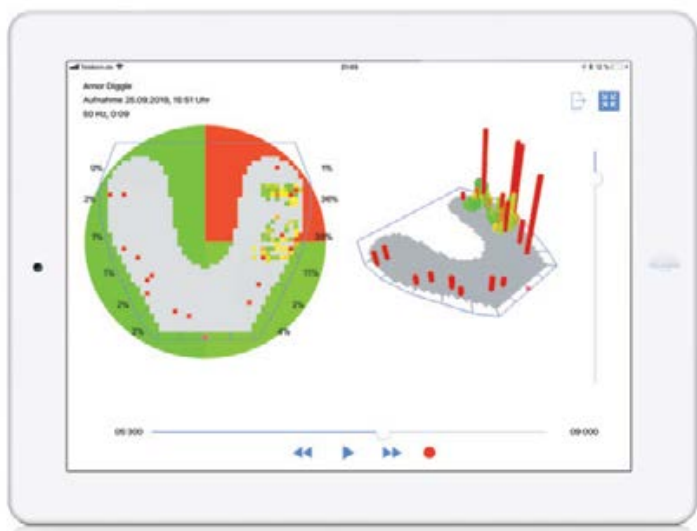

\section{(W) $\frac{\text { OccluSense }}{\text { by Bausch }}$}

WE MAKE OCCLUSION VISIBLE ${ }^{\circledR}$

Dr. Jean Bausch GmbH \& Co. KG | Oskar-Schindler-Str. 4 | 50769 Köln | Germany
More information: www.occlusense.com and YouTube 


\section{EDITORIAL}

01 The cost of publishing in today's scientific e-world

Constantinus Politis

\section{WHO:COVID-19 ADVICE}

03 Basic protective measures against the new coronavirus

\section{CONTINUING EDUCATION ONLINE}

\section{JADA CE Online}

\section{ORIGINAL ARTICLES}

COMMUNITY DENTISTRY: Effectiveness of school-based fluoride mouth

07 rinsing program in schoolchildren from Kandy District, Sri Lanka

Chandra Herath, Tharanga Nandasena, Kaung Myat Thwin, Anushka Abeysundara, Sampath Ratnayake, Hiroshi Ogawa, Hideo Miyazaki, Takeyasu Maeda

PREVENTIVE DENTISTRY: Arrest of early carious lesions after professional

15 application of different fluoride agents

1 Graciela Liliana Klemonskis, Celina Cornejo, Mariana Toral, Pablo Andrés Salgado, Aldo Fabián Squassi

\begin{tabular}{|c|c|c|}
\hline Visits & $\begin{array}{c}\mathbf{F M R ,} \mathbf{n = 1 9 8} \\
\mathbf{n}(\%)\end{array}$ & $\begin{array}{c}\text { Control, } \mathbf{n = 2 1 7} \\
\mathbf{n}(\%)\end{array}$ \\
\hline Baseline & $178(89.9)$ & $205(94.5)$ \\
\hline 1 $^{\text {th visit }}$ & $165(83.3)$ & $194(89.4)$ \\
\hline $\mathbf{2}^{\text {nd }}$ visit & $149(75.3)$ & $143(65.9)$ \\
\hline $3^{\text {rd }}$ visit & $154(77.8)$ & $137(63.1)$ \\
\hline
\end{tabular}

DENTAL RADIOLOGY:Volume, asymmetry and reciprocal relationships

20 between paranasal sinuses: a 3D segmentation study on head CT-scans

Giulia Andrea Guidugli, Daniele Gibelli, Michaela Cellina,

Antonio Giancarlo Oliva, Luisa Barni, Patrizia Sartori, Chiarella Sforza

OCCLUSION ANDTMJ: Analysis of stress generated in the enamel

28 of an upper first premolar: a finite element study

Andreea Stănuşi, Veronica Mercut, Monica Scrieciu, Luminița Dăguci, Sanda Mihaela Popescu, Monica Mihaela lacov Crăițoiu, Ştefan Castravete, Marina Olimpia Amărăscu

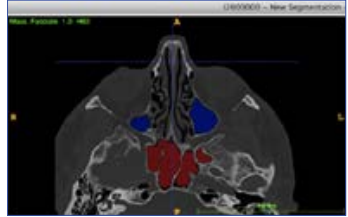

ORAL IMPLANTOLOGY: Immediate/early radiological findings following

35 transcrestal sinus augmentation using a minimally invasive implant device Liat Chaushu, Hadar Better, Joseph Nissan, Samuel Porphirio Xavier, Adi Lorean, Gavriel Chaushu
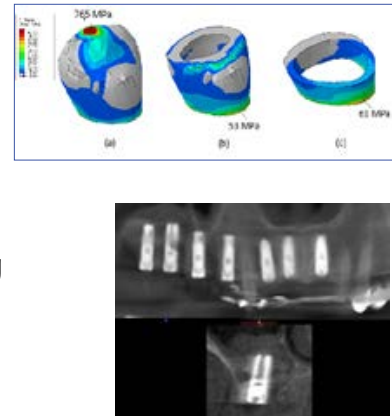


\section{REVIEW ARTICLES}

4.4 ANESTHESIOLOGY: Unclarities about articaine: efficacy and the risk of paresthesia

Nicolas de Ridder, Constantinus Politis

ORTHODONTICS: Stability of skeletal class III malocclusion after 52 and meta-analysis

Abdolreza Jamilian, Ludovica Nucci, Ali Fateh, Mitra Toliat, Alireza Darnahal, Madi Alassadi, Chin Wei Wang

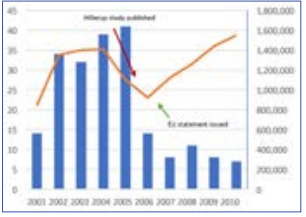

\section{PRODUCT NEWS}

The gold standard for detecting buried dental implants -

69 RomiPointer ${ }^{\mathrm{TM}}$ Implant Detector of Romidan Ltd., Israel Florin - Eugen Constantinescu

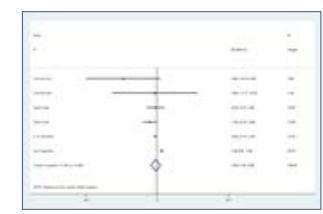

\section{BOOK REVIEWS}

Treating the Complete Denture Patient
Carl F. Driscoll, William Glen Golden

72 Digital Restorative Dentistry

72 A Guide to Materials, Equipment, and Clinical Procedures Faleh Tamimi, Hiroshi Hirayama

73 Clinical Cases in Pediatric Dentistry Amr M. Moursi, Amy L. Truesdale

74 Dental Digital Photography

From Dental Clinical Photography to Digital Smile Design Feng Liu

Practical Procedures in

75 the Management of Tooth Wear

Subir Banerji, Shamir B. Mehta, Niek Opdam, Bas Loomans

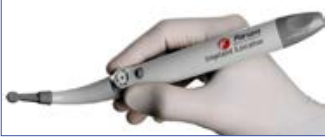

76 Implants in the Aesthetic Zone

76 A Guide for Treatment of the Partially Edentulous Patient Todd R. Schoenbaum
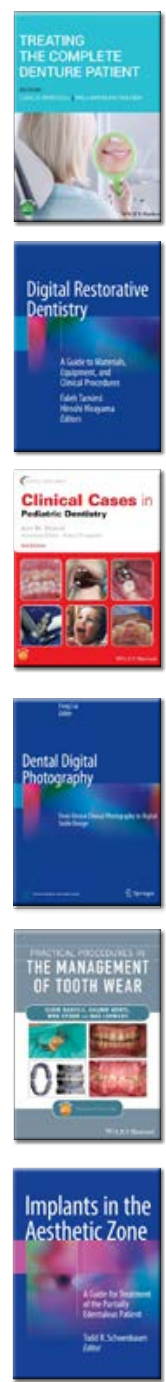

\section{INSTRUCTIONS FOR AUTHORS}

78 Instructions for authors 
Gabriel Octavian Lazăr

"Carol Davila" University of Medicine and Pharmacy, Bucharest, Romania

Phys, PhD, Professor

Gavriel Chaushu

DMD, MSc, Professor, Head

Rabin Medical Center, Beilinson Campus, Petah Tikva, Israel

Nicoleta llie Hom-Lay Wang

Professor

University of Michigan, Ann Arbor, MI, USA Dipl-Eng, PhD, Professor, Department of Operative Dentistry and Periodontology, Faculty
of Medicine, Ludwig-Maximilians-University of Munich, LMU, Munich, Germany

Letizia Perillo
MS, PhD Professor

Mauro Marincola

MD, DDS, Clinical Professor

8. State University of Cartagena, Cartagena, Colombia

MD, MS, PhD, Professor

George E. Romanos

Stony Brook University, Stony Brook, NY USA

Head, Dean, University of Campania Luigi Vanvitelli, Naples, Italy
Hande Şar Sancakli

DDS, PhD, Associate Professo

FDI Regional CE Director Europe, Geneva-Cointrin, Switzerland
Senior Editors

Lakshman Perera Samaranayake

Hon DSC, FDSRCS (Edin), FDS RCPS (Glas), FRACDS, FRCPath (UK), BDS, DDS (Glas)

FHKCPath, FCDSHK, FHKAM (Pathology), FHKAM (Dental Surgery), Professor

University of Sharjah, Sharjah, United Arab Emirates

Hiroshi Ogawa

DDS, MDSC, PhD, Associate Professor

Niigata University, Niigata, Japan

\section{Mahesh Verma}

BDS, MDS, MBA, FAMS, FDSRCS (England), FDSRCPSG (Glasgow), FDSRCS (Edinburgh)

$\mathrm{PhD}(\mathrm{HC})$, Professor

Maulana Azad Institute of Dental Sciences, New Delhi, India

Yongsheng Zhou

DDS, PhD, Professor and Chair, Associate Dean

Department of Prosthodontics, School of Stomatology (PKUSS), Peking University

12 Beiiing, P.R.China

Emeritus Editors-in-Chief

\section{Peter E. Dawson}

DDS, Founder Emeritus of The Dawson Academy

Saint Petersburg, FL, USA

Adi A. Garfunkel

DMD, PhD, Professor Emeritus

8. Hadassah Hebrew University, Jerusalem, Israel

Robert Louis Ibsen

DDS, OD, FAGD, FACD, FICD

Founder \& President DenMat Corporation, Santa Maria, CA, USA

Senior

Bruce Robert Donof Medicine Harvard University, Boston, MA, USA

Rolf Ewers

MD, DMD, PhD Professor and Chairman em. Medical University of Vienna, Vienna, Austria

Adrian Podoleanu

Eng, PhD, Professor, FInstP, FOSA, FSPIE, Professor University of Kent, Canterbury, Kent, UK

Kasturi Warnakulasuriya $\operatorname{MDSC}$ (Melb), PhD (Bristol), FDSRCS (Eng) FRACDS, FRCPath (UK), FFOP(RCPA), FICD FILT FMedSci, Professor King's College London, London, UK

Prathip Phantumvanit

DDS, MS, FRCDT, Professor Thammasat University, Bangkok, Thailand

Rudolf Slavicek

Medical University of Vienna, Vienna, Austria

Jacques Vanobbergen

MDS, PhD, Professor Em. Professor and Chairman Gent University, Gent, Belgium

Julian B. WOELFEL

DDS, Dr Odont, Professor

Aarhus University, Aarhus, Denmark

DDS, FACD, FICD, Professor Emeritus

College of Dentistry, The Ohio State University, Columbus, Ohio, U.S.A
David Wray

\section{Alexandre Mersel}

DDS, PhD, Professor, Director of Studies

Geneva Institute of Medical Dentistry (GIMD), Versoix, Switzerland

David Wray

MD (Honours), BDS, MB ChB, FDS, RCPS (Glasgow), FDS RCS (Edinburgh) F Med SC Professor Emeritus, Professor, University of Glasgow, Glasgow, UK

\section{Associate Editors-in-Chief}

Vasile Iulian Antoniac, Eng, PhD, Professor, Habi Vice Dean, University "Politehnica” of Bucharest

Bucharest, Romania

Akira Aoki, DDS, PhD, Professor, Section of Periodontology,

Department of Hard Tissue Engineering, Graduate School of

Medical and Dental Sciences, Tokyo Medical and Dental University

(TMDU), Tokyo, Japan

Noemí Bordoni, DDS, PhD, Director

Public Health Research Institute, University of Buenos Aires Buenos Aires, Argentina

Radu Septimiu Câmpian, DMD, MD, Professo

Dean, "luliu Hațieganu" University of Medicine and Pharmacy

Cluj-Napoca, Cluj-Napoca, Romania

Sergiu Ciobanu, DDS, PhD, Professor, Dean

"Nicolae Testemițanu" State Medical and Pharmaceutical

University Chişinău, Chişinău, Moldova

François Duret, DDS, DSO, PhD, MS, MD, PhD, Professor

Acad (ANCD) University of Montpellier, Montpellier, France

Michael Frank, DDS, PhD

ERO President, President Dental Chamber Hesse

Frankfurt am Main, Germany

The Stomatology Edu Journal (Stoma Edu J)

is a scientific magazine of the Romanian Association of Oral

Rehabilitation and Posturotherapy - ROPOSTURO, a partner of the FDI

regular member, the Romanian Society of Stomatology - RSS (founded

in 1923) under the aegis of The Romanian Academy.

Editor Office

Stomatology Edu Journal, 102-104 Mihai Eminescu st., ${ }^{\text {nd }}$ District,

R0-020082 Bucharest, ROMANIA, Tel/Fax: + 40314327930,

e-mail: stomatology.edu@gmail.com,www.stomaeduj.com

Editors-in-Chief

Marco Ferrari, Constantinus Politis,

Marian-Vladimir Constantinescu

Managing Editor

Luigi M Gallo, PhD, Dr Eng, MEng

Professor and Chairman, University of Zürich

Zürich, Switzerland

Klaus Gotfredsen, DDS, PhD, Dr Odont

University of Copenhagen, Copenhagen, Denmark

Maria Greabu, MD, PhD

"Carol Davila" University of Medicine and Pharmacy Bucharest Bucharest, Romania

Peter Hermann, DMD, MSC, PhD, Professor and Head

Vice-Rector, Semmelweis University Budapest

Budapest, Hungary

Ecaterina Ionescu, DDS, PhD, Professor, Vice-Rector

"Carol Davila" University of Medicine and Pharmacy Bucharest

Bucharest, Romania

Amid I Ismail, BDS, MPH, MBA, Dr Ph, Dean

Amid I Ismail, BDS, MPH, MBA, Dr Ph, D
Temple University, Philadelphia, PA, USA

Vjekoslav Jerolimov, DDS, PhD, Acad (CASA)
Vjol

Vjekoslav Jerolimov, DDS, PhD,
University of Zagreb, Zagreb, Croatia

University of Zagreb, Zagreb, Croatia
Veronica Mercut, DMD, PhD, Professor, Dean

Veronica Mercut, DMD, PhD, Professor, Dean
University of Medicine and Pharmacy Craiova, Dolj, Romania
Georg B. Meyer, DMD, PhD, Drhc, Professor and Chairman Ernst-Moritz-Arndt University, Greifswald, Germany

\section{ROPOSTURO}

Romanian Association of Oral Rehabilitation and Posturotherapy

10, Ionel Perlea St., $1{ }^{5}$ District, RO-010209 Bucharest, Romania

Tel: +4021 314 1062, Fax: +4021312 1357

e-mail: roposturo@gmail.com; www.roposturo.ro

Technical Editors

Gabriel Octavian Lazar, Edgar Moraru

Project Editor

Irina-Adriana Beuran

Design Editor

Dragoș Georgian Guțoi

Cover by

Arch. Florin Adamescu
Takahiro Ono, DDS, PhD, Chief Professor

Takahiro Ono, DDS, PhD, Chief P
Niigata University, Niigata, Japan

Niigata University, Niigata, Japan
Poul Erik Petersen, DDS, Dr Odont, BA, MSc, Professor

Poul Erik Petersen, DDS, Dr Odont, BA, MSc, Prof
WHO Senior Consultant, University of Copenhagen

Copenhagen,Denmark

Mariano Alonso Sanz, DDS, MSD, PhD, Professor

Complutense University of Madrid, Madrid, Spain

Gottfried Schmalz, DDS, PhD, Drhc, Professor

Acad (Leopoldina), University of Regensburg

Regensburg, Germany

Anton Sculean, DMD, Drhc, MS, Professor

University of Bern, Bern, Switzerland

Igor Alexandrovici Shugailov, MD, PhD, Professor

Vice-Rector, "A.I. Evdokimov" Moscow State University of Medicine and Stomatology, Moscow, Russia

Adam Stabholz, DDS, PhD, Professor, Head

The Hebrew University-Hadassah, Jerusalem, Israel

Zrinka Tarle, DMD, PhD, Professor, Dean

University of Zagreb, Zagreb, Croatia

Douglas A. Terry, DDS, PhD, Clinical Assistant Professor

University of Texas, Houston, IX, USA

\section{Publisher Office}

Romanian Academy Publishing House

Calea 13 Septembrie, $5^{\text {th }}$ District

R0-050711 Bucharest, Romania
Tel: +40213188146, Fax: +40213182444

e-mail: edacad@ear.ro, www.ear.ro

Technical Editor

Doina Argeșanu

Editorial Assistant

Monica Stanciu

Computer Editing

Florin-Eugen Constantinescu 


\section{Associate Editors}

Rafael Benoliel, DDS, PhD, BDS, Professor, Associate Dean The State University of New Jersey Newark, NJ, USA Dana Cristina Bodnar, DDS, PhD, Professor "Carol Davila" University of Medicine and Pharmacy Bucharest, Bucharest, Romania

Romeo Călărașu, MD, PhD, Professor, Acad (ASM) "Carol Davila" University of Medicine and Pharmacy Bucharest, Bucharest, Romania

Asja Čelebić, DDS, MSC, PhD, Professor

University of Zagreb, Zagreb, Croatia

Daniele Maria Gibell

$\mathrm{MD}$, PhD, Assistant Professor, University of Milan

Milan, Italy

Lola Giusti, DDS, CERT, Associate Professor

University of the Pacific, San Francisco, CA, USA

Galip Gürel, DDS, MSC

Dentis Dental Clinic, Istanbul, Turkiye

Fawad Javed, BDS, PhD

University of Rochester, NY, USA

Joannis Katsoulis, DMD, PhD, MAS, Professor

University of Bern, Bern, Switzerland

Anastassia E Kossioni, DDS, PhD, Associate Professor

University of Athens, Athens, Greece

Luca Levrini, DDS, PhD, Professor

University of Insubria, Varese, Italy

Giorgio Lombardo, MD, DDS, Professor

University of Verona, Verona, Italy

Armelle Maniere-Ezvan, DDS, PhD, Professor

Nice Sophia-Antipolis University, Nice, France

Domenico Massironi, DDS, PhD

MSC Massironi Study Club, Melegnano (MI), Italy

Noshir R. Mehta, DMD, MDS, MS, Professor, Assoc. Dean

Tufts University, Boston, MA, USA

Marian Neguț, MD, PhD, Professor, Acad (ASM)

"Carol Davila"University of Medicine and Pharmacy

Bucharest, Bucharest, Romania

Jean-Daniel Orthlieb, DDS, PhD, Professor, Vice-Dean

Aix Marseille University, Marseille, France

Letizia Perillo, MD, MS, PhD, Professor, Head, Dean

University of Campania Luigi Vanvitelli, Naples, Italy

Paula Perlea, DDS, PhD, Professor, Dean

"Carol Davila"University of Medicine and Pharmacy

Bucharest, Bucharest, Romania

Chiarella Sforza, MD, PhD, Professor

University of Milan, Milan, Italy

mucler, MD, PhD, Professor,

Charles University Prague, Prague, Czech Republic

Roberto Carlo Spreafico, DM, DMD

Busto-Arsizio (MI), Italy

Jon B Suzuki, DDS, PhD, MBA, Professor, Associate Dean

Temple University, Philadelphia, PA, USA

\section{Editors}

Sorin Andrian, DDS, PhD, Professor and Chairman

"Gr. T. Popa" University of Medicine and Pharmacy laşi lași, Romania

Vasile Astărăstoae, MD, PhD, Professor

"Gr. T. Popa" University of Medicine and Pharmacy lași

lași, Romania

Gabriela Băncescu, MD, PhD, Professor

"Carol Davila"University of Medicine and Pharmacy Bucharest Bucharest, Romanis

Alexandru Dumitru Brezoescu, DDS, Chairma

Dentists' College, Bucharest, Bucharest, Romania

Octavian Buda, MD, PhD, Professor

"Carol Davila" University of Medicine and Pharmacy Bucharest

Bucharest, Romania

Arnaldo Castellucci, DDS, PhD

Florence, Italy

Ingrìda Čēma, DDS, PhD, Professor

Riga Stradins University, Riga, Latvia

Rayleigh Ping-Ying Chiang, MD, MMS

Taipei Veterans General Hospital, Taipei, Taiwan

loan Dănilă, DDS, PhD, Professor

"Gr. T. Popa"University of Medicine and Pharmacy lași

Yuri, Dekhtyar, Eng, Dr phys, Professor

Yuri Dekhtyar, Eng, Dr phys, Profess

Riga Technical University, Riga, Latvia
Valeriu Fala, DDS, PhD, MSc, Associate Professor

"Nicolae Testemițanu" State University of Medicine and Pharmacy

"Chişinău, Chişinău, Republic of Moldov

Daniela Aparecida Godoi Gonçalves, DDS, PhD, Professor

UNESP - Univ Est Paulista, Araraquara, Brazil

Martin D Gross, BDS, LDS, MSc, Associate Clinical Professor

Tel Aviv University, Tel Aviv, Israel

Emilian Hutu, DDS, PhD, Professor

"Carol Davila" University of Medicine and Pharmacy Bucharest Bucharest, Romania

Andrei Cristian lonescu, DDS, PhD

University of Milan, Milan, Italy

Abdolreza Jamilian, DDS, PhD, Professor

Islamic Azad University, Tehran, Iran

Joanna Kempler DDS, PhD, Associate Professor

University of Maryland, Baltimore, MD, USA

Amar Hassan Khamis, PhD, DEA, MSC, BSc, Professor

Mohammed Bin Rashid University of Medicine and Health

Sciences (MBRU), Dubai, UAE

Henriette Lerner, DDS, PhD

Baden-Baden, Germany

Paulo Ribeiro de Melo, DDS, PhD, Professor

University of Porto, Porto, Portugal
Annalisa Monaco, DDS, MSc, Associate Professor

University of L'Aquila, L'Aquila, Italy

lina Mussurlieva, DDS, PhD, Professor

Medical University of Plovdiv, Plovdiv, Bulgaria

Radmila R. Obradović, DDS, PhD, Associate Professor

University of Nišs, Niš, Serbia

Sever Toma Popa, DDS, PhD, Professor

"Iuliu Hațieganu" University of Medicine and Pharmacy Cluj-Napoca Cluj-Napoca, Romania

Mihaela Răescu, DDS, PhD, Professor

"Titu Maiorescu" University, Bucharest, Romania

Iulia Romanova, DMS, PhD, Professor

Odessa National Medical University "ONMedU", Odessa, Ukraine

Mare Saag, DDS, PhD, Professor

University of Tartu, Tartu, Estonia

Fabio Savastano, MD, MOrth, Professor

University Jaume I Castellon, Castellon, Spain

Luc De Visschere, DDS, PhD, Professor

Gent University, Gent, Belgium

Constantin Marian Vârlan, DDS, PhD, Professor

"Carol Davila" University of Medicine and Pharmacy Bucharest

Bucharest, Romania

Irina Nicoleta Zetu, DDS, PhD, Professor

"Gr. T. Popa" University of Medicine and Pharmacy lași, lași, Romania

\section{Editorial Advisory Board}

\section{Marcus Oliver Ahlers, DDS, PD}

Department of Operative Dentistry and Preventive Dentistry

University Medical Center Hamburg-Eppendorf,

Hamburg University Eppendorf, Hamburg, Germany

Cristina Maria Borțun, DDS, PhD, Professor and Head

Prosthetic Dentistry Technology Department

Faculty of Dental Medicine, "Victor Babeș" University of Medicine

and Pharmacy Timișoara, Timișoara, Romania

Bogdan Calenic, DDS, PhD, Associate Professor

Biochemistry Department, Faculty of Dental Medicine

"Carol Davila" University of Medicine and Pharmacy Bucharest

Bucharest, Romania

Nardi Casap-Caspi, DMD, MD, Professor and Head

Oral and Maxillofacial Surgery Department

Hadassah School of Dental Medicine

Hebrew University Hadassah Jerusalem, Jerusalem, Israel

Paulo G. Coelho, DDS, PhD, Professor

Hansjorg Wyss Department of Plastic Surgery

NYU Langone Health, NYU School of Medicine, New York University New York NY, USA

Daniel Edelhoff, CDT, DMD, PhD, Professor and Head

Department of Prosthodontics, Faculty of Medicine

Ludwig-Maximilians - München University, München, Germany

Claudia Maria de Felicio, MD, PhD, Professor

Orofacial Motricity Unit, Department of Ophthalmology and

Otolaryngology, School of Medicine, Universidade de São Paulo

(USP) Ribeirão Preto, Brazil

Dorjan Hysi, DMD, MsC, PhD, Associate Professor, Chair

Conservative Dental Department, Faculty of Dental Medicine Tirana

University of Medicine Tirana, Tirana, Albania

DDS, MD, PhD, Associate Professor

Oral and Maxillofacial Surgery Department, Faculty of Medicin

Ludwig-Maximilians- München University, München, Germany

Rodica Luca, DDS, PhD, Professor

Pedodontics Department, Faculty of Dental Medicine

"Carol Davila" University of Medicine and Pharmacy Bucharest

Bucharest, Romania

Mariam Margvelashvili-Malament, DDS, MSC, PhD, Professor Department of Prosthodontics and Operative Dentistry, School of Dental Medicine, Tufts University, Boston, MA, USA

Domenico Massironi, DDS

Demenico Massironi, DDS

MEG - Master Educational Group, Melegnano (MI), Italy

Physiology and Biophysics Department, Institute of Biomedical

Sciences, Faculty of Medicine, University of Chile, Santiago, Chile

Mutlu Özcan, DDS, PhD, Professor, Hea

Dental Biomaterials Unit, Clinic of Fixed and Removable

Prosthodontics and Dental Material Science, Center of Dental

Medicine (ZZM), University of Zürich, Zürich, Switzerland

Mariana Păcurar, DDS, PhD, Professor and Head,

Orthodontics and DentoFacial Orthopedics Department, Faculty of

Dental Medicine, University of Medicine and Pharmacy Târgu Mures

Târgu Mureș, Romania

Alexandru Eugen Petre, DDS, PhD, Professor

Department of Fixed Prosthodontics and Occlusology

"Carol Davila" University of Medicine and Pharmacy Bucharest

Bucharest, Romania

Sanda Mihaela Popescu, DDS, PhD, Professor and Head

Dental Rehabilitation and Medical Surgery Emergencies

Department, Faculty of Dental Medicine, University of Medicine and

Pharmacy of Craiova, Dolj, Romania

Elena Preoteasa, DDS, PhD, Professor and Head

Complete Denture Department, Faculty of Dental Medicine

"Carol Davila" University of Medicine and Pharmacy Bucharest

Bucharest, Romania

Alina Pürienè, BS, PhD, Dr habil, Professor

Periodontics Department, Institute of Odontology

Faculty of Medicine, Vilnius University, Vilnius, Lithuania

Lucien Reclaru, Eng, PhD, Biomaterials Consultant

University of Geneva, Geneva, Switzerland

Stephen F. Rosenstiel, BDS, MSD, Professor and Chair

Restorative and Prosthetic Dentistry, College of Dentistry

The Ohio State University Columbus, Columbus, OH, USA

Martina Schmid-Schwap, DDS, PhD, Professor

Department of Prosthodontics, Bernhard Gottlieb

University of Dentistry, Medical University of Vienna,

Vienna, Austria

Gregor Slavicek, DDS, PhD, Professor

Steinbeis Transfer Institute of Biotechnology in Interdisciplinary

Dentistry, Steinbeis University Berlin, Berlin, Germany

Marius Steigmann, DDS, PhD, Professor

Steigmann Implant Institute, Neckargemund, Germany

Gianluca Martino Tartaglia, DDS, PhD, Associate Professor

Laboratory of Functional Anatomy of the Stomatognathic Apparatus,

Department of Biomedical Sciences for Health, Faculty of Medicine

University of Milan, Milan, Italy

Bernard Touati, DDS, PhD, Assistant Professor

Prosthodontics Department, Faculty of Odontology, Paris V

University, Paris, France

Tamara Tserakhava, DDS, PhD, Professor and Chair

Department of Pediatric Dentistry, Dental Faculty, Belarusian State

Medical University Minsk, Belarus

Sorin Uram-Țuculescu, DDS, PhD, Assistant Professor

Prosthodontics Department, School of Dentistry

Virginia Commonwealth University Richmond, Richmond, VA, USA

Reviewers-in-Chief

Stephen F. Rosenstiel, BDS, MSD, Professor Emeritus

The Ohio State University Columbus, Columbus, OH, USA

Mihaela Rodica Păuna, DDS, PhD, Professor

"Carol Davila"University of Medicine and Pharmacy Bucharest

Bucharest, Romania

Nissan Joseph, DMD, Associate Professor

Tel Aviv University, Tel Aviv, Israe

\section{Reviewers}

Petr Bartak, Prague, Czech Republic

Cristian Niky Cumpătă, Bucharest, Romania

Andrezza Lauria de Moura, São Paulo, Brazil

Nikolay Ishkitiev, Sofia, Bulgaria

Barbara Janssens, Gent, Belgium

John Kois, Seattle, WA, USA

Cinel Malita, Bucharest, Romania

Enrico Manca, Cagliari, Italy

Vlademir Margvelashvili, Tbilisi, Georgia

Costin Marinescu, München, Germany

Marina Melescanu-Imre, Bucharest, Romania

Joel Motta Júnior, Manaus, AM, Brazil

Hazem Mourad, Qassim, Saudi Arabi

Paula Perlea, Bucharest, Romania

Nikola Petricevic, Zagreb, Croatia

Cristina Teodora Preoteasa, Bucharest, Romani

Robert Sabiniu Şerban, Bucharest, Romani

Elina Teodorescu, Bucharest, Romania

Mei-Qing Wang, Xi'an, China

English Language Editor-in-Chief

Roxana-Cristina Petcu, Phil, PhD, Professor

Faculty of Foreign Languages, University of Bucharest

Bucharest, Romania

\section{English Language Editors}

Valeria Clucerescu, Biol.

Niculina Smaranda Ion, Phil

Honorary Statistical Advisers

Radu Burlacu, PhD, Bucharest, Romania

loan Opris, PhD, Associate Scientist, Miami, USA

Book Reviewers

Iulia Ciolachi, DMD, Bucharest, Romania

Florin-Eugen Constantinescu, DMD, PhD Student

Bucharest, Romania

\section{Project Editor}

Irina-Adriana Beuran, $\mathrm{DMD}, \mathrm{PhD}$

Falty of Delacicine "C Pharmacy Bucharest, Bucharest, Romania

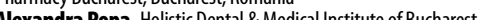
ROPOSTURO, Bucharest, Romania

\section{Technical Edito}

Gabriel Octavian Lazar, Bucharest, Romania

Valentin Miroiu, Bucharest, Romania

Edgar Moraru, Bucharest, Romania

\section{Indexing Databases}
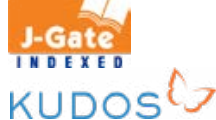

$\$$ Dimensions

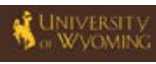

Crossref

S. WorldCat

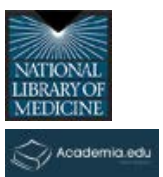

ROMEO 


\section{UCLA Napa Implant Symposium in conjuction with International Academy for Oral \& Facial Reconstruction (IAOFR)}

June 4-6, 2020 • Vista Collina Resort, Napa, CA

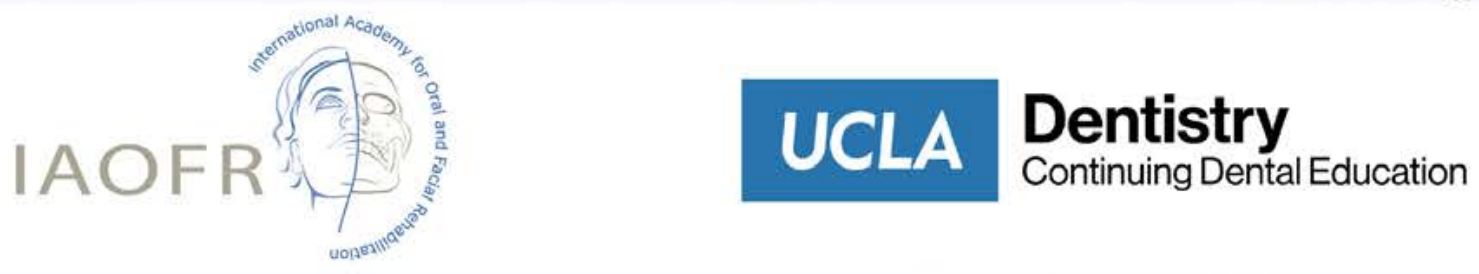

IAOFR members visit iaofr.org to register and for additional information

Co-Moderators

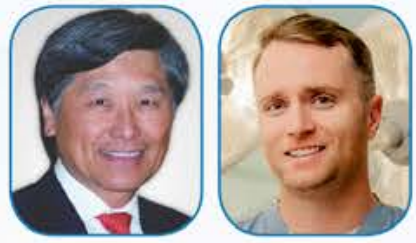

Peter K. Moy, DMD, UCLA School of Dentistry

Todd R. Schoenbaum, DDS, UCLA School of Dentistry

IAOFR Consensus Working Group Leaders

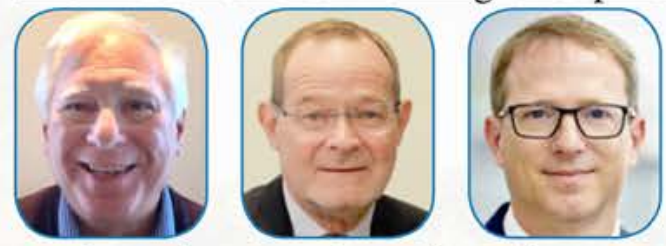

Prof. Stephen Feinberg (USA)

Prof. Piet Haers (UK)

Prof. Franz Kramer (Germany)

Prof. Constantinus Politis (Belgium)

Prof. Hendrik Terheyden (Germany)

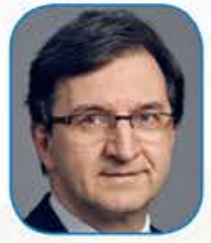

Group 1 - Oncology

Group 2 - Atrophic Jaws / Implant Rehabilitation

Group 3 - Congenital Deformities

Group 4 - Acquired Defects (Trauma, Medicine, Pathology)

Group 5 - Research \& Development

\section{IAOFR Speakers}
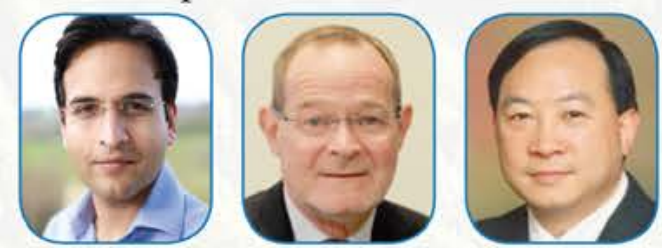

Dr. Satinder Chandur (UK)

Prof. Piet Haers (UK)

Prof. Cheung Lim Kwong (Hong Kong)

Prof. Constantinus Politis (Belgium)
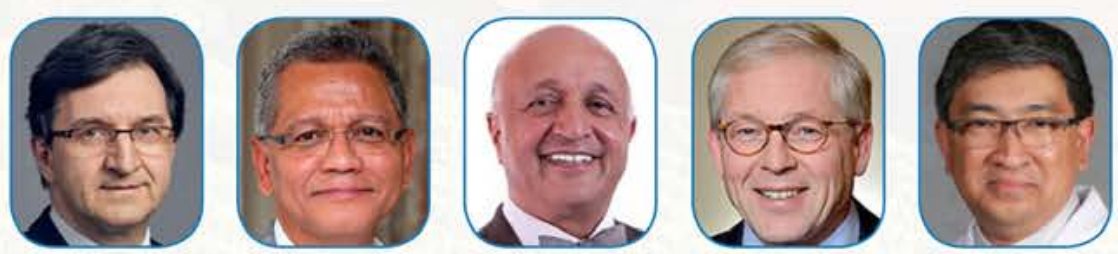

Prof. Gerry M. Ragoebar (Netherlands) Prof. Ashok Sethi (UK)

Prof. Hendrik Terheyden (Germany)

Prof. Alvin G. Wee (USA)

\section{UCLA Speakers}
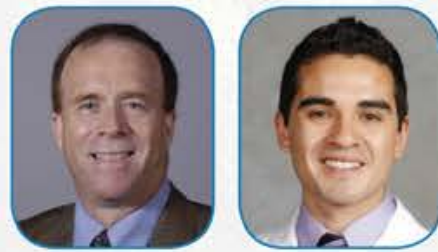

Dr. Michael Block (USA)

Dr. Ivan Chiccon (USA)

Dr. Alireza Moshaverinia (USA)
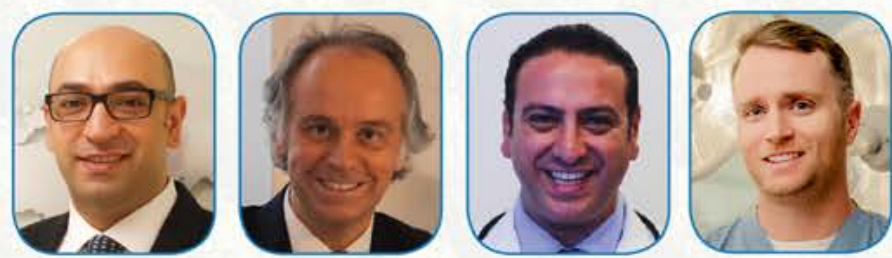

Dr. Alessandro Pozzi (Italy)

Dr. Nader Salib (USA)

Dr. Todd Schoenbaum (USA) 


\section{The cost of publishing in today's scientific e-world}

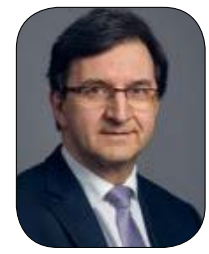

Constantinus POLITIS

MD, DDS, MM, MHA, PhD

Professor \& Chairperson

Editor-in-Chief

Dear readers,

Dear authors,

According to Stephen Buranyi, scientific writer with the Guardian, scientific publishing is a vast business, with revenues varying between the music recording and film industries, but far more profitable. Therefore, it is not difficult to understand why the scientific publishing business is so profitable. After all, researchers need publications to advance in their career. The majority of scientific journals offer article submissions using online manuscript manager platforms, which resulted in a transition from editorial staff to contributing authors to complete the submission process and to comply with a whole series of journal guidelines. If research teams want to access their own publications, they often have to pay subscription fees to the journal in which the publication appeared. Although these licensing contracts are often arranged centrally, where universities conclude contracts with major publishing companies. It becomes even better if the authors want to publish their articles open access. A few thousand euros per accepted manuscript is no exception. Would you like your figures to be published in color? No problem, but extra fees are charged. No manuscript in proper English without the aid of a specialized editing and proofreading company: a costly companion. Not difficult to understand why the editorial world is contaminated with questionable and predatory journals that keep young scientists lurking from decent journals. The business model is further fuelled by the universities longing for rankings. Rankings are necessary to attract investors and for international prestige. A high ranking requires a high number of publications numbers, citations and $h$-indexes, which only increases the pressure on researchers. The only way out is an inter-university platform of open access journals with thorough peer review and statistical assistance that even further improve the manuscripts and contributions quality. This, however, requires changing grant approval criteria by national, European and international funding bodies. When a career evaluation is conducted by the universities, these open-access publication metrics should be included in the evaluation criteria. Within this traditional scientific world of profit-making organizations there is room for simple-hearted journals with broad access, a wide range of interest and free contributions with a swift peer review process, still flexible for entry-level contributions. As soon as an impact factor is assigned to a journal, the number and quality of the submissions increases and an upward swing begins. In the meantime, the Editorial Board of the Stomatology Edu Journal responds meticulously to all requirements to meet the compliance standards of global citation databases and free full-text archives on biomedical and life sciences journals.

Sincerely yours,

C. Politis

Editor-in-Chief 


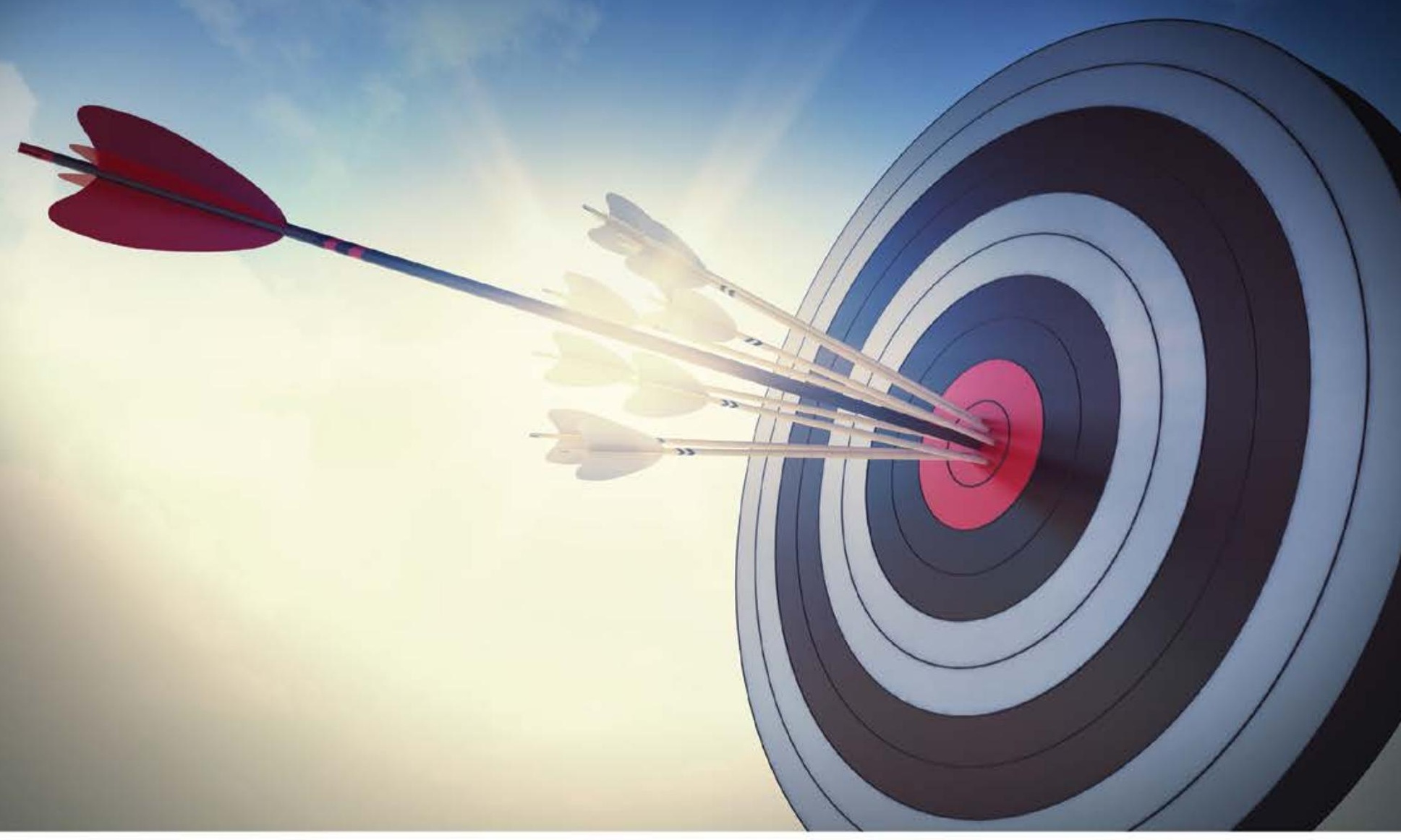

Our new Turbine Generation

High Quality for Precise Operation

More power, smaller heads, high quality - In other words: High torque and ideal sight at high quality made in Germany. No matter if you choose T3 Boost or T3 mini: both turbines offer high power, give you full control at all times and are working very quietly. Due to its small head, T3 mini allows for outstanding sight and T3 Boost offers maximum power at a whisper tone. Made in Germany, the turbines offer an attractive price-performance ratio.

dentsplysirona.com/turbines 


\section{World Health Organization}

\section{BASIC PROTECTIVE MEASURES AGAINST THE NEW CORONAVIRUS}

Stay aware of the latest information on the COVID-19 outbreak, available on the WHO website and through your national and local public health authority. Most people who become infected experience mild illness and recover, but it can be more severe for others. Take care of your health and protect others by doing the following:

\section{Wash your hands frequently}

Regularly and thoroughly clean your hands with an alcohol-based hand rub or wash them with soap and water.

Why? Washing your hands with soap and water or using alcohol-based hand rub kills viruses that may be on your hands.

\section{Maintain social distancing}

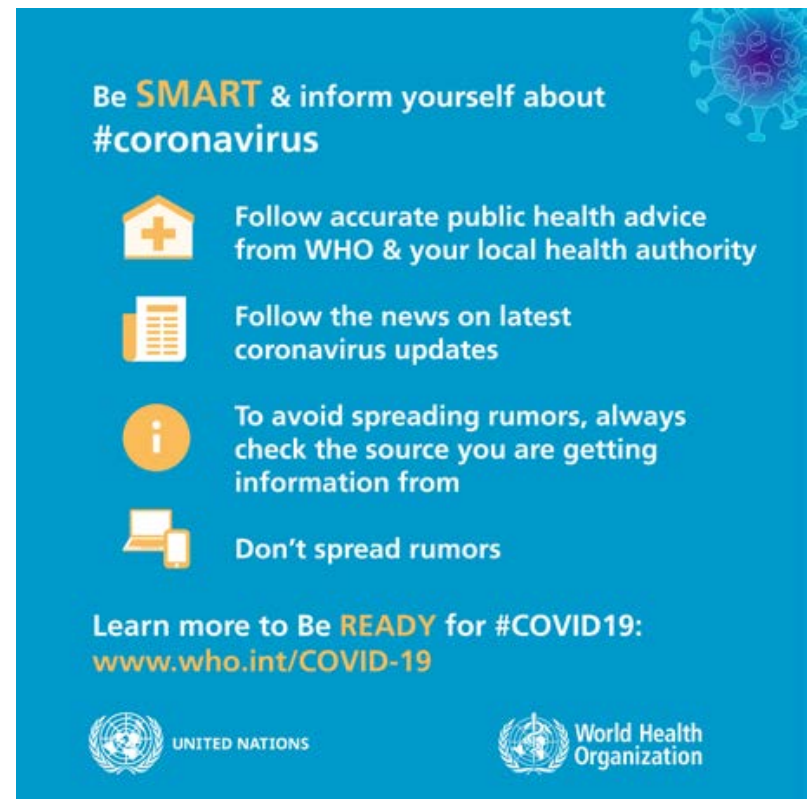

Maintain at least 1 metre (3 feet) distance between yourself and anyone who is coughing or sneezing.

Why? When someone coughs or sneezes they spray small liquid droplets from their nose or mouth which may contain virus. If you are too close, you can breathe in the droplets, including the COVID-19 virus if the person coughing has the disease.

\section{Avoid touching eyes, nose and mouth}

Why? Hands touch many surfaces and can pick up viruses. Once contaminated, hands can transfer the virus to your eyes, nose or mouth. From there, the virus can enter your body and can make you sick.

\section{Practice respiratory hygiene}

Make sure you, and the people around you, follow good respiratory hygiene. This means covering your mouth and nose with your bent elbow or tissue when you cough or sneeze. Then dispose of the used tissue immediately.

Why? Droplets spread virus. By following good respiratory hygiene you protect the people around you from viruses such as cold, flu and COVID-19.

\section{If you have fever, cough and difficulty breathing, seek medical care early}

Stay home if you feel unwell. If you have a fever, cough and difficulty breathing, seek medical attention and call in advance. Follow the directions of your local health authority. 


\section{Stay informed and follow advice given by your healthcare provider}

Stay informed on the latest developments about COVID-19. Follow advice given by your healthcare provider, your national and local public health authority or your employer on how to protect yourself and others from COVID-19.

Why? National and local authorities will have the most up to date information on whether COVID-19 is spreading in your area. They are best placed to advise on what people in your area should be doing to protect themselves.

\section{Protection measures for persons who are in or have recently visited (past 14 days) areas where COVID-19 is spreading}

\section{Be SAFE from \#coronavirus}

if you are $60+$ or if you have an underlying condition like:

Cardiovascular disease

Cls Respiratory condition

\section{Diabetes}

by avoiding crowded areas or places where you might interact with people who are sick.

Learn more to Be READY for \#COVID19: www.who.int/COVID-19

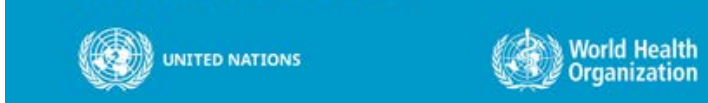

Follow the guidance outlined above.

Stay at home if you begin to feel unwell, even with mild symptoms such as headache and slight runny nose, until you recover. Why? Avoiding contact with others and visits to medical facilities will allow these facilities to operate more effectively and help protect you and others from possible COVID-19 and other viruses.

If you develop fever, cough and difficulty breathing, seek medical advice promptly as this may be due to a respiratory infection or other serious condition. Call in advance and tell your provider of any recent travel or contact with travelers. Why? Calling in advance will allow your health care provider to quickly direct you to the right health facility. This will also help to prevent possible spread of COVID-19 and other viruses. 


\section{stonacolij}

Stoma Edu J. 2020;7(1):05

From The Journal of the American Dental Association

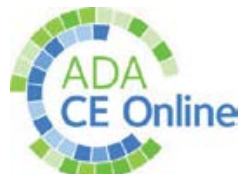

\section{JADA ONIINE CE EXAMS}

http://jada.ada.org/ce/home

http://jada.ada.org/ceworksheets

January 2020

Micah B. Goldfarb, Anderson T. Hara, Adam T. Hirsh, Joana C. Carvalho, Gerardo Maupomé

ARE DENTAL PATIENTS ABLE TO PERCEIVE EROSIVE TOOTH WEAR ON ANTERIOR TEETH?: AN INTERNETBASED SURVEY ASSESSING AWARENESS AND RELATED ACTION

J Am Dent Assoc. 2019 Dec; 151 (1): 10-15. Doi: 10.1016/j.adaj.2019.07.036

https://jada.ada.org/article/S0002-8177(19)30583-5/fulltext

This article has an accompanying online continuing education activity available at: http://jada.ada.org/ce/home. 


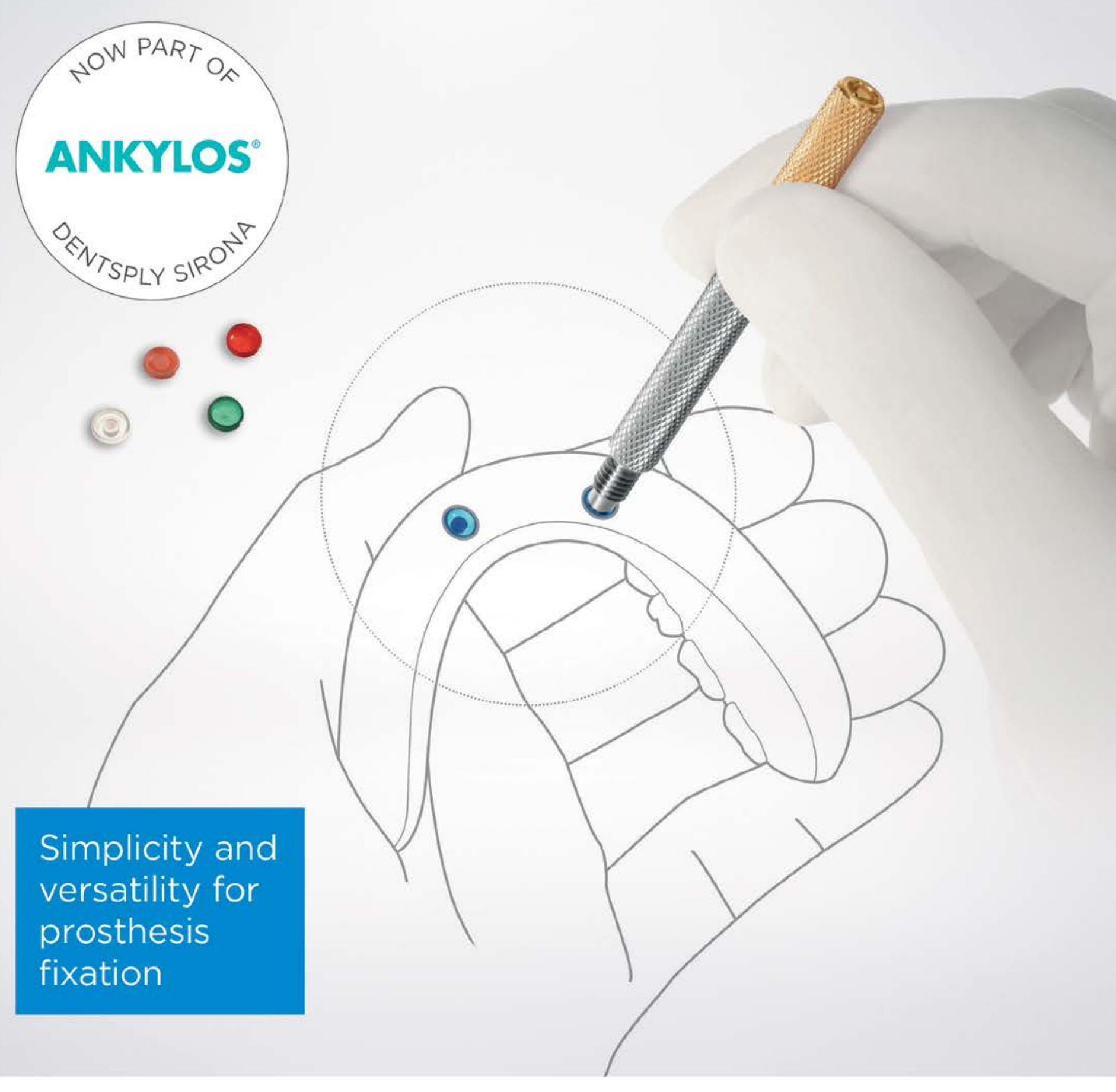

Ankylos ${ }^{\oplus}$

The Locator ${ }^{\circledR}$ concept 


\title{
EFFECTIVENESS OF SCHOOL-BASED FLUORIDE MOUTH RINSING PROGRAM IN SCHOOLCHILDREN FROM KANDY DISTRICT, SRI LANKA
}

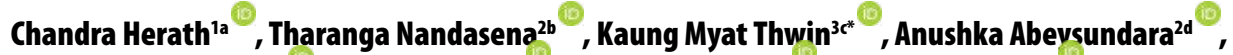 \\ Sampath Ratnayake ${ }^{4 e}$, Hiroshi Ogawa ${ }^{3 f}$, Hideo Miyazaki ${ }^{3,5 g}$, Takeyasu Maeda ${ }^{6 h}$ \\ 'Department of Community Dentistry, Faculty of Dental Sciences, University of Peradeniya, Peradeniya, Sri Lanka \\ 2Department of Basic Science, Faculty of Dental Sciences, University of Peradeniya, Peradeniya, Sri Lanka \\ ${ }^{3}$ Division of Preventive Dentistry, Department of Oral Health Science, Graduate School of Medical and Dental Sciences, Niigata University, Niigata, Japan \\ ${ }^{4}$ Army Hospital, Sri Lanka Army, Sri Lanka \\ 5Department of Dental Hygiene and Welfare, Meirin Junior College, Niigata, Japan \\ ${ }_{6}^{6}$ Faculty of Dentistry, Graduate School of Medical and Dental Sciences, Niigata University, Niigata, Japan
}

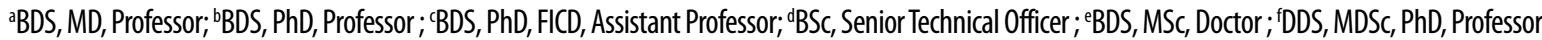

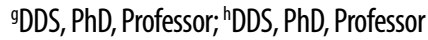

ABSTRACT DOI: https://doi.org/10.25241/stomaeduj.2020.7(1).art.1

Introduction: Dental caries is still epidemic and a significant public health problem in developing countries. No research on a fluoride mouth rinsing program has been conducted in Sri Lanka yet. Therefore, the purpose of this study was to evaluate the effectiveness of a supervised school-based $0.2 \%$ sodium fluoride mouth rinsing program among 6 year-old Sri Lanka school children.

Material and Methods: This study was conducted on 415 school children from the Yatinuwara educational zone of the Kandy district, Sri Lanka from January 2011 to January 2014. The children were allocated into two groups by adjusting their socio-demographic background and the fluoride level in drinking water at school level; Group 1 received $0.2 \%$ sodium fluoride mouth rinses weekly, and Group 2 was the control group. A clinical oral examination and oral health education were performed at baseline and annual follow-ups.

Results: At the baseline, the mean age of school children in the intervention group and the control group were $6.17 \pm 0.41$ years and $6.08 \pm 0.50$ years, respectively. Almost all of the children (>90\%) used fluoride toothpaste in both groups. After the fluoride mouth rinsing program, the intervention group (77.8\%) showed higher caries free proportion than the control group (63.1\%),

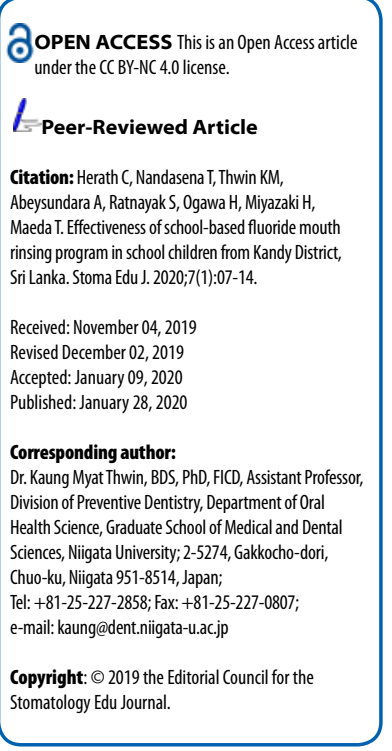
although no statistically significant difference occurred. The mean DMFT and DMFS indices in the intervention group were significantly lower than those in the control group.

Conclusion: The school-based fluoride mouth rinsing program indicated a significant tendency of preventing future caries incidence among children with permanent dentition.

\section{KEYWORDS}

Fluoride Mouth Rinsing; Dental Caries; 6 Year-Old; Schoolchildren; Sri Lanka.

\section{INTRODUCTION}

Dental caries is still epidemic and a significant public health problem in many developing countries [1]. Sri Lanka is one of developing countries in South Asia, and the children's oral health is in poor condition [2-4]. According to the 2015-16 National Oral Health Survey, the prevalence of dental caries in 5 year-old children was $63.1 \%$, and the prevalence of untreated active caries was $60.7 \%$. Out of 5 -year-olds who had experienced dental caries, $96.2 \%$ of them had active caries. Further more, as early as the age of 5-6 years old, some children already had caries on their newly erupted permanent teeth [5]. It is considered as a significant public health problem in Sri Lankan children. It has become a burden not only to the bearers and their families but also to the country [6]. Moreover, it has a great impact on the health policy makers [7]. This increasing burden might be mainly due to the increased rate of sugar consumption and inadequate exposure to fluoride [7-9]. In a region of Sri Lanka, the fluoride 
levels in water bases showed a great variation from less than 0.05 to $5 \mathrm{ppm}$ [10]. These are very high altitude areas that are exposed to heavy rain throughout the year, and showed very low fluoride levels in drinking water, namely 0.05 to $0.001 \mathrm{ppm}$. It is the area where our study sample originated. Only $14.7 \%$ of the Sri Lankan population get the desired level of fluoride concentration of around $1 \mathrm{mg} / \mathrm{L}$ through natural drinking water supplies [11]. The evidence-based preventive methods such as topical fluoride applications, fluoride mouth rinsing, diet modifications and good oral hygiene practices are widely used for public caries prevention $[2,12]$. Daily use of fluoride toothpaste and school-based fluoride mouth rinse programs are recommended to control dental caries in children and adolescents, especially for communities in low fluoridated areas [13]. According to oral health report of the World Health Organization (2013), a reduction in level of caries can be achieved through a joint action of the community, professionals and individuals [14]. The weekly use of fluoride mouth rinse is practiced as a group activity at community levels because it is safe and effective [15]. The effect of fluoride mouth rinses on the incidence of dental caries in children has been extensively investigated, and its effectiveness has been demonstrated for $15 \%-45 \%$ in reducing dental caries over a period of 2-5 years [15-18].

The Ministry of Health, Nutrition and Indigenous Medicine, Sri Lanka has started school dental services since 1953. The school dental therapists of the primary health care team had the main responsibility to provide preventive oriented oral health services for schoolchildren aged 3-13 years old [19]. However, no research on fluoride mouth rinsing program has been conducted in Sri Lanka yet. Therefore, the purpose of this study was to evaluate the effectiveness of the School-based Fluoride Mouth Rinsing (S-FMR) program among 6 year old Sri Lankan schoolchildren.

\section{MATERIALS AND METHODS}

\subsection{Study population}

This study was carried out in the Yatinuwara educational zone of the Kandy district, Sri Lanka from January 2011 to January 2014. The six schools came from urban, semi-urban and rural areas and were randomly selected based on the probability proportional to size sampling method. Via the school authorities, an elaborative explanation on the background, objectives, methods and significance of the study was presented to children aged 6 years and to their parents or guardians gathered in large forums. Following the explanation, the written consent was obtained from the schools, participating children and their parents or guardians. The S-FMR program started with a total of 415 schoolchildren in the study (Fig. 1). During the 3 years of fluoride mouth rinsing program, there was no drop out since none of the participants moved to any other school, or quit the school during the period. Although there were a number of additional entries to the schools, they were not included in the statistical analysis and so the final number of children who completed the study was 415 .

\subsection{Study setting}

Basic socio-demographic information (gender, age, school category, frequency of tooth brushing, usage of tooth paste with fluoride, frequency of intake of sweet food, parents who brush children teeth, income of the family, father's and mother's education levels, and knowledge on factors that influence tooth decay) of schoolchildren were taken at the baseline. Fluoride concentrations were estimated in the sources of drinking water (deep wells, tube wells, steams, and running tap water) of each student participating in the study and the mean fluoride level was $0.078 \mathrm{ppm}$. There were no significant differences in the fluoride level among the six schools. The participants were instructed and obliged to use fluoridated tooth paste at the baseline and the annual follow-ups. Various types of fluoridated toothpastes are available in local market, which is imported brands as well as locally manufactured brands.

The available fluoridated toothpastes in Sri Lanka usually contain 850 - $1000 \mu \mathrm{g} / \mathrm{gF}$ in soluble form. Further more, parents and children were methodically educated on oral health including frequency of tooth brushing, usage of tooth paste with fluoride, frequency of intake of sweet food, parents' involvement during tooth brushing, the knowledge of factors that influence tooth decay, information about nutrition intake and eating habits at the baseline of the study and then annually in order to minimize the different confounding factors and adjust the socio-demographic factors in the sample. The children of the six schools were divided into two groups by adjusting their socio-demographic background and fluoride level in drinking water at school level (which applied a comparison design):: an intervention group (FMR) and a control group.

\subsection{Clinical oral examination}

All the clinical oral examinations were performed by two trained examiners. The calibration of the two dentists whom trained by a public health expert using gold standard. Linear weighted Kappa values for intra-examiner and inter-examiner variability were 0.85 and 0.80 , respectively.

A clinical oral examination was conducted to assess dentition status at the baseline and annual followups based on WHO criteria for dental caries [20].

The schoolchildren were examined using plane mouth mirrors and metallic periodontal probes under good day light to record Decayed (D), Missing $(\mathrm{M})$ and Filled (F) teeth. The findings were recorded using the DMFT index and DMFS index. If at the point 


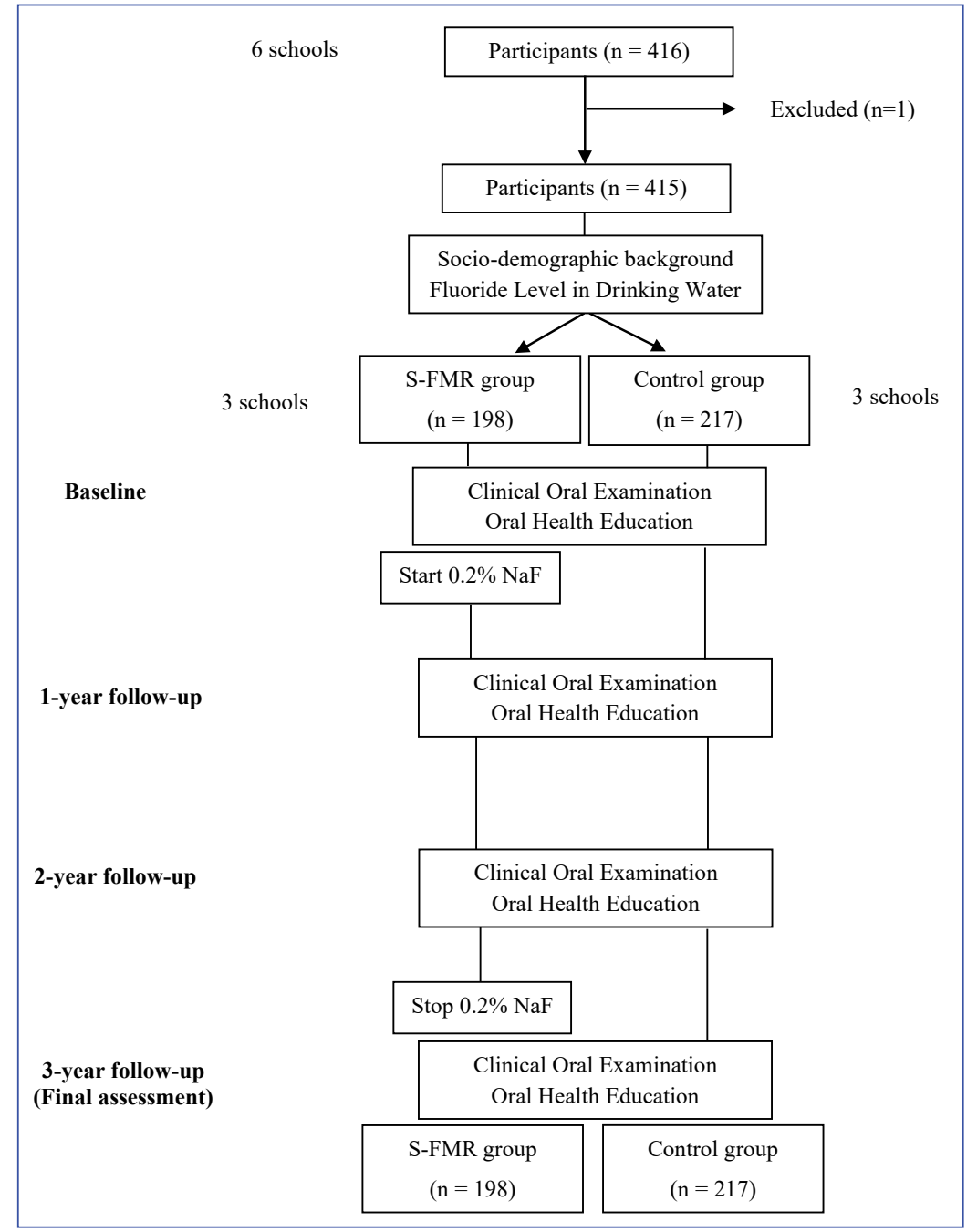

I Figure 1. Flow chart of the study design. n: number of participants, NaF: Sodium Fluoride, S-FMR: School-based Fluoride Mouth Rinse program. the examiners noted the total of 'zero' DMFT/DMFS in clinical oral examination, it defined as "caries free".

\subsection{Fluoride Mouth Rinsing}

$0.2 \%$ sodium fluoride (NaF) 900 ppmF (Wako Product Number 196-01975, USA) was used for the intervention in this study. The children were trained for mouth rinsing using normal water for three months to avoid the swallowing of fluoride solution. After obtaining the standard practice without swallowing and leaving solutions in cups, the prepared $0.2 \% \mathrm{NaF}$ solutions were provided weekly to the schools by investigators.

A teacher was allocated to distribute fluoride solution to each class in each school. The class teacher distributed the plastic cups containing 10 $\mathrm{ml}$ of fluoride solution to participating children according to the schedule.

Children rinsed for a minute according to the teacher's instructions.

The class teachers directly supervised the mouth rinsing program and maintained the records for three years. The final assessment of caries risk was done to evaluate the effectiveness of the program in January 2014. The control group was also intervened as 'placebo' and so they performed regular mouth rinse activity with drinking water. Furthermore, they were repeatedly and annually educated on oral health including the frequency of tooth brushing, usage of tooth paste with fluoride, frequency of intake of sweet food, parents' involvement during tooth brushing knowledge on factors that influence tooth decay, information about nutrition intake and eating habits.

\subsection{Statistical analysis}

The expected outcome of the study was that the mean DMFT and DMFS in the intervention group would be at a lower value than the control group after the weekly exposure to fluoride mouth rinsing. Therefore, the variables of study were exposure and no exposure of six year-old schoolchildren to $0.2 \%$ fluoride mouth rinse for three years and DMFT level and DMFS level in permanent dentition.

A statistical analysis was carried out using the statistical software SPSS 23.0 (SPSS, Chicago, IL, USA). Chi-square, independent t-test and ANOVA tests were performed between the mean differences between the intervention group and the control group at the baseline and the annual follow-ups. The level of statistical significance for all tests was set at $\mathrm{p}<0.05$. 
ITable 1. Socio-demographic background at baseline between two groups.

\begin{tabular}{|c|c|c|}
\hline & $\begin{array}{c}\text { FMR, } n=198 \\
n(\%)\end{array}$ & $\begin{array}{c}\text { Control, } n=217 \\
n(\%)\end{array}$ \\
\hline $\begin{array}{l}\text { Gender } \\
\text { Male } \\
\text { Female }\end{array}$ & $\begin{array}{r}101(51.0) \\
97(49.0)\end{array}$ & $\begin{array}{l}111(51.2) \\
106(48.8)\end{array}$ \\
\hline $\begin{array}{l}\text { Location } \\
\text { Urban } \\
\text { Sub-urban } \\
\text { Rural }\end{array}$ & $\begin{array}{r}70(35.4) \\
100(50.5) \\
28(14.1)\end{array}$ & $\begin{array}{r}83(38.3) \\
109(50.2) \\
25(11.5)\end{array}$ \\
\hline $\begin{array}{l}\text { Father's education level } \\
\text { University level } \\
\text { High school level } \\
\text { Below high school level }\end{array}$ & $\begin{array}{r}28(14.1) \\
125(63.2) \\
45(22.7)\end{array}$ & $\begin{array}{r}45(20.8) \\
122(56.2) \\
50(23.0)\end{array}$ \\
\hline $\begin{array}{l}\text { Mother's education level } \\
\text { University level } \\
\text { High school level } \\
\text { Below high school level }\end{array}$ & $\begin{array}{r}29(14.6) \\
134(67.7) \\
35(17.7)\end{array}$ & $\begin{array}{r}40(18.4) \\
148(68.2) \\
29(13.4)\end{array}$ \\
\hline $\begin{array}{l}\text { Family's income } \\
\text { High (> Rs. 20000) } \\
\text { Middle (Rs. 10000 - 20000) } \\
\text { Low (<Rs. 10000) }\end{array}$ & $\begin{array}{r}23(11.3) \\
72(36.9) \\
103(51.8)\end{array}$ & $\begin{array}{r}29(13.4) \\
59(29.2) \\
129(57.4)\end{array}$ \\
\hline $\begin{array}{l}\text { Frequency of tooth brushing } \\
\text { Once a day } \\
\text { Twice a day } \\
\text { Three times and above a day }\end{array}$ & $\begin{array}{r}27(13.6) \\
151(76.3) \\
20(10.1)\end{array}$ & $\begin{array}{r}34(15.7) \\
155(71.4) \\
28(12.9)\end{array}$ \\
\hline $\begin{array}{l}\text { Use of fluoride toothpaste } \\
\text { Yes } \\
\text { No } \\
\text { Don't know }\end{array}$ & $\begin{aligned} 185 & (93.4) \\
3 & (1.5) \\
10 & (5.1)\end{aligned}$ & $\begin{aligned} 201 & (92.6) \\
5 & (2.3) \\
11 & (5.1)\end{aligned}$ \\
\hline
\end{tabular}

FMR: Fluoride Mouth Rinse, $n:$ number of participants, Family income: average monthly income of the Kandy district, 1 US $\$=R s .100$, by X2 test ( $p<0.05$ )

\subsection{Ethical approval}

The study design was approved by the Research Committee and Ethical Review committee of the Faculty of Dental Sciences, University of Peradeniya, Sri Lanka (Ethical clearance No. FDS-RERC/2009/13/ Herath2). The study permission was also obtained from the Zonal Education Authority of Kandy District, Central Province of Sri Lanka.

\section{RESULTS}

Four hundred and sixteen schoolchildren at age 6 were initially recruited for the study. However, one child was excluded from the study due to the absence of the consent form. Therefore, 415 schoolchildren were finally included in the study. Out of them, 198 children (male: 101, female: 97) were recruited for the intervention group and 217 children (male: 111, female: 106) for the control group.
As shown in Figure 1, their socio-demographic background and fluoride level in drinking water were adjusted in both groups. Then, the intervention group was introduced to $0.2 \% \mathrm{NaF}$ mouth rinse under the supervision of school teachers for consecutive three years. There were no dropouts from the study during the study. Although there was a number of additional lateral entries to the S-FMR program, they were not included into the study. During the three years of the program, a clinical oral examination and oral health education (basic knowledge about dental diseases and oral hygiene care) were performed in both groups annually. The socio-demographic background of the study population at the baseline between the two groups is summarized in Table 1 . At the baseline, the mean ages of schoolchildren in the FMR group and the control group were 6.17 \pm 0.41 years and $6.08 \pm 0.50$ years, respectively. There were no significant differences in mean age, 
Table 2. Percentage of caries free school children in the FMR and control groups.

\begin{tabular}{|c|c|c|}
\hline Visits & $\begin{array}{c}\text { FMR, } \mathbf{n = 1 9 8} \\
\mathbf{n}(\%)\end{array}$ & $\begin{array}{c}\text { Control, } \mathbf{n = 2 1 7} \\
\mathbf{n}(\%)\end{array}$ \\
\hline Baseline & $178(89.9)$ & $205(94.5)$ \\
\hline $\mathbf{1}^{\text {th }}$ visit & $165(83.3)$ & $194(89.4)$ \\
\hline $\mathbf{2}^{\text {nd }}$ visit & $149(75.3)$ & $143(65.9)$ \\
\hline $\mathbf{3}^{\text {rd }}$ visit & $154(77.8)$ & $137(63.1)$ \\
\hline
\end{tabular}

FMR: Fluoride Mouth Rinse, n: number of participants, by independent $t$-test $(p<0.05)$

proportions of male and female, and other sociodemographic data between the two groups. Over $75 \%$ of students in both groups show that their parents have above high school level education; $77.3 \%$ (father) and $72.3 \%$ (mother) in the FMR group and $77.0 \%$ (father) and $86.6 \%$ (mother) in the control group. However, the family income for the majority of the students shows low level in both groups.

All schoolchildren brushed their teeth at least once a day. Yet, the frequency of tooth brushing twice a day was $76.3 \%$ in the FMR group and $71.4 \%$ in the control group, which is the standard and recommended practice. Almost all schoolchildren (>90\%) used fluoride toothpaste in both groups. The results of the percentage of caries-free in the FMR and control groups for consecutive four visits are shown in Table 2.

The percentage of caries-free schoolchildren was calculated with permanent dentitions; if DMFT is equal to zero, this child was considered as a cariesfree. No significant differences were observed in proportion of caries-free in both groups during the program. The caries-free level in the FMR group, which was less comparative to the control at the baseline and $1^{\text {st }}$ visit, was higher than the control group since the $2^{\text {nd }}$ visit.

When compared after the FMR program, the intervention group (77.8\%) shows higher percentage of caries-free than the control (63.1\%). Table 3 shows the comparison of the FMR and the control groups based on DMFT and DMFS. At the baseline, the DMFT index in FMR and control groups were $0.03 \pm 0.22$ and $0.11 \pm 0.47$, where the DMFS level in the FMR and control groups were $0.04 \pm 0.31$ and $0.13 \pm 0.54$, respectively. There were no significant differences in mean DMFT and DMFS between the two groups at the baseline and $1^{\text {st }}$ visit.

The mean number of DMFT and DMFS in the FMR group was significantly lower than that in the control group at the $2^{\text {nd }}$ visit and $3^{\text {rd }}$ visit.

As within groups, the mean DMFT and DMFS were significantly increased from baseline to the $3^{\text {rd }}$ visit in the FMR group. In the control group, there was no significant difference from baseline to the $1^{\text {st }}$ visit whereas there were significant differences during the $2^{\text {nd }}$ and $3^{\text {rd }}$ visits.

\section{DISCUSSION}

Dental caries caused by multi-etiological factors is largely preventable with evidence-based preventive methods. However, the prevalence of dental caries among children has risen in developing countries in recent years because there are very frail preventive care projects compared with developed countries. Beside the increased burden of dental caries in Sri Lanka, the evidence-based fluoride mouth rinsing program in school has not been implemented yet. This is the first intervention study to evaluate the anti-caries effect of school based fluoride mouth rinsing (S-FMR) program among 6 years old Sri Lankan schoolchildren. The present study included 6 year-old 198 schoolchildren in the S-FMR program and 217 children who did not receive any fluoride application. Table 2 included the timely caries-free status of permanent dentition in schoolchildren of both groups. The FMR group showed less reduction of the caries-free proportion than the control group, although there were no statistical differences between the two groups during the program. A higher proportion (77.8\%) of the children in the FMR group remained caries-free at the end of the study compared to the control group (63.1\%). This implies that the caries level in the FMR group was $22.2 \%$ and $36.9 \%$ in the control group. Furthermore, it is less than the reported prevalence of dental caries for 12 year-old Sri Lankan population which is $30.4 \%$ and the Kandy district population which is $35 \%$ [5]. Even though the present study did not carry out the computation of percentage reduction of dental caries due to S-FMR program, when compared with the results of a systematic review [22], it showed a comparable level of caries reduction which would be observed in permanent dentition ranging from $15 \%$ to $67 \%$. When compared to the study carried out in Sarawak which was $24.2 \%$ [11], the caries-free percentage was very high in the present study as $77.8 \%$. At the baseline, the mean DMFT and DMFS values in both groups were not statistically significant due to adjusting nearly equal recruitment of schoolchildren into the study from urban, semi-urban and rural areas. Moreover, they all were from geographically comparable background, which reported to have very low fluoride level in the natural drinking water (0.078 ppmF) [11]. The previous studies also recommended that school based fluoride mouth rinsing should be implemented in areas of fluoride-deficient communities $[10,21]$. Furthermore, a study on a school based fluoride mouth rinsing program in Japan concluded that community-oriented health measure should be contributed to caries prevention of the permanent teeth in areas where water fluoridation is not available [22]. According to the National Oral Health 
ITable 3. Mean number of DMFT and DMFS in two groups.

\begin{tabular}{|c|c|c|c|c|c|c|}
\hline & \multicolumn{2}{|c|}{ DMFT (SD) } & \multirow{2}{*}{ p-value } & \multicolumn{2}{|c|}{ DMFS (SD) } & \multirow{2}{*}{$p$-value } \\
\hline & FMR & Control & & $F M R$ & Control & \\
\hline Baseline & $0.03(0.22)$ & $0.11(0.47)$ & 0.965 & $0.04(0.31)$ & $0.13(0.54)$ & 0.992 \\
\hline $1^{\text {st }}$ Visit & $0.32(0.74)^{*}$ & $0.19(0.62)$ & 0.067 & $0.40(0.96)^{*}$ & $0.26(0.92)$ & 0.191 \\
\hline $2^{\text {nd }}$ Visit & $0.44(0.83)^{*}$ & $0.76(1.01)^{*}$ & 0.03 & $0.54(1.06)^{*}$ & $1.06(1.48)^{*}$ & 0.04 \\
\hline $3^{\text {rd }}$ Visit & $0.64(0.89)^{*}$ & $0.90(1.02)^{*}$ & 0.07 & $0.85(1.25)^{*}$ & $1.32(1.61)^{*}$ & 0.07 \\
\hline
\end{tabular}

FMR: Fluoride Mouth Rinse, n: number of participants, DMFT: decayed, missing, and filled permanent teeth, DMFS: decayed, missing, and filled permanent tooth surfaces, SD: Standard Deviation.

Mean values within each row are analyzed by using ANOVA test $(p<0.05)$, NS: statistically not significant.

Mean values within each column are analyzed by using one way repeated ANOVA test $(p<0.05),(*)$ : statistically significant.

Survey in 2015-16 [5], the FMR group in this study even though showed a similar DMFT level with 12-year-old Sri Lankan population which was 0.6 (1.6) it rather less than the Kandy district population (0.8). Furthermore, when compared to the study carried out in Sarawak [10], the DMFT value at the end of the program was significantly less. The mean DMFT and DMFS were significantly decreased in the FMR group than in the control group during the $2^{\text {nd }}$ and $3^{\text {rd }}$ visits, respectively. This finding supported the previous studies which were performed in several communities [10,24,25]. In accordance with our findings, the present study demonstrated that weekly use of $0.2 \% \mathrm{NaF}$ (900 ppm F) has a significant caries-preventive effect in children. Therefore, the S-FMR programs are regarded as a highly effective caries-preventive strategy. A previous systematic review concluded that supervised regular use of fluoride mouth rinse in daily or weekly or fortnightly basis with $0.05 \% \mathrm{NaF}$ (230 ppm F) or $0.2 \% \mathrm{NaF}(900$ ppm F) in children and adolescents could achieve a satisfactory caries reduction in tooth surfaces [25]. On the other hand, Jagan et al reported that the effectiveness of fluoride mouth rinse with low concentration $(0.05 \% \mathrm{NaF})$ is not significant on caries reduction [26]. Furthermore, its effectiveness is said to be more significant in caries prevention with the early introduction of fluoride mouth rinses to children [22]. In this study, children aged 6 years participated in the S-FMR program, as they are the age group that start to attend primary schools. The previous studies concluded that fluoride mouth rinsing programs should start at a younger age, and continue up to the age of 12 years in order for more children to remain caries-free through their school years [25]. The measurements for FMR uses among preschoolchildren were performed in Japan, and reported FMR could be performed by preschoolchildren safely and efficiently [22]. This suggests that the S-FMR program should start at a younger age, such as the preschool period to further enhance the impact of the caries-preventive effects. In this study, basic knowledge of oral hygiene care such as the use of fluoridated toothpaste with correct tooth brushing was delivered via the oral health education in both groups during the follow-up visits.
Low levels of oral health knowledge will hinder the sound understanding of oral health care, and result in a poor oral health outcome [27]. The previous review studies reported that daily use of fluoridated toothpaste had a significant caries-preventive effect in children $[12,28,29]$. The oral health situation would be enhanced by a combination of the S-FMR program together with provision of oral health education for further impressive results.

The limitation of this study includes the assignment of subjects to test and control groups which was known to the examiners (not performed to single or double blind), which is common to studies. Further, the diagnostic criteria applied are based on those stated by WHO (1997), in which the initial lesions (white sports) are not considered. In consequence, there may be under-registration. Nevertheless, this study could provide useful information about school-based weekly fluoride mouth rinsing programs in fluoride-deficient areas. The positive benefit of weekly sodium fluoride mouth rinses on caries reduction would be a major population-based strategy to improve the oral health situation in Sri Lankan children. In addition, to get the maximum impact on caries prevention, the school-based fluoride mouth rinsing program could be combined with other additional preventive activities including reinforced use of fluoride toothpaste and supervised tooth brushing through oral health education to parents, guardians, school teachers as well as schoolchildren to further caries reduction.

\section{CONCLUSION}

Based on the findings of this study, we have found evidence that weekly $0.2 \% \mathrm{NaF}$ mouth rinse had a significant tendency of preventing future caries incidence among children in permanent dentition.

\section{CONFLICT OF INTEREST}

The authors declare no conflict of interest.

\section{AUTHOR CONTRIBUTIONS}

$\mathrm{CH}$ : Proposal writing, program organizing, clinical 
examination, DMFT calculation, manuscript writing; TN: Concept, data gathering and recording DMFT calculation, data entry, manuscript writing; KT: Data analysis, manuscript writing, critical review of manuscript; AA: Mouth wash preparation, mouthwash distribution, data recording, data entry; SR: Clinical examination, DMFT calculation, data recording, data entry; $\mathrm{HO}$ : Data analysis, manuscript writing, critical review of manuscript; HM: Concept, protocol, proposal writing, data analysis, critical review of manuscript; TM: Concept, protocol, critical review of manuscript.

\section{REFERENCES}

1. Kaung MT, Zaitsu T, Uneo M, Kawaguchi Y. Early childhood caries and related risk factors among Myanmar preschool children. Int J Clin Prev Dent. 2016;12(4):229-236.

[CrossRef] Google Scholar

2. Kumarihamy SLM, Subasinghe LD, Jayasekara $P$, et al. The prevalence of early childhood caries in 1-2 yrs olds in a semiurban area of Sri Lanka. BMC Res Notes. 2011:4:336.

[Full text links] [CrossRef] [PubMed] Google Scholar Scopus

3. Perera PJ, Abeyweera NT, Fernando MP, et al. Prevalence of dental caries among a cohort of preschool children living in Gampaha district Sri Lanka : a descriptive cross sectional study. BMC Oral Health. 2012;12:49.

[Full text links] [CrossRef] [PubMed] Google Scholar Scopus

4. World Health Organization. 2008-2013 Action plans for the global strategy for the prevention and control of non-communicable diseases. World Health Assembly Document A53/14. Geneva, CH: World Health Organization; 2009.

https://www.who.int/nmh/publications/9789241597418/en/

5. Ministry of Health, Nutrition and Indigenous Medicine, Sri Lanka. National Oral Health Survey (2015-2016)., Colombo, Sri Lanka: Ministry of Health, Nutrition and Indigenous Medicine; 2018. Dental caries: 33-38.

http://www.health.qov.Ik/moh final/english/public/elfinder/ files/publications/2019/NOHS2015-2016.pdf

6. Kassebaum NJ, Smith AGC, Bernabé E, et al. Global, regional, and national prevalence, incidence, and disability-adjusted life years for oral conditions for 195 countries, 1990-2015: a systematic analysis for the global burden of diseases, injuries, and risk factors. J Dent Res. 2017;96(4):380-387.

[Full text links] [PubMed] Google Scholar Scopus

7. Jürgensen $N$, Petersen $P E$. Oral health and the impact of socio-b havioral factors in a cross sectional survey of 12-year old school children in Laos. BMC Oral Health. 2009;9:29.

[CrossRef] Google Scholar Scopus

8. Perera I, Ekanayake L. Relationship between dietary patterns and dental caries in Sri Lankan adolescents. Oral Health Prev Dent. 2010; 8(2):165-72.

[Full text links] [CrossRef] [PubMed] Google Scholar Scopus 9. Department of Census and Statistics, Ministry of Finance and Planning, Sri Lanka. Household Income and Expenditure Survey 2006/07. Final Report. Colombo, Sri Lanka: Department of Census and Statistics; 2008.

http://www.statistics.gov.Ik/HIES/HIES2006 07Website/ Publications/HIES200607Final\%20ReportWeb\%20.pdf

10. Chen CJ, Ling KS, Esa R, et al. A school-based fluoride mouth rinsing programme in Sarawak: a 3-year field study. Community Dent Oral Epidemiol. 2010;38(4):310-314.

[Full text links] [CrossRef] [PubMed] Google Scholar Scopus

11. Ranasinghe N, Kruger E, Chandrajith R, et al. The heterogeneous nature of water well fluoride levels in Sri Lanka: an opportunity to mitigate the dental fluorosis. Community Dent Oral Epidemiol. 2019;47(3):236-242.

[Full text links] [CrossRef] [PubMed] Google Scholar Scopus

12. Peterson PE. Prevention of dental caries through the effective use of fluoride - the public health approach. Stoma Edu J. 2016;3(3-4):130-140.

[CrossRef] Google Scholar

13. Rugg-Gunn A, Bánóczy J. Fluoride toothpastes and fluoride mouthrinses for home use. Acta Med Acad. 2013;42(2):168-178. Review.

[Full text links] [CrossRef] [PubMed] Google Scholar Scopus

14. Petersen PE, Ogawa $\mathrm{H}$. Prevention of dental caries through the use of fluoride--the WHO approach. Community Dent Health. 2016;33(2):66-68.

[PubMed] Google Scholar Scopus

\section{ACKNOWLEDGEMENT}

This study was supported by the Niigata University and the University of Peradeniya Cooperation Agency Partnership Program and the Sri Lanka Dental Association - under the 2010 grant . The authors thank all participating schoolchildren, parents or guardians, school authorities and teachers who provided their fullest cooperation during the program.

15. Twetman S, Keller MK. Fluoride rinses, gels and foams: an update of controlled clinical trials. Caries Res. 2016;50 Suppl 1:3844. [Full text links] [CrossRef] [PubMed] Google Scholar Scopus 16. Petersen PE, Phantumvanit P. Perspectives in the effective use of fluoride in Asia. J Dent Res. 2012;91(2):119-121.

[Full text links] [CrossRef] [PubMed] Google Scholar Scopus

17. Matsuyama Y, Aida J, Taura K, et al. School-based fluoride mouth-rinse program dissemination associated with decreasing dental caries inequalities between Japanese prefectures: an ecological study. J Epidemiol. 2016 5;26(11):563-571.

[Full text links] [CrossRef] [PubMed] Google Scholar Scopus

18. Shahid M. Regular supervised fluoride mouthrinse use by children and adolescents associated with caries reduction. Evid Based Dent. 2017;18(1):11-12.

[Full text links] [CrossRef] [PubMed] Google Scholar Scopus

19. Ranasinghe N, Kruger E, Tennant M. Spatial distribution of ground water fluoride levels and population at risk for dental caries and dental fluorosis in Sri Lanka. Int Dent J. 2019; 69(4):295 302.

[Full text links] [CrossRef] [PubMed] Google Scholar Scopus 20. World Health Organization. Oral health surveys: basics methods, 4th edition. Geneva, CH: World Health Organization; 1997.

https://apps.who.int/iris/handle/10665/41905

21. Takeuchi R, Kawamura K, Kawamura S, et al. Effect of schoolbased fluoride mouth-rinsing on dental caries incidence among schoolchildren in the Kingdom of Tonga. J Oral Sci. 2012;54(4):343347.

[Full text links] [CrossRef] [PubMed] Google Scholar

22. Komiyama K, Kimoto K, Taura K, et al. National survey on school-based fluoride mouth-rinsing programme in Japan: regional spread conditions from preschool to junior high school in 2010. Int Dent J. 2014;64(3):127-137.

[Full text links] [CrossRef] [PubMed] Google Scholar Scopus

23. Levin KA, Jones CM, Wight $C$, et al. Fluoride rinsing and dental health inequalities in 11-year-old children: an evaluation of a supervised school-based fluoride rinsing programme in Edinburgh. Community Dent Oral Epidemiol. 2009;37(1):19-26.

[Full text links] [CrossRef] [PubMed] Google Scholar Scopus

24. Nakamura A, Sakuma S, Yoshihara A, et al. Long-term followup of the effects of a school-based caries preventive programme involving fluoride mouth rinse and targeted fissure sealant: evaluation at 20 years old. Int Dent J. 2009;59(4):215-221.

[Full text links] [PubMed] Google Scholar Scopus

25. Marinho VC, Chong LY, Worthington HV, Walsh T. Fluoride mouthrinses for preventing dental caries in children and adolescents. Cochrane Database Syst Rev. 2016;7(7):CD002284.

[Full text links] [CrossRef] [PubMed] Google Scholar Scopus 26. Jagan P, Fareed N, Battur $H$, et al. Effectiveness of sodium fluoride mouth rinses on the prevention of dental caries: A systematic review. J Indian Assoc Public Health Dent. 2015; 13(2): 110-115. doi: 10.4103/2319-5932.159042

Google Scholar Scopus

27. Thwin KM, Zaitsu $T$, Ueno $M$, Kawaguchi $Y$. Effects of oral health education in Myanmar preschool children and guardians. J Investig Clin Dent. 2018;9(3):e12346.

[Full text links] [CrossRef] [PubMed] Google Scholar Scopus

28. Miller FY, Campus G, Giuliana G, et al. Topical fluoride for preventing dental caries in children and adolescents. Curr Pharm Des. 2012;18(34):5532-5541.

[Full text links] [CrossRef] [PubMed] Google Scholar Scopus

29. Bansal A, Ingle NA, Kaur N, et al. Recent advancements in fluoride: a systematic review. J Int Soc Prev Community Dent. 2015;5(5):341-346.

[Full text links] [CrossRef] [PubMed] Google Scholar 


\section{Chandra HERATH}

BDS, MS (Rest), FDS (Paed), RCS (Eng), Professor Department of Community Dentistry Faculty of Dental Sciences University of Peradeniya Peradeniya, Sri Lanka

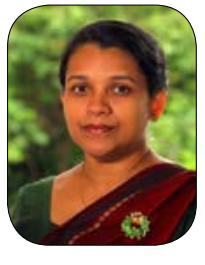

Chandra Herath, is a Professor in Paedodontics. She joined the Faculty of Dental Sciences, University of Peradeniya, Sri Lanka in 1997 and obtained her Fellowship in Paediatric Dentistry from the Royal College of Surgeons, England in 2003. She has published over 15 research papers in local and international journals. She is the President elect of the Association of Specialists in Restorative Dentistry, Sri Lanka and the Joint Secretary of the South Asian Academy of Paediatric Dentistry. Her research interests are related to early childhood caries, dental trauma, developmental anomalies of teeth and children with special health care needs. She has immensely contributed to upgrading Paediatric Dentistry in Sri Lanka by developing undergraduate and postgraduate curricula, conducting workshops and delivering lectures for health care professionals and the general public.

Orestions

\section{Which of the following method is more cost-effective to the developing country to carry out the school-based study to prevent dental caries?}

Da. Water fluoridation method;

ab. Use of fluoride mouth rinses;

uc. Use of fluoride toothpastes;

$\square$ d. Milk fluoridation method.

\section{What is the effect of fluoride on teeth?}

$\square$ a. Demineralize the enamel;

ab. Discolor the enamel;

ac. Remineralize the enamel;

$\square$ d. No effect on enamel.

\section{What is the optimal level of fluoride in the fluoride mouth rinses to be used once a week?}

पa. 100-300 ppm;

ab. 300-500 ppm;

口c. $800-1000$ ppm;

口d. $>1500 \mathrm{ppm}$.

\section{What is not an advantage of fluoride mouth rinsing program in school?}

Da. Cost effective;

ab. Time consuming;

uc. Can practice at community level;

$\square d$. Less attention by participants.

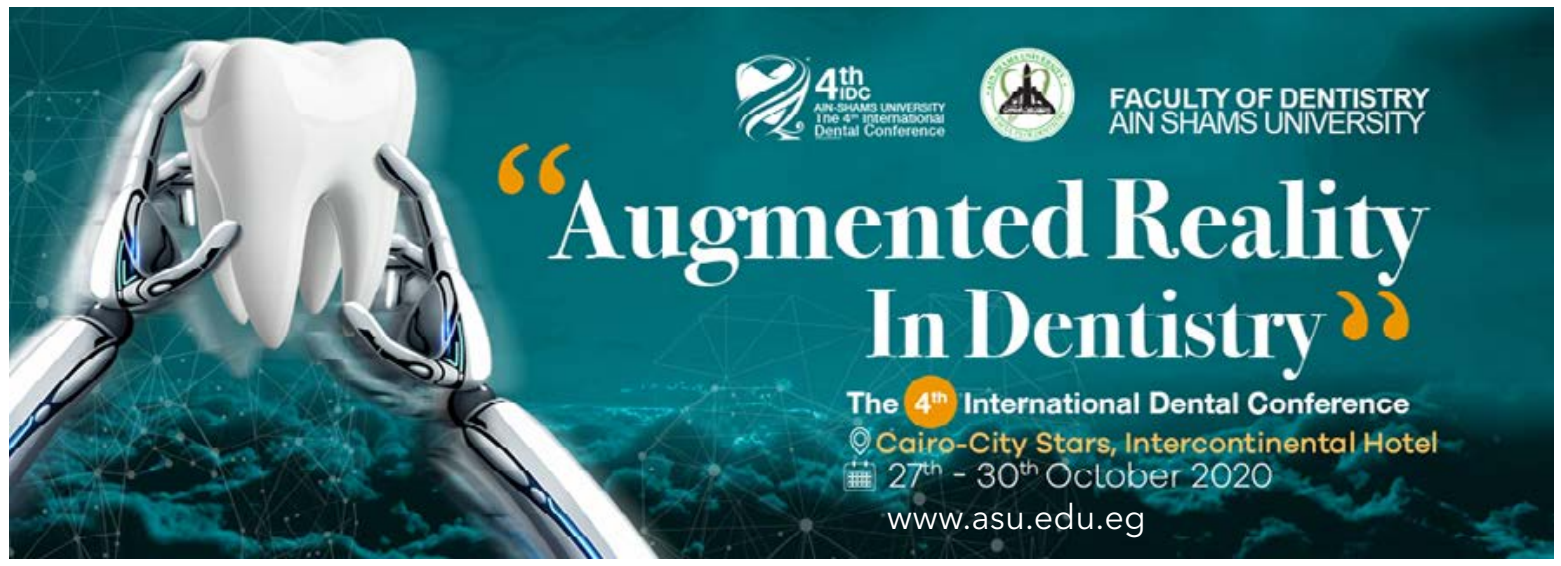




\title{
ARREST OF EARLY CARIOUS LESIONS AFTER PROFESSIONAL APPLICATION OF DIFFERENT FLUORIDE AGENTS
}

\author{
Graciela Liliana Klemonskis $^{\text {1a }} \odot$, Celina Cornejo $^{\text {th }} \odot$, Mariana Toral'c $^{\circledR}$, Pablo Andrés Salgado ${ }^{\text {1d }} \odot$, \\ Aldo Fabián Squassi ${ }^{1{ }^{*}}$
}

${ }^{1}$ Chair of Department of Preventive and Community Dentistry, Faculty of Dentistry, University of Buenos Aires, Buenos Aires, Argentina

aDDS, PhD, Associated Professor; b, DDS; 'dic. Biol. Sc., Associated Proffesor; ' $D D S$, PhD, Chairman

ABSTRACT DOI: https://doi.org/10.25241/stomaeduj.2020.7(1).art.2

Objective: To compare the effectiveness of three professionally applied fluoride agents in arresting early carious lesions in young permanent teeth.

Methods: Aquasi-experimentalstudywasperformed.Eligiblepopulation:Schoolchildren aged 5-7 years presenting at least one permanent molar with early active carious lesion. Sample: 107 dental surfaces with early occlusal carious lesions (lesion code=1-2; activity code=2 -ICDAS II criteria-). Study design: (1) Baseline diagnosis, performed by 2 researchers (Kappa inter-observer: 0.8). (2) Application of a protocol for cariogenic infection control. (3) Participant assignment to groups: matched according to complexity of treatment needs at baseline: Group 1(G1) 5\% NaF varnish Duraphat ${ }^{\circledR}$ ( $n=53$ ); Group 2 (G2) 5\% $\mathrm{NaF}$ varnish containing $\beta$-TCP tricalcium phosphate $(n=33)$ Clinpro White Varnish $^{\circledR}$; Group 3 (G3) resin-modified glass ionomer cement varnish Clinpro XT Varnish ${ }^{\circledast}(n=19)$. (4) Single professional application of a fluoride agent. (5) Caries assessment 1 year post-treatment. Statistical analysis. The frequency of (a) early caries lesion remineralization one year post-treatment and (b) carious lesions that remained active but showed no progression 1 year post-treatment were calculated. Chi-Square and proportion comparison tests for independent

OOPEN ACCESS This is an Open Access article under the CCBY

EPeer-Reviewed Article

Citation: Klemonskis GL, Cornejo C, Toral M, Salgado PA, Squassi AF. Arrest of early carious lesions after professiona application of different fluoride agents. Stoma Edu J. 2020;7(1):15-19.

Received: October 25, 2019 Revised: November 27, 2019 Accepted: February 18, 2020 Accepted: February 18, 2020
Published: February 19, 2020 Published: February 19, 2020

Corresponding author: Professor Aldo Squassi, Od, PhD Chair of Preventive and Community Dentistry, Faculty of Dentistry, University of Buenos Aires, Buenos Aires, Argentina. Marcelo T. de Alvear 2142, C1122AAH, Buenos Aires, Argentina Tel/Fax: +54-11-5287-6254, e-mail: asquassi@gmail.com

Copyright: $\odot 2020$ the Editorial Council for the Stomatology Edu Journal. samples were used to evaluate differences among groups.

Results: Proportion of arrested lesions 1-year post treatment: G1=54.5\%, $\mathrm{G} 2=43.4 \%, \mathrm{G} 3=47.4 \%$. No statistical difference was found among groups $(p<0.05)$. Proportion of lesions remaining active at 1 year showing no caries progression: $\mathrm{G} 1=69 \%, \mathrm{G} 2=80 \%, \mathrm{G} 3=100 \%$. No statistical difference was found among groups $(\mathrm{p}<0.05)$.

Conclusion: The three professionally applied fluoride agents showed similar effectiveness in arresting early carious lesions in young permanent teeth 1 year post-application.

\section{KEYWORDS}

Tooth Remineralization; Fluoride Varnishes; Caries Arrest; Preventive Dentistry; Topical Fluorides.

\section{INTRODUCTION}

The conventional treatment of caries lesions has historically focused on the mechanical treatment of the lesion. Such an approach [17] disregards the ecological imbalances in the oral cavity, involves restorations that require replacement and which become larger with time, and can result in tooth loss. Successive investigations have reported findings that support a paradigm shift in the treatment of caries. The "Ecological Plaque Hypothesis" [1415] emphasizes the dynamic relation between the environment and the composition of the oral microbiota. Imbalances in the resident microflora have an impact on the environment, disrupting the demineralization/remineralization balance at the biofilm-enamel interface. When this imbalance continues, the carious lesion becomes visible [7]. Fluoride plays a key role in the prevention and control of dental caries. The cariostatic effect of fluoride can be attributed mainly to its ability to influence ion exchange reactions at the plaque-enamel interface, even at low concentrations (0.2-1 ppm), facilitating calcium and phosphate precipitation [6]. Because of its inorganic composition, saliva contributes to remineralization [10-12]. When fluoride is applied in high concentrations (in vehicles such as varnishes and gels), a calcium fluoride precipitate is produced on the surface of the enamel and in the plaque. This calcium fluoride acts as a temporary storage of fluoride, which is released when the $\mathrm{pH}$ drops [11]. Hence, varnishes and gels deliver fluoride to the 


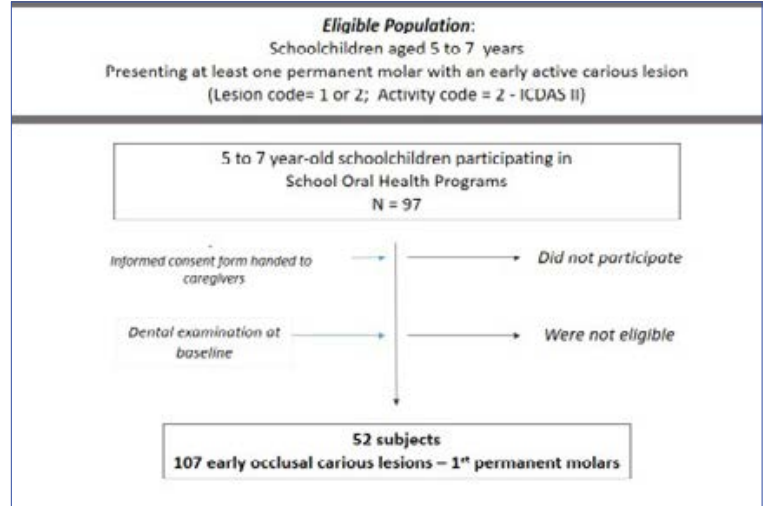

Figure 1. Sampling method.

enamel surface and to the subsurface of carious lesions, where calcium fluoride deposits and acts as a reservoir of fluoride ions [16]. The presence of fluoride ions during the demineralization stage guarantees the incorporation of fluoride into the apatite crystals, forming crystalline structures that are more resistant to acid challenge [21]. Fluorides can contribute both to decreasing lesion progression and to arresting or repairing lesions. These effects have been studied in vitro and in situ. A meta-analysis on four studies showed that $5 \%$ sodium fluoride $(\mathrm{NaF})$ varnish remineralized approximately two thirds of caries lesions in children [22]. Different compounds have been added to fluoride varnishes with the aim to achieve improved mineralizing effects. However, addition of chlorhexidine or calcium fluoride has not shown significant clinical benefits [4-8-1]. The addition of $\beta$ tricalcium phosphate ( $\beta T C P$ ) to fluoride varnish improved the protective ability of the varnish on primary teeth, based on microhardness readings[2].

Objective: To compare the effectiveness of 3 professionally applied fluorides in arresting incipient carious lesions in young permanent teeth.

\section{MATERIALS AND METHODS}

A quasi-experimental study was conducted. Nonprobability consecutive sampling was used to select participants (Fig.1). A baseline diagnosis was performed to identify eligible subjects. The eligible population comprised schoolchildren aged 5 to 7 years, attending public schools in the city of Buenos Aires, presenting at least 1 permanent molar with activeincipient caries lesion (corresponding to lesion codes 1 and 2 and activity status 2 according to ICDAS II criteria) [20].

The study was conducted within the framework of a dental care program for schoolchildren in suburban neighborhoods, in school settings. Schoolchildren complying with the eligibility criteria and whose legal guardians signed the informed consent form were included in the study.

Fifty-two subjects had at least one early carious lesion in a permanent molar. The final study sample

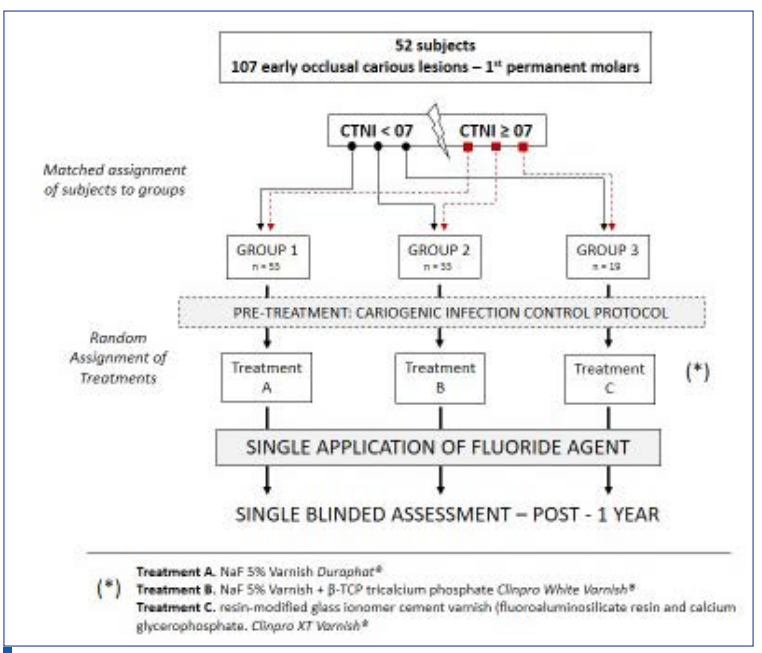

Figure 2. Study design.

comprised 107 tooth surfaces with early occlusal carious lesions.

\subsection{Study design}

The subjects were divided into three groups matched according to the caries treatment needs, which was determined according to the severity of the carious lesion $\left(\mathrm{CTNI}^{19} \leq 6-\right.$ no caries lesion involving the pulp; does not require complex treatments / CTNI $\geq 7$ - presence of caries lesion involving the pulp; requires pulp therapy or surgery). The treatments (professionally applied fluoride) were randomly assigned to each group.

Group A: 5\% Sodium Fluoride Varnish (Duraphat ${ }^{\circledR}$ )

Group B: Sodium Fluoride varnish containing $\beta$-TCP tricalcium phosphate (Clinpro White Varnish ${ }^{\circledR}$ )

Group C: Glass ionomer modified with fluoroaluminosilicate resin and calcium glycerophosphate (Clinpro XT Varnish $^{\circledR}$ ). In compliance with the protocol, all subjects received a preventive treatment protocol, which included measures to control factors influencing the biofilm formation and structure, such as biofilm retention sites and active cavitated carious lesions: training and supervision of oral tooth brushing, supragingival scaling in cases presenting calculus, polishing of restorations, and restoration of cavitated carious lesions with no pulpal involvement using an atraumatic restorative technique (ART). Primary and permanent teeth presenting caries lesions with pulpal involvement were endodontically treated or extracted according to the type of pulpal involvement (PUFA index) and size of the tooth remnant, thus determining the subsequent restoration.

The corresponding fluoride was applied on the lesions once, following the manufacturers' instructions. The lesions were assessed one year postfluoride application (simple blinding technique: the examiner was blinded to the treatment allocation of the subjects). The diagnosis and assessment of the lesions were performed by two researchers who were calibrated against a gold standard examiner (Kappa interrater agreement value $>0.8$ ). The statistical 


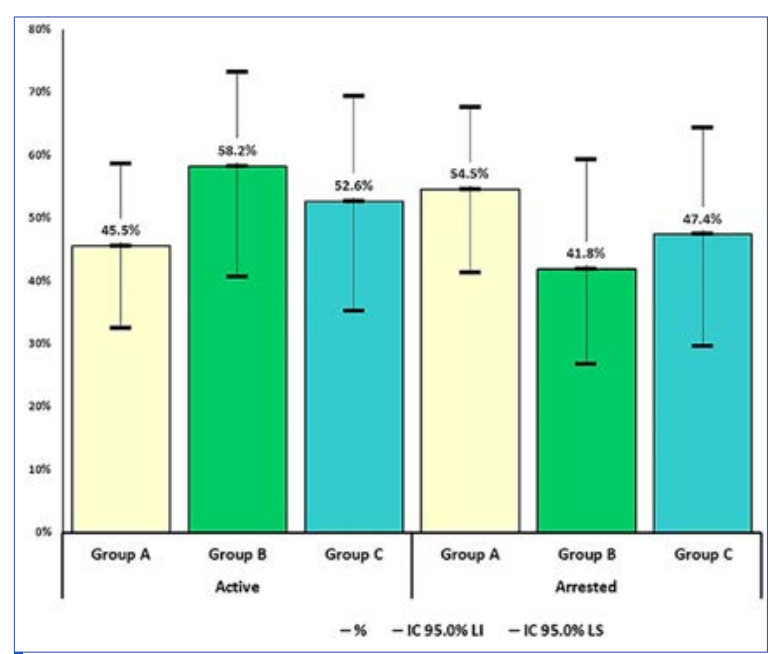

Figure 3. Arrest of early carious lesion 1 year post-treatment.

analysis involved calculating the frequency of (a) early carious lesion remineralization one year posttreatment and of (b) carious lesions that remained active but showed no progression one year posttreatment. The groups were compared using the Chi square test and the comparison of proportions for independent samples. Due to the sample size, a Bootstrap technique was apllied with Montecarlo sampling methods (1000 samples $-95 \% \mathrm{Cl}$ level). A binomial exact test was used to compare groups.

\subsection{Compliance with Ethical Requirements}

The caregivers/legal guardians of the schoolchildren signed an informed consent form authorizing the child's participation in the study. All the schoolchildren who participated in the study gave their assent for the treatment.

The present research work was approved by the ethics committee of the University of Buenos Aires (UBACyT 20020120100324BA).

\section{RESULTS}

The percentage of early carious lesions that became stabilized according to ICDAS II criteria one year post-treatment was $54.5 \%$ in Group 1 (Duraphat ${ }^{\circledR}$ ), $41.8 \%$ in Group 2 (Clinpro White varnish), and $47.4 \%$ in Group 3 (Clinpro XT varnish). No statistically significant differences were observed among groups (Pearson Chi square test: $d f=2 ; p$-value $=0,529$ ). The tests were adjusted for all pairwise comparisons within a row of each innermost subtable using the Bonferroni correction (Fig. 3). As regards the caries progression, $91.4 \%$ of lesions in Group 1, 83.3\% of lesions in Group 2, and $100.0 \%$ of lesions in Group 3 showed no progression, with no significant differences among groups (Pearson Chi square test: $d f=2 ; p$-value $=0,201$ ) (Fig. 4). When considering the sub-set of lesions that remained active one year post-treatment, the percentage of lesions showing no caries progression was $80.0 \%$ in Group 1, 69.0\% in Group 2, and $100.0 \%$ in Group 3; no significant

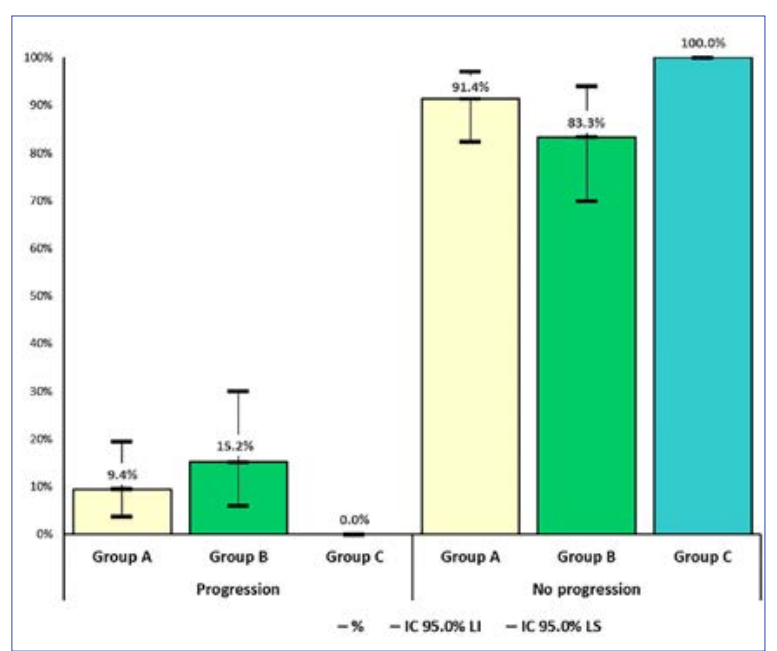

Figure 4. Early carious lesion progression 1 year post-treatment.

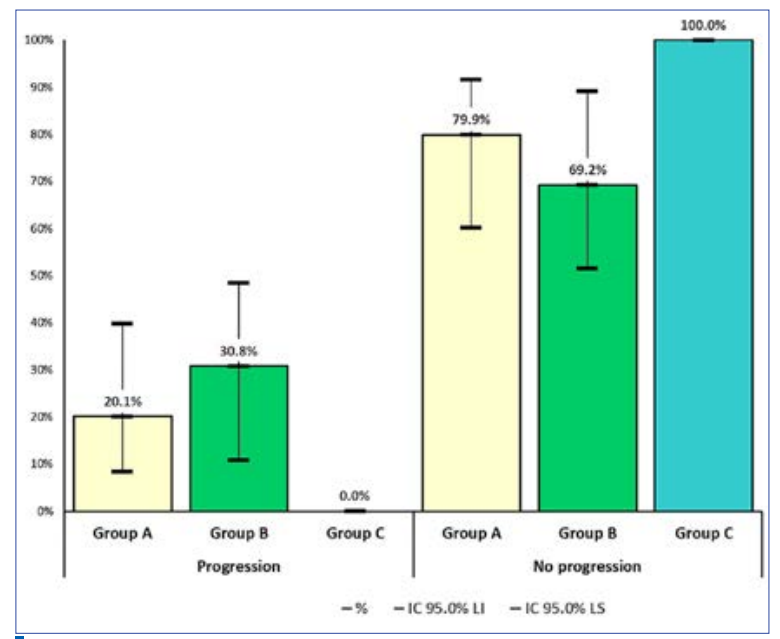

Figure 5. Early carious lesion progression among lesions remaining active 1 year after treatment.

differences were observed among groups (Fig.5). In all cases the tests were adjusted for all pairwise comparisons within a row of each innermost subtable using the Bonferroni correction. In Group C, this category was not used in comparisons because its column proportion is equal to zero or one

After appliyng the Bootstrap technique, no significant differences were found for caries arrest ( $p$ value Exact Test $=0,577$ (CI95\%: 0,544-0,569)); caries progression ( $p$ value Exact Test $=0,225$ (CI95\%:0,214$0,236)$ ); and early carious lesion progression among lesions remaining active ( $p$ value Exact Test $=0,274$ (CI95\%: 0,263-0,286).

\section{DISCUSSION}

The professional application of fluoride varnishes to treat early enamel carious lesions is a noninvasive, easy to use and low cost procedure compared to conventional mechanical treatments. The effectiveness of fluoride varnishes in primary caries prevention has been widely investigated, and recommendations for its use in primary and clinical 


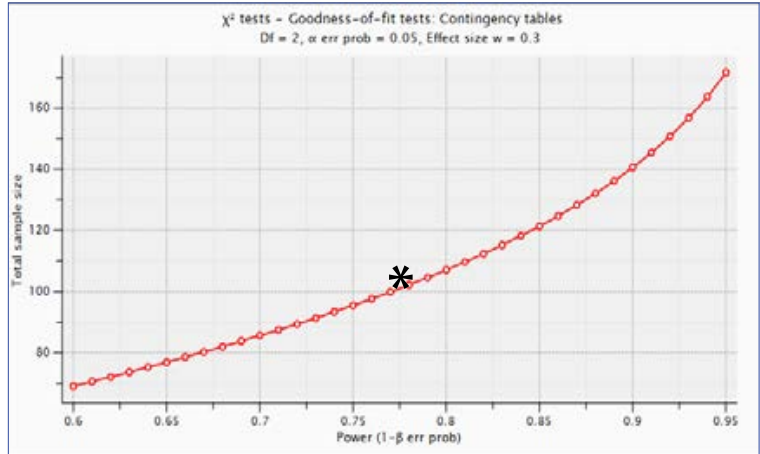

Figure 6. Power analysis.

permanent dentitions are supported by conclusive scientific evidence [18-13]. Nevertheless, few studies have assessed the effect of fluoride on early carious lesions, especially those located in the pit and fissure system. According to a systematic review [22], six clinical trials demonstrated the remineralizing effect of $5 \% \mathrm{NaF}$ varnish. The results of a meta analysis on four of the six clinical trials showed an overall percentage of remineralised enamel caries of $63.6 \%$ (Cl 95\%: 36.0\% - 91.2\%). A number of studies have evaluated early carious lesion remineralization using $5 \% \mathrm{NaF}$ varnish, by measuring the reduction in white spot lesion size 4-8, and determining the percentage of remineralized carious lesions, in a range between $81.2 \%$ and $71.4 \%$ [1-5-3]. The results of the works mentioned above are not comparable with the results of the present study given the differences in the localization of the studied lesions, type of dentition, frequency of application of the varnish, and duration of the studies. The arrest and progression of active incipient occlusal caries in the first permanent molars of six-year old children were analyzed [9]. The results after one year application of $5 \% \mathrm{NaF}$ varnish (Duraphat ${ }^{\circledR}$ ) showed remineralization in $83.3 \%$ of lesions and caries progression in $5.5 \%$ of lesions. The results of the present study however, showed $54.4 \%$ caries arrest and $16.7 \%$ progression in the $5 \%$ $\mathrm{NaF}$ treated group. The differences may be due to the characteristics of the studied populations, the setting where the studies were conducted, and the

\section{REFERENCES}

1. Almeida MQ, Costa OXI, Ferreira JMS, et al. Therapeutic potentia of Brazilian fluoride varnishes: an in vivo study. Braz Dent J. 2011;22(3):193-197.

[Full text links] [CrossRef] [PubMed] Google Scholar Scopus

2. Al Amoudi SA, Sharat CP, AlOmari M. The effect of the addition of tricalcium phosphate to $5 \%$ sodium fluoride varnishes on the microhardness of enamel of primary teeth. Int J Dent. 2013:2013:486358.

[Full text links] [CrossRef] [PubMed] Google Scholar Scopus

3. Autio-Gold JT, Courts F. Assessing the effect of fluoride varnish on early enamel carious lesions in the primary dentition. J Am Dent Assoc. 2001;132(9):1247-1253; quiz 1317-1318. [Full text links] [CrossRef] [PubMed] Google Scholar Scopus

4. de Amorim RG, Leal SC, Bezerra AC, et al. Association of chlorhexidine and fluoride for plaque control and white spo lesion remineralization in primary dentition. Int J Paediatr Dent. 2008;18(6):446-451.

[Full text links] [CrossRef] [PubMed] Google Scholar Scopus

5. Du M, Cheng N, Tai B, et al. Randomized controlled trial on fluoride varnish application for treatment of white spot lesion after fixed orthodontic treatment. Clin Oral Investig. 2012;16(2):463-468.

[Full text links] [CrossRef] [PubMed] Google Scholar Scopus diagnostic criteria applied in each study. The work presented here is the first in vivo study on carious lesion arrest using a fluoride varnish containing $\beta$-TCP tricalcium phosphate. Other studies evaluated the effectiveness of professional application of fluoride varnishes containing calcium fluoride $(6 \%$ Difluoride $\mathrm{XII}^{\oplus}$ ) on remineralization of white spot lesions in permanent anterior teeth, and found no differences compared to lesions treated with $5 \%$ $\mathrm{NaF}$ varnish [8-1]. In the present work, goodnessof-fit was lower than 0.8. Further studies using a larger sample size to decrease the probability of a beta error are necessary (Fig.6). As a strength of this study, we consider that it contributes to the current knowledge on the effectiveness of different fluoride varnishes in arresting early occlusal carious lesions in young permanent molars. The results presented here may prove relevant to decision making in the private practice setting as well as in public health care programs.

\section{CONCLUSION}

The three fluorides studied here showed similar effectiveness in arresting early carious lesions in young permanent teeth one year after application.

\section{CONFLICT OF INTEREST}

The authors declare no conflict of interest.

\section{AUTHOR CONTRIBUTIONS}

GLK: Data analysis, Manuscript drafting, CC and MT: Data gathering, Data interpretation, PAS: Data interpretation, Data analysis, AFS: Protocol design, Data interpretation, Manuscript revision.

\section{ACKNOWLEDGEMENTS}

The authors thank to Municipalidad de Tigre and Universidad de Buenos Aires (Grant UBACYT 20020120100324BA).

6. Fejerskov $\mathrm{O}$. Changing paradigms in concepts on dental caries: consequences for oral health care. Caries Res. 2004;38(3):182-191. [Full text links] [CrossRef] [PubMed] Google Scholar Scopus

7. Fejerskov O, Nyvad B, Kidd E. A. M. Pathology of dental caries. In: Fejerskov O, Kidd E (ed). Dental caries - The disease and its clinical management. 2nd ed. Oxford: Blackwell Munksgaard; 2008. Chap. 3 8. Ferreira JMS, Aragão AKR, Rosa ADB, et al. Therapeutic effect of two fluoride varnishes on white spot lesions: a randomized clinical trial. Braz Oral Res. 2009;23(4):446-451.

[Full text links] [CrossRef] [PubMed] Google Scholar Scopus

9. Flório FM, Pereira AC, Meneghim Mde C, Ramacciato JC. Evaluation of non-invasive treatment applied to occlusal surfaces. ASDC J Dent Child. 2001;68(5-6):326-331, 301.

[PubMed] Google Scholar Scopus

10. Hall AF, Buchanan CA, Millett DT, et al. The effect of saliva on enamel and dentine erosion. J Dent. 1999;27(5):333-339.

[CrossRef] [PubMed] Google Scholar Scopus

11. Horowitz AM. Introduction to the symposium on minimal intervention techniques for caries. J Pub Health Dent. 1996;56(3):133-134

[Full text links] [CrossRef] [PubMed] Google Scholar Scopus 
12. Imfeld T. Prevention of progression of dental erosion by professional and individual prophylactic measures. Eur J Oral Sci. $1996 ; 104(2(P t 2)): 215-220$.

[Full text links] [CrossRef] [PubMed] Google Scholar Scopus

13. Marinho VC, Worthington HV, Walsh T, Clarkson JE. Fluoride varnishes for preventing dental caries in children and adolescents. Cochrane Database Syst Rev. 2013;(7):CD002279. [CrossRef] [PubMed] Google Scholar Scopus

14. Marsh PD. Are dental diseases examples of ecological catastrophes? Microbiology. 2003;149(Pt 2):279-294.

[CrossRef] [PubMed] Google Scholar

15. Marsh PD. Dental plaque as a biofilm and a microbial community - implications for health and disease. BMC Oral Health. 2006;6(Suppl 1):S14.

[Full text links] [CrossRef] [PubMed] Google Scholar Scopus 16. Øgaard B, Ten Bosch JJ. Regression of white spot enamel lesions. A new optical method for quantitative longitudinal evaluation in vivo. Am J Orthod Dentofacial Orthop. 1994;106(3):238-242.

[Full text links] [CrossRef] [PubMed] Google Scholar Scopus

17. Peters MC. Strategies for noninvasive demineralized tissue repair. Dent Clin North Am. 2010;54(3):507-525.

[Full text links] [CrossRef] [PubMed] Google Scholar Scopus

18. Petersen PE, Lennon MA. Effective use of fluorides for the prevention of dental caries in the 21st. century: the WHO approach. Community Dent Oral Epidemiol. 2004;32(5):319-321.

[Full text links] [CrossRef] [PubMed] Google Scholar Scopus

19. Piovano S, Squassi A, Bordoni N. [Dental caries index: state of the art.] Rev Fac Odontol. (Univ Buenos Aires). 2010;25(58):29-43. [Article in Spanish]

20. Pitts NB. Modern concepts of caries measurement. J Dent Res. 2004;83 Spec No C:C43-C47.

[Full text links] [CrossRef] [PubMed] Google Scholar Scopus

21. Rošin-Grget K, Peroš K, Šutej I, Bašić K. The cariostatic mechanisms of fluoride. Acta Med Acad. 2013;42(2):179-188.

[CrossRef] Google Scholar Scopus

22. Shiqian Gao S, Zhang S, Lei Mei M, et al. Caries remineralisation and arresting effect in children by professionally applied fluoride treatment - a systematic review. BMC Oral Health. 2016;16:12.

[Full text links] [CrossRef] [PubMed] Google Scholar Scopus

\section{Graciela Liliana KLEMONSKIS \\ DDS, PhD, Associated Professor \\ Chair of Preventive and Community Dentistry \\ Faculty of Dentistry \\ University of Buenos Aires \\ Buenos Aires, Argentina}

Graciela Liliana Klemonskis studied dental medicine at the Faculty of Dentistry, University of Buenos Aires, where she obtained her DDS. After graduation, she pursued her professional training and attended a Master's Program in Public Health (MSc) at the same university. That program focused on Oral Health Systems and Services Management. She went on to get her PhD in Dentistry, specializing in Epidemiology and Public Health. Dr Klemonskis is also a Researcher member at Institute of Public Health Research, University of Buenos Aires.

Teaching areas: oral epidemiology; community dentistry; strategic planning; oral health systems and services.

\section{Regarding this study...}

\section{1.... the final sample comprised:}

a. 107 tooth surfaces with early occlusal carious lesions;

b. 52 tooth surfaces with early occlusal carious lesions;

口c. 94 tooth surfaces with early occlusal carious lesions;

d. 45 tooth surfaces with early occlusal carious lesions.

\section{2.... the proportion of arrested lesions 1-year post treatment was:}

$\square$ a. less than $50 \%$ in the three groups with no statistical difference among groups;

b. over $50 \%$ in the three groups with no statistical difference among groups;

ac. over $40 \%$ in the three groups with no statistical difference among groups;

$\square$ d. less than $40 \%$ in the three groups with no statistical difference among groups.

\section{3. ... the proportion of lesions showing progression 1-year post treatment was:}

a. less than $20 \%$ in the three groups with no statistical difference among groups;

b. over $10 \%$ in the three groups with no statistical difference among groups;

ac. over $80 \%$ in the three groups with no statistical difference among groups;

d. less than $10 \%$ in the three groups with no statistical difference among groups.

\section{4. ...subjects within experimental groups were matched according:}

a. caries experience;

b. caries treatment needs;

ac. presence of restorations ;

ad. age. 


\title{
VOLUME, ASYMMETRY AND RECIPROCAL RELATIONSHIPS BETWEEN PARANASAL SINUSES: A 3D SEGMENTATION STUDY ON HEAD CT-SCANS
}

\author{
Giulia Andrea Guiduglit,2a $\left(\right.$ Daniele Maria Gibellib ${ }^{1-}$, Michaela Cellina ${ }^{3 c}\left(\right.$, Antonio Giancarlo Oliva ${ }^{34}$, \\ Luisa Barni $^{1 e}(\mathbb{D})$, Patrizia Sartori ${ }^{1 f(D)}$, Chiarella Sforza ${ }^{1 g^{*}}$ (D) \\ 'Department of Biomedical Sciences for Health, University of Milan, I-20133 Milan, Italy \\ 2Department of Orthopedics and Traumatology, Lugano Regional Hospital, CH-6900 Lugano, Switzerland \\ ${ }^{3}$ Department of Radiology, Fatebenefratelli Hospital, ASST Fatebenefratelli Sacco, I- 20157 Milan, Italy \\ ${ }_{a, c, d} M D ;{ }^{b} M D, P h D ; e, f B S C$, PhD; ${ }^{9} M D$, Professor
}

Introduction: Very little is known about the morphology of paranasal sinuses, especially with respect to symmetry.

Methodology: The head CT-scans of 100 patients (50 male, 50 female) were retrospectively analyzed. The volume segmentation of frontal, sphenoid and maxillary sinuses was performed through semi-automatic segmentation. An asymmetry index was extracted, and differences according to sex and side were assessed through ANOVA test $(p<0.05)$. Pearson test was applied to verify possible correlation between age and volume and asymmetry index in different paranasal sinuses and sexes $(p<0.05)$.

Results: On average, male sinuses were larger in volume than female ones $(p<0.01)$. Generally, volumes of the three sinuses were significantly related each other in both sexes (correlation coefficients ranging between 0.34 and 0.58). In both sexes, the maxillary sinus was less asymmetric than the other two types, without significant sex-related differences $(p>0.05)$. Significant inverse correlations between sinus volume and asymmetry index were found for the sphenoid and maxillary sinuses in males, and for the maxillary sinus in females. No correlation of sinus volume or asymmetry index with age was found, with

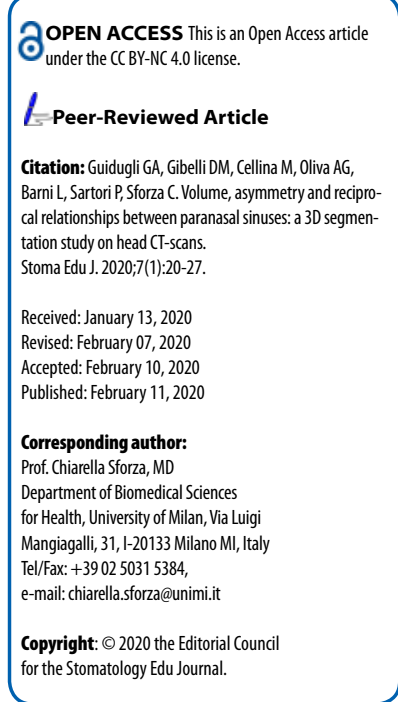
the exception of maxillary volume/age in females.

Conclusion: The present results may find practical applications in planning surgical procedures involving paranasal sinuses.

KEYWORDS

Anatomy; CT-Scan; Segmentation; Paranasal Sinuses; Surgery.

\section{INTRODUCTION}

The paranasal sinuses are air-filled anatomical structures inside the skull and facial bones forming a complex interconnected system communicating with the nasal cavities through an ostium [1,2]. There are four paired paranasal sinuses: the maxillary, frontal and sphenoid sinuses, and the ethmoid cells, with great inter- and intra-individual variations. Shape and size of the paranasal sinuses are probably the most variable of all the anatomical structures of the entire body [3,4]. Genetic diseases, infectious and environmental conditions may influence these variations [5]. A detailed knowledge of anatomy and anatomic variations of paranasal sinuses has become mandatory in the recent years due to advances in imaging technology and in functional endoscopic sinus surgery (FESS) which represents the current standard treatment for chronic paranasal sinus pathology [6]. To detect sinus pathologies, determine therapy, plan endonasal surgeries and avoid careless manipulation, detailed knowledge of their morphology has a crucial clinical value [7].

Despite the great importance of this topic, the morphological characteristics of paranasal sinuses are incompletely known. Most of the studies performed on adults analyzed the maxillary sinuses, and very few investigations considered the maxillary, frontal and sphenoid sinuses together, and especially their symmetry [8].

The development of the paranasal sinuses starts in the late embryonic period and continues into young adulthood [8]. The maxillary sinus is the first sinus to appear and starts from ectodermal cells between the $7^{\text {th }}$ and $10^{\text {th }}$ week of development and grows until 17 years of life. It develops from a shallow groove expanding from the primitive infundibulum to the maxilla. After birth, the growth of the maxillary sinus 


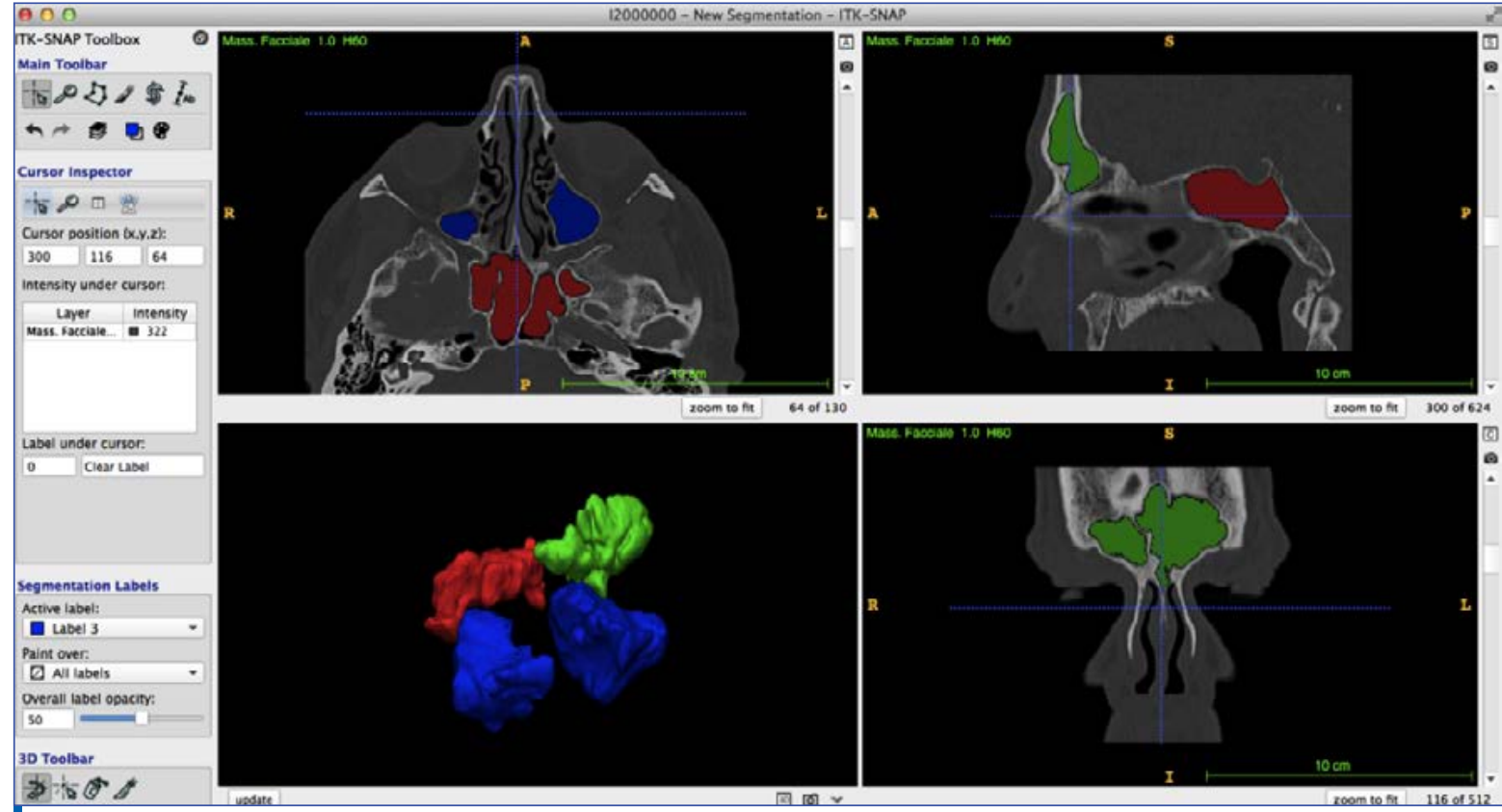

Figure 1. Example of 3D segmentation on CT-scan: in the lower left box, the 3D models of frontal, sphenoid and maxillary sinuses.

is biphasic: the first spurt occurs during the first three years then again between the ages of 7-12. After the age of 12, the growth slowly continues until adulthood. The sphenoid sinus develops as evagination of the spheno-ethmoidal recess about the $3^{\text {rd }}$ intrauterine month and reaches full size at the age of 7 . In extreme cases of pneumatization the optic nerve and internal carotid artery may lie naked within the sinus cavity [9]. The frontal sinus is the most variable; its development begins during the $16^{\text {th }}$ prenatal week as a direct continuation of the embryonic infundibulum and frontal recess superiorly, or by upward migration of anterior ethmoidal air cells to penetrate the inferior aspect of the frontal bone between its outer and inner tables. The right and left sides of the frontal sinuses develop independently as a result of bone resorption and septations [10]. It remains as a cul de sac within the frontal bone till 2 years of age.

The pneumatization process continues till the age of 9 , but the volume, height and width of frontal sinuses continue to increase until the age of 20 related to the growth pattern and grade of craniofacial structures $[11,12]$.

During the sinus development, struts, structural components and bony deposition are crucial to protect against external physical forces. Several interindividual differences in shape and behavior patterns can be noticed. According to Kim et al. [8], three different explanations can be considered. The first one is that the incessant conflict between epithelial expansion (formation of cavities) and bony deposition (protection from the external environment) can undergo different patterns, and produces a great variability. The second and third hypotheses try to explain differences between individuals through heredity: for the second one pneumatization is genetically determined and for the latter hypothesis the degree of pneumatization also depends on the pathological involvement during childhood [8]. In recent years, the threedimensional segmentation of medical image data has been largely applied to the morphological evaluation of the upper airways, included the paranasal sinuses. The volume of air cavities is the simplest and most significant parameter for the evaluation of the paranasal sinuses [13]. Several investigations analyzed the volume of paranasal sinuses $[8,10,14-17]$, but little is known about their symmetry, and the calculation of asymmetry indices has been performed only in forensic contexts $[17,18]$. In the present study, we segmented CTscan images to create three-dimensional models of the maxillary, frontal and sphenoid sinuses, and calculated their volume. The aim of the study was to investigate inter and intra-individual variations and possible correlations of the sinuses' volume and pneumatization in a large sample of adults. The results will improve knowledge concerning the morphological characteristics of paranasal sinuses.

\section{METHODS AND MATERIALS}

\subsection{Sample}

For this study, 100 head CT-scans were selected from the database of a hospital in Northern Italy and analyzed retrospectively. The CT-scans were anonymized according to local and international ethic rules. The study followed the guidelines of the Helsinki Declaration and was approved by the local ethical committee (7331/2019). The mean age of the male patients was $49.32 \pm 18.9$ years (range, 21-91 years), while the mean age of the female patients was $57.1 \pm 22.8$ years (range, 20-91 years). No differences were found in the age distribution between males and females (Student's t test, $p>0.05$ ). The most 
ITable 1.Volume of paranasal sinuses in 100 healthy subjects (mean \pm SD).

\begin{tabular}{|c|c|c|c|c|c|c|c|c|c|}
\hline & \multicolumn{3}{|c|}{ Frontal sinuses } & \multicolumn{3}{c|}{ Sphenoid sinuses } & \multicolumn{3}{c|}{ Maxillary sinuses } \\
\hline & Right & Left & Total & Right & Left & Total & Right & Left & Total \\
\hline Males & $4.2 \pm 2.2$ & $5.4 \pm 3.6$ & $9.6 \pm \mathrm{w} 5.04$ & $5.4 \pm 3.6$ & $5.6 \pm 3.4$ & $10.9 \pm 5.3$ & $16.4 \pm 5.1$ & $15.9 \pm 5.6$ & $32.3 \pm 10.4$ \\
\hline Females & $2.2 \pm 1.4$ & $2.7 \pm 1.8$ & $4.9 \pm 2.8$ & $4.4 \pm 2.6$ & $3.9 \pm 2.2$ & $8.3 \pm 2.9$ & $13.2 \pm 3.8$ & $13.1 \pm 3.6$ & $26.3 \pm 6.9$ \\
\hline M+F & $3.2 \pm 2.1$ & $4.0 \pm 3.1$ & $7.2 \pm 4.7$ & $4.9 \pm 3.2$ & $4.7 \pm 2.9$ & $9.6 \pm 4.4$ & $14.8 \pm 4.8$ & $14.9 \pm 4.9$ & $29.3 \pm 9.3$ \\
\hline
\end{tabular}

All values are expressed in $\mathrm{cm}^{3}$

Table 2. Correlation coefficients among sinus volumes.

\begin{tabular}{|c|c|c|c|}
\hline & Frontal & Sphenoid & Maxillary \\
\hline Frontal & & $0.34^{*}$ & $0.36^{* *}$ \\
\hline Sphenoid & $0.58^{* *}$ & & $0.36^{* *}$ \\
\hline Maxillary & 0.23 & $0.47^{* *}$ & \\
\hline
\end{tabular}

Female values are in italics; ${ }^{*} \mathrm{p}<0.05 ;{ }^{* *} \mathrm{p}<0.01$
Table 3. Correlation coefficients among age, sinus volumes and a symmetry indices.

\begin{tabular}{|c|c|c|c|c|c|c|c|}
\hline & & \multicolumn{3}{|c|}{ Volume } & \multicolumn{3}{c|}{ Asymmetry } \\
& Sex & Frontal & Sphenoid & Maxillary & Frontal & Sphenoid & Maxillary \\
\hline Age & Females & -0.02 & -0.04 & -0.07 & -0.14 & -0.06 & $0.29^{*}$ \\
\hline Age & Males & -0.13 & -0.21 & -0.24 & 0.14 & -0.14 & 0.16 \\
\hline
\end{tabular}

Female values are in italics; ${ }^{*} p<0.05$ frequent clinical requests for CT-scan were screening for fractures in case of trauma $(57.3 \%)$, suspected sinusitis (20.0\%), neurological symptoms (12.7\%). Subjects with paranasal sinuses aplasia, chronic paranasal sinus pathology, edentulism, maxillofacial fractures or congenital craniofacial abnormalities, or any pathological conditions involving paranasal sinuses were excluded from the study.

\subsection{CT-scan acquisition}

All CT-scans were acquired through the same instrument, a second generation dual-source scanner, Somatom Definition Flash (Siemens, Forchheim, Germany). The acquisition parameters were: kV: 120; mAs: 320; collimation: $40 \times 0.6 \mathrm{~mm}$; tube rotation: 1 sec; reconstruction thickness: $3 \mathrm{~mm}$; reconstruction filters: H21s smooth for soft tissues and H60 sharp for bone.

\subsection{Data collection}

Volume segmentation from the DICOM files was performed by a single operator using a semi-automatic segmentation with the freeware ITK-SNAP (Fig. 1) [19]. Volume was automatically calculated through VAM $^{\otimes}$ (Vectra Analysis Module, version 2.8.3, Canfield Scientific Inc., USA) [20].

Intra-operator repeatability of segmentation through ITK-SNAP had already been tested: no significant differences between repeated segmentations and volume measurements were found, with a random error explaining less than $1 \%$ of sample variance [21]. The sinus side prevalence was assessed for every pair of sinuses, and an asymmetry index was calculated as follows:

$\mid\left(\right.$ volume $_{\mathrm{r}}$ - volume $) /$ ( volume $_{\mathrm{r}}+$ volume $\left._{\mathrm{l}}\right) \times 100 \mid$

Where volume is the volume of the right sinus, volume, the volume of the left sinus. The index ranges from 0 (perfect symmetry) to 100 (totally asymmetrical).

\subsection{Statistical analysis}

The normal distribution and homoscedasticity for volumes and asymmetry index were assessed respectively through Jarque-Bera test and Bartlett tests. Tests were run through the MATLAB statistic toolbox. Possible statistically significant differences in volume and asymmetry index according to sex and type of sinus were assessed through the twoway ANOVA test. In case of statistically significant differences according to type of sinus, post-hoc tests were performed through the Tukey's Honestly Significant Difference (HSD), separately for males and females. Pearson correlation coefficients were calculated between age, sinus volume and asymmetry index.

A p value of 0.05 or less was considered significant.

\section{RESULTS}

The volume measurements are listed in Table 1. On average, male sinuses were larger in volume than female ones $(F=38.87, p<0.0001)$, with the maxillary sinus being about three (sphenoid sinus) and four (frontal sinus) times larger than the other ones ( $F=387.75 ; p<0.0001)$.

Post-hoc HSD tests found that both the frontal and sphenoid sinuses were significantly smaller than the maxillary one in both males and females $(p<0.01)$; in addition, in females also the difference between frontal and sphenoid sinuses was significant $(p<0.01)$. No significant sex $x$ sinus interaction was found $(F=1.96, p=0.1427)$.

The volumes of the three sinuses were significantly related to each other in both sexes, except for the maxillary and frontal sinuses volumes in males (Table 2). However, in all cases the correlation coefficients were generally low, ranging between 0.34 and 0.58 . No correlation of sinus volume with age was found (Table 3).The side prevalence was assessed for every pair of sinuses (Fig. 2). In both males and females the 


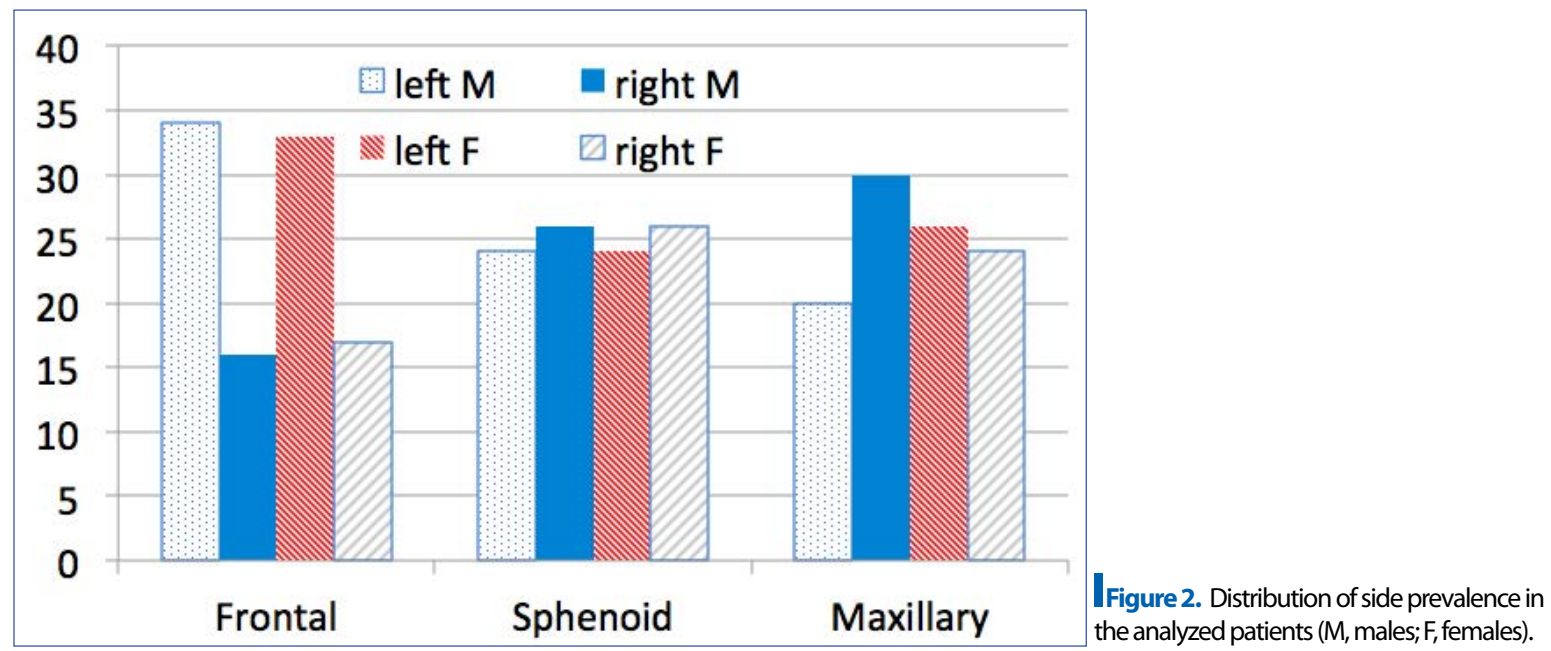

ITable 4. Asymmetry indices in the analyzed paranasal sinuses (mean $\pm S D$ ).

\begin{tabular}{|c|c|c|c|}
\hline & Frontal & Sphenoid & Maxillary \\
\hline Males & $22.28 \pm 18.36$ & $36.96 \pm 26.00$ & $7.47 \pm 8.40$ \\
\hline Females & $28.69 \pm 18.59$ & $37.89 \pm 27.89$ & $8.11 \pm 8.51$ \\
\hline M+F & $25.48 \pm 18.66$ & $37.43 \pm 26.83$ & $7.79 \pm 8.42$ \\
\hline
\end{tabular}

All values are $\%$.

left frontal sinus was prevailing in about two-thirds of patients ( $68 \%$ males and $66 \%$ females). For the sphenoid sinus, the larger volume was in the right side in $52 \%$ of patients (both males and females). The right maxillary sinus was prevalent in $60 \%$ of males and in $48 \%$ of females. Only $26 \%$ of subjects had the same side prevailing for all sinuses ( $17 \%$ left side and $9 \%$ right side).

The asymmetry indices calculated for the three pairs of sinuses and according to sex are reported in Table 4. In both sexes, the maxillary sinus was the less asymmetric of the other two, its asymmetry index being approximately one third of the frontal sinus and one fifth of the sphenoid sinus ( $F=58.53$, $\mathrm{p}<0.0001$ ).

Post hoc tests found that both the frontal and sphenoid sinuses were significantly more asymmetric than the maxillary one ( $p<0.01$ for both comparisons in both sexes), while the difference between the frontal and sphenoid sinuses was significant only in males $(p<0.01)$. No significant sex differences $(\mathrm{F}=1.4, \mathrm{p}=0.2377)$ and sex $\mathrm{x}$ sinus interactions were found $(F=0.7, p=0.4974)$. No correlations of sinus asymmetry with age were found, except for the maxillary sinus in females: older women had more asymmetric sinuses (Table 3 ).

Significant inverse correlations between the sinus volume and asymmetry index were found for the sphenoid $(r=-0.28, p<0.05)$ and maxillary $(r=-0.39$, $\mathrm{p}<0.01)$ sinuses in males, and for the maxillary sinus in females $(r=-0.37, p<0.01)$ : in all occasions, larger sinuses were less asymmetric (Fig. 3).

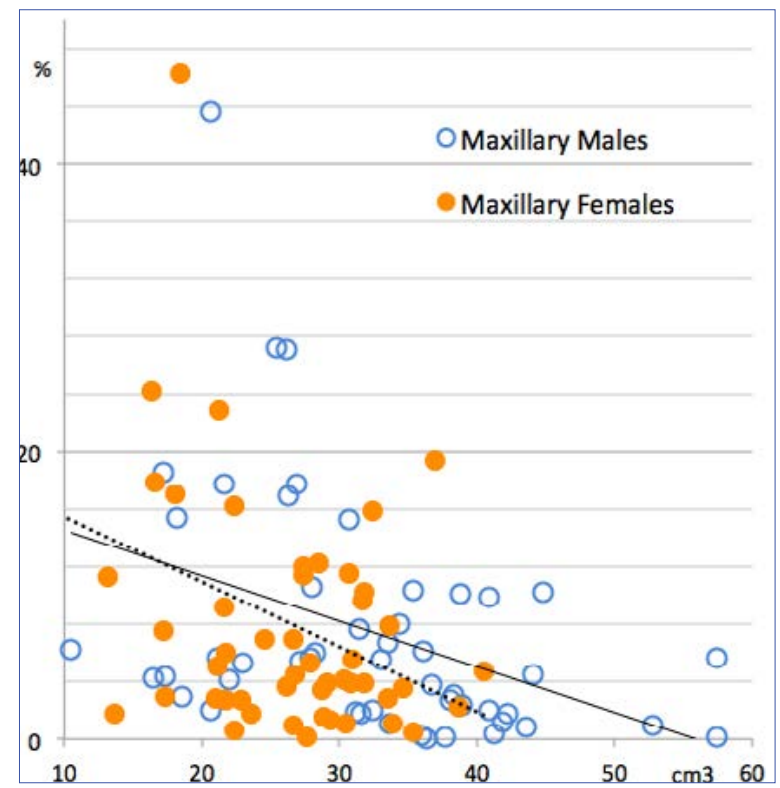

IFigure 3. Correlation between maxillary sinus volume (X axis) and asymmetry index ( $Y$ axis) in males (open circles, continuous line) and in females (closed circles, interrupted line). Both regressions are significant $(p=0.01)$.

\section{DISCUSSION}

The morphology of paranasal sinuses represents a long-time debated issue. In the last decades, the technological improvements and widening of applications of paranasal sinuses surgery have required further investigations to clarify some aspects still unexplored, such as the asymmetry of these structures. To the best of ourknowledge, several studies have assessed the volume of the paranasal sinuses but very few studies have considered the frontal, maxillary and sphenoid sinuses together [17]. In addition, very few studies used an asymmetry index in order to evaluate the side prevalence for every pair of sinuses $[8,22,23]$. Only Kim et al. [8] and Yoshino et al. [24] provided some calculations of the frontal sinus asymmetry but within forensic contexts. They proposed a "bilateral asymmetry index" (BAI) calculated dividing the smaller sinus by the larger one multiplied by 100 and used it for 
ITable 4. Paranasal sinuses volume in literature (mean \pm SD). All values are $\mathrm{cm}^{3}$.

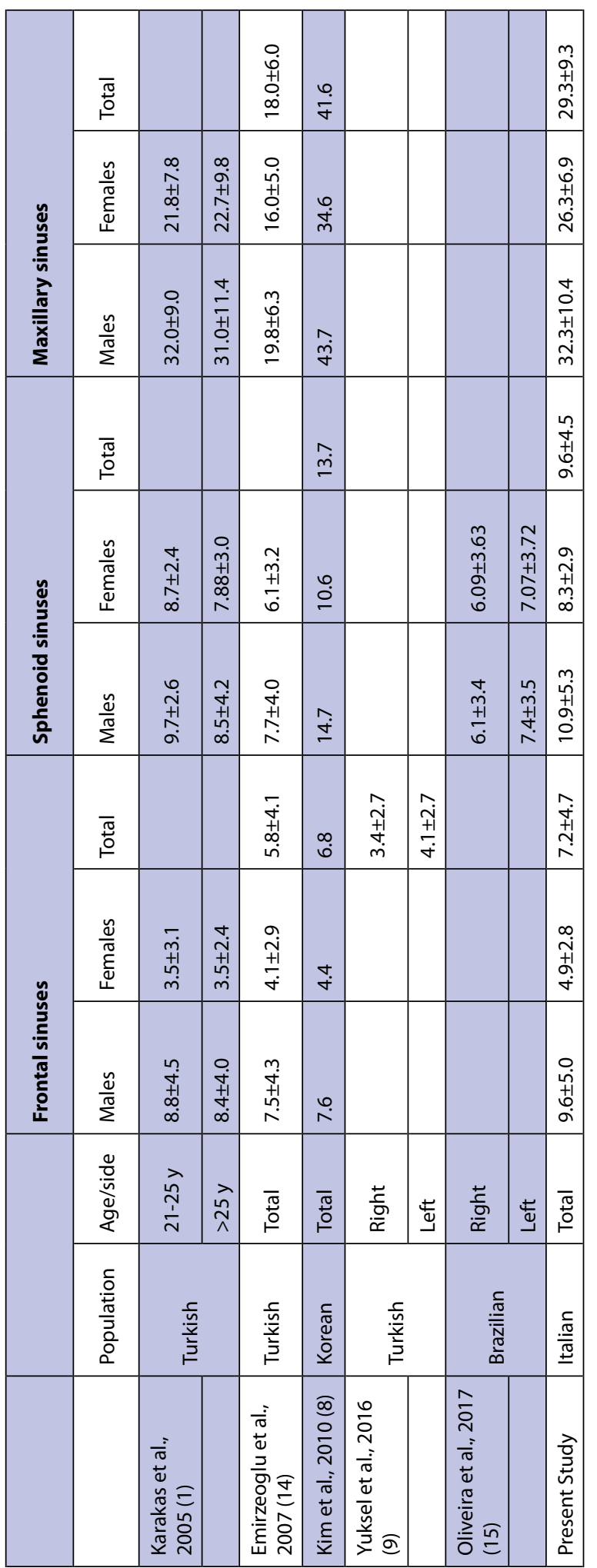

classification purposes. This index maximizes the asymmetry values, and it was considered useful for individual identification, but it has not been applied to surgery. As far as sinus volumes are concerned, the comparison with existing literature highlights differences in values according to authors: these discordances may be explained by ethnic variations and by discrepancies in defining cranial structure.
As far as the Italian population is concerned, values for sphenoid volume are well in line with those already published in a previous publication [25]. Interestingly, different authors reporting data from the same population show discordances in volume measurements $[10,14,15]$; this detail may confirm the importance of ethnic variability which may be extended also to geographical location of different population groups. Another possible variant which may explain discordances in literature is the variety of techniques for volume extraction: however, Karakas and Kavakli found results similar to those of the present study for all three pairs of sinuses, although they used the Cavalieri principle to extract volume, and not a segmentation software (Table 5). On the other side, the Cavalieri principle was also used by Emirzeoglu et al. [15] to estimate the sinus volume, obtaining slightly different results from those currently calculated with semi-automatic segmentation for frontal and sphenoidal sinuses, and smaller values for the maxillary sinus. The use of the Cavalieri principle for the paranasal sinuses has been criticized because of the complex morphology of these organs. The method estimates the organ volume starting from a sample of cross sections, but they may not be sufficiently representative for the organ shape, thus producing unreliable results.

Nonetheless, even if Kim et al. [18] used a segmentation software similar to that applied in the current study, their results are pretty different, with somewhat smaller values for the frontal sinus, and larger for the sphenoidal and maxillary ones. Moreover, also the segmentation protocol used by Oliveira et al. [16] in their analysis of the sphenoid sinus morphology was similar to the present one, but they obtained 1.2-1.6 larger volumes in both sexes. Therefore, possible differences due to the segmentation method cannot be excluded, although its influence cannot be clearly separated from the ethnic variability. Anyway, but for the differences in volumetric measurements, all studies are concordant on the sexual dimorphism of paranasal sinuses, with male structures always larger than the female ones $[10,14,15]$. An interesting result from the present study concerns the correlation between the volumes of different paranasal sinuses: Emirzeoglu et al. [15] found a high correlation between the volumes of the maxillary-frontal and maxillary-ethmoidal sinuses for female subjects, while in the male group the volumes of all sinuses correlated well with each other except for the frontal-sphenoid sinuses. These data confirm that paranasal sinuses are somehow linked one type to another: generally, the similarities in size of different types of paranasal sinuses may be explained by genetic variables involved in their development [8]. However, although statistically significant, the correlation coefficient is low (under 0.70) in all cases; this additional information seems to demonstrate that other factors (probably acquired and/or environmental) may be involved 
in sinuses development. Finally, the present study provided novel data concerning the morphological characteristics of paranasal sinuses: first, both their volume and asymmetry seem not to be related to age, with the exception of maxillary sinus volume in females. Cohen et al. explored the same topic and found that both maxillary and sphenoid sinuses volumes are related with age (they decrease with age) in both sexes [17]. These discordances may be explained in different ways: with respect to the maxillary sinuses, possible alterations of the upper dental profile may represent a bias in assessing volumetric differences. On the other side, differences in sphenoid volume need to be explained, although the ethnic variable may have a role. Another innovative information concerns the significant correlation between the asymmetry index and volume (the smallest the sinuses, the most asymmetric). This has not been reported in literature yet, and proves that asymmetry and volume are somehow linked. However, again the coefficients are too small to exclude other possible variables in determing paranasal sinuses morphology. In the present study the volume segmentation of frontal, sphenoid and maxillary sinuses was performed using semi-automatic segmentation with the freeware ITK-SNAP. Although literature reports several investigations measuring the volume of paranasal sinuses, the systematic study of their asymmetry has been neglected so far. The asymmetry index applied in the current study is of easy calculation, and can complement the analysis of sinus volumes.

\section{CONCLUSIONS}

The current results show that paranasal sinuses in the single individual share some similarities in size possibly explained by underling genetic

\section{REFERENCES}

1. Karataş D, Koç A, Yüksel F, et al. The effect of nasal septal deviation on frontal and maxillary sinus volumes and development of sinusitis. J Craniofac Surg. 2015;26(5):1508-1512.

[Full text links] [CrossRef] [PubMed] Google Scholar Scopus

2. Natsis $\mathrm{K}$, Karabatakis V, Tsikaras $\mathrm{P}$, et al. Frontal sinus anatomical variations with potential consequences for the orbit. Study on cadavers. Morphologie. 2004;88(280):35-38.

[Full text links] [CrossRef] [PubMed] Google Scholar Scopus

3. Jang YJ, Park HM, Kim HG. The radiographic incidence of bony defects in the lateral lamella of the cribriform plate. Clin Otolaryngol Allied Sci. 1999;24(5):440-442.

[Full text links] [CrossRef] [PubMed] Google Scholar Scopus

4. Lorkiewicz-Muszyńska D, Kociemba W, Rewekant A, et al. Development of the maxillary sinus from birth to age 18. Postnatal growth pattern. Int J Pediatr Otorhinolaryngol. 2015;79(9):1393-1400. [Full text links] [CrossRef] [PubMed] Google Scholar Scopus 5. Değermenci $M$, Ertekin $T$, Ülger $H$, et al. The age-related development of maxillary sinus in children. J Craniofac Surg. 2016;27(1):e38-e44.

[Full text links] [CrossRef] [PubMed] Google Scholar Scopus

6. Vaid S, Vaid N. Normal anatomy and anatomic variants of the paranasal sinuses on computed tomography. Neuroimaging Clin $N$ Am. 2015;25(4):527-548.

[Full text links] [CrossRef] [PubMed] Google Scholar Scopus characteristics modulated by local modification due to environmental and acquired factors. Aging does not seem to be a key factor in explaining sinus dimensions and asymmetry, at least in healthy adults, but the two aspects are significantly related, with a larger asymmetry in small sinuses.

The present data may provide a contribution for improving our knowledge concerning the development of paranasal sinuses and possible factors involved in this process. Also, surgical treatments involving paranasal sinuses should consider these characteristics to better plan complex interventions.

\section{CONFLICT OF INTEREST}

The authors declare no conflict of interest.

\section{AUTHORS CONTRIBUTIONS}

GG: conception and design of the study, data acquisition, data analysis, drafting the article, final approval. DG: conception and design of the study, data analysis, data interpretation, drafting the article, revising the article, final approval. MC: data acquisition, data analysis, drafting the article, final approval. AO: data interpretation, revising the article, final approval. LB: data acquisition, revising the article, final approval. PS: data interpretation, revising the article, final approval. CS: conception and design of the study, data interpretation, revising the article, final approval.

\section{Drs. Guidugli and Gibelli equally contributed to this work.}

7. Tingelhoff $\mathrm{K}$, Moral $\mathrm{Al}$, Kunkel $\mathrm{ME}$, et al. Comparison between manual and semi-automatic segmentation of nasal cavity and paranasal sinuses from CT images. Conf Proc IEEE Eng Med Biol Soc. 2007;2007:5505-5508.

[Full text links] [CrossRef] [PubMed] Google Scholar Scopus

8. Kim J, Song SW, Cho JH, et al. Comparative study of the pneumatization of the mastoid air cells and paranasal sinuses using three-dimensional reconstruction of computed tomography scans. Surg Radiol Anat. 2010;32(6):593-599.

[Full text links] [CrossRef] [PubMed] Google Scholar Scopus

9. Gibelli D, Cellina M, Gibelli S, et al. Relationship between sphenoid sinus volume and protrusion of internal carotid artery and optic nerve: a 3D segmentation study on maxillofacial CTscans. Surg Radiol Anat. 2019;41(5):507-512.

[Full text links] [CrossRef] [PubMed] Google Scholar Scopus

10. Yüksel Aslier NG, Karabay N, Zeybek G, et al. The classification of frontal sinus pneumatization patterns by CT-based volumetry. Surg Radiol Anat. 2016;38(8):923-930.

[Full text links] [CrossRef] [PubMed] Google Scholar Scopus

11. Buyuk SK, Simsek H, Karaman A. The relationship between frontal sinus morphology and skeletal maturation. Folia Morphol (Warsz). 2018;77(3):503-508.

[CrossRef] [PubMed] Google Scholar Scopus 
12. Rossouw PE, Lombard CJ, Harris AM. The frontal sinus and mandibular growth prediction. Am J Orthod Dentofac Orthop. 1991;100(6):542-546.

[Full text links] [CrossRef] [PubMed] Google Scholar Scopus

13. Park IH, Song JS, Choi $\mathrm{H}$, et al. Volumetric study in the development of paranasal sinuses by CT imaging in Asian: a pilot study. Int J Pediatr Otorhinolaryngol. 2010;74(12):1347-1350.

[Full text links] [CrossRef] [PubMed] Google Scholar Scopus

14. Karakas A, Kavakli S. Morphometric examination of the paranasal sinuses and mastoid air cells using computed tomography. Ann Saudi Med. 2005;25(1):41-45.

[Full text links] [CrossRef] [PubMed] Google Scholar Scopus

15. Emirzeoglu M, Sahin B, Bilgic S, et al. Volumetric evaluation of the paranasal sinuses in normal subjects using compute tomography images: a stereological study. Auris Nasus Larynx. 2007;34(2):191-195.

[Full text links] [CrossRef] [PubMed] Google Scholar Scopus

16. Oliveira JMM, Alonso MBCC, de Sousa E Tucunduva MJAP, et al. Volumetric study of sphenoid sinuses: anatomical analysis in helical computed tomography. Surg Radiol Anat. 2017;39(4):367374

[Full text links] [CrossRef] [PubMed] Google Scholar Scopus

17. Cohen O, Warman M, Fried M, et al. Volumetric analysis of the maxillary, sphenoid and frontal sinuses: a comparative computerized tomography based study. Auris Nasus Larynx. 2018;45(1):96-102.

[Full text links] [CrossRef] [PubMed] Google Scholar Scopus

18. Kim DI, Lee UY, Park SO, et al. Identification using frontal sinus by three-dimensional reconstruction from computed tomography. J Forensic Sci. 2013;58(1):5-12.

[Full text links] [CrossRef] [PubMed] Google Scholar Scopus
19. Yushkevich PA, Yang G, Gerig G. ITK-SNAP: an interactive too for semi-automatic segmentation of multi-modality biomedical images. Conf Proc IEEE Eng Med Biol Soc. 2016;2016:3342-3345. [Full text links] [CrossRef] [PubMed] Google Scholar Scopus

20. Yushkevich PA, Gerig G. ITK-SNAP: an interactive medica image segmentation tool to meet the need for expert-guided segmentation of complex medical images. IEEE Pulse. 2017;8(4):54-57. [CrossRef] Google Scholar

21. Codari M, Zago M, Guidugli GA, et al. The nasal septum deviation index (NSDI) based on CBCT data. Dentomaxillofac Radiol. 2016;45(2):20150327.

[Full text links] [CrossRef] [PubMed] Google Scholar

22. Al-Abri R, Bhargava D, Al-Bassam W, et al. Clinically significant anatomical variants of the paranasal sinuses. Oman Med $J$ 2014:29(2):110-113.

[Full text links] [CrossRef] [PubMed] Google Scholar Scopus

23. Kanat A, Yazar U, Ozdemir B, et al. Frontal sinus asymmetry: is it an effect of cranial asymmetry? X-ray analysis of 469 normal adult human frontal sinus. J Neurosci Rural Pract. 2015;6(4):511-514.

[Full text links] [CrossRef] [PubMed] Google Scholar

24. Yoshino M, Miyasaka S, Sato H, Seta S. Classification system of frontal sinus patterns by radiography. Its application to identification of unknown skeletal remains. Forensic Sci Int 1987;34(4):289-299.

[Full text links] [CrossRef] [PubMed] Google Scholar Scopus

25. Gibelli D, Cellina M, Gibelli S, et al. Volumetric assessment of sphenoid sinuses through segmentation on CT scan. Surg Radiol Anat. 2018;40(2):193-198.

[Full text links] [PubMed] Google Scholar Scopus

\section{Giulia Andrea GUIDUGLI}

$M D$

Department of Orthopedics and Traumatology Lugano Regional Hospital

$\mathrm{CH}-6900$ Lugano, Switzerland

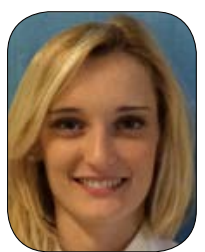

Dr. Giulia Andrea Guidugli is a medical doctor currently attending a Residency program in Orthopedics and Traumatology (Lugano Regional Hospital, Switzerland). Her fields of research are the morphological and metrical assessment of anatomical characteristics of bones, paranasal sinus and upper airways, including the analysis of facial anatomy in both healthy and pathological conditions through the study of $\mathrm{CT}$ and 3D reconstruction of the upper airways.

\section{Daniele Maria GIBELLI}

$\mathrm{MD}, \mathrm{PhD}$

LAFAS-Laboratory of Functional Anatomy of the Stomatognathic System Department of Biomedical Sciences for Health University of Milan I-20133 Milan, Italy

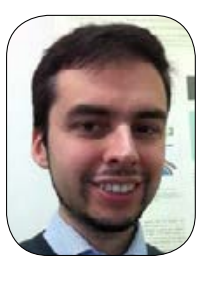

Dr. Daniele Maria Gibelli is a senior researcher in Human Anatomy in Department of Biomedical Sciences for Health, University of Milan, Italy. His fields of research are the morphological and metrical assessment of anatomical characteristics of bones and teeth, including anatomical dimorphism, their modification with age, ethnic variability and the analysis of individualizing characteristics. He also deals with the analysis of facial anatomy both in healthy and pathological conditions, for studies concerning the assessment of facial symmetry, modifications with mimicry and anatomical uniqueness of facial structures. 


\section{Questions}

\section{When does the development of paranasal sinuses start?}

$\square$ a. Childhood;

ab. Fetal period;

ac. Puberty;

पd. Adult age

\section{On average, the volume of paranasal sinuses:}

$\square$ a. Is higher in females than in males;

ab. Is equal in males and females;

$\square$ c. Is higher in males than in females;

ud. Cannot be analysed through 3D segmentation

\section{Which paranasal sinus is the least asymmetric?}

\section{Da. Frontal sinus;}

ab. Sphenoid sinus;

uc. Maxillary sinus;

ud. Ethmoid cells.

\section{For which paranasal sinus a positive correlation was found between volume and age?}

口a. Frontal sinus;

ab. Sphenoid sinus;

ac. Maxillary sinus;

ad. None.

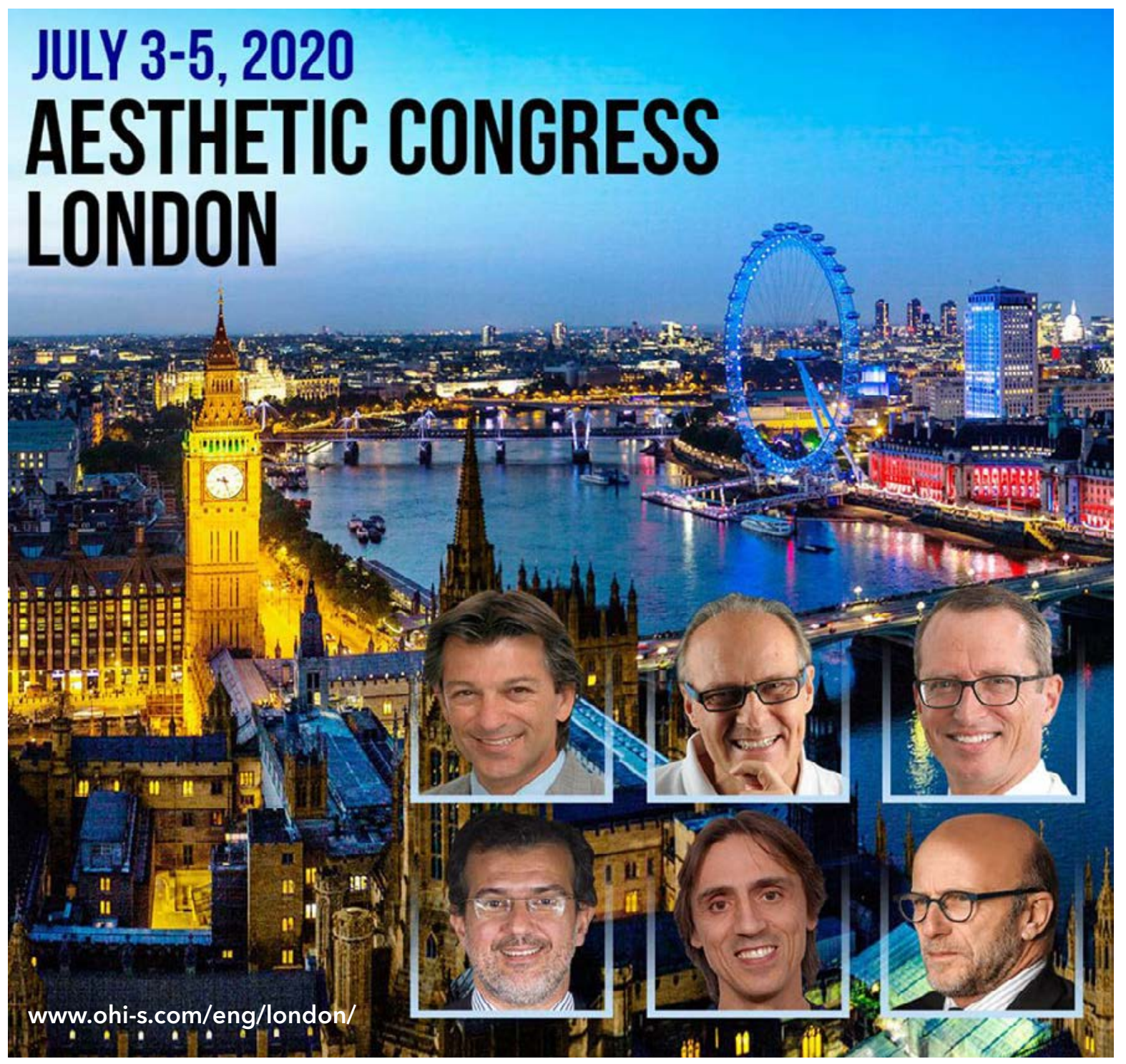




\title{
ANALYSIS OF STRESS GENERATED IN THE ENAMEL OF AN UPPER FIRST PREMOLAR: A FINITE ELEMENT STUDY
}

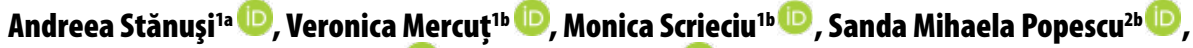

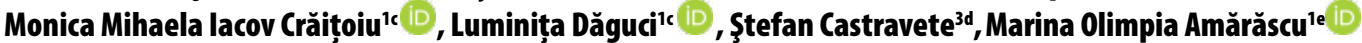

'Department of Proshodontics, Faculty of Dentistry, University of Medicine and Pharmacy of Craiova, Craiova, Romania 2Department of Oral Rehabilitation, Faculty of Dentistry, University of Medicine and Pharmacy of Craiova, Craiova, Romania

${ }^{3}$ Caelynx Europe SRL, Craiova, Romania

aPhDstudent; 'bProfessor; 'Associate Professor; ${ }^{\text {dEngineer; }}$ 'Lecturer

ABSTRACT DOI: https://doi.org/10.25241/stomaeduj.2020.7(1).art.4

Introduction: This study investigated the distribution and magnitude of stress generated in the enamel of an upper first premolar, after applying normal and excessive occlusal loads in a vertical and horizontal direction, using Finite Element Analysis (FEA).

Methodology: A 3D virtual model of an upper first premolar was analyzed. The CT images of the tooth were converted into 3D data using the program MIMICS and Finite Element Analysis (FEA) was used for the stress study. To better understand the distribution of stress generated by occlusal loading, the situation of the enamel in various 3D virtual models was presented. 14 scenarios for the occlusal loading of the virtual models of the upper first premolar were obtained and the areas with the highest concentration of stress were emphasized.

Results: In the model with the tooth intact, stress values were higher than the admissible ones in the simulation of the excessive vertical loading, normal horizontal loading and excessive horizontal loading. Stress was found in the buccal cusp area and in the cervical area, mainly on the buccal side of the tooth. In the models with horizontal occlusal tooth wear, stress values were higher

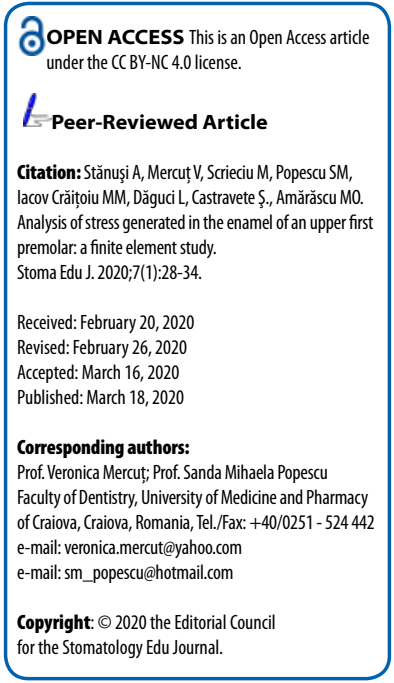
than the admissible ones in the simulation of the excessive vertical loading. Stress was found in the cervical area. In the models with oblique occlusal tooth wear, stress values were higher than the admissible ones in the simulation of the normal and excessive horizontal loading. Stress was found mainly in cervical area, on the buccal side of the tooth.

Conclusions: The most harmful loads were the heavy vertical ones and the horizontal ones, no matter the magnitude.

\section{KEYWORDS}

Tooth Wear; Finite Element Analysis; Stress, Non-Carious Cervical Lesions.

\section{INTRODUCTION}

Non-carious cervical lesions involve the loss of hard dental tissues in the cervical areas of the teeth, without carious activity $[1,2]$. These lesions are important because, in a first stage, they can produce gingival retractions associated with teeth sensitivity [3], and in an advanced stage they can determine endodontic pathology and even the fracture of the teeth involved [4]. Furthermore, non-carious cervical lesions are important because of their high prevalence (5-85\%) [5]. Initially, the toothbrush/ dentifrice abrasion was considered to be the cause for the loss of dental tissues in the cervical area, as stated by Zsigmondy in 1894 [6]. He described these lesions as being wedge-shaped and distributed on the buccal surface of the upper frontal teeth. In 1991, Grippo named the non-carious cervical lesions produced by the mechanism of occlusal loads as "abfraction lesions", so that they could be easily differentiated from the erosion and abrasion lesions [7]. Recently, a series of studies [7-16] claim that many factors are involved in the genesis of non-carious cervical lesions: heavy occlusal loads, biocorrosion, and abrasion. These factors could be encountered individually or in association. It was suggested that heavy occlusal loads from mastication, swallowing and parafunctional movements determine tooth flexure and high stress concentration in the cervical area with the development of enamel cracks. In 2012 Grippo et al. described the mechanism via which heavy occlusal loads generate stress in the cervical area [12]. Depending on the direction of forces, in the tooth structure there appear forces of compression, tension, flexion and shear, all known as stress, which generate fatigue at the enamel-dentine 
ITable 1. Dental materials properties.

\begin{tabular}{|c|c|c|c|c|}
\hline Properties & Enamel & Dentin & Pulp & Periodontal ligament \\
\hline Elastic Modulus of Young (GPa) & $80.35[32-34]$ & $19.89[22,23]$ & $0.002[22]$ & $0.069[22,23]$ \\
\hline Poisson Ratio & $0.33[32-34]$ & $0.31[22,23]$ & $0.45[22]$ & $0.45[22,23]$ \\
\hline
\end{tabular}

ITable 2. Ultimate tensile and compressive strength of dental enamel.

\begin{tabular}{|c|c|}
\hline Ultimate Properties & Enamel \\
\hline Tensile Strength (MPa) & $24[8]$ \\
\hline Compressive Strength (MPa) & $62[13]$ \\
\hline
\end{tabular}

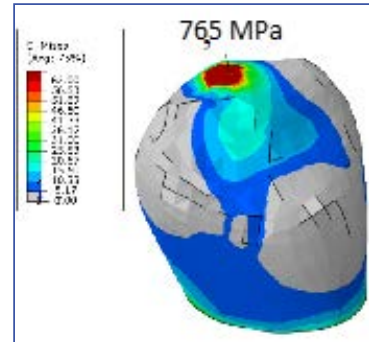

(a)

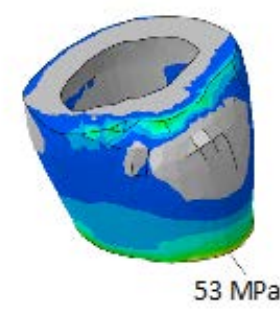

(b)

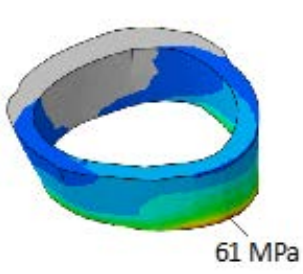

(c)

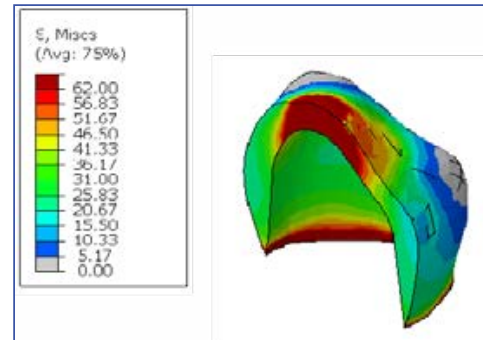

(a)

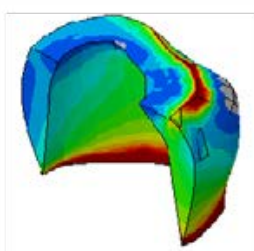

(b)

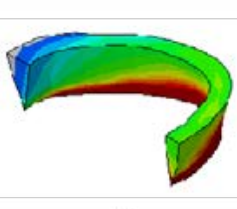

(c)
IFigure 1. Von Mises Stress in enamel: a) intact premolar; b) horizontal tooth wear version 1 ; c) horizontal tooth wear version 2.

IFigure 2. Von Mises Stress in enamel: a) intact premolar; b) horizontal tooth wear version $1 ;$ c) horizontal tooth wear version 2.

junction at the point of force application, and in the case of the non-carious cervical lesions, away from that point [12]. The effects of stress in teeth depend on the magnitude, direction, frequency, point of force application, but also on the axis of the teeth, their form, structure and mobility $[12,17]$. The areas most affected by abfraction lesions are located on the buccal surfaces of teeth, in the cervical zone, with the highest prevalence amongst upper and lower premolars $[8,15,16,18]$. Initially, abfraction lesions appear at the enamel-cement junction in the enamel structure, as a result of reduced thickness of enamel in that area, the absence of enamel rods and low frequency of Hunter Schreger Bands [19]. The aim of this study was to investigate the distribution and magnitude of stress generated by normal and heavy occlusal loads, which were directed vertically and horizontally in the enamel of an upper first premolar, using Finite Element Analysis (FEA) and the virtual model from a previous study [20]. Finite Element Analysis (FEA) is a numerical procedure used in dentistry for the simulation of various clinical situations, in order to study the distribution of stress in the tooth structure and the restorative materials, as a result of occlusal loading [21].

\section{MATERIAL AND METHODS}

The 3D virtual model of the upper first premolar was made using the CT images of a 14 year-old patient [20]. The CT images were converted into 3D data using the MIMICS program (Materialise NV, Leuven, Belgium, 1992) and the 3D virtual model obtained was analysed using Finite Element Analysis (FEA) and the Abaqus/CAE program (ABAQUS Software, S.A.R.L., Versailles, France, 1994). The 3D virtual model consisted of all the tissues of the given premolar: enamel, dentine, pulp and periodontal ligament. The alveolar bone was reconstructed as a parallelepiped, to which the tooth was not rigidly fixed, and between these two structures the periodontal ligament was simulated. The finite element model was a 3D model with tetrahedral elements resulting in 47548 elements and 68504 nodes. The average size of an element was approximately $0.5 \mathrm{~mm}$ per surface. For the elastic modulus of Young and Poisson's ratio of the dental tissues, data from the literature were used as shown in Table 1. The values obtained for the tensions generated in enamel were compared to the ultimate values of tensile and compressive strength 


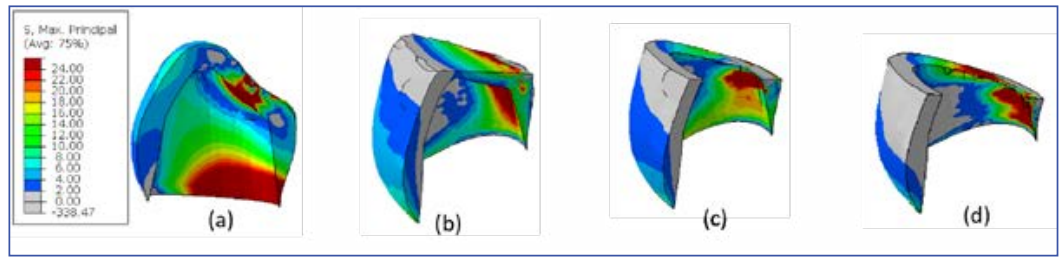

(d)

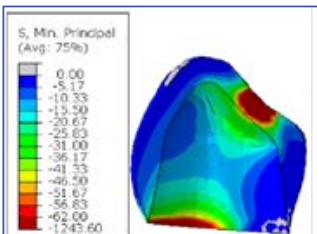

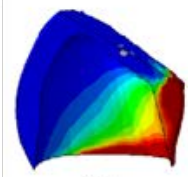

(b)

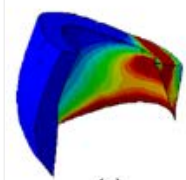

(c)

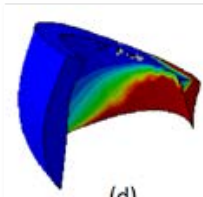

(d)
Figure 3. Tensile stress in enamel: a) intact premolar; b) lateral tooth wear version $1 ; c$ ) lateral tooth wear version 2; d) lateral tooth wear version 3 .

IFigure 4. Compressive stress in enamel:a) intact premolar; b) lateral tooth wear version $1 ;$ c) lateral tooth wear version 2; d) lateral tooth wear version 3 . for enamel used in other studies (Table 2) $[8,13]$.

To better understand the distribution of stress generated by occlusal loading, the situation of enamel in various 3D virtual models was presented. A virtual model of the upper first premolar with no lesion was used to create five more models with different degrees of occlusal tooth wear. The occlusal tooth wear models used in this study represent simulations of some clinical conditions encountered in clinical practice as a consequence of the occlusal load in static mandibular position (occlusal horizontal tooth wear) - 2 models, and the occlusal load in lateral movements of the jaw (oblique occlusal tooth wear) -3 models. Using these models, various scenarios emerged for the occlusal loading applied as a flat surface of a block, in a vertical and horizontal direction. A normal vertical load $(\mathrm{F}=180 \mathrm{~N})$ and an excessive vertical load ( $\mathrm{F}=532 \mathrm{~N}$ ) [24] were applied on the virtual model with the intact premolar and on the two models with horizontal occlusal tooth wear, there resulting six scenarios for the vertical occlusal loading. Also, a normal horizontal load ( $F=180 \mathrm{~N})$ and an excessive horizontal load ( $F=532 \mathrm{~N}$ ) [35] were applied on the virtual model with the intact premolar and on the three models with oblique occlusal tooth wear, there resulting eight scenarios for the horizontal occlusal loading. The study was approved by the Ethics Committee of the Faculty of Dental Medicine of University of Medicine and Pharmacy of Craiova (no. 257/12.10.2019). An informed consent for using the $\mathrm{CT}$ was obtained from the patient.

\section{RESULTS}

In the simulations with horizontal occlusal tooth wear the Von Mises Stress, which is a combination of compressive, tensile and shear stress, the compressive stress was dominant. In the simulations with oblique occlusal tooth wear, the dominant stress was both compressive (Min Principal Stress, the maximum values are negative) and tensile (Max Principal Stress, the maximum values are negative).

\section{a - Simulation of normal vertical load, $F=180 \mathrm{~N}$} In the simulation of a normal vertical loading $(\mathrm{F}=180 \mathrm{~N})$, in the model with the intact premolar, a compressive stress higher than $62 \mathrm{MPa}$, located in the superficial layer of enamel, at the buccal cusp was observed (Fig. 1a). In the models with horizontal occlusal tooth wear, the values of compressive stress were lower. The highest ones were found in the palatal cervical area, but they did not exceed 62MPa (Fig. 1 b, c).

\section{b - Simulation of excessive vertical load, $F=532 \mathrm{~N}$}

In the simulation of an excessive vertical loading $(\mathrm{F}=532 \mathrm{~N})$, in all models, the compressive stress was higher than $62 \mathrm{MPa}$ (Fig. 2 a, b, c), the maximum value being found in the model with the intact premolar (Fig. 2a). Regarding the distribution of the compressive stress in enamel, in the model with the intact premolar, it was located at the buccal cusp affecting the whole enamel layer and in the cervical area (Fig. 2a). In the models with horizontal occlusal tooth wear, the maximum values for the compressive stress were located in the cervical area of the enamel (Fig. 2 b, c).

\section{c-Simulation of normal horizontal load, $F=180 \mathrm{~N}$}

In the simulation of normal horizontal loading $(\mathrm{F}=180 \mathrm{~N})$, in the model with the intact premolar, the tensile stress (Max Principal Stress) exceeded $24 \mathrm{MPa}$ in the occlusal area and in the cervical lingual distal area (Fig. 3a). In the models with oblique occlusal tooth wear, the highest values for the tensile stress were found at the palatal cusp (Fig. 3 b, c, d).

The values for the compressive stress generated exceeded $62 \mathrm{MPa}$ in the buccal cervical area and in the occlusal area in the model with the intact premolar (Fig. 4a). In the models with oblique occlusal tooth wear, these small values for the compressive stress were found at the palatal cusp and in the cervical palate-distal area (Fig. 4 b, c, d).

\section{$d$ - Simulation of excessive horizontal load, $F=532 \mathrm{~N}$}

In the simulation of an excessive horizontal loading $(\mathrm{F}=532 \mathrm{~N})$ in the model with the intact premolar, the tensile stress (Max Principal Stress) exceeded $24 \mathrm{MPa}$ in the occlusal area and in the cervical disto- linguo-mesial area (Fig. 5a). In the models with oblique occlusal tooth wear, these high values for the tensile stress were found in the occlusal and 

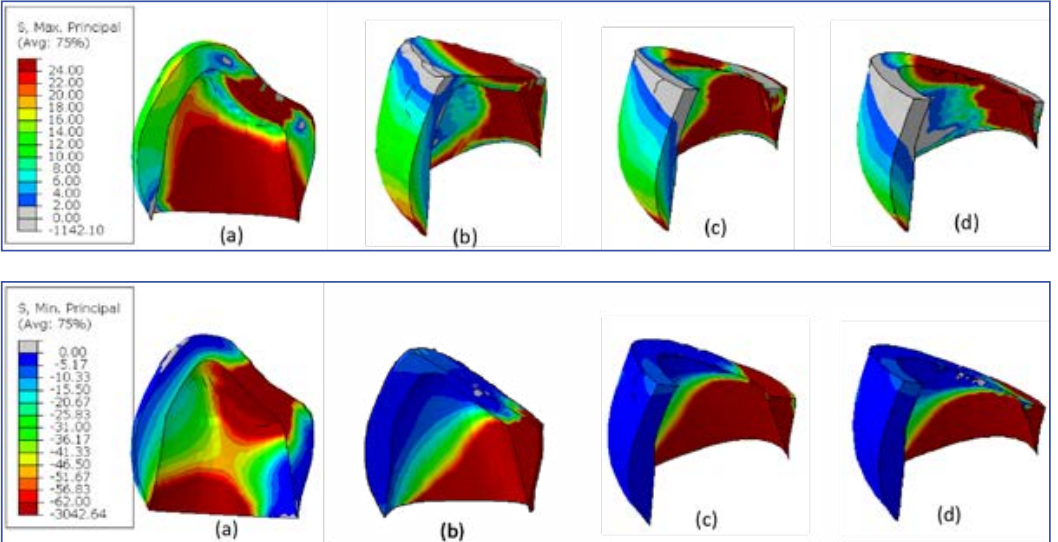

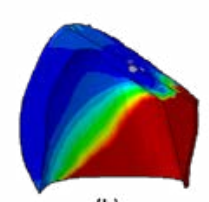

(b)

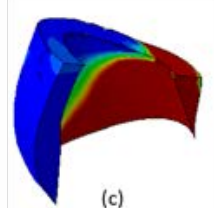

(c)

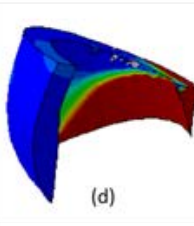

(d)
Figure 5. Tensile stress in enamel: a) intact premolar; b) lateral tooth wear version $1 ; c$ ) lateral tooth wear version 2; d) lateral tooth wear version 3.

Figure 6. Compressive stress in enamel: a) intact premolar; b) lateral tooth wear version $1 ; c)$ lateral tooth wear version 2; d) lateral tooth wear version 3 . palatal area and less in the cervical area (Fig. 5 b, c, d). The values for the compressive stress (Min Principal Stress) generated exceeded $62 \mathrm{MPa}$ in the occlusal area and in the cervical buccal area in the model with the intact premolar (Fig. 6a). In the models with oblique occlusal tooth wear, these small values for the compressive stress were found in the occlusal and palatal area, towards the distal part of the tooth (Fig. 6 b, c, d).

14 scenarios for the occlusal loading of the virtual models of the upper first premolar were obtained and the areas with the highest concentration of stress were enhanced. In the model with the tooth intact, the stress values were higher than the admissible ones in the simulation of the excessive vertical loading, normal horizontal loading and excessive horizontal loading. Stress was found in the buccal cusp area and in the cervical area, mainly on the buccal side of the tooth. In the models with horizontal occlusal tooth wear, the stress values were higher than the admissible ones in the simulation of the excessive vertical loading. The stress was found in the cervical area. In the models with oblique occlusal tooth wear, the stress values were higher than the admissible ones in the simulation of the normal and excessive horizontal loading. The stress was found mainly in cervical area, on the buccal side of the tooth. The most harmful forces were the excessive vertical ones and the horizontal ones, no matter the magnitude.

\section{DISCUSSIONS}

This study aimed to analyse the distribution and magnitude of stress generated by normal ( $F=180$ $\mathrm{N})$ and excessive ( $\mathrm{F}=532 \mathrm{~N}$ ) occlusal loads, directed vertically and horizontally. The stress obtained represents the effect of the cumulative action of the compressive and tensile stress in the dental tissues. For this study, a 3D virtual model of an upper first premolar was used. Clinical experience and data from the literature $[8,16,18]$ showed that the upper first premolar had a great susceptibility towards abfraction lesions. Meanwhile, its form and the way the occlusal forces are distributed in its structure make it liable for fractures. For the conversion of the CT images into 3D data the MIMICS program (Materialise NV, Leuven, Belgium, 1992) was used as it was used in prior studies [20, 25-27]. For the stress analysis Finite Element Analysis (FEA) was applied as it was used in prior studies [28-39].

A similar study was performed by Lee et al. in 2002 [8], also using the Finite Element Analysis (FEA) in which a normal vertical force $(F=170 \mathrm{~N})$ was applied at the buccal cusp of an upper second premolar. The highest value of the tensile stress was observed in the cervical area, namely 13.55 MPa [8]. In our study, for the normal vertical force of $180 \mathrm{~N}$, the values for the Von Mises Stress in the cervical area were around 10-15 MPa. The results of our study are similar to those found by Lee et al in-their study in 2002 [8]. In both studies the value of the tensile stress obtained in the cervical area was lower than the admissible one. In 2003, Rees and Jagger [5] performed a study using the Finite Element Analysis (FEA) in order to find an explanation for the high prevalence of noncarious cervical lesions in maxillary teeth. In that study they used three 2D models, representing an upper incisive, upper canine and upper premolar and through the Finite Element Analysis (FEA) recorded the magnitude of stress in the cervical area, obtained after applying a force of $500 \mathrm{~N}$. In the case of the upper premolar, force was applied at the buccal cusp and angulated 45 degrees in a buccal and apical direction. They recorded the tensile stress and compared the values obtained on the buccal surfaces with the ones obtained on the palatal surfaces. The values obtained were similar. Our study had results in accordance with the results obtained in the Rees and Jagger study. However, practice has proven that abfraction lesions were rarely found on the palatal surfaces of the teeth [5] and this phenomenon could be correlated with stress corrosion, meaning that the association between stress and acidic substances cause more lesions than if these factors act alone. Acidic substances are removed by saliva from the palatal surfaces of teeth 6 times more rapidly than the ones located on the buccal surfaces [5]. Furthermore, the enamel affected by demineralization can regain its mechanical resistance as a result of the action of different substances and even saliva [14]. Clinically, these excessive forces or the ones with a horizontal 
direction can be identified in the case of occlusal interferences [39-41], any other clinical situation that modifies occlusion, such as parafunctions, bruxism $[42,43]$ and treatment procedures $[44,45]$. Other studies have tried to find evidence for the causal relationship between occlusion and noncarious cervical lesions $[41,46]$. In these studies, the presence of non-carious cervical lesions was associated with the presence of occlusal wear facets. If excessive occlusal forces can cause noncarious cervical lesions, it would be expected that parafunctional habits such as bruxism and clenching would increase the progression of non-carious cervical lesions. Two studies reported a correlation between bruxism and non-carious cervical lesions [42]. In 2017, Duangthip et al. [47] performed a review to search for correlations between excessive occlusal loads and abfraction lesions and found such an association in $81 \%$ of cases.

\section{CONCLUSIONS}

This study showed the distribution and magnitude of stress obtained in the virtual 3D model of an upper first premolar, after applying normal and excessive, vertical and horizontal forces. The most harmful

\section{REFERENCES}

1. LittleStar ML, Summit JB. Non-carious cervical lesions: an evidence-based approach to their diagnosis. Tex Dent $\mathrm{J}$. 2003;120(10):972-980.

[PubMed] Google Scholar Scopus

2. Michael JA, Townsend GC, Greenwood LF, Kaidonis JA Abfraction: separating fact from fiction. Aust Dent J. 2009;54(1):2-8.

[Full text links] [CrossRef] [PubMed] Google Scholar Scopus

3. Lafzi A, Abolfazli N, Eskandari A. Assessment of the etiologic factors of gingival recession in a group of patients in Northwest Iran. J Dent Res Dent Clin Dent Prospects. 2009;3(3):90-93. doi:10.5681/joddd.2009.023.

[Full text links] [PubMed] Google Scholar

4. Pereira FA, Zeola LF, de Almeida Milito G, et al. Restorative material and loading type influence on the biomechanical behavior of wedge shaped cervical lesions. Clin Oral Investig. 2016;20(3):433-441.

[Full text links] [CrossRef] [PubMed] Google Scholar Scopus 5. Rees JS, Jagger DC. Abfraction lesions: myth or reality? J Esthet Restor Dent. 2003;15(5):263-271.

[Full text link] [CrossRef] [PubMed] Google Scholar Scopus 6. Zsigmondy U. [About the wedge-shaped defects on the facia surfaces of the Zajn necks]. [Article in German]. Österr Ungar Vjhrschr Zahnärzte. 1894;1:439-442.

[Full text links]

7. Konagala RK, Mandava J, Anupreeta A, et al. The "Abfraction - Paradox" - A literature review on biomechanics, diagnosis and management. Int J Sci Res (Ahmedabad). 2018;7(6):46-49. [Full text links]

8. Lee $\mathrm{HE}$, Lin $\mathrm{CL}$, Wang $\mathrm{CH}$, et al. Stresses at the cervical lesion of maxillary premolar--a finite element investigation. J Dent. 2002;30(7-8):283-290.

[Full text links] [CrossRef] [PubMed] Google Scholar Scopus

9. Grippo JO, Simring M, Schreiner S. Attrition, abrasion, corrosion and abfraction revisited: a new perspective on tooth surface lesions [published correction appears in J Am Dent Assoc. 2004 Oct;135(10):1376]. J Am Dent Assoc. 2004;135(8):1109-1165. [Full text links] [CrossRef] [PubMed] Google Scholar Scopus 10. Addy M, Shellis RP. Interaction between attrition, abrasion and erosion in tooth wear. Monogr Oral Sci. 2006;20:17-31.

[Full text links] [CrossRef] Google Scholar Scopus

11. Borcić J, Antonić R, Urek MM, et al. 3-D stress analysis in first maxillary premolar. Coll Antropol. 2007;31(4):1025-1029.

[Full text links] [PubMed] Google Scholar Scopus forces were the excessive vertical ones and the horizontal ones, no matter the magnitude. Regarding the tooth morphology, the least favourable models for the distribution of stress were the ones with the intact premolar and with lateral tooth wear.

In current practice, these situations are found in the case of occlusal interferences, parafunctions and bruxism.

\section{CONFLICT OF INTEREST}

The authors declare no conflict of interest.

\section{AUTHOR CONTRIBUTIONS}

AS, VM: Concept, protocol, manuscript writing; MS, SMP, MMIC, LD, AMO: Manuscript writing, critical review of manuscript; SC: concept, data entry, data analysis, critical review of manuscript.

\section{ACKNOWLEDGMENTS}

Acknowledge persons who have made substantive contributions to the study. Specify grant or other financial support, citing the name of the supporting organization and grant number.

12. Grippo JO, Simring M, Coleman TA. Abfraction, abrasion, biocorrosion, and the enigma of noncarious cervical lesions: a 20year perspective. J Esthet Restor Dent. 2012;24(1):10-23. [Full text links] [CrossRef] [PubMed] Google Scholar Scopus 13. Chun $\mathrm{K}$, Choi $\mathrm{H}$, Lee J. Comparison of mechanical property and role between enamel and dentin in the human teeth. J Dent Biomech. 2014;5:1758736014520809.

[Full text links] [CrossRef] [PubMed] Google Scholar Scopus 14. Shellis RP, Addy M. The interactions between attrition, abrasion and erosion in tooth wear. Monogr Oral Sci. 2014;25:32-45. [CrossRef] [PubMed] Google Scholar Scopus

15. Nascimento MM, Dilbone DA, Pereira PN, et al. Abfraction lesions: etiology, diagnosis, and treatment options. Clin Cosmet Investig Dent. 2016;8:79-87.

[Full text links] [CrossRef] [PubMed] Google Scholar Scopus

16. El-Marakby AM, Al-Sabri FA, Alharbi SA, et al. Noncarious cervical lesions as abfraction: etiology, diagnosis, and treatment modalities of lesions: a review article. Dentistry. 2017;7(6):438.

[CrossRef] Google Scholar

17. Kuroe T, Caputo AA, Ohata N, Itoh H. Biomechanical effects of cervical lesions and restoration on periodontally compromised teeth. Quintessence Int. 2001;32(2):111-118.

[PubMed] Google Scholar Scopus

18. Bader ID, Shugars DA. Variation in clinical decision making related to caries. In: Fejerskov O, Kidd EAM, editors. Dental caries: the disease and its clinical management. 2nd ed. Oxford, UK: Blackwell Munksgaard Ltd; 2008.

19. Lynch CD, O'Sullivan VR, Dockery P, et al. Hunter-Schreger Band patterns in human tooth enamel. J Anat. 2010;217(2):106-115.

[Full text links] [CrossRef] [PubMed] Google Scholar Scopus 20. Stănuși A, Mercuț V, Scrieciu M, et al. Effects of occlusal loads in the genesis of non-carious cervical lesions - a finite element study. Romanian Journal of Oral Rehabilitation. 2019;11(1):73-81. Google Scholar

21. Zeola LF, Pereira FA, Galvão AdaM, et al. Influence of non carious cervical lesions depth, loading point application and restoration on stress distribution pattern in lower premolars: a 2D finite element analysis. Biosci J. 2015;31(2):648-656. Google Scholar Scopus

22. Gurbuz T, Sengul F, Altun C. Finite element stress analysis of short-post core and over restorations prepared with different restorative materials. Dent Mater J. 2008;27(4):499-507. [Full text links] [CrossRef] [PubMed] Google Scholar Scopus 
23. Munari LS, Cornacchia TP, Moreira AN, et al. Stress distribution in a premolar 3D model with anisotropic and isotropic enamel. Med Biol Eng Comput. 2015;53(8):751-758.

[Full text links] [CrossRef] [PubMed] Google Scholar Scopus

24. Larson TD. The effect of occlusal forces on restorations. J Mich Dent Assoc. 2014;96(9):38-47.

[PubMed] Google Scholar

25. Huang Z, Chen Z. Three-dimensional finite element modeling of a maxillary premolar tooth based on the micro-CT scanning: a detailed description. J Huazhong Univ Sci Technolog Med Sci. 2013;33(5):775-779.

[Full text links] [CrossRef] [PubMed] Google Scholar Scopus 26. Sang $\mathrm{YH}, \mathrm{Hu} \mathrm{HC}$, Lu SH, et al. Accuracy assessment of three-dimensional surface reconstructions of in vivo teeth from cone-beam computed tomography. Chin Med J (Engl). 2016:129(12):1464-1470.

[Full text links] [CrossRef] [PubMed] Google Scholar Scopus 27. Vătu $M$, Crăitoiu $M M$, Vintilă $D$, et al. Determination of resistance forces from mandibular movements through dynamic simulation using kinematic analysis and finite elements method. Romanian Journal of Oral Rehabilitation. 2018;10(1):20-28.

Google Scholar

28. Palamara JE, Palamara D, Messer HH. Strains in the marginal ridge during occlusal loading. Aust Dent J. 2002;47(3):218-222.

[Full text links] [CrossRef] [PubMed] Google Scholar Scopus 29. Nishigawa G, Matsunaga T, Maruo Y, et al. Finite element analysis of the effect of the bucco-lingual position of artificial posterior teeth under occlusal force on the denture supporting bone of the edentulous patient. J Oral Rehabil. 2003;30(6):646652.

[Full text links] [CrossRef] [PubMed] Google Scholar Scopus

30. Dejak B, Młotkowski A, Romanowicz M. Finite element analysis of stresses in molars during clenching and mastication. J Prosthet Dent. 2003;90(6):591-597.

[Full text links] [CrossRef] [PubMed] Google Scholar

31. De Jager N, Pallav P, Feilzer AJ. The influence of design parameters on the FEA-determined stress distribution in CADCAM produced all-ceramic dental crowns. Dent Mater.

2005;21(3):242-251.

[Full text links] [CrossRef] [PubMed] Google Scholar Scopus

32. De Jager $N$, de Kler $M$, van der Zel JM. The influence of different core material on the FEA-determined stress distribution in dental crowns. Dent Mater. 2006;22(3):234-242.

[Full text links] [CrossRef] [PubMed] Google Scholar Scopus

33. Ates M, Cilingir A, Sülün T, et al. The effect of occlusal contact localization on the stress distribution in complete maxillary denture. J Oral Rehabil. 2006;33(7):509-513.

[Full text links] [CrossRef] Google Scholar Scopus

34. Hattori $Y$, Satoh $C$, Kunieda $T$, et al. Bite forces and their resultants during forceful intercuspal clenching in humans. $J$ Biomech. 2009;42(10):1533-1538.

[Full text links] [CrossRef] [PubMed] Google Scholar Scopus
35. Coelho PG, Silva NR, Thompson VP, et al. Effect of proximal wall height on all-ceramic crown core stress distribution: a finite element analysis study. Int J Prosthodont. 2009;22(1):78-86.

[PubMed] Google Scholar Scopus

36. Fu G, Deng F, Wang $L$, Ren A. The three-dimension finite element analysis of stress in posterior tooth residual root restored with postcore crown. Dent Traumatol. 2010;26(1):64-69.

[Full text links] [CrossRef] [PubMed] Google Scholar Scopus

37. Jiang W, Bo H, Yongchun G, LongXing N. Stress distribution in molars restored with inlays or onlays with or without endodontic treatment: a three-dimensional finite element analysis. J Prosthet Dent. 2010;103(1):6-12.

[CrossRef] Google Scholar Scopus

38. Hasegawa A, Shinya A, Nakasone Y, et al. Development of 3D CAD/FEM analysis system for natural teeth and jaw bone constructed from X-Ray CT images. Int J Biomater. 2010;2010:659802.

[Full text links] [CrossRef] Google Scholar

39. Brandini DA, Trevisan CL, Panzarini SR, Pedrini D. Clinical evaluation of the association between noncarious cervical lesions and occlusal forces. J Prosthet Dent. 2012;108(5):298-303.

[Full text links] [CrossRef] [PubMed] Google Scholar Scopus

40. Brandini DA, Pedrini D, Panzarini SR, et al. Clinical evaluation of the association of noncarious cervical lesions, parafunctional habits, and TMD diagnosis. Quintessence Int. 2012;43(3):255-262. [Full text links] [PubMed] Google Scholar Scopus

41. Wood ID, Kassir AS, Brunton PA. Effect of lateral excursive movements on the progression of abfraction lesions. Oper Dent 2009;34(3):273-279.

[FullTextLink] [CrossRef] [PubMed] Google Scholar Scopus

42. Ommerborn MA, Schneider C, Giraki M, et al. In vivo evaluation of noncarious cervical lesions in sleep bruxism subjects. J Prosthet Dent. 2007:98(2):150-158.

[Full text links] [CrossRef] [PubMed] Google Scholar Scopus

43. Antonelli JR, Hottel TL, Garcia-Godoy F. Abfraction lesionswhere do they come from? A review of the literature. J Tenn Dent Assoc. 2013;93(1):14-21.

[PubMed] Google Scholar

44. Bernhardt O, Gesch D, Schwahn C, et al. Epidemiologica evaluation of the multifactorial aetiology of abfractions. J Oral Rehabil. 2006;33(1):17-25.

[Full text links] [CrossRef] [PubMed] Google Scholar Scopus

45. Vasudeva $G$, Bogra $P$. The effect of occlusal restoration and loading on the development of abfraction lesions: A finite element study. J Conserv Dent. 2008;11(3):117-120.

[Full text links] [CrossRef] [PubMed] Google Schola

46. Telles D, Pegoraro LF, Pereira JC. Incidence of noncarious cervical lesions and their relation to the presence of wear facets. $J$ Esthet Restor Dent. 2006;18(4):178-184.

[Full text links] [CrossRef] [PubMed] Google Scholar Scopus

47. Duangthip $\mathrm{D}$, Man $\mathrm{A}$, Poon $\mathrm{PH}$, et al. Occlusal stress is involved in the formation of non-carious cervical lesions. A systematic review of abfraction. Am JDent 2017·30(4):212-220.

[Full text links] [PubMed] Google Scholar Scopus

\section{Andreea STĂNUŞI}

DMD, PhD Student, Prosthodontic Medical Resident Department of Proshodontics

Faculty of Dentistry

University of Medicine and Pharmacy of Craiova

Craiova, Romania

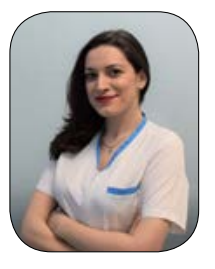

Andreea Stănuşi (DOB: September 22, 1992) graduated from the Faculty of Dentistry, University of Medicine and Pharmacy of Craiova in 2017 and became Medical Resident in Prosthodontics. As a student, she held various positions: President of the Craiova Stomatology Students Society (2013-2014), Member of the Faculty Council (2016-2017), Member of the University Senate (2016-2017). As a postgraduate her activity is still connected with the academic life. In 2017 she became a PhD student under the guidance of University Professor Veronica Mercuț, her research interest being the etiology and treatment of tooth wear. In 2019 she published the results of an experiment in which the stress involved in the etiology of tooth wear was examined ("Effects of occlusal loads in the genesis of non-carious cervical lesions - a Finite Element Study"). 


\section{Orestions}

\section{Non-carious cervical lesions can produce in a first stage:}

Da. endodontic pathology;

ab. gingival retractions associated with teeth sensitivity;

uc. fracture of the teeth involved;

ad. periodontal pockets.

\section{The areas most affected by abfraction lesions are located on:}

Da. enhanced thickness of enamel in that area;

ab. reduced thickness of dentine in that area;

ac. the high frequency of Hunter Schreger Bands;

$\square d$. the low frequency of Hunter Schreger Bands.

\section{Abfraction lesions appear at the enamel-cement junction in the enamel structure, as a result of:}

Da. less than $20 \%$ in the three groups with no statistical difference among groups;

$\square$ b. over $10 \%$ in the three groups with no statistical difference among groups;

ac. over $80 \%$ in the three groups with no statistical difference among groups;

$\square d$. less than $10 \%$ in the three groups with no statistical difference among groups.

\section{The excessive forces or the ones with a horizontal direction involved in the etiology of NCCL, can be identified in the following clinical situations apart from:}

Da.occlusal interferences;

Db. parafunctions;

ac. bruxism;

$\square d$. procedures that do not modify occlusion.
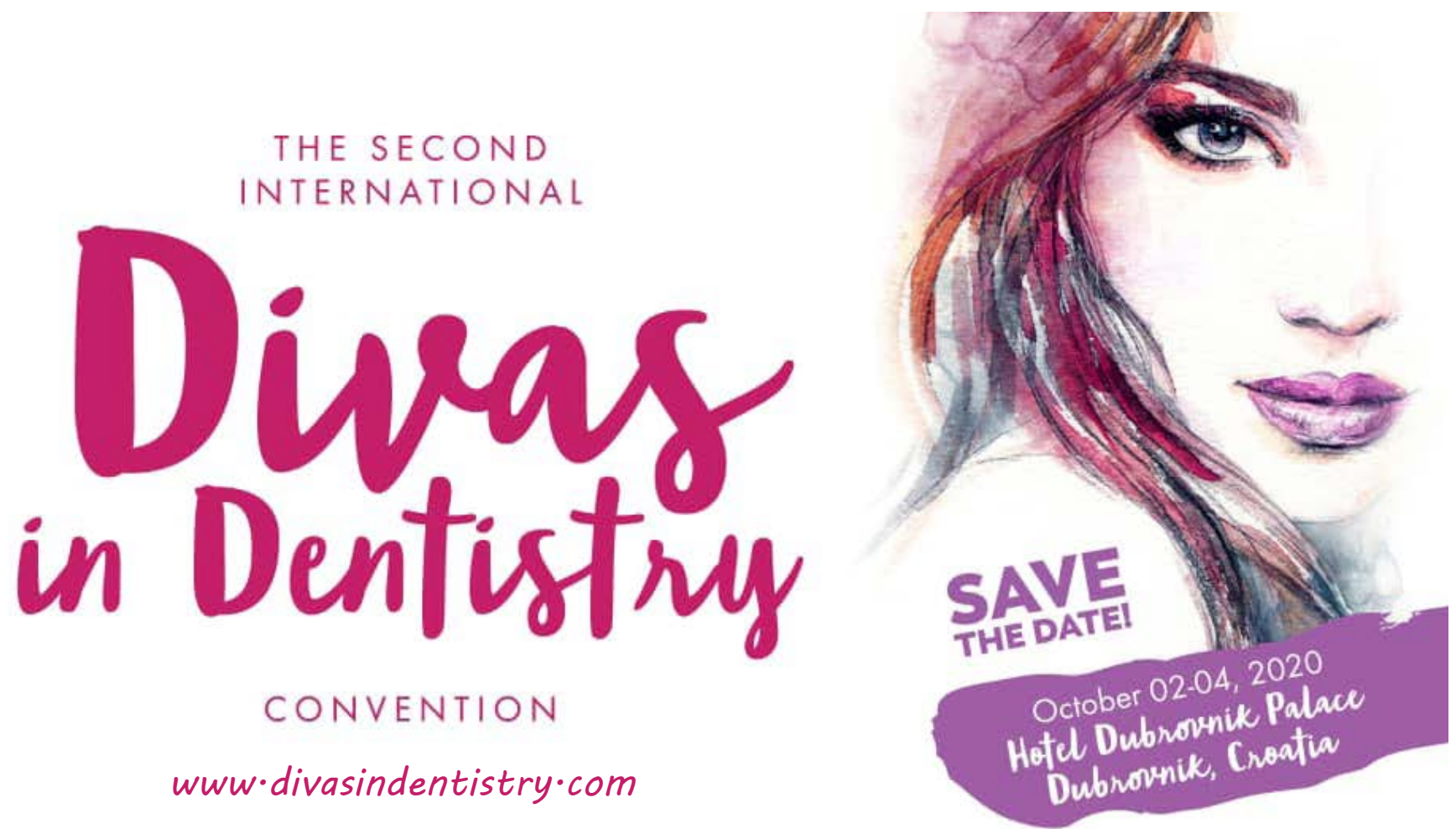


\title{
IMMEDIATE/EARLY RADIOLOGICAL FINDINGS FOLLOWING TRANSCRESTAL SINUS AUGMENTATION USING A MINIMALLY INVASIVE IMPLANT DEVICE
}

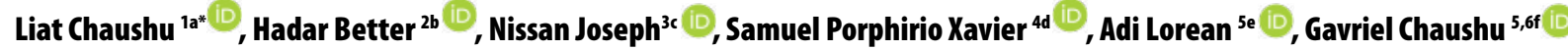 \\ 'Department of Periodontology and Implant Dentistry, The Maurice and Gabriela Goldschleger School of Dental Medicine, Tel Aviv University, Tel Aviv, Israel \\ 2Private practice, Tel Aviv, Israel. Co Founder Maxillent LTD \\ ${ }^{3}$ Department of Oral Rehabilitation, The Maurice and Gabriela Goldschleger School of Dental Medicine, Tel Aviv University, Tel Aviv, Israel \\ ${ }^{4}$ Department of Oral and Maxillofacial Surgery and Periodontology, School of Dentistry of Ribeirão Preto, University of São Paulo, São Paulo, Brazil \\ ${ }^{5}$ Department of Oral and Maxillofacial Surgery, The Maurice and Gabriela Goldschleger School of Dental Medicine, Tel Aviv University, Tel Aviv, Israel \\ ${ }^{6}$ Department of Oral and Maxillofacial Surgery, Rabin Medical Center, Petah Tiqwa, Israel
}

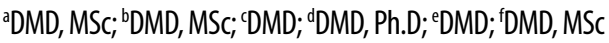

ABSTRACT

DOI: https://doi.org/10.25241/stomaeduj.2020.7(1).art.5

Introduction: Description of the immediate/early (up to one week) cone beam tomographic findings following maxillary sinus augmentation using a minimally invasive implant device.

Methodology: Aself-tapping endosseous dental implant containing an internal channel that allows the introduction of liquids through the implant body and into the maxillary sinus was used for sinus augmentation. A periapical radiography was performed at the end of the procedure. For those cases where the periapical radiograph could not demonstrate a clear postoperative result, a cone beam computerized tomography $(C B C T)$ was performed at the end of the procedure. When a CBCT device was not available an early CBCT was performed within 1 week. Twenty immediate/early postoperative CBCT's were retrospectively evaluated for descriptive purposes.

Results: 25 immediate postoperative CBCT's were reviewed. The following radiological phenomena were noted and described - the postoperative appearance of the Schneiderian membrane; grafting material; new generated bone volume.

Conclusion: Dental CBCT should be the gold standard for immediate/early

OPEN ACCESS This is an Open Access article
under the CC BY-NC 4.0 license.
Citation: Chaushu L, Better H, Nissan J, Xavier SP,
Lorean A, Chaushu G. Immediate / early radiological
findings following transcrestal sinus augmentation
using a minimally invasive implant device. Stoma Edu J.
2020;7(1):35-41.
Received: November 15, 2019
Revised: January 09, 2020
Accepted: January 23, 2020
Published: January 28, 2020
Corresponding author:
Dr. Liat Chaushu, DMD, MSc
Department of Periodontology and Implant Dentistry,
The Maurice and Gabriela Goldschleger School of Dental
Medicine, Tel Aviv University, Tel Aviv, Israel.
Fax: $+972-86219999$, Tel: $+972-507821832$
e-mail: liat.natanel@gmail.com
Copyright: $\odot 2020$ the Editorial Council
for the Stomatology Edu Journal.
postoperative imaging, following transcrestal sinus augmentation using a minimally invasive implant device, to document post grafting conditions and allow early intervention in failures.

\section{KEYWORDS}

Dental; Oral Surgical Procedures; Preprosthetic; Radiography;

Sinus Floor Augmentation.

\section{INTRODUCTION}

Augmentation of the maxillary sinus floor followed by simultaneous or delayed placement of dental implants is a well-established technique for implantsupported rehabilitation of the partially or completely edentulous patient [1-15]. Few studies documented a patient's perception of recovery after sinus-floor augmentation [16]. The average patient should expect recovery within 5 days. As a result, patients may refuse the procedure due to fear, morbidity or other considerations. Several surgical techniques for sinus floor augmentation were described. The classical lateral window approach was described by Tatum in 1986 [17]. This surgical approach allows the clinician complete direct view of the sinus and enables sinus floor augmentation to the full extent necessary. However, it involves a significant amount of trauma to the patient [16]. The crestal approach was described by Summers in 1994 [18]. This surgical procedure minimizes much of the postoperative morbidity, however, it limits the surgeons' direct vision and is limited in its ability to augment the entire sinus floor.

The hydraulic sinus membrane elevation was first described by Chen and Cha in 2005 [19]. This is a variant of the Summers' technique. The fluid pressure from the drilling instrument is used to gently raise the sinus membrane from the sinus floor.

The present study focuses on a new procedure and a dedicated dental implant (iRaise sinus lift System by Herzliya, Tel Aviv, Israel) using the crestal approach $[4,5]$. This technique combines advantages of both 


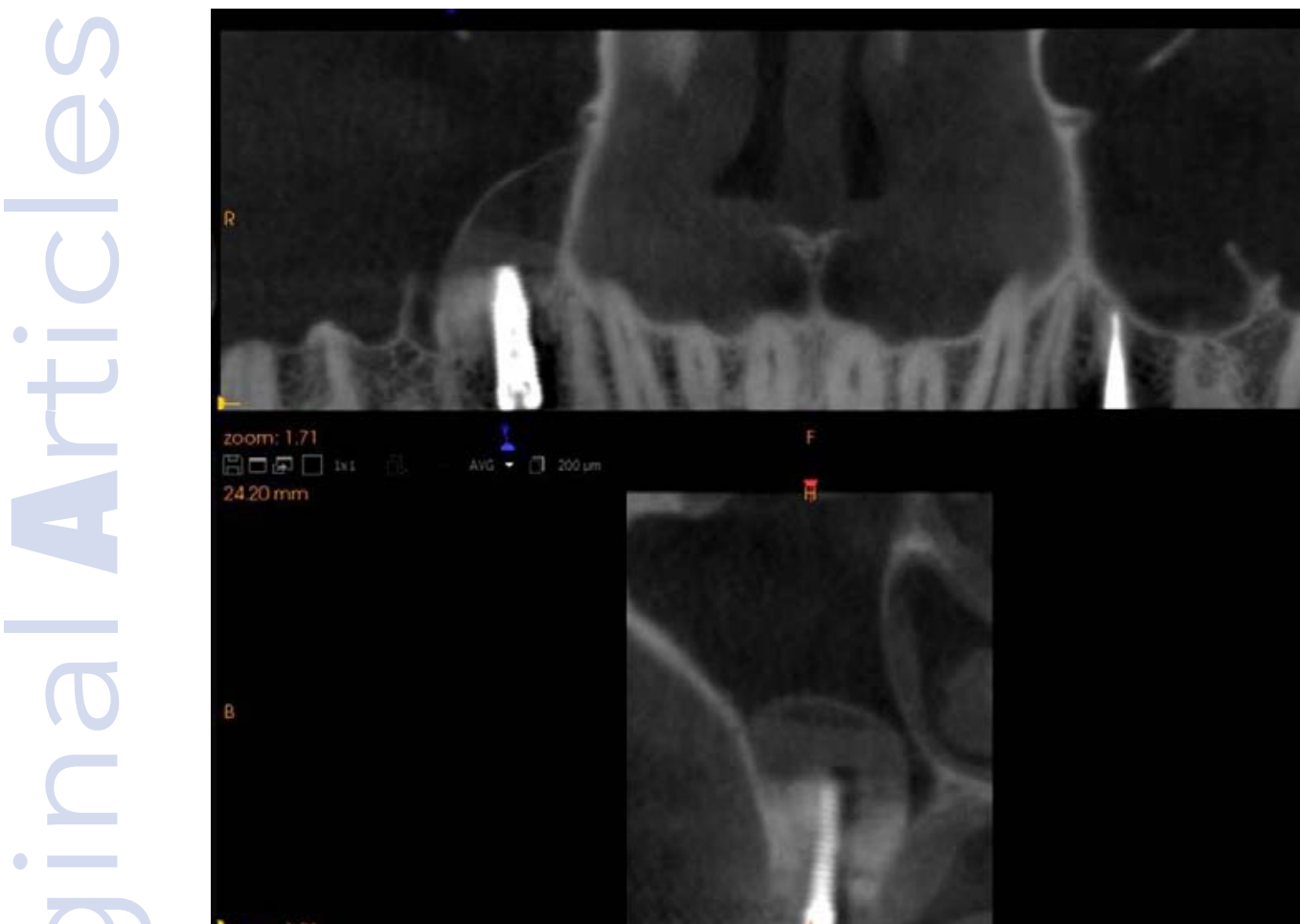

Figure 1. Immediate postoperative view of a single implant.

the Tatum and Summers approaches, enabling sinus floor augmentation to the full extent necessary with minimum postoperative morbidity. Cone beam computed tomography (CBCT) provides a highly sophisticated format to precisely define the jaw structure and locate critical anatomic structures [20], and CBCT has been used in diagnosis, implant treatment [21], and evaluation of the changes after the sinus augmentation $[6,9,12,14,21-23]$. In the present study, the immediate and early (up to one week) tomographic findings following maxillary sinus augmentation using a minimally invasive implant device will be described.

\section{MATERIALS AND METHODS}

The dental implant used in this trial was a self-tapping endosseous dental implant $[4,5]$. It contains an internal channel that allows the introduction of liquids through the implant body and into the maxillary sinus. The device was approved for clinical testing by the ethical committees of the Israeli Ministry of Health following extensive preclinical and bench testing. The device also has a Conformité Européenne (CE) approval Health Canada and is allowed for distribution in Europe, Canada and Israel. The study was approved by the ethical committee of the Tel Aviv University.

\subsection{Surgical procedure}

Prophylactic antibiotics were administered $1 \mathrm{~g}$ of amoxicillin, 1 hour before the procedure). The patient performed a one-minute mouth wash with a chlorhexidine gluconate $0.2 \%$ solution. Surgery commenced with local anesthesia and a crestal incision, without vertical extensions, along the maxillary ridge.
Relatively small full thickness mucoperiosteal flaps were reflected. The osteotomy site was marked with a small round bur. An osteotomy was started at the implantation site with a $3.2-\mathrm{mm}$ twist drill to a depth of $3 \mathrm{~mm}$. The second drill is a flat tip drill up to 1 to $2 \mathrm{~mm}$ below the Schneiderian membrane, as measured by the preoperative radiograph. In some cases the operator used drills stoppers in order to accurately drill to the planed point under the sinus floor, in other cases the operator used a free hand drill with depth marking only. A periapical radiograph with a depth guide was performed in order to verify the drilling angulation and depth. The osteotomy site was widened to the desired diameter with the full drilling sequence for either a 4.2 or $5.0 \mathrm{~mm}$-diameter implant. The sinus floor was opened with a drill with an active diamond tip designed to atraumatically penetrate the sinus floor under the Schneiderian membrane with out damaging the membrane. The length of the implant (ranging from 13 to $16 \mathrm{~mm}$ ) was selected based on the residual bone height: a 13-mm length implant was used for bone heights of up to $5 \mathrm{~mm}$, a $14.5-\mathrm{mm}$ length implant was used for bone heights of up to $6.5 \mathrm{~mm}$, and a $16-\mathrm{mm}$ length implant was used for bone heights of up to $8 \mathrm{~mm}$. The implant was first inserted into the osteotomy until it reached the end of the prepared osteotomy. The implant was then slowly advanced until the sinus floor was penetrated (approximately $1 \mathrm{~mm}$ ). A periapical radiograph was performed in some cases in order to determine whether the implant penetrated the sinus floor. A saline syringe $(0.9 \%$ sodium chloride sterile saline solution) was connected to the implant via the tubing port. Saline solution was gently injected through the implant and into the sinus. Slight bleeding was 


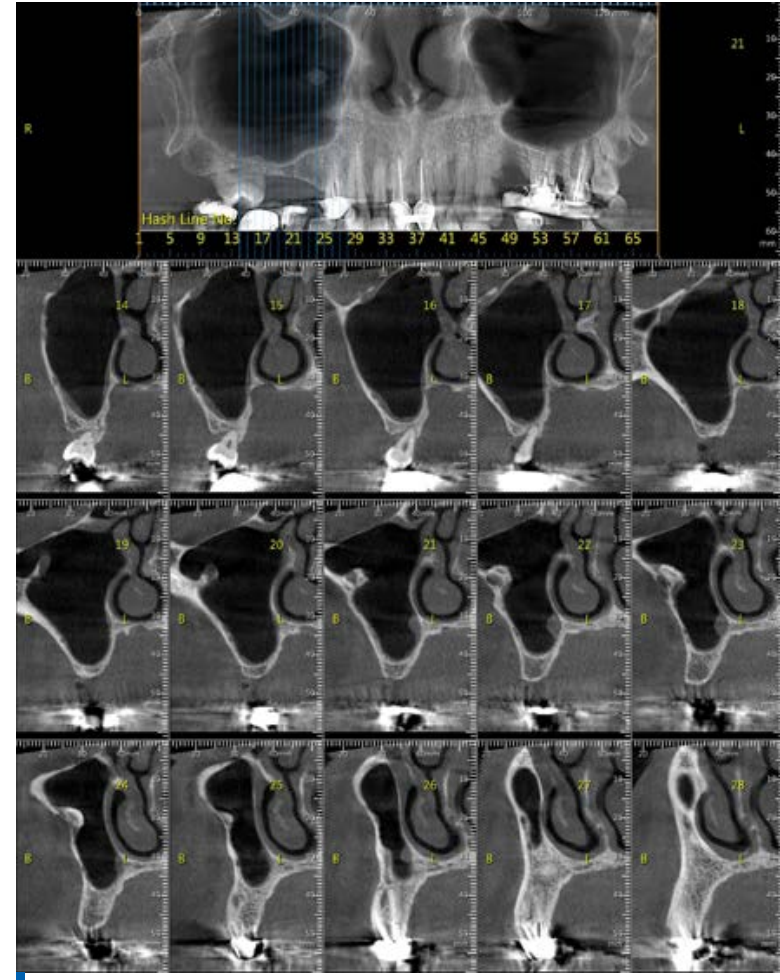

Figure 2a. Preoperative CT demonstrating slight thickening of the Schneiderian membrane.

noted in the retracted saline solution. This phenomenon served as a further indication that the implant tip penetrated the cortex. Blood was observed in the tubing upon stopping the injection or slightly draining fluid. Blood originated from the severed blood vessels connecting the Schneiderian membrane to the sinus bony walls. Typically, 2 to $3 \mathrm{~cm}^{3}$ of saline were required, depending on the size of the sinus, the number of implants, and the required elevation. The saline solution was retracted back into the syringe and the saline syringe was disconnected from the tubing port. A flowable bone graft filled syringe was then connected to the tubing port. The desired volume of bone graft material was then slowly injected through the implant into the sinus. The amount of bone graft ranged from 1 to $3 \mathrm{~cm}^{3}$, average $2.1 \mathrm{~cm}^{3}$. The bone graft syringe was subsequently disconnected from the tubing port and then the applicator and tubing together were disconnected from the implant. The implant was then fully inserted through the osteotomy into the bone graft until the coronal aspect of the implant was aligned with the maxillary alveolar crest. The gingival flaps were then sutured.

A periapical radiography was performed at the end of the procedure. For those cases where the periapical radiograph could not demonstrate a clear postoperative result, a CBCT was performed at the end of the procedure. When a $C B C T$ device was not available an early CBCT was performed within 1 week. Twenty immediate/early postoperative CBCT's were retrospectively evaluated for descriptive purposes.

Following the procedure the patients were instructed to perform mouth rinsing for 1 minute with $0.2 \%$ chlorhexidine solution, twice a day, for 10 days. Post-

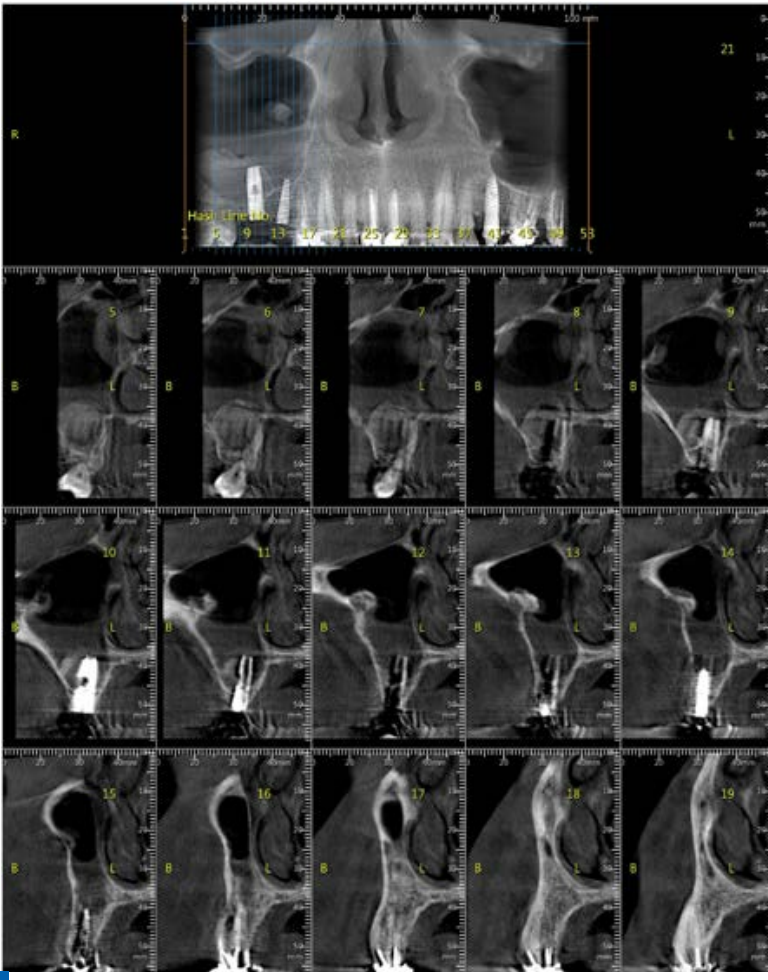

Figure $2 \mathbf{b}$. Postperative CT demonstrating moderate thickening of the Schneiderian membrane.

operative analgesia was used as needed. Nose drops (topical decongestants such as oxymetazoline) were used in the relevant nostril twice a day for a week. Antibiotics were prescribed at the clinician's discretion (as usually given in bone grafting procedures): $3 \times 500 \mathrm{mg}$ amoxicillin for 7 days.

\section{RESULTS}

25 immediate postoperative CBCT's were reviewed. The following radiological phenomena were noted:

O Schneiderian membrane (Fig. 1)

A clear membrane was noted in all CBCT scans allowing a distinction between the grafted area and the rest of the sinus. The Scneiderian membrane appeared as a narrow hyperdense line.

OLack of membrane perforation (Fig. 1)

The thin line of the Schneiderian membrane is seen encircling the entire new content (air, water, bone) without any perforated area. None of the included materials is seen outside the membrane, within the sinus.

O Postoperative swelling of the sinus membrane (Fig. 2)

All cases demonstrated a slight postoperative swelling of the sinus membrane without any signs of inflammation.

OPalatal coverage of the membrane (Fig. 1)

The membrane is not necessarily elevated for all the bony walls. The elevation is probably proportional to the amount of residual alveolar ridge, pressure from the injectable fluids and connection between the membrane and the bone.

OFlush and compact adaptation of the grafting material (Fig. 1) 


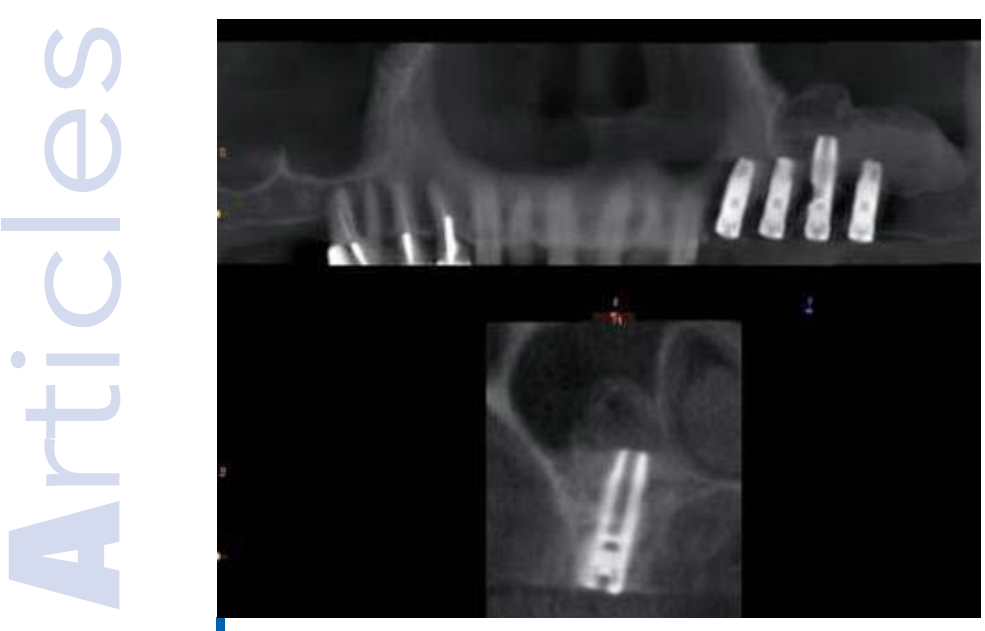

Figure 3. Immediate postoperative view of multiple implant placement.

Cases without additional implant placement demonstrated flush and compact adaptation of the bone graft to the sinus floor. When additional implants were inserted irregular combinations of the hyperdense and hypodense areas were noted as a result fluid insertion and graft extrusion during the osteotomy preparation. (Figs. 3,4)

OCreation of 4 layers according to molecular weight (Fig. 1)

Some immediate postoperative CBCT's demonstrated 4 layers according to molecular weight. The most crestal is the original residual alveolar ridge. The second is the injected bone graft. The third as water / blood from the severed Schneiderian membrane vessels and the most apical layer was air.

The layers may be arranged in either a homogenous pattern or in a completely non-homogenous one. Another factor is probably the additional drilling into the sinus floor while adding implant, which can stir the bone graft and fluid inside the space created under the Schneiderian membrane. (it is possible that it may take time for the layers to become homogeneous as when you mix oil and water)

O Elevation direction (Figs. 1-4)

There is no absolute control of the elevation amount and direction. The membrane may be elevated either superiorly, distally, mesially, palatally or any combination of the above.

\section{Membrane shape}

In some cases the membrane obtains a ball/balloon like appearance (Fig. 1) whereas in others it may obtain a completely irregular plastic shape (Figs. 3,4).

\section{DISCUSSION}

Injectable bone substitutes are a combination of xenografts, allografts, alloplasts and liquid components. Injectable alloplast proved to be very useful when applied via a minimally invasive dental implant device. The fluid organic components serve as a binder for the anorganic bone substitute particles. The organic materials prevent wash out of the particles from the grafted site.[24] In order to allow optimal flow characteristics injectable grafts are further

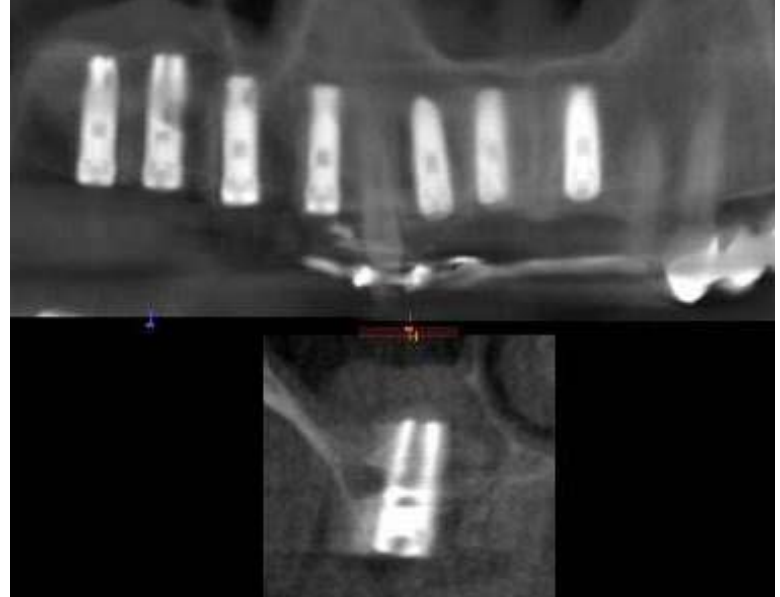

Figure 4. Immediate postoperative view of multiple implant placement.

diluted. As a result the injected grafting material can easily glide between the Schneiderian membrane and the sinus floor without causing pain or injury [25]. For clinical purposes prolonged storage of such ready-to-use injectable bone substitute materials is mandatory. A neutral $\mathrm{pH}$ is the best solution for this requirement $[25,26]$. Their fluidity and adaptability to the host tissue is another mandatory requirement. Thus, it can be speculated that the hyper dense view of the Schneiderian membrane is a result of the increased concentration of the bone substitute macromolecules adapting fast to the membrane as a result of their fluidity. Sinus membrane integrity is essential for the success of the transcrestal sinus augmentation. Membrane perforations occur in $0-21.4 \%$ of the transcrestal procedures [27-28]. Ruling out in such cases is mandatory since there is very limited possibility to repair such tears jeopardizing the entire hydraulic elevation procedure. A clinical option is doing a valsalva maneuver and observing the osteotomy site that no air bubbles are coming out during the maneuver. A dental CBCT provides conclusive post op information about such a perforation either by following the white hyperdense membrane line or making sure there is no dislodged graft material in the sinus beyond the Schneiderian membrane. Injectable bone substitutes affect sedimentation the creation of precipitation layers according to the law of gravity [24-26]. This is the explanation for the 4 layers noted on CBCT - residual alveolar ridge, injectable bone graft, water and blood, air. This arrangement allows us to assure the intimate contact of the graft to the native bone permitting good graft consolidation. On the other hand, this finding should also raise the question of whether studies concerning bone resorption along time represent true resorption or are merely an expression of water and air content disappearance. Such questions should be taken in consideration in future studies allowing us to better understand the resorptive processes following sinus augmentation [29-31]. The graft consolidation gradient is a term describing new bone formation on the one hand vs. bone substitute disappearance [33]. Since we are talking about a gradient, both phenom- 
ena are evaluated as a function of the distance from either the host bone or the implant. Behavior close to the host bone will teach us concerning the new volume consolidation while close to the implant - concerning osseointegration. Injectable grafts are fast resorbing materials [32]. It is known that such materials disappear relatively fast from both sites allowing new bone formation. Therefore, we should dedicate all our efforts to exposing the palatal site and elevating the sinus membrane. Otherwise, the palatal part of the bone will not participate in the formation of new bone. As a result, lower new bone quantity and quality will be formed, lowering the biomechanical abilities of the inserted new implants to withstand occlusal forces [33]. Neverthless, there are reports in the literature that just tenting of the Schneiderian membrane without bone graft may be sufficient in order to create new bone under the elevated and separated from the sinus floor Schneiderian membrane. Probably blood clot is transformed into bone in that situation [34]. Due to Pascal's law it is difficult to obtain complete control of the membrane elevation. Water will search the lowest resistant point to detach the membrane from the sinus floor $[35,36]$. Therefore, if we have any doubt it is better to use more fluid for elevation, to allow bony exposure and better fluidity of the bone grafting material. While membrane thickness in humans ranges from 24$350 \mu \mathrm{m}$ with a mean of $40 \mu \mathrm{m}$, in animals it ranges 68-318 $\mu \mathrm{m}$ [37]. Animal model studies led to the wrong conclusion that the Schneiderian membrane is elastic and responds to pressure like a balloon. The present study clearly shows that the "balloon" behavior is rather the exception than the rule. The more frequently seen behavior is plastic, obtaining

\section{REFERENCES}

1. Xavier SP, Dias RR, Sehn FP, et al. Maxillary sinus grafting with autograft vs. fresh frozen allograft: a split-mouth histomorphometric study. Clin Oral Implants Res. 2015;26(9):10801085.

[Full text links] [CrossRef] [PubMed] Google Scholar Scopus

2. Xavier SP, Silva ER, Kahn A, et al. Maxillary sinus grafting with autograft versus fresh-frozen allograft: a split-mouth evaluation of bone volume dynamics. Int J Oral Maxillofac Implants. 2015;30(5):1137-1142.

[Full text links] [CrossRef] [PubMed] Google Scholar Scopus 3. Sehn FP, Dias RR, de Santana Santos T, et al. Fresh-frozen allografts combined with bovine bone mineral enhance bone formation in sinus augmentation. J Biomater Appl. 2015:29(7):1003-1013. [Full text links] [CrossRef] [PubMed] Google Scholar Scopus 4. Better $H$, Slavescu D, Barbu $H$, et al. Patients perceptions of recovery after maxillary sinus augmentation with a minimally invasive implant device. Quintessence Int. 2014;45(9):779-787. doi:10.3290/j.qi.a32510

[Full text links] [PubMed] Google Scholar Scopus

5. Better $\mathrm{H}$, Slavescu D, Barbu $\mathrm{H}$, et al. Minimally invasive sinus lift implant device: a multicenter safety and efficacy trial preliminary results. Clin Implant Dent Relat Res. 2014;16(4):520-526.

[Full text links] [CrossRef] [PubMed] Google Scholar Scopus

6. Mardinger O, Chaushu G, Sigalov S, et al. Factors affecting changes in sinus graft height between and above the placed implants. Oral Surg Oral Med Oral Pathol Oral Radiol Endod. 2011;111(1):e6-e11.

[Full text links] [CrossRef] [PubMed] Google Scholar Scopus

7. Mardinger $\mathrm{O}$, Moses $\mathrm{O}$, Chaushu $\mathrm{G}$, et al. Challenges associated with reentry maxillary sinus augmentation. Oral Surg Oral Med Oral Pathol Oral Radiol Endod. 2010;110(3):287-291. any possible shape. This is one more reason why there are fewer chances for tearing the membrane during elevation with the hydraulic technique vs. the balloon technique.

Hydraulic sinus elevation is not a new idea. Sinus endoscopy maybe an additional (albeit invasive) technique to assure lack of sinus membrane perforation. $\mathrm{CBCT}$ is probably more precise but involves $\mathrm{X}$-ray exposure. An additional disadvantage is the inability to detect small rupture immediately after surgery. A long-time comparative randomized study can give us more precise information.

\section{CONCLUSION}

Dental CBCT is considered the gold standard for sinus diagnosis and surgical planning of sinus augmentation. The present study suggests that CBCT should also be the gold standard for immediate or early postoperative imaging, following transcrestal sinus augmentation, using minimally invasive implant device, to document post grafting conditions and allow early intervention in failures.

\section{CONFLICT OF INTEREST}

The authors declare no conflict of interest.

\section{AUTHOR CONTRIBUTIONS}

$\mathrm{CL}$ : study design, data collection, writing the manuscript; $\mathrm{BH}$ : data collection; NJ: approval of the final version; XSP: approval of thefinal version; LA: data collection; CG: study design, data collection, writing the manuscript.
[Full text links] [CrossRef] [PubMed] Google Scholar

8. Chaushu G, Vered M, Mardinger O, Nissan J. Histomorphometric analysis after maxillary sinus floor augmentation using cancellous bone-block allograft. J Periodontol. 2010;81(8):1147-1152. [CrossRef] [PubMed] Google Scholar Scopus

9. Manor Y, Mardinger O, Bietlitum I, et al. Late signs and symptoms of maxillary sinusitis after sinus augmentation. Oral Surg Oral Med Oral Pathol Oral Radiol Endod. 2010;110(1):e1-e4.

[CrossRef] [PubMed] Google Scholar Scopus

10. Chaushu G, Mardinger O, Calderon S, et al. The use of cancellous block allograft for sinus floor augmentation with simultaneous implant placement in the posterior atrophic maxilla. J Periodontol. 2009;80(3):422-428.

[CrossRef] [PubMed] Google Scholar Scopus

11. Mardinger $O$, Nissan J, Chaushu G. Sinus floor augmentation with simultaneous implant placement in the severely atrophic maxilla: technical problems and complications. J Periodontol. 2007;78(10):1872-1877.

[CrossRef] [PubMed] Google Scholar Scopus

12. Shlomi B, Horowitz I, Kahn A, et al. The effect of sinus membrane perforation and repair with Lambone on the outcome of maxillary sinus floor augmentation: a radiographic assessment. Int J Oral Maxillofac Implants. 2004;19(4):559-562. [PubMed] Google Scholar Scopus

13. Mazor Z Peleg M, Garg AK, Chaushu G. The use of hydroxyapatite bone cement for sinus floor augmentation with simultaneous implant placement in the atrophic maxilla. A report of 10 cases. J Periodontol. 2000;71(7):1187-1194. [CrossRef] [PubMed] Google Scholar Scopus

14. Peleg M, Chaushu G, Mazor Z, et al. Radiological findings of the post-sinus lift maxillary sinus: a computerized tomography 
follow-up. J Periodontol. 1999;70(12):1564-1573.

[CrossRef] [PubMed] Google Scholar Scopus

15. Peleg M, Mazor Z, Chaushu G, Garg AK. Sinus floor augmentation with simultaneous implant placement in the severely atrophic maxilla. J Periodontol. 1998;69(12):1397-1403.

[CrossRef] [PubMed] Google Scholar Scopus

16. Mardinger $\mathrm{O}$, Poliakov $\mathrm{H}$, Beitlitum I, et al. The patient's perception of recovery after maxillary sinus augmentation: a prospective study. J Periodontol. 2009;80(4):572-576.

[CrossRef] [PubMed] Google Scholar Scopus

17. Tatum H Jr. Maxillary and sinus implant reconstructions. Dent Clin North Am. 1986;30(2):207-229.

Google Scholar Scopus

18. Summers RB. A new concept in maxillary implant surgery: the osteotome technique. Compendium. 1994;15(2):152-162.

[PubMed] Google Scholar Scopus

19. Chen L, Cha J. An 8-year retrospective study: 1,100 patients receiving 1,557 implants using the minimally invasive hydraulic sinus condensing technique. J Periodontol. 2005;76(3):482-491.

[CrossRef] [PubMed] Google Scholar Scopus

20. Garg AK, Vicari A. Radiographic modalities for diagnosis and treatment planning in implant dentistry. Implant Soc. 1995;5(5):7-11. [PubMed] Google Scholar Scopus

21. Wanschitz F, Figl M, Wagner A, Ewers R. Measurement of volume changes after sinus floor augmentation with a phycogenic hydroxyapatite. Int J Oral Maxillofac Implants. 2006;21(3):433-438. [PubMed] Google Scholar Scopus

22. Kirmeier R, Payer M, Wehrschuetz M, et al. Evaluation of threedimensional changes after sinus floor augmentation with different grafting materials. Clin Oral Implants Res. 2008;19(4):366-372.

[Full text links] [CrossRef] [PubMed] Google Scholar Scopus

23. Szabó G, Suba Z, Hrabák K, et al. Autogenous bone versus betatricalcium phosphate graft alone for bilateral sinus elevations (2- and 3-dimensional computed tomographic, histologic, and histomorphometric evaluations): preliminary results. Int J Oral Maxillofac Implants. 2001;16(5):681-692.

[CrossRef] [PubMed] Google Scholar

24. Uda H, Sugawara Y, Nakasu M. Experimental studies on hydroxyapatite powder-carboxymethyl chitin composite: injectable material for bone augmentation. J Plast Reconstr Aesthet Surg. 2006;59(2):188-196.

[Full text links] [CrossRef] [PubMed] Google Scholar Scopus

25. Gérentes P, Vachoud L, Doury J, Domard A. Study of a chitin-based gel as injectable material in periodontal surgery. Biomaterials. 2002;23(5):1295-1302.

[Full text links] [CrossRef] [PubMed] Google Scholar Scopus

26. Weiss P, Gauthier O, Bouler JM, et al. Injectable bone substitute using a hydrophilic polymer. Bone. 1999;25(2 Suppl):67S-70S.

[Full text links] [CrossRef] [PubMed] Google Scholar Scopus

27. Kim DY, Itoh Y, Kang TH. Evaluation of the effectiveness of a wate

lift system in the sinus membrane-lifting operation as a sinus surgical instrument. Clin Implant Dent Relat Res. 2012;14(4):585-594.
[Full text links] [CrossRef] [PubMed] Google Scholar Scopus

28. Tan WC, Lang NP, Zwahlen M, Pjetursson BE. A systematic review of the success of sinus floor elevation and survival of implants inserted in combination with sinus floor elevation. Part II: transalveolar technique. J Clin Periodontol. 2008;35(8 Suppl):241-254

[Full text links] [CrossRef] [PubMed] Google Scholar Scopus

29. Xavier SP, Silva ER, Kahn A, et al. Maxillary sinus grafting with autograft versus fresh-frozen allograft: a split-mouth evaluation of bone volume dynamics. Int J Oral Maxillofac Implants. 2015;30(5):1137-1142.

[Full text links] [CrossRef] [PubMed] Google Scholar Scopus

30. Sbordone C, Toti P, Guidetti F, et al. Volumetric changes after sinus augmentation using blocks of autogenous iliac bone or freeze-dried allogeneic bone. A non-randomized study. J Craniomaxillofac Surg. 2014;42(2):113-118.

[Full text links] [CrossRef] [PubMed] Google Scholar Scopus

31. Berberi A, Bouserhal $L$, Nader $N$, et al. Evaluation of threedimensional volumetric changes after sinus floor augmentation with mineralized cortical bone allograft. J Maxillofac Oral Surg. 2015;14(3):624-629.

[Full text links] [CrossRef] [PubMed] Google Scholar Scopus

32. Busenlechner D, Huber CD, Vasak C, et al. Sinus augmentation analysis revised: the gradient of graft consolidation. Clin Oral Implants Res. 2009;20(10):1078-1083.

[Full text links] [CrossRef] [PubMed] Google Scholar Scopus 33. Tepper G, Haas R, Zechner W, et al. Three-dimensional finite element analysis of implant stability in the atrophic posterio maxilla: a mathematical study of the sinus floor augmentation. Clin Oral Implants Res. 2002;13(6):657-665.

[Full text links] [CrossRef] [PubMed] Google Scholar Scopus

34. Jungner M, Cricchio G, Salata LA, et al. On the Early Mechanisms of Bone Formation after Maxillary Sinus Membrane Elevation: An Experimental Histological and Immunohistochemical Study. Clin Implant Dent Relat Res. 2015;17(6):1092-1102.

[Full text links] [CrossRef] [PubMed] Google Scholar Scopus

35. Pommer B, Watzek G. Gel-pressure technique for flapless transcrestal maxillary sinus floor elevation: a preliminary cadaveric study of a new surgical technique. Int J Oral Maxillofac Implants. 2009:24(5):817-822.

[PubMed] Google Scholar Scopus

36. Pommer $B$, Unger $E$, Sütö $D$, et al. Mechanical properties of the Schneiderian membrane in vitro. Clin Oral Implants Res. 2009;20(6):633-637.

[Full text links] [CrossRef] [PubMed] Google Scholar Scopus

37. Watzek G, Pommer B, Strbac GD. Status quo analysis. In: Watzek $\mathrm{G}$, editor. The precrestal sinus lift from illusion to reality. London, UK: Quintessence Publishing Co. Ltd; 2012.

Google Scholar

\section{Liat CHAUSHU \\ DMD, MSC Department of Periodontology and Implant Dentistry The Maurice and Gabriela Goldschleger School of Dental Medicine Tel Aviv-University Tel Aviv, Israel

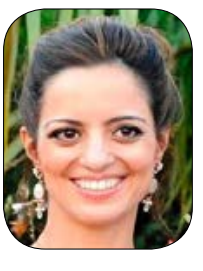

Graduated magna cum laude at Maurice and Gabriela Goldschleger school of Dental Medicine, Tel Aviv University, Tel Aviv, Israel. Completed her MSc. Degree at Sackler Faculty of Medicine, Tel Aviv University, Tel Aviv, Israel. Graduate of the periodontology program and member of the department of periodontology and implant dentistry, the Maurice and Gabriela Goldschleger School of Dental Medicine, Tel Aviv University, Tel Aviv, Israel. Graduate of the European federation of periodontology. A member of the Israeli society of Periodondology and Osseointegration. A member of the European Federation of Periodontology. A member of Israeli Dental Association. Lectures nationally and internationally. Published over 20 manuscripts in peer-reviewed journals. Founder of an Israeli start-up company, Implant B, with a unique patent for the treatment of peri-implant disease. 


\section{Ouestions}

\section{How many layers were noted postoperatively?}

ㅁ. 1;

ab. 2;

ac. 3;

ad. 4.

\section{Perforations can be noted easily in the postop CBCT:}

口a. Yes;

ab. No;

ac. It is not possible to see perforations on CBCT;

$\square \mathrm{d}$. Resorbable collagen membranes should always be placed on the Schneiderian membrane.

3. The Schneiderian membrane always appears as a balloon following sinus elevation:

口a. Yes;

ab. No;

ac. It is not possible to see the Schneiderian membrane on CBCT;

$\square$ d. Only if you use a balloon for sinus elevation.

\section{The 4 layers are best noted in cases of :}

口a. Single implant;

ab. Multiple implants;

ac. Not relevant;

ad. Similar.

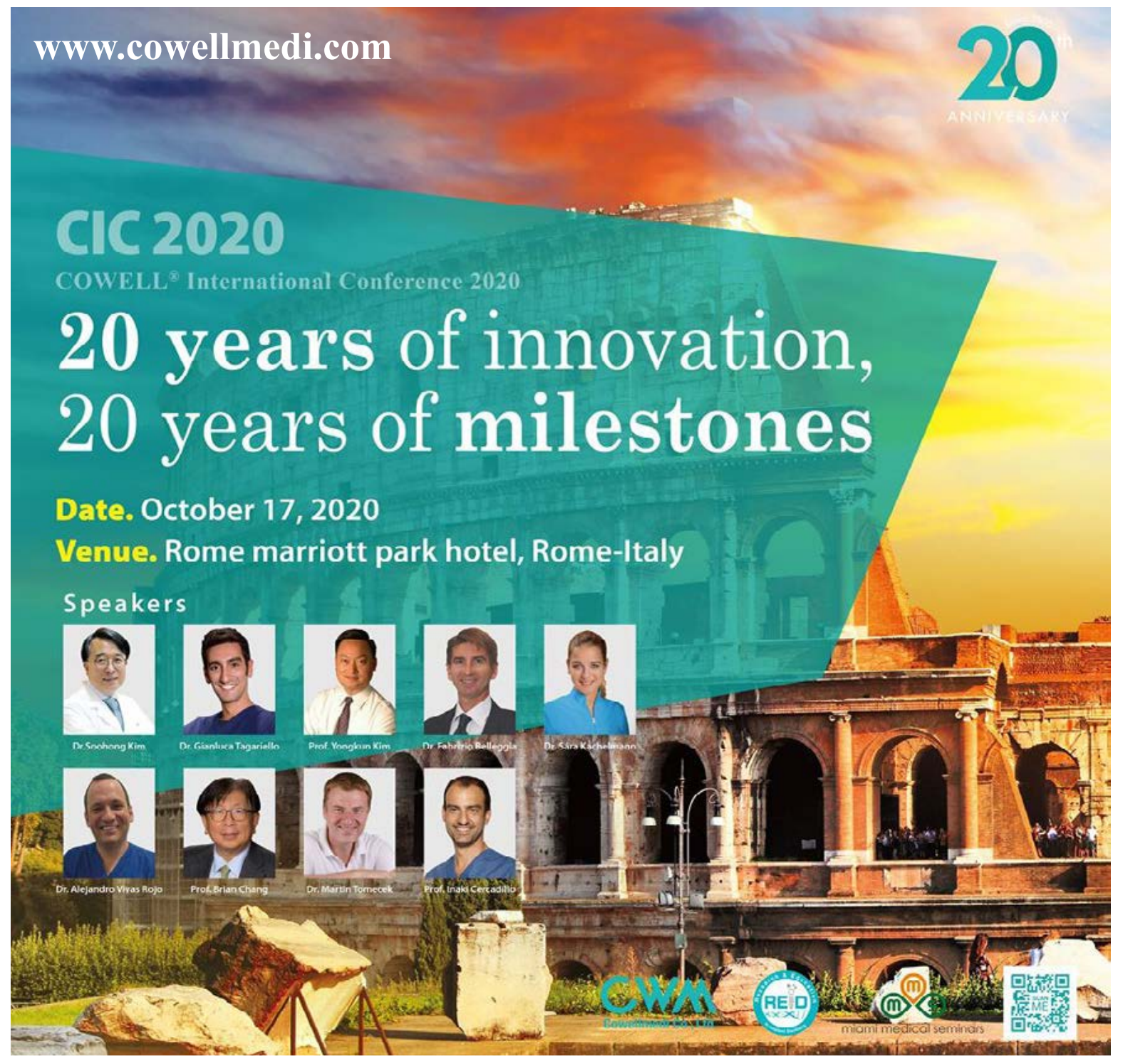


s.

\section{APOS}

$\mathrm{JS}_{\mathrm{S}}$

$=$

The 9 th international

Orhodontic Congress

\section{(9h 10e)}

The 12th Asian Pacific Orthodontic Conference (12th APOC)

The 79th Annual Meeting of the Japanese Orthodontic Society (79th J05)

\section{Broadening}

the Vision in

Orthodontics

-Orthodontics as the starting point for health science-

4th Oct. Sun.-7th Oct Wed.,
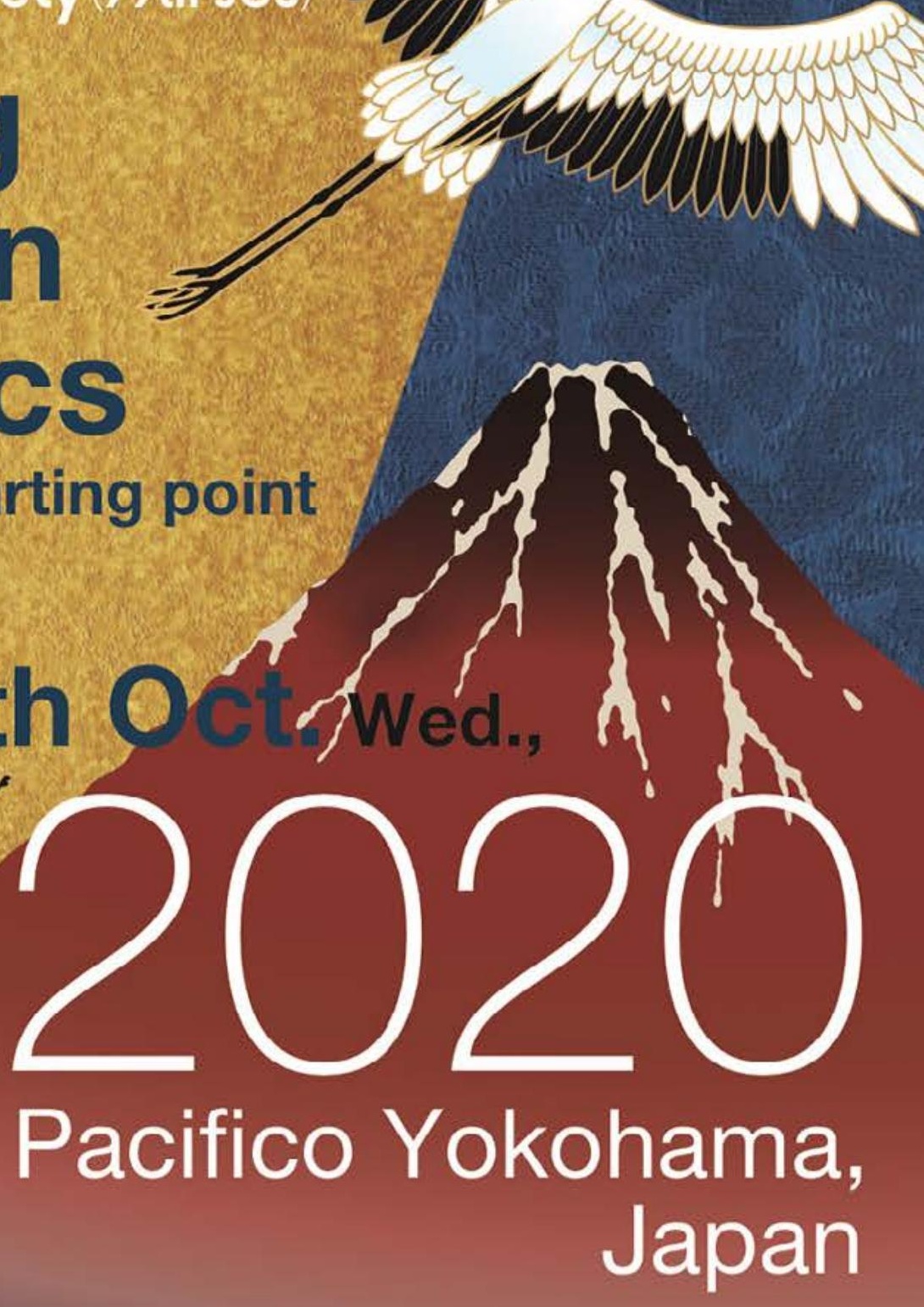

http://www.wfo2020yokohama.org/ 


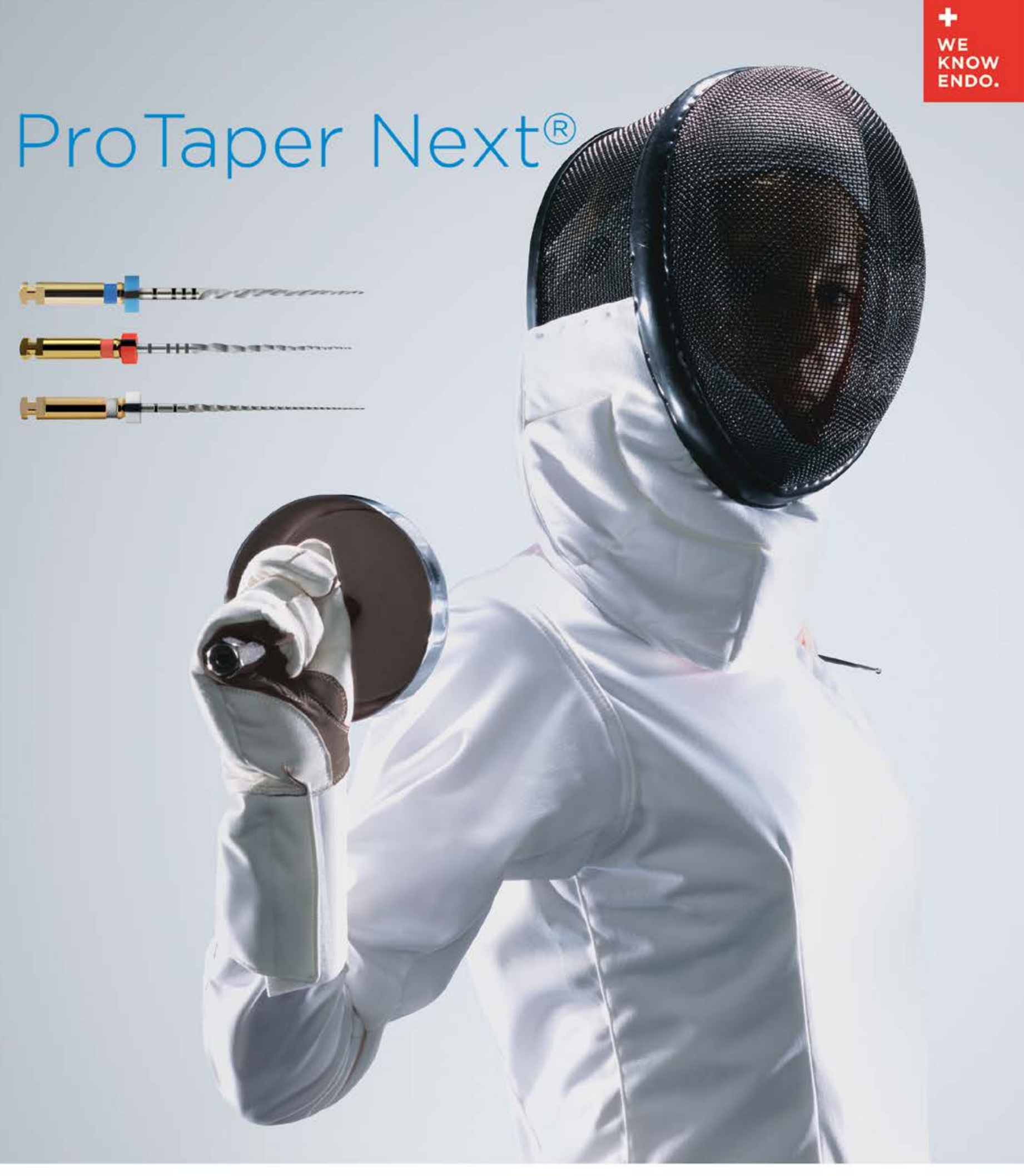

Office \& Showroom

98A Vulturilor Street, $3^{\text {rd }}$ District

RO-030857 Bucharest, Romania

Tel: +40774074094

e-mail:office.romania@dentsplysirona.com

\section{Dentsply Sirona}




\title{
UNCLARITIES ABOUT ARTICAINE: EFFICACY AND THE RISK OF PARESTHESIA
}

\author{
Nicolas de Ridder ${ }^{1 a}$, Constantinus Politis ${ }^{1 b^{*}}$ (D) \\ 'Department of Oral and Maxillo-Facial Surgery, Faculty of Medicine, Catholic University of Leuven, Leuven, Belgium \\ aMD, Student in Master of Medicine; ${ }^{b} \mathrm{MD}, \mathrm{DDS}, \mathrm{MM}, \mathrm{MHM}, \mathrm{PhD}$, Professor and Head
}

ABSTRACT DOI: https://doi.org/10.25241/stomaeduj.2020.7(1).art.6

Background: Articaine is a very popular local anesthetic in dentistry. A lot of claims have been made about articaine over the years, both positive and negative. Many clinicians claim articaine is superior to lidocaine. However, since a study in 1995 claiming an increased risk of paresthesia, there has been debate about whether this is true or not.

Objective: To review the current literature to clarify the current ambiguities about the possible superior efficacy and the alleged higher risk of paresthesia.

Data sources: As a basis, a handbook on local anesthesia was read, as well as its references to the topics of interest. Afterward, the literature was searched for publications about both the efficacy and the risk of paresthesia from 1990 to 2019.

Study selection: Articles about the efficacy with clear data and minimal risk of bias were selected. For paresthesia, the original articles were selected as well as more recent reviews highlighting the flaws in the first studies.

Data extraction: Information about the efficacy and the possible superiority of articaine compared to lidocaine was extracted. For paresthesia, the most important historical publications were reviewed and more recent reviews were

OOPEN ACCESS This is an Open Access article
under the CC BY-NC 4.0 license.
Citation: de Ridder N, Politis C. Unclarities about articaine:
efficacy and the risk of paresthesia.
Stoma Edu J. 2020;7(1):44-51.
Received: January 22, 2020
Revised: February 13, 2019
Accepted: February 20, 2020
Published: February 22, 2020
Corresponding author:
Professor Constantinus Politis, MD, DDS, MM, MHM, PhD,
Head, Department of Oral and Maxillo-Facial Surgery,
Faculty of Medicine, Catholic University of Leuven,
Kapucijnenvoer 33, BE-3000 Leuven, Belgium
Tel: / Fax: 0032 (0)16332462,
e-mail: constantinus.politis@uzleuven.be
Copyright: $\odot$ 2020 the Editorial Council
for the Stomatology Edu Journal.
evaluated.

Data synthesis: These data were synthesized in an overview consisting of two parts. First, the properties of articaine were review and what was learned about the efficacy of articaine in relation to other local anesthetics was discussed. Secondly, an overview of the history of paresthesia was given and the flaws and unclarities were highlighted.

KEYWORDS

Articaine; Epinephrine; Efficacy; Paresthesia; Dentistry.

\section{INTRODUCTION}

Articaine is an amide dental local anesthetic, synthesized in 1969 in Germany.

It was specifically developed for dental use and got its approval for clinical use in countries all over the world in the years to follow. It became increasingly popular and is now the second most used local anesthetic in dentistry.

Annually, approximately $600,000,000$ cartridges are manufactured [1]. In 2018 the market share of articaine was $39,3 \%$ in the United States, and as much as $97 \%$ in Germany $[1,2]$.

However, lidocaine still remains the golden standard for local anesthesia.

Over the years, articaine has been the subject of intense discussion and (anecdotal) claims (both good and bad). Some of the good claims include a supposedly better potency, faster onset of anesthesia and a higher success rate.
The bad claim is mainly an alleged increased risk of paresthesia. Some of these claims have been shown to be correct (like the success in buccal infiltration anesthesia in the adult mandible).

However, on a lot of other claims or initial reports there is no scientific evidence to prove them or the results are contradictory.

\section{MATERIALS AND METHODS}

As background information and the basis of this review, Malamed's Handbook of Local Anesthesia (seventh edition) was read.

Afterward, searches were made on PubMed, Trip database and Limo with different combinations of the following keywords: safety, clinical characteristics, paresthesia, efficacy, lidocaine, articaine, local anesthetics, epinephrine. A selection was made of the most relevant articles to make this narrative review. 


\section{CLINICAL CHARACTERISTICS}

Articaine hydrochloride (or4-methyl-3-[2-(propylamino) propionamido]-2-hiophenecarboxylic acid methyl ester) is used in dental cartridges of $1.8 \mathrm{~mL}$. These cartridges contain $72 \mathrm{mg}$ of articaine and 0.09 to 0.18 $\mathrm{mg}$ of epinephrine, depending on the concentration (1:200,000 and 1:100,000 respectively) [1].

\subsection{Articaine}

Although it is classified as an amide anesthetic, articaine is considered a unique entity within the amide local anesthetics. It has different properties compared to the other local anesthetics. Most importantly, it contains an ester-linkage that can be hydrolyzed by plasma-esterases and turns articaine in an inactive compound: articainic acid [2]. This rapid manner of inactivation is the same biotransformation that occurs in the elimination of ester anesthetics [1]. This contributes greatly to the low systemic toxicity of the drug. This mechanism also gives articaine its relatively short elimination half-life of only 27 minutes (compared to 90 minutes for lidocaine) [2]. Secondly, it contains an aromatic thiophene ring which would ensure greater lipid solubility. This would increase potency because articaine is better in penetrating tissue and bone [3]. Finally, articaine has a high degree of protein binding (95\%). This high degree of protein binding may account for a longer duration of anesthetic effect as well for the increased tendency to bind to the protein receptor [1].

Clinically, the drug works by binding reversibly to the alfa-unit of the voltage-gated sodium channels in the nerve, thereby preventing the propagation of action potentials [3]. This gives pulpal anesthesia for approximately 60 minutes and soft tissue anesthesia for 3 to 5 hours, making articaine an intermediate-acting anesthetic [4]. There is a theory suggesting that local saturation of serum esterases would cause a delay in local metabolism of articaine. This mechanism would account for the prolonged anesthetic effect while the systemic toxicity remains low [4]. A study showing high alveolar blood levels of articaine post-extraction with an increased metabolic rate from articaine to articainic acid supports these claims [5]. As with all drugs, the clinician should be careful not to elicit overdose reactions by using too much of the drug. Articaine has a maximum recommended dose of $7.0 \mathrm{mg} /$ $\mathrm{kg}$ [1]. A cartridge contains $1.8 \mathrm{~mL}$ of anesthetic solution, so for articaine $4 \%$ it equals $72 \mathrm{mg}$ of articaine. A normal healthy adult of $72 \mathrm{~kg}$ would have a maximum recommended dose of $504 \mathrm{mg}$. This equals 7 cartridges. These maximum dosages are well above the dosages normally needed in routine dental care (normally a maximum of about three to four cartridges are needed during routine dental care). With six cartridges you could achieve anesthesia of a full adult mouth [1]. Nevertheless, exceeding the maximum recommended dose is the most frequent cause of overdose reactions in dental patients [1]. That is why it is important to always calculate this maximum dosage. If used within this range, articaine is a safe drug to use. However, in some cases (like certain cardiac patients) a dose restriction could be advisable to maximize safety, as discussed in another review. There are also other important things to remember to safely use dental local anesthetics and prevent overdose reactions. Basic injection techniques should be applied when administering local anesthetics to minimize the chance of an overdose reaction. Careful aspiration should be performed prior to every injection to avoid accidental intravascular injection [1]. Furthermore, one of the most important factors for overdose appears to be the rate of injection: ideally a cartridge is administered over a period of more than 60 seconds. A rapid injection (less than 15 seconds) results in significantly elevated blood levels when accidentally administered intravenously, facilitating an overdose reaction [1].

\subsection{Epinephrine}

Epinephrine is added to the anesthetic solution as a vasoconstrictor. This has several benefits: First of all, it elicits vasoconstriction in the blood vessels, which does not only delay the absorption of the local anesthetic and thereby decreasing systemic toxicity, but it also gives hemostasis, less per operative blood loss and better visibility. Secondly, it increases the depth as well as the duration of action of anesthesia, prolonging and enhancing the anesthetic effect. Because of this, the dose of anesthetic used can be reduced [1].

The addition of epinephrine does have its implications: because of its effects on the myocardium and the vascular tone, a dose restriction to a maximum of $40 \mu \mathrm{g}$ per appointment as stated by Bennett and Malamed $[2,6]$. This equals four cartridges of epinephrine 1:200,000. The safe use of $\leq 4$ cartridges of the higher concentrated anesthetic lidocaine (1:100,000 epinephrine) was recently confirmed in a systematic review [7]. A lot of the other contra-indications or possible interactions in the package leaflet of articaine are included because of the addition of epinephrine as well. It should be noted however that the doses of epinephrine used in dentistry are minimal.

One $1.8 \mathrm{~mL}$ of 1:100,000 and 1:200,000 epinephrine contains 0.018 and $0.009 \mathrm{mg}$ respectively. This dose is rather low compared to other uses of epinephrine in medicine $(0.3$ to $1 \mathrm{mg}$ in case of anaphylactic shock) [1]. In these small quantities, the systemic cardiovascular effects are modest to negligible depending on the type of patient [1]. Of course, it should be mentioned that in some cases it is not safe to use articaine (like some refractory unstable heart 
ITable 1. Successful pulpal anesthesia.

\begin{tabular}{|c|c|c|c|}
\hline & Articaine & Lidocaine & P-value \\
\hline $\begin{array}{c}\text { Mandibular } \\
\text { second molar }\end{array}$ & $75 \%$ & $45 \%$ & 0.0001 \\
\hline $\begin{array}{c}\text { Mandibular first } \\
\text { molar }\end{array}$ & $87 \%$ & $57 \%$ & 0.0001 \\
\hline $\begin{array}{c}\text { Mandibular } \\
\text { second premolar }\end{array}$ & $92 \%$ & $67 \%$ & 0.0001 \\
\hline $\begin{array}{c}\text { Mandibular first } \\
\text { premolar }\end{array}$ & $86 \%$ & $61 \%$ & 0.0001 \\
\hline
\end{tabular}

Robertson D, Nusstein J, Reader A, Beck M, McCartney M. The anesthetic efficacy of articaine in buccal infiltration of mandibular posterior teeth. J Am Dent Assoc. 2007;138:1104-1112, Table 1

diseases) [1]. However, these are all contraindications to general elective dental care as well and need immediate attention from a medical specialist.

\section{EFFICACY}

There are some reports of clinicians who state that 'in their opinion' articaine has a faster onset following injection. However, in a study comparing the time of onset of pulpal anesthesia after an inferior alveolar nerve block (IANB) between $2 \%$ lidocaine and $4 \%$ articaine in 1554 patients, these claims were not supported [2].

It has also been claimed that articaine may provide palatal anesthesia when given as maxillary buccal infiltration [1]. Although this claim is anecdotal, it could be attributed to the greater lipid solubility.

\subsection{Mandibular infiltration}

A claim that has been shown to be true is the significant success of articaine used by buccal infiltration in the mandible.

When articaine was used for mandibular infiltration in adults, it has been proven that the chances of success are significantly greater in comparison to lidocaine (see Table 1) [8].

The time of onset for pulpal anesthesia was also significantly shorter for articaine in the first and second molar, and the first premolar (see Table 2) [8]. Another study found similar results concerning the mandibular incisor: Both the duration and the success rate of pulpal anesthesia was considerably longer with the articaine solution [9].

The reason for this increased success rate could be the relatively thin cortical plate, subject to the potent penetrating capability of articaine [2].

Kanaa et al. did research on the addition of articaine or lidocaine infiltration to improve the success rate of anesthesia following an IANB [10].

As is turns out, articaine gives the best improvement in success rate comparing to lidocaine $(55,6 \%$ to $91,7 \%$ for the first molar, $66,7 \%$ to $88,9 \%$ for the second molar) [10].
ITable 2. Onset time of pulpal anesthesia.

\begin{tabular}{|c|c|c|c|}
\hline & $\begin{array}{c}\text { Articaine } \\
\text { onset } \pm \text { SD } \\
\text { (min) }\end{array}$ & $\begin{array}{c}\text { Lidocaine } \\
\text { onset } \pm \text { SD } \\
\text { (min) }\end{array}$ & P-value \\
\hline $\begin{array}{c}\text { Mandibular } \\
\text { second } \\
\text { molar }\end{array}$ & $4.6 \pm 4.0$ & $11.1 \pm 9.50$ & 0.0001 \\
\hline $\begin{array}{c}\text { Mandibular } \\
\text { first molar }\end{array}$ & $4.2 \pm 3.1$ & $7.7 \pm 4.3$ & 0.0002 \\
\hline $\begin{array}{c}\text { Mandibular } \\
\text { second } \\
\text { premolar }\end{array}$ & $4.3 \pm 2.3$ & $6.9 \pm 6.6$ & 0.0014 \\
\hline $\begin{array}{c}\text { Mandibular } \\
\text { first } \\
\text { premolar }\end{array}$ & $4.7 \pm 2.4$ & $6.3 \pm 3.1$ & 0.0137 \\
\hline
\end{tabular}

Robertson D, Nusstein J, Reader A, Beck M, McCartney M. The anesthetic efficacy of articaine in buccal infiltration of mandibular posterior teeth. $J$ Am Dent Assoc. 2007;138:1104-1112, Table 2

\subsection{Conclusion}

A meta-analysis by Katyal in 2010 comparing articaine with lidocaine concluded that articaine has a higher anesthetic success in the posterior first molar area, while the safety is comparable with lidocaine (RR $1.31,95 \% \mathrm{Cl}$ of 1.12 to 1.54 ) [11]. However, the variability of anesthetic success of certain techniques and the effect of local inflammation were not taken into account $[4,11]$. Yapp provided a comprehensive overview of seventeen papers comparing the efficacy of articaine [4]. Ten papers found no significant difference, while 7 papers did find an advantage for articaine (however each review investigated different clinical situations) [4]. As a conclusion, the overall efficacy of articaine is similar to lidocaine. For mandibular infiltrations, mental nerve blocks and a buccal infiltration following an IANB, articaine does appear to have a significant advantage [4]. Paxton and Thome reviewed all 27 publications until 2010 reporting on the efficacy of articaine [12]. These publications showed a variability of outcomes, but nevertheless their meta-analysis did show a significant difference $(9.21 \%$ higher proportion of success, $95 \% \mathrm{Cl} 2.56 \%$ to $15.58 \%$ ) [2]. This suggested an advantage for articaine, at least in some clinical situations [13]. Furthermore, articaine was compared with 1:100,000 and 1:200,000 epinephrine concentrations and no significant difference was found [12]. However, it should be noted that all these studies are only low to moderate-quality evidence so conclusions must be critically reviewed.

\section{PARESTHESIA}

Local anesthetics are used to achieve anesthesia in the desired area to perform a pain-free procedure. Normally this anesthesia wears off in a matter of hours, but there have been reports of paresthesia after local anesthetic use.

This paresthesia is a neuropathy that can manifest itself as a loss of sensation (anesthesia), burning/ tingling sensation (dysesthesia) or pain (allodynia, hyperesthesia) [2]. 
ITable 3. Risk of paresthesia from local anesthetic drugs.

\begin{tabular}{|c|c|c|c|}
\hline & 2007 & 2012 & Result \\
\hline Lidocaine & 0.64 & 0.5 & $\begin{array}{l}<1.0, \text { less than } \\
\text { expected }\end{array}$ \\
\hline Articaine & 1.19 & 0.97 & $\sim 1$, expected \\
\hline Mepivacaine & NA & 2.2 & $\begin{array}{l}>1.5 \text {, higher than } \\
\text { expected }\end{array}$ \\
\hline Prilocaine & 4.96 & 3.25 & $\begin{array}{l}>3.0 \text {, higher than } \\
\text { expected }\end{array}$ \\
\hline
\end{tabular}

The ratio derived from the percentage of reported cases of paresthesia divided the percent market share of the drug.

Malamed SF. Articaine 30years later. Oral Health. 2016; Table9

There have been studies reporting a higher incidence of paresthesia with the use of $4 \%$ local anesthetics like prilocaine and articaine. An overview of the history of this controversy is given below.

\subsection{History}

Everything started with a retrospective study by Haas and Lennon in 1995 [13]. They examined voluntary submissions that dentists made to their insurance agency. They found 143 cases of paresthesia over a 20-year period (1973 to 1993), excluding those associated with surgery [13].The paresthesia involved the lingual nerve, the inferior alveolar nerve or a combination of both [13]. Based on the distribution of the market share of local anesthetics in Ontario in 1993, articaine and prilocaine had a relatively higher risk of developing paresthesia [13]. In 1993, 10 of the 14 reports of paresthesia were related to articaine, the other 4 to prilocaine. This equals an overall risk of 1:785,000. The individual rates reported for articaine $(1: 588,235)$ and prilocaine $(1: 440,529)$ were a lot higher than the other anesthetics $(1: 1,250,000)$ [13]. Almost all of the forthcoming papers claiming an increased risk of paresthesia refer to this paper as the original source. Hillerup and Jensen conducted a study (2006) reviewing insurance claims in Denmark, where articaine was introduced in 2001 [14]. They claimed that articaine had a higher tendency to cause paresthesia as it was most reported to the Danish Medicines Agency by dentists [14]. They declared that articaine should not be the anesthetic of choice when administering an IANB until factual information is available, a statement consequentially recommended by the Danish Dental Association as well [14]. In this review, $77 \%$ of the cases reviewed involved only the lingual nerve, and not the inferior alveolar nerve [14]. In response, the Pharmacovigilance Working Committee of the European Union reviewed articaine use in 57 different countries addressing the controversy about paresthesia [15]. They estimated the number of patients receiving articaine is around 100 million annually [15]. In October 2006 they published the following report: "This investigation is a follow-up to an inquiry initiated in 2005. This enquiry resulted from suspicions that were raised
Table 4. Relative risks of paresthesia in Ontario, Canada and the United States.

\begin{tabular}{|c|c|c|}
\hline & Ontario, Canada & United States \\
\hline Mepivacaine & $1: 1,250,000$ & $1: 623,112,900$ \\
\hline Lidocaine & $1: 1,125,000$ & $1: 181,076,673$ \\
\hline Bupivacaine & NA & $1: 123,286,050$ \\
\hline Overall risk & $1: 785,000$ & $1: 13,800,970$ \\
\hline Articaine & $1: 440,000$ & $1: 4,159,848$ \\
\hline Prilocaine & $1: 588,000$ & $1: 2,070,678$ \\
\hline
\end{tabular}

Malamed SF.Articaine 30 years later. Oral Health. 2016; Table 8

in Denmark, that a local anesthetic, articaine, was responsible for an increased risk of nerve injuries compared with the risk associated with other local anesthetics (mepivacaine, prilocaine, lidocaine)" [15]. The report concluded: "Regarding articaine, the conclusion is that [the] safety profile of the drug has not significantly evolved since its initial launch (1999 in Denmark). Thus, no medical evidence exists to prohibit the use of articaine according to the current guidelines listed in the summary of product characteristics" [15]. "All local anesthetics may cause nerve injury (they are neurotoxins). The occurrence of sensory impairment is apparently slightly more frequent following use of articaine and prilocaine. However, considering the number of patients treated, sensory impairments rarely occur. For example, the incidence of sensory impairment following the use of articaine is estimated to be 1 case in 4.6 million treated patients" $[2,15]$. Furthermore, they reported that there are different incidents that can result in a nerve injury: mechanical injury due to needle trauma, direct drug toxicity or neural ischemia for example [15]. The Danish Medicines Agency followed up with this study in October 2011 (117/43) [16]. Their database of side effects comprised 160 reports of adverse reactions related to articaine between 20012005 , most of which concerning nerve damage [16]. However, since 2005 they have observed a drop in the number of new adverse reaction reports. For 2011, up until the first of October they only received 2 reports of possible sensory impairment [16]. This drop in the number of adverse effects can be explained by two phenomena: the Weber Effect and the effect of publicity on drug prescription and usage [2]. Both phenomena will be clarified later.

Pogrel also wrote some interesting papers about articaine over the years [17-21]. In a 2007 paper, Pogrel investigated 57 nonsurgical cases of paresthesia following local anesthetic administration from 2003 to 2005 [16,17]. His update on this paper in 2012 reported on an additional 41 cases from 2006 to 2011 [18]. In both reviews, Pogrel compared the percentage of the market share of the local anesthetic to the proportion of the incidences of paresthesia reports $[17,18]$. Articaine had a ratio of 1.19 in 2007 and 0.98 in 2012 [17,18]. Lidocaine did 
I Table 5. Reports of paresthesia following local anesthesia with the most common local anesthetics.

\begin{tabular}{|l|c|c|}
\hline & $\begin{array}{c}\text { Cases of } \\
\text { paresthesia }\end{array}$ & All ADRs \\
\hline Lidocaine & 247 & 7,720 \\
\hline Bupivacaine & 99 & 2,843 \\
\hline Articaine & 85 & 254 \\
\hline $\begin{array}{l}\text { Combinations of } \\
\text { local anesthesia }\end{array}$ & 45 & 2,687 \\
\hline Prilocaine & 30 & 396 \\
\hline Other & 67 & 4,647 \\
\hline Total & 573 & 18,574 \\
\hline
\end{tabular}

ADR:Adverse drug reactions

Piccinni C, Gissi DB, Gabusi A, Montebugnoli L, Poluzzi E. Paraesthesia after Local Anaesthetics: An Analysis of Reports to the FDA Adverse Event Reporting System. Basic and Clinical Pharmacology and Toxicology. 2015; Table 2

better than expected an only had a ratio of 0.64 in 2007 and 0.5 in 2012 [18]. The results are shown in table 3 (see Table 3 ) $[2,17,18]$. Following these results, Pogrel concluded that there is no disproportionate nerve involvement for articaine [22]. Prilocaine, however, does show a higher incidence (ratio 4.96 and 2.2 in 2007 and 2012 respectively) [22]. One of the points of criticism noted in this paper is that in the reports to outside agencies there is no mentioning whether the paresthesia was transient or permanent (as most of the paresthesias eventually recover) [23]. The Australian regulatory body issued a warning statement against articaine as well following a 2011 paper by Kingon discussing 5 case reports of paresthesia following local anesthetic administration [22]. However, in 2 of these cases, the only thing the patient experienced was an 'electric shock' with the injection [22]. Garisto conducted research in the United States in July 2010 with data gathered from the US Food and Drug Administration (FDA) Adverse Event Reporting System (AERS) between 1997 and 2008 [23]. From the 248 cases, of which $94.5 \%$ happened as a result of an IANB, there was as much as $89 \%$ that exclusively involved the lingual nerve [23]. Of these 248 cases, 108 resolved in a time period between 1 to 736 days [23]. In this study Garisto compared the incidences with the paper of Haas and Lennon (1995): It appears the difference in incidence is more than a tenfold (see Table 4) [13,24]. It is noteworthy that the FDA website for AERS warns that the AERS data has limitations: Reports do not require to prove a causal relationship, reports do not always contain enough detail and not all adverse events are reported [24]. Therefore, they state that AERS cannot be used to calculate incidences for the US population [24]. Another study analyzed the data of the AERS in the United States from 2005-2011.573 cases of paresthesia were identified out of the 18,574 reports [25]. Table 5 gives an overview of the reports for the most common anesthetics (see Table 5).

\subsection{Unclarities}

There are numerous comments or thoughts to be made about the controversy about paresthesia and
Iable 6. Lingual nerve involvement in reported cases of paresthesia.

\begin{tabular}{|c|c|c|c|}
\hline Authors & Country & Year & $\begin{array}{c}\text { Lingual } \\
\text { Nerve } \\
\text { Involvement } \\
\text { (\%) }\end{array}$ \\
\hline $\begin{array}{c}\text { Haas and } \\
\text { Lennon }\end{array}$ & Canada & 1995 & 70.6 \\
\hline $\begin{array}{c}\text { Hillerup and } \\
\text { Jensen }^{15}\end{array}$ & Denmark & 2006 & 77.0 \\
\hline Garisto et al. $^{24}$ & United States & 2010 & 92.7 \\
\hline Kingon et al. $^{23}$ & Australia & 2011 & 80.0 \\
\hline
\end{tabular}

Malamed SF. Articaine 30years later. Oral Health. 2016; Table 8

about the studies performed. What is the rationale behind the fact that the vast majority of paresthesias occurs after an IANB? Less than $5 \%$ of the cases involve the maxilla, while roughly half of the dental work is in the maxilla [2]. Why are these cases of paresthesia rather specific to the use of an IANB and not with alternative nerve blocks (like GowGates) [2]. Why are there no similar reported toxicity cases with articaine use in the other branches of medicine (plastic surgery, dermatology, ...) [3]. Some elements concerning the hypothesis of the neurotoxicity as the cause of the cases of paresthesia remain unexplained. As seen in the previous papers the vast majority of cases of paresthesia involved the lingual nerve, in the Garisto paper even 89\% involved exclusively the lingual nerve (see Table 6) $[2,13,14,22,23]$. If neurotoxicity caused paresthesia we would expect the inferior alveolar nerve to be involved much more commonly. Opening the mouth to deposit the cartridge could stretch out the lingual nerve, preventing it from being pushed away by the needle and being damaged [2]. In another paper, he explained this discrepancy could be partially explained by the fact that the lingual nerve only consists of one to three fascicles, while the IAN consists of five to seven fascicles [21]. The claim of a possible higher intrinsic toxicity of articaine $4 \%$ compared to lidocaine $2 \%$, which could possibly explain a higher incidence of paresthesia, was not supported in in-vitro investigations [26]. While some remain believing in the intrinsic higher neurotoxicity of the $4 \%$ anesthetics, others believe there are factors usually involved to cause the paresthesia (primarily mechanical trauma) [1]. There are a lot of different ways nerve paresthesia could be explained: Trauma by contact of the nerve sheath with the needle, hemorrhage into or around the neural sheath as the pressure on the nerve will increase, edema following surgical procedures[1]. Keep in mind that one does not exclude the other. Next, focus will be on the Weber Effect and the effect of publicity. The Weber Effect is an epidemiological event that constitutes a rise in reporting of adverse events after its regulatory approval, with a peak at the end of its second year 


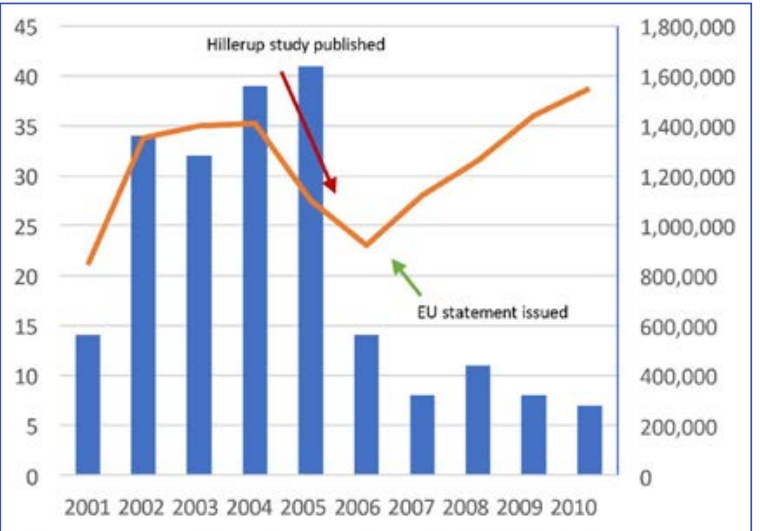

Figure 1. Articaine use and reports of paresthesia (Denmark).

Malamed SF. Handbook of Local Anesthesia. 7thed.St Louis:Mosby;2019, Figure 20.9

(see Fig. 1) [1,2]. Afterward, the reports steadily decline while prescribing rates keep rising steadily [2]. This is a replicable and verified phenomenon [27]. Publicity (whether positive or negative) affects how much drugs are used and prescribed [2]. Implemented on this debate, we conclude that indeed the use of articaine decreased after the paper of Hillerup and the recommendation of the Danish Dental Association [2]. After the EU report explaining there was no significant evidence, the use increased again [2]. Another potential confounder might be the age of the dentist, as more numerous younger, inexperienced dentists use articaine as an anesthetic [26]. The last remark is the inconsistency of the reported risks on paresthesia. As already mentioned, the variation between the reported risks is tremendous, pleading there must be some kind of bias. In his 2000 paper, Pogrel estimated the risk of permanent nerve damage following an IANB at 1 in 26,762 injections [19]. Therefore, he stated that a dentist would reasonably encounter at least one case in their career [19]. For a risk of 1 in 785,000 as mentioned in the Ontario paper however, this would mean a practitioner would encounter a paresthesia once every 436 years (averaging 1,800 injections every year) [28]. Another overall incidence reported is $1: 13,800,970$ in the US [2]. To put these risks into perspective: the risk of being struck by lightning in a given year in the US is between 1 in 328,000 and 1 in 700,000 [1].

\subsection{Conclusion}

The studies reporting an increased risk of paresthesia contain a lot of bias: The total duration of paresthesia, the injection technique, the size of the needle and even the anesthetic used (in 30\% of the incidents reported) are examples of data that are not always documented in these papers [28]. A 2011 review by Yapp highlights the flaws in studies concerning articaine: All studies reporting an increased risk contain bias in data recruitment and are retrospective [4]. They are not suitable for a strong recommendation [4]. He concluded that "although there may be controversy regarding its safety and advantages in comparison to other local anesthetics, there is no conclusive evidence demonstrating neurotoxicity or significantly superior anesthetic properties of articaine for dental procedures" [4]. Van der Sleen evaluated 1000 patients receiving an IANB, and concluded that no long-term injury will be caused as long as the mandibular nerve is not manipulated [29]. When applying a local anesthetic would result in paresthesia, these are only temporary and the cause remains unknown [29]. The most common cause of nerve injury remains mechanical trauma like surgery or third molar extractions.

Malamed makes the following recommendation: For the administration of an IANB you can continue to use articaine $4 \%$ with epinephrine $1: 100,000$ or $1: 200,000$, provided you use the correct injection techniques [2]. If, however, the practitioner is not convinced by the absence of scientific evidence or still concerned, an alternative could be to use lidocaine $2 \%$ with epinephrine 1:100,000 followed by infiltration anesthesia with articaine in the desired area to improve effectiveness [2].

\section{DISCUSSION}

In the early days of the drug, there were a lot of anecdotal claims that articaine would function faster and better than other anesthetics. Different metaanalyses confirmed that the safety profile of articaine is similar to that of lidocaine $[9,10]$. In certain clinical situations, articaine does have a significant advantage over lidocaine (mainly for infiltration anesthesia in the posterior mandibula) $[4,11,12]$. However, there is no convincing evidence to suggest that articaine has an overall superiority in efficacy over lidocaine. In 1995 a retrospective study about paresthesia occurrence after the administration of local anesthetics started a controversial debate whether or not articaine causes more paresthesias than lidocaine [11]. In the following years, numerous papers were published, and different recommendations were sent out by different regulatory bodies. All these reports on the alleged higher incidence by articaine show contradictory results, widely varying incidences, and incomplete or biased data. Malamed, well-known in matters related to local anesthesia and a proponent of articaine, wrote an interesting overview of the subject $[4,11,12]$. Whether negative or positive, most of the time one single author is proclaiming his/her own beliefs without high-quality clinical evidence like a randomized controlled trial or a proper meta-analysis to back it up. Because of the rarity of the complication, an RCT would require too large of a sample size. In 2006 the European Pharmacovigilance System concluded there was no scientific or clinical evidence of a greater risk associated with articaine after examining all available clinical data from the Septodont database [2]. The Danish authorities confirmed these conclusions after reevaluation in 2012 [2]. Up until now, 
there is no conclusive evidence that articaine would cause a larger number of paresthesias in proportion to its market share [2].

\section{CONCLUSION}

Investigations on the superiority of articaine showed an advantage over lidocaine in certain situations (like infiltration anesthesia in the posterior mandible). There is insufficient evidence to state that articaine has an overall superiority to lidocaine. Due to the lack of conclusive evidence, the choice of local anesthetic should be purely based on the practitioner's experience and personal preference.

Concerning the topic of paresthesia, there exists no scientific evidence proving the alleged higher risk of articaine on paresthesia. The available research on the matter predominantly comprises the convictions of one single author, whether positive or negative, without high-quality evidence. The main causal factor for paresthesia is still mechanical violation during

\section{REFERENCES}

1. Malamed SF. Handbook of local anesthesia . Seventh edition. St. Louis, MO: Elsevier Inc; 2020.

2. Malamed SF. Articaine 30 years later. Oral Health. [Internet] 2016. [Full text links]

3.Snoeck M. Articaine: a review of its use for local and regional anesthesia. Local Reg Anesth. 2012;5:23-33.

[Full text links] [CrossRef] [PubMed] Google Scholar Scopus

4.Yapp KE, Hopcraft MS, Parashos P. Articaine: a review of the literature. Br Dent J. 2011;210(7):323-329.

[Full text link] [CrossRef] [PubMed] Google Scholar

5.Oertel R, Richter $\mathrm{K}$, Weile $\mathrm{K}$, et al. A simple method for the determination of articaine and its metabolite articainic acid in dentistry: Application to a comparison of articaine and lidocaine concentrations in alveolus blood. Methods Find Exp Clin Pharmacol. 1993;15(8):541-547.

[PubMed] Google Scholar Scopus

6. Bennett CR. Monheim's local anesthesia and pain control in dental practice, 7th edition. St. Louis, MO: CV Mosby; 1984

7.Godzieba A, SmektałaT, Jędrzejewski M,Sporniak-TutakK.Clinical assessment of the safe use local anaesthesia with vasoconstrictor agents in cardiovascular compromised patients: a systematic review.MedSciMonit. 2014:20:393-398. doi:10.12659/MSM.889984 [Full text links] [PubMed] Google Scholar Scopus

8. Robertson D, Nusstein J, Reader A, et al. The anesthetic efficacy of articaine in buccal infiltration of mandibular posterior teeth. Am Dent Assoc. 2007 Aug;138(8):1104-1112;

[Full text link] [PubMed] Google Scholar Scopus

9. Meechan JG, Ledvinka JIM. Pulpal anaesthesia for mandibular central incisor teeth: A comparison of infiltration and intraligamentary injections. Int Endod J. 2002;35(7):629-634. [Full text link] [CrossRef] [PubMed] Google Scholar Scopus

10. Kanaa MD, Whitworth JM, Corbett IP, Meechan JG. Articaine buccal infiltration enhances the effectiveness of lidocaine inferior alveolar nerve block. Int Endod J. 2009;42(3):238-246. [Full text link] [CrossRef] [PubMed] Google Scholar Scopus

11. Katyal V. The efficacy and safety of articaine versus lignocaine in dental treatments: A meta-analysis. J Dent. 2010;38(4):307-317. [Full text link] [CrossRef] [PubMed] Google Scholar Scopus

12. Paxton K, Thome DE. Efficacy of articaine formulations: quantitative reviews. Dent Clin North Am. 2010;54(4):643-653.

[Full text link] [CrossRef] [PubMed] Google Scholar Scopus

13. Haas DA, Lennon D. A 21 year retrospective study of reports of paresthesia following local anesthetic administration. J Can Dent Assoc. 1995;61(4):319-330.

[PubMed] Google Scholar Scopus

14. Hillerup $S$, Jensen R. Nerve injury caused by mandibular block analgesia. Int J Oral Maxillofac Surg. 2006;35(5):437-443.

[Full text link] [CrossRef] [PubMed] Google Scholar Scopus

15. Stenver DI, Case number: 3200-1367, Adverse effects from surgery or tooth extractions. The lingual nerve is most frequently affected rather than the inferior alveolar nerve due to its anatomy. It should be kept in mind that a sensory disturbance after local anesthetic use in non-surgical cases still remains an extremely rare event.

\section{CONFLICT OF INTEREST}

The authors declare no conflict of interest.

\section{FUNDING}

This article did not require funding.

\section{ACKNOWLEDGMENTS}

This study was conducted as a master thesis to acquire the degree of master in medicine at the Catholic University of Leuven. anaesthetics used in relation with dental care with a special focus on anaesthetics containing articaine. Pharmacovigilance Working Party of the European Union. 20 October, 2006.

16. Danish Medicines Agency (Laegemiddel Styrelsen), Report 25 October 2011

17. Pogrel MA. Permanent nerve damage from inferior alveolar nerve blocks - an update to include articaine. J Calif Dent Assoc. 2007:35(4):271-273.

[Full text link] [PubMed] Google Scholar Scopus

18.PogrelMA.Permanentnervedamagefrominferioralveolarnerve blocks: a current update. J Calif Dent Assoc. 2012;40(10):795-797. [Full text link] [CrossRef] [PubMed] Google Scholar Scopus

19. Pogrel MA, Thamby S. Permanent nerve involvement resulting from inferior alveolar nerve blocks [published correction appears in J Am Dent Assoc. 2000;131(10):1418]. J Am Dent Assoc. 2000;131(7):901-907.

[Full text link] [PubMed] Google Scholar Scopus

20. Pogrel MA, Thamby S. The etiology of altered sensation in the inferior alveolar, lingual, and mental nerves as a result of dental treatment. J Calif Dent Assoc. 1999;27(7):531-538. [PubMed] Google Scholar Scopus

21. Pogrel MA, Schmidt BL, Sambajon V, Jordan RCK. Lingual nerve damage due to inferior alveolar nerve blocks: a possible explanation. J Am Dent Assoc. 2003;134(2):195-199. [Full text link] [CrossRef] [PubMed] Google Scholar Scopus

22. Kingon A, Sambrook P, Goss A. Higher concentration local anaesthetics causing prolonged anaesthesia. Do they? A literature review and case reports. Aust Dent J. 2011;56(4):348-351.

[Full text link] [CrossRef] [PubMed] Google Scholar

23. Garisto GA, Gaffen AS, Lawrence HP, et al. Occurrence of paresthesia after dental local anesthetic administration in the United States [published correction appears in J Am Dent Assoc 2010;141(8):944]. J Am Dent Assoc. 2010;141(7):836-844.

[Full text link] [CrossRef] [PubMed] Google Scholar Scopus

24. U.S. Food and Drug Administration Center for Drug Evaluation and Research, Office of Post-Marketing Drug Risk Assessment. Revised 9 January 2009. http://www.fda.gov/Drugs/ GuidanceComplianceRegulatorylnformation/Surveillance/ AdverseDrugEffects/default.htm.

25. Piccinni C, Gissi DB, Gabusi A, et al. Paraesthesia after local anaesthetics: an analysis of reports to the FDA Adverse Event Reporting System. Basic Clin Pharmacol Toxicol. 2015;117(1):52-56. [Full text link] [CrossRef] [PubMed] Google Scholar Scopus 26. Hopman AJG, Baart JA, Brand HS. Articaine and neurotoxicity - a review. Br Dent J. 2017;223(7):501-506. [Full text link] [CrossRef] [PubMed] Google Scholar Scopus 27. Hartnell NR, Wilson JP. Replication of the Weber effect using postmarketing adverse event reports voluntarily submitted to the United States Food and Drug Administration. Pharmacotherapy. 


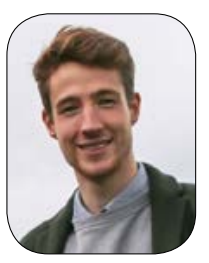

Nicolas De Ridder (DOB: 28th of May, 1996) obtained his bachelor's degree in Medicine at the Catholic University of Leuven, Belgium (magna cum laude). He is currently in his final year of master in Medicine, expected to graduate in July 2020. He has acquired experience in internships in the department of Stomatology, Oral and Maxillofacial surgery under the supervision of Professor Constantinus Politis at UZ Leuven.

\section{Ouestions}

\section{What is the most common cause of overdose reactions or complications in dental treatment with local anesthetics?}

$\square$ a. Using an excessive total dose of the drug;

b. Not complying with the listed contraindications;

ac. Use in children;

ad. Use in cardiovascular compromised patients.

\section{What is true about the efficacy of articaine compared to lidocaine?}

$\square$ a. Articaine is overall the superior local anesthetic;

b. The efficacy of articaine is similar to that of lidocaine, with an advantage in certain clinical situations;

ac. Articaine is an inferior local anesthetic compared to lidocaine;

$\square \mathrm{d}$. Articaine is a better local anesthetic than lidocaine, but it is not worth the benefit because of its higher risks.

\section{Which of the following statements concerning the pharmacological properties about articaine is not true?}

$\square$ a. Articaine has a shorter elimintation half-life than most other local anesthetics;

b. Articaine has a thiophene ring ensuring greater lipid solubility;

口c. Articaine contains an ester-linkage that can be hydrolyzed by plasma-esterase, making it a hybrid molecule;

$\square$ d. Articaine has a low degree of protein-binding, just as most other local anesthetics.

\section{The incidence of paresthesia for articaine is:}

$\square$ a. Significantly lower than lidocaine;

b. In relation to its market share;

ac. Higher than prilocaine;

$\square$ d. Higher than its market share. 


\title{
STABILITY OF SKELETAL CLASS III MALOCCLUSION AFTER ORTHOGNATHIC SURGERY AND ORTHODONTIC TREATMENT: A SYSTEMATIC REVIEW AND META-ANALYSIS
}

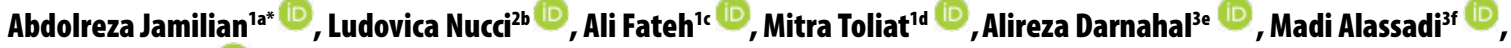 \\ Chin Wei Wang ${ }^{3 g}$ (D)
}

'Department of Orthodontics, Cranio-Maxillofacial Research Center, Tehran University of Medical Sciences, Islamic Azad University, Tehran, Iran ${ }^{2}$ Multidisciplinary Department of Medical-Surgical and Dental Specialties, Dental School, University of Campania Luigi Vanvitelli, Naples, Italy ${ }^{3}$ Department of Periodontics and Oral Medicine, School of Dentistry, University of Michigan, Ann Arbor, MI 48109, USA

aDDS, MSc, Professor; ${ }^{b}$ Undergraduate Dental Student; 'DDS, Executive Manager; ${ }^{\mathrm{a} P}$ ost Doctorate Student; ${ }^{\mathrm{f}}$ Post Doctorate Student; ${ }^{9} \mathrm{DDS}$, Clinical Assistant Professor, Director of Predoctoral Periodontics

ABSTRACT DOI: https://doi.org/10.25241/stomaeduj.2020.7(1).art.7

Background: Relapse is one of the major concerns in the correction of skeletal class III malocclusion.

Objective: The purpose of this systemic review was to evaluate the degree of relapse on skeletal class III patients who received bimaxillary surgery or mandibular setback with orthodontic treatment.

Data Sources: A search of the literature was performed in the databases of PubMed, Google Scholar Beta, Scopus, Web of Science, and the Cochrane Library.

Study Selection: Out of the 165 articles identified, 73 studies were obtained, once duplicated articles were excluded. Then, 40 other records were excluded due to titles and abstracts, and 20 were removed for not fulfilling exclusion/ inclusion criteria. 11 studies met the final inclusion criteria. Some cephalometric data during T1-T2-T3 were measured.

Data Extraction: SNA did not have any significant changes within less than 2 years but it increased significantly after 2 years. SNB did not have any significant changes in more than 2 years' follow-up, while it rose significantly in less than 2 years. Overjet decreased significantly after 2 years but not earlier than this duration. Overbite intensified significantly in more than 2 years and not earlier.

OOPEN ACCESS This is an Open Access article
under the CC BY-NC 4.0 license.
Peer-Reviewed Article
Citation: Jamilian A, Nucci L, Fateh A, Toliat M,
Darnahal A, Alassadi M, Wang CW. Stability of skeletal Class
III malocclusion after orthognathic surgery and orthodontic
treatment: a systematic review and meta-analysis.
Stoma Edu J. 2020;7(1):52-67.
Received: February 06, 2020
Revised: February 13, 2020
Accepted: February 14, 2020
Published: February17, 2020
Corresponding author:
Professor Abdolreza Jamilian
Department of Orthodontics, TUMS School of Dentistry,
Cranio-Maxillofacial Research Center, Tehran University of
Medical Sciences, Illamic Azad University, Tehran, Iran
No 14, Pesiyan Ave., Vali Asr St., Tehran, 1986944768, rran
Tel/Fax: 00982122011892, e-mail: info@jamilian.net
Copyright: $\odot$ 2020 the Editorial Council
for the Stomatology Edu Journal.
Data Synthesis: SNA and overbite increased significantly after 2 years. SNB increased significantly before 2 years and did not have any changes after it. Overjet was significantly reduced after 2 years.

\section{KEYWORDS}

Class III; Skeletal and Dental Changes; Stability; Bimaxillary Surgery or Mandibular Setback; Systematic Review and Meta-Analysis.

\section{INTRODUCTION}

Moderate to severe skeletal class III patients often require a combined orthodontic and surgical approach for treatment. It has been reported that skeletal class III malocclusion is the most frequent deformity corrected by combined orthognathic surgery and orthodontic treatment [1-4]. However, bimaxillary surgery has gradually become more popular to correct class III malocclusion [5-7].

It has been estimated that $20 \%$ to $25 \%$ of all Class III cases have true mandibular prognathism suggesting that at least $75 \%$ of all class III malocclusions have some degree of maxillary retrusion. Given this scenario, the surgical treatment has been regarded as the best approach to achieve the best results in adult cases [8]. Post-surgical relapse is one of the major concerns in the correction of skeletal class III malocclusion. It has been shown that there is a greater tendency for relapse after bimaxillary osteotomy [9]. Similarly, LaBanc et al [10] reported that due to increased incidence of relapse, bimaxillary surgery should only be performed for specific indications; for example two-jaw surgery has greater relapse than single-jaw surgery.

On the contrary, Proffit et al [11] found that better stability and predictable results can be obtained after two-jaw surgery. Immediate relapse can be identified after surgery which may occur due to intraoperative error such as imprecise planning, inaccurate osteosynthesis, or failure to fix the joint. On the other hand, late relapse can be detected 


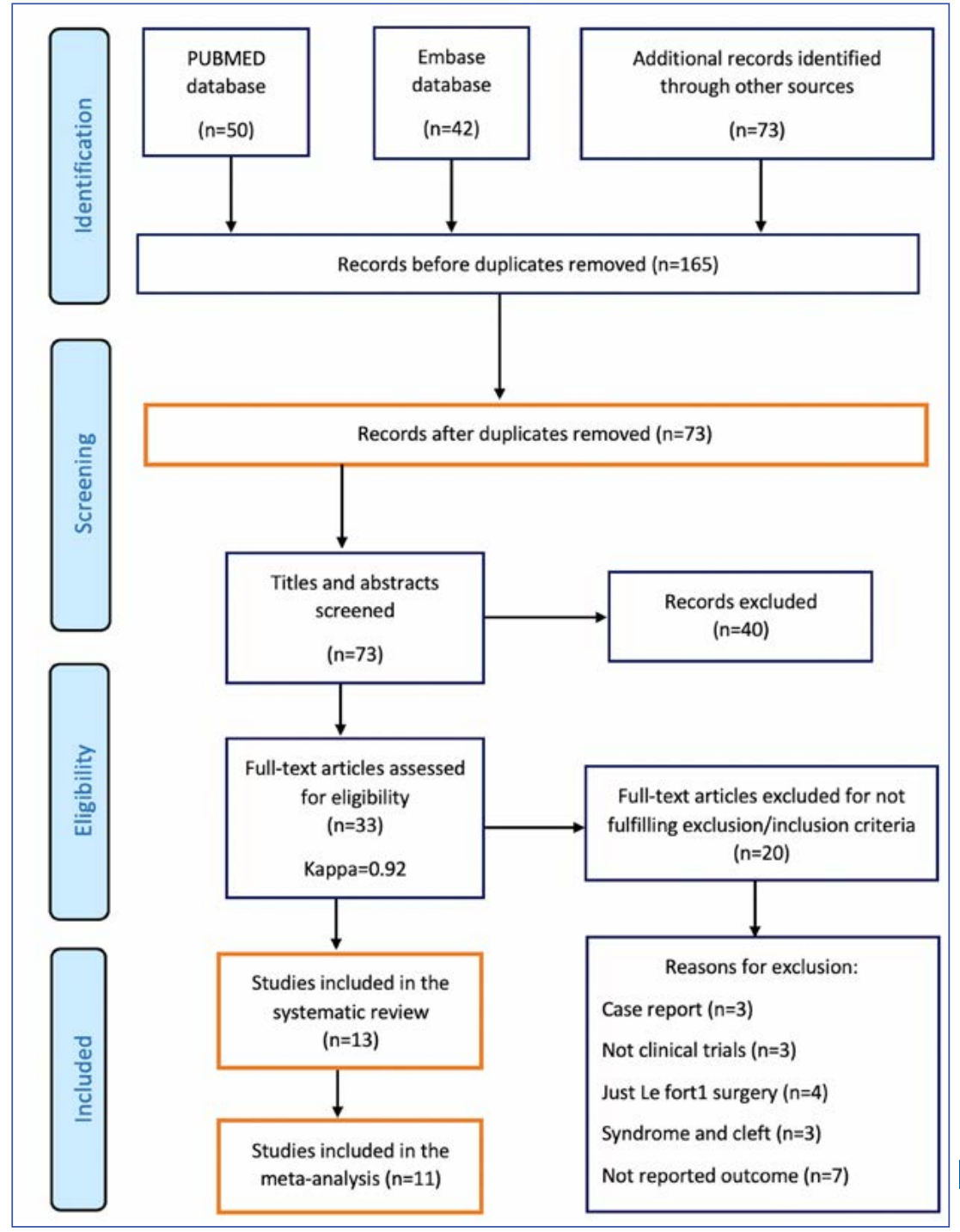

Figure 1. PRISMA flowchart of article retrieval.

once a considerable period has elapsed since the day of the surgical procedure. Late relapse may occur due to unstable occlusal relationships, growth spurts, absence of myofunctional adaptation, or persistent tongue or orofacial muscle habits [12]. A study [5] revealed that the rate of short-term relapse of bilateral sagittal split osteotomy setback surgery is $9.9 \%-62.1 \%$, and long-term relapse is between $14.9 \%$ and $28.0 \%$, at point $B$.

To the best of our knowledge, there has been no meta-analysis evaluating the stability of skeletal changes after a combined orthodontic and surgical procedure for treatment of skeletal Class III patients in short- and long-term follow ups.

The question is: "How much of the treatment effects remains stable by the end of follow-up?"

Objectives: The aim of this study was a meta-analysis of the literature on the stability of skeletal class III malocclusion.

Patients often require a combined orthodontic and surgical approach after bimaxillary surgery. This meta-analysis was undertaken to explore the parameters related to the skeletal stability in surgical correction of skeletal Class III malocclusion.

\section{MATERIALS AND METHODS}

\subsection{Protocol and registration}

This systematic review was based on a specific protocol developed and piloted following the guidelines outlined in the PRISMA-P statement [13]. Furthermore, the procedure and reporting followed the guidelines of the Cochrane Handbook for Systematic Reviews of Interventions [14] and the PRISMA statement, [15] respectively.

2.2. Information sources, search strategy, and study selection

A literature search was performed using PubMed, Google Scholar Beta, Scopus, Web of Science, and the Cochrane Library to identify articles reporting combined orthodontic and surgical approach for treatment of skeletal class III malocclusion in nongrowing patients.

The search process was conducted independently by two coauthors (AJ and AD) for articles published up to December 2018.

All titles and abstracts were evaluated, and duplicate studies were removed. 


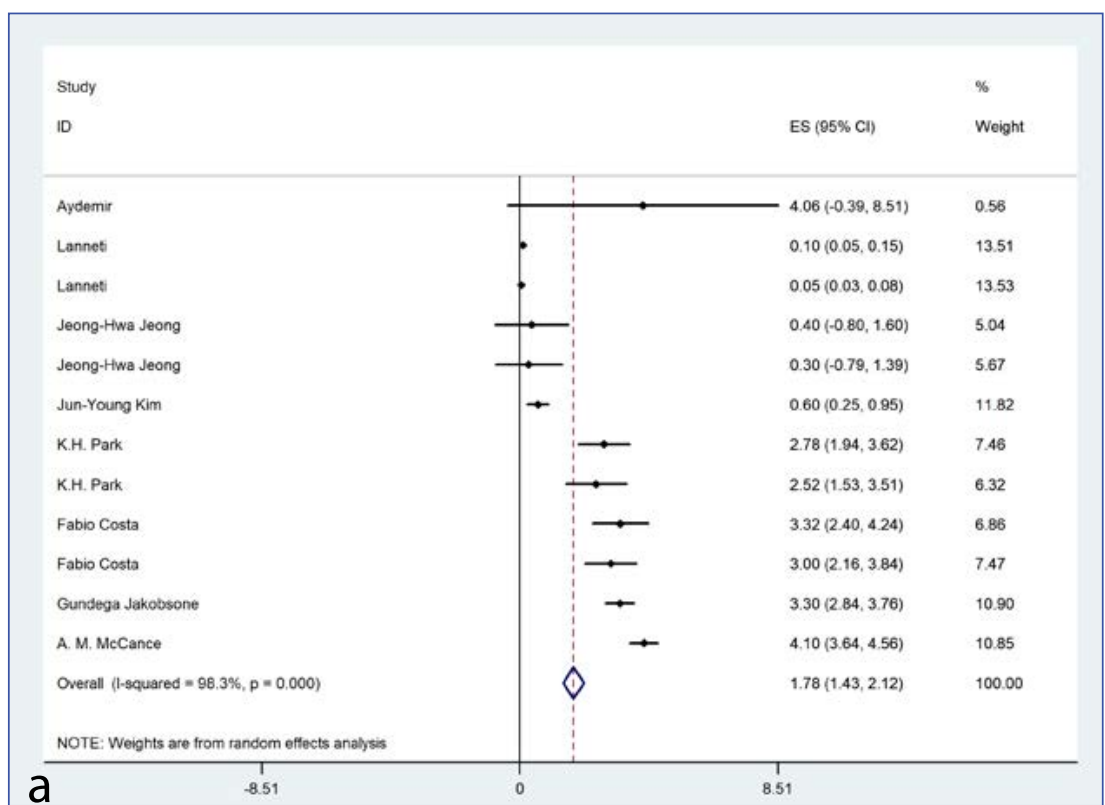

IFigure 2a. Before surgery T1 - After surgery T2, (T1-T2) SNA.

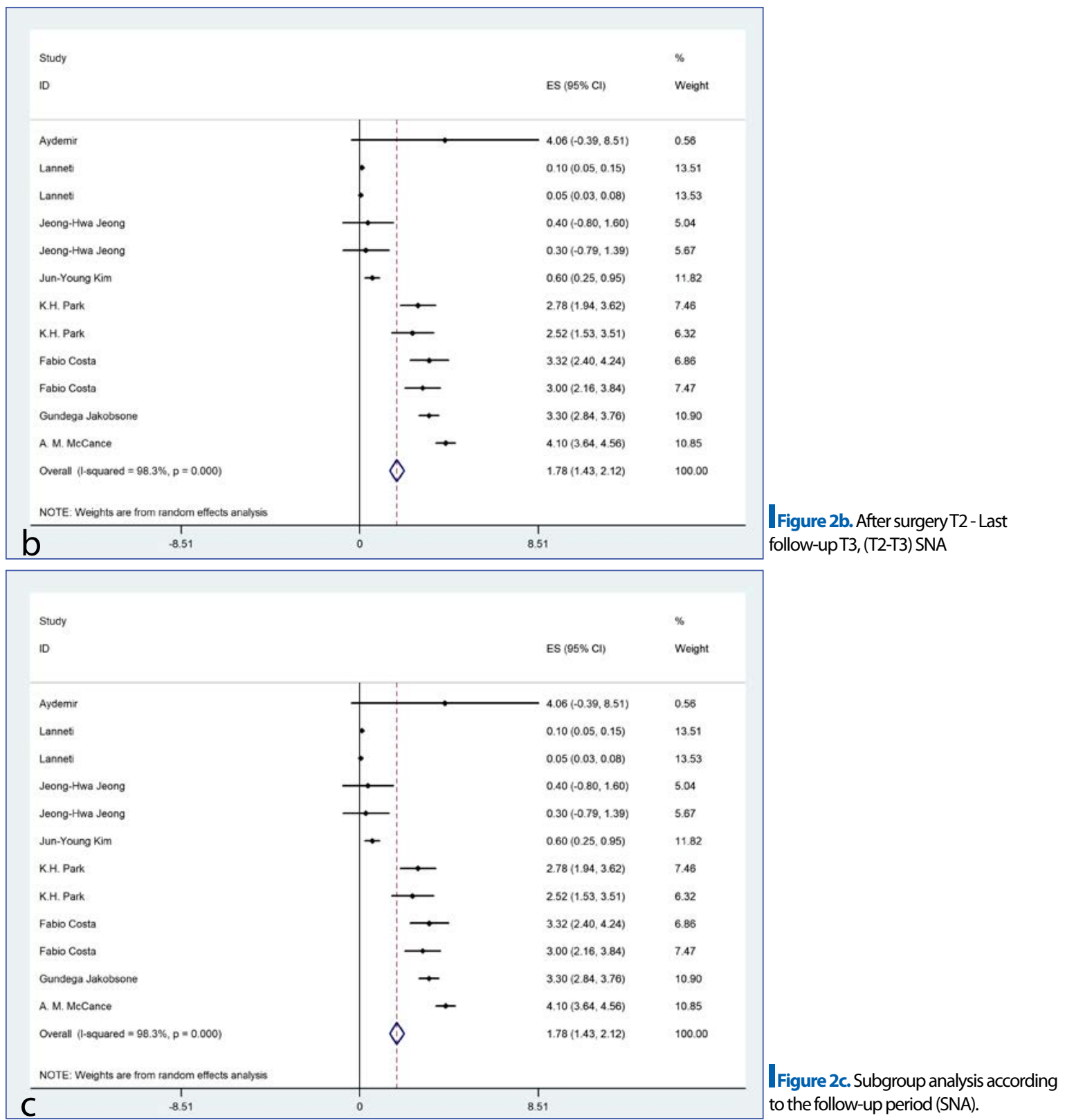

1. Less than 2 years. ; 2 . More than 2 years. 


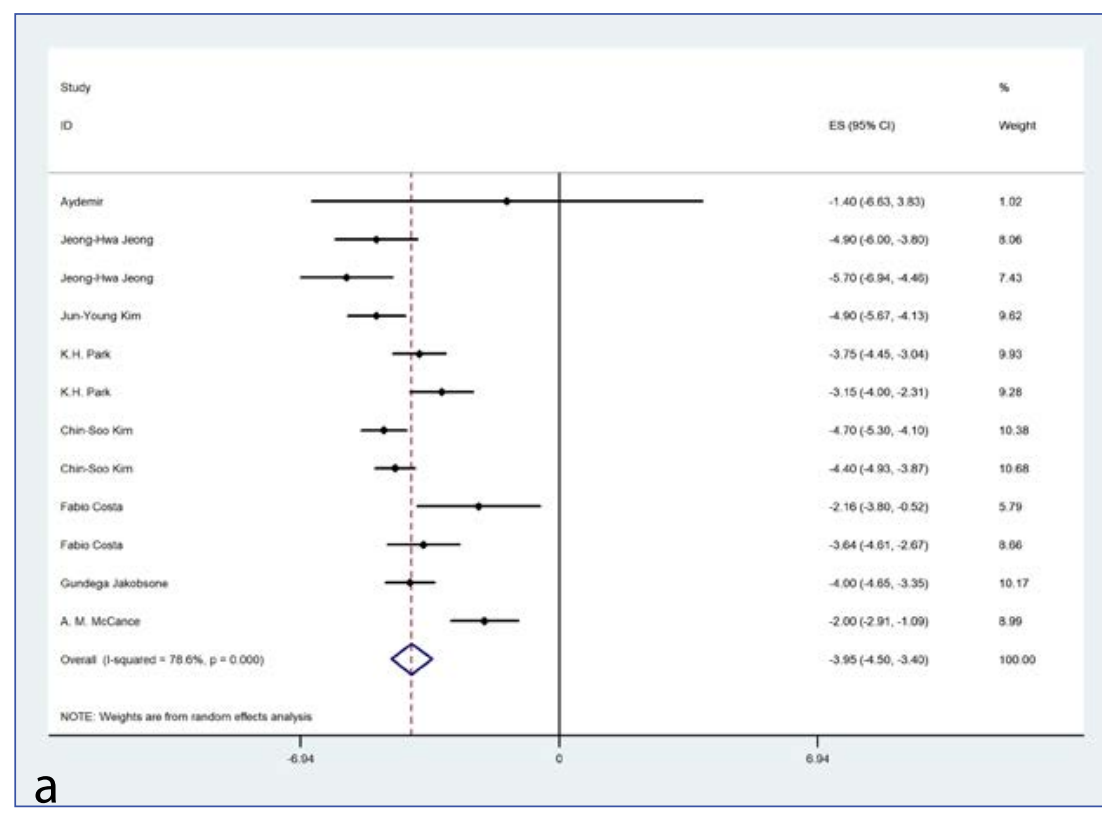

I Figure 3a. Before surgery T1 - After surgery T2, (T1-T2) SNB.

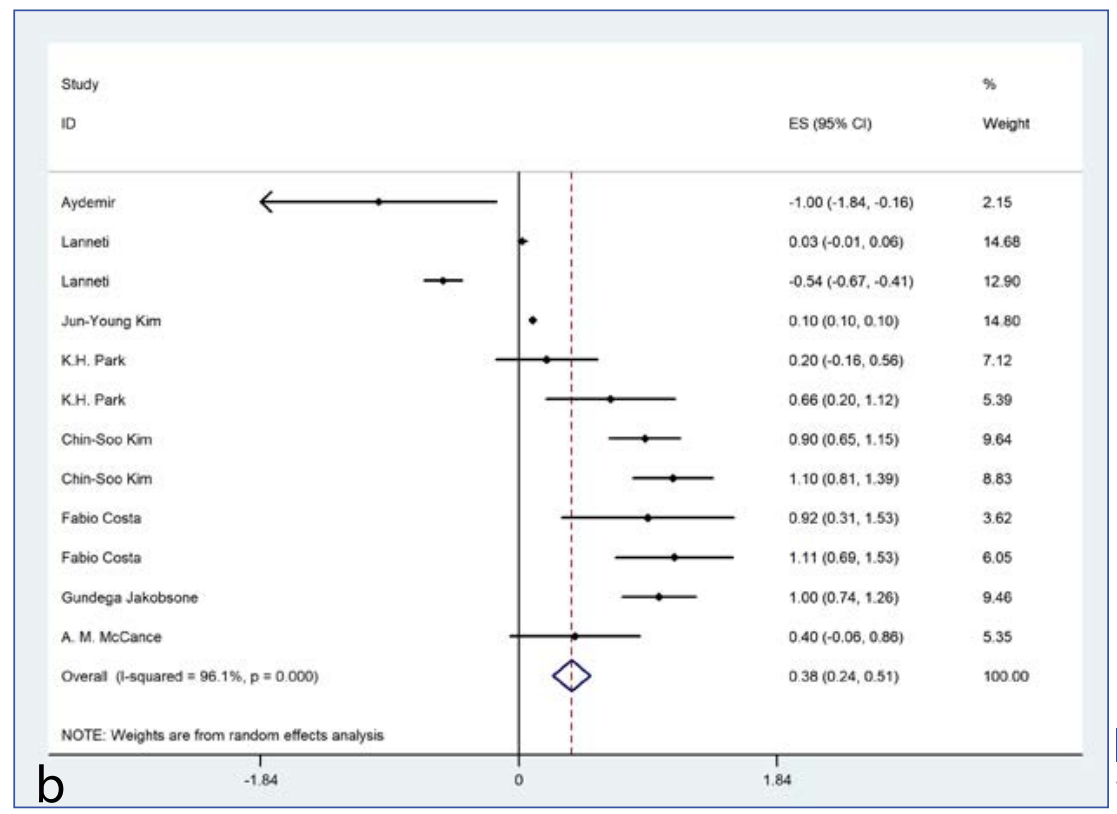

I Figure 3b. After surgery T2 - Last follow-up T3, (T2-T3) SNB.

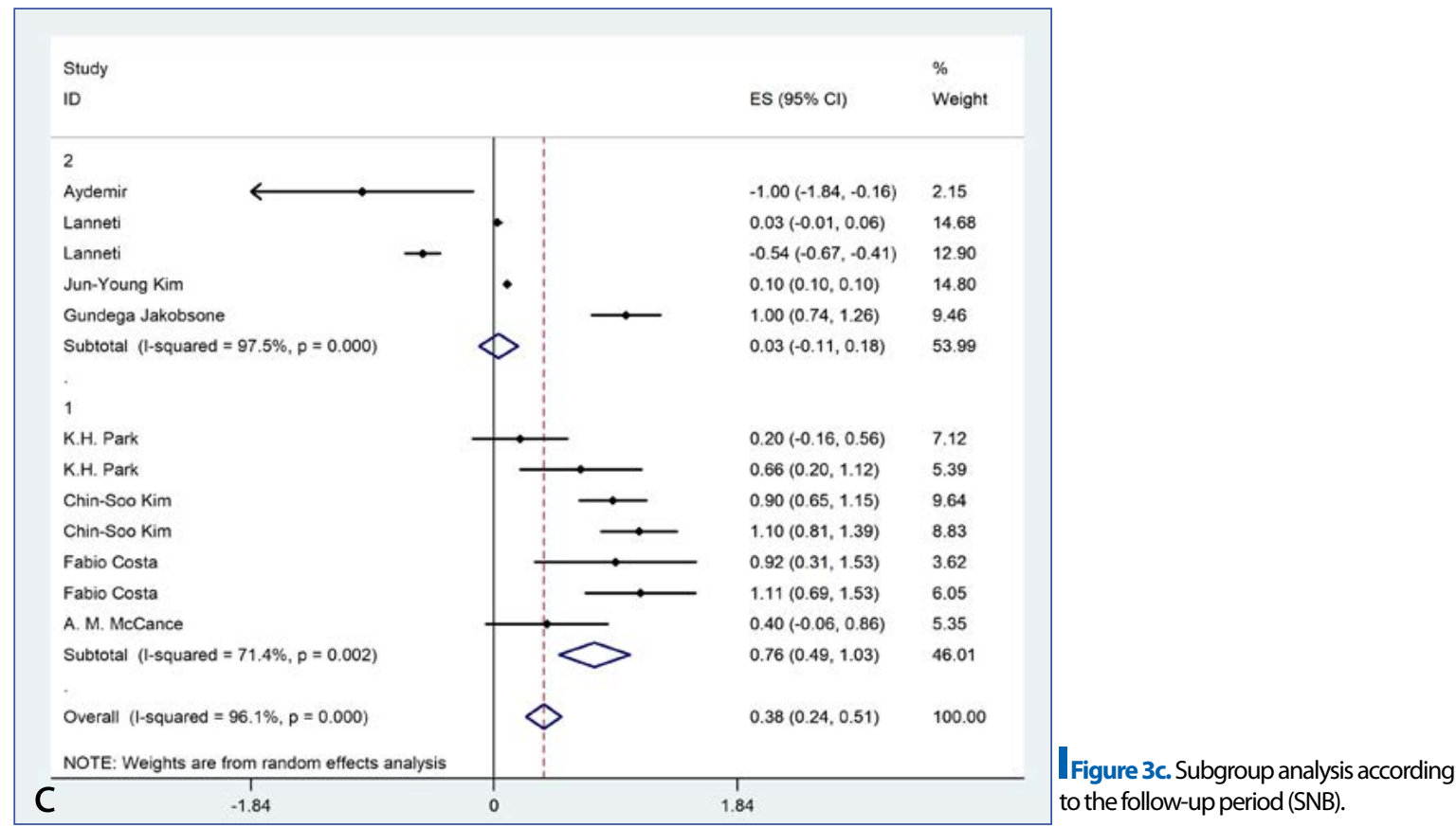

1. Less than 2 years. ; 2 . More than 2 years. 


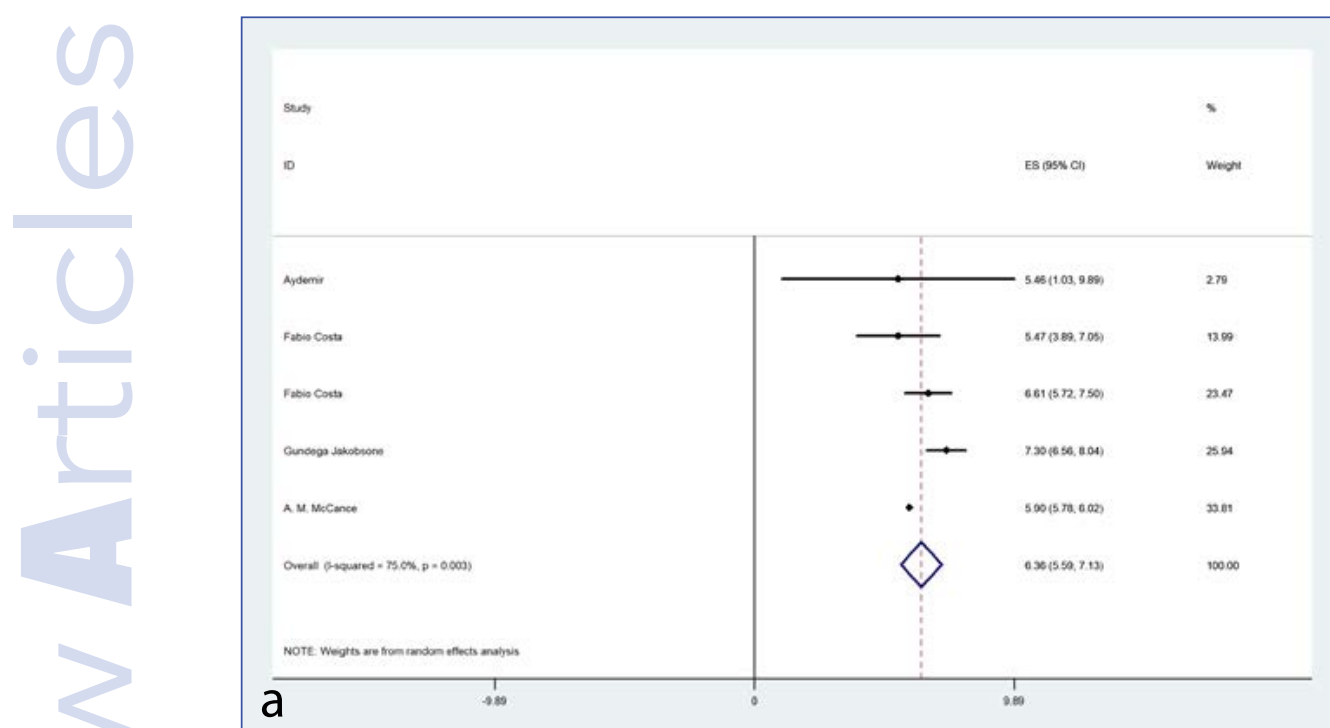

I Figure 4a. Before surgery T1 - After surgery $\mathrm{T}_{2}$, (T1-T2) ANB.

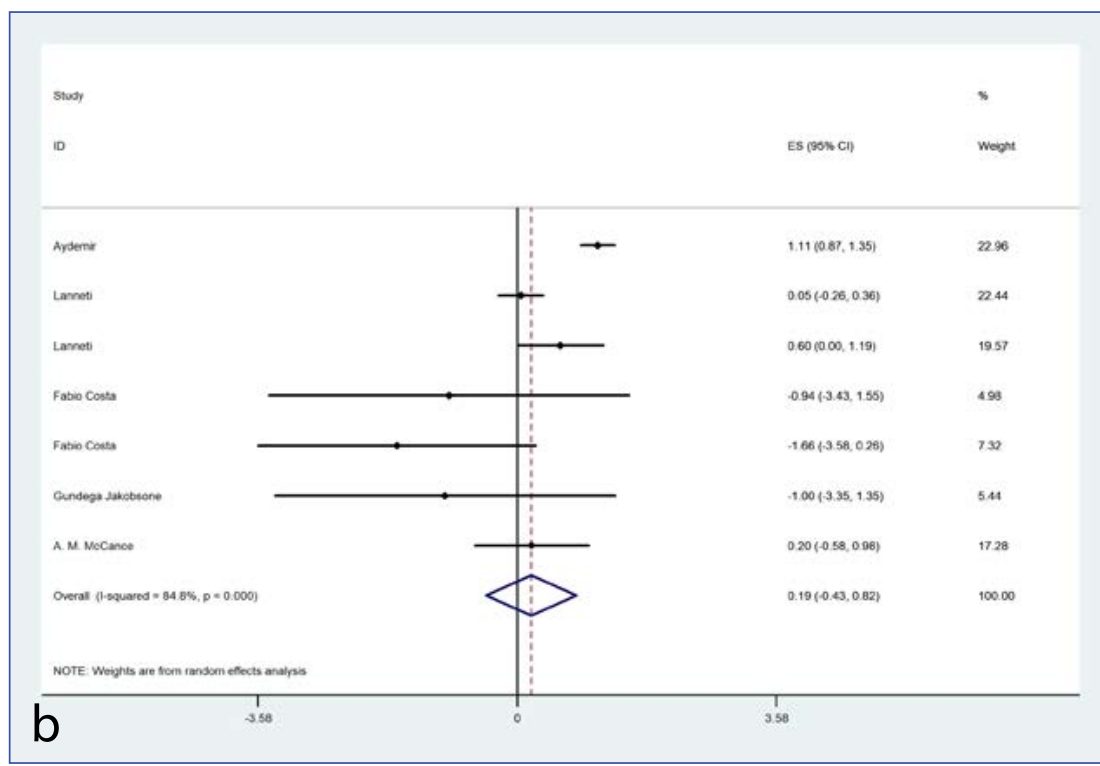

I Figure 4b. After surgery T2 - Last follow-up T3, (T2-T3) ANB.

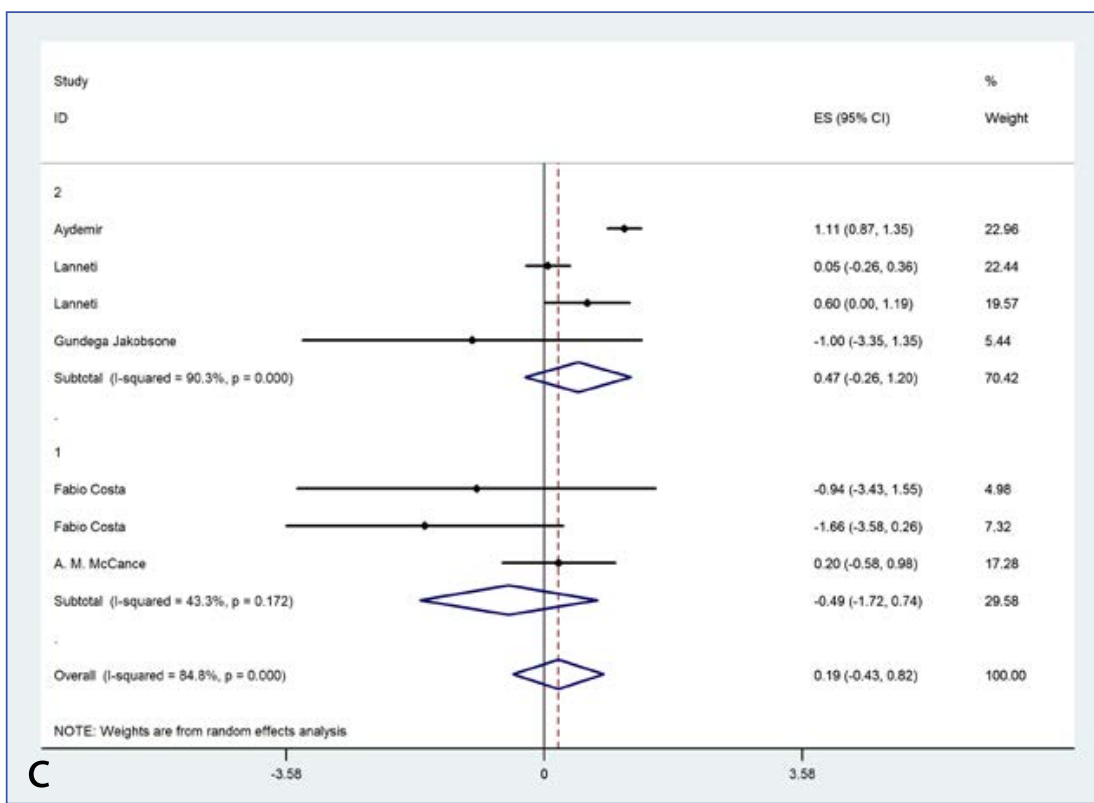

IFigure 4c. Subgroup analysis according 1. Less than 2 years. ; 2 . More than 2 years. to the follow-up period (ANB). 


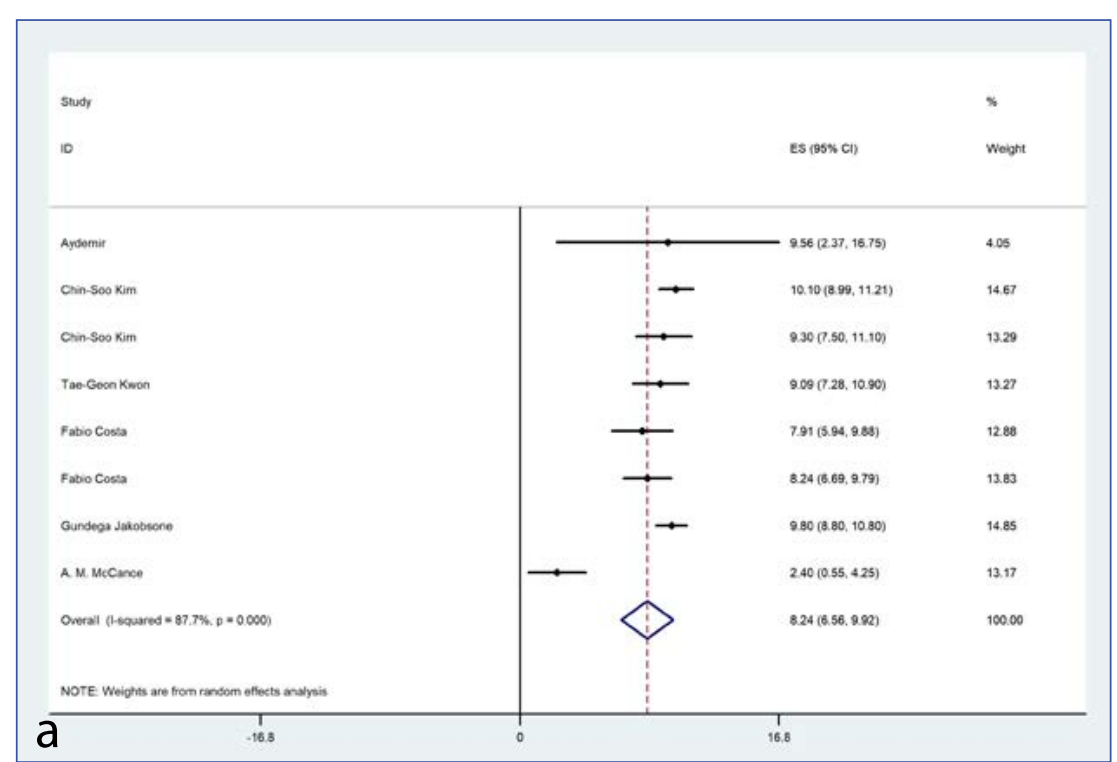

IFigure 5a. Before surgery $\mathrm{T1}$ - After surgery T2, (T1-T2) Overjet.

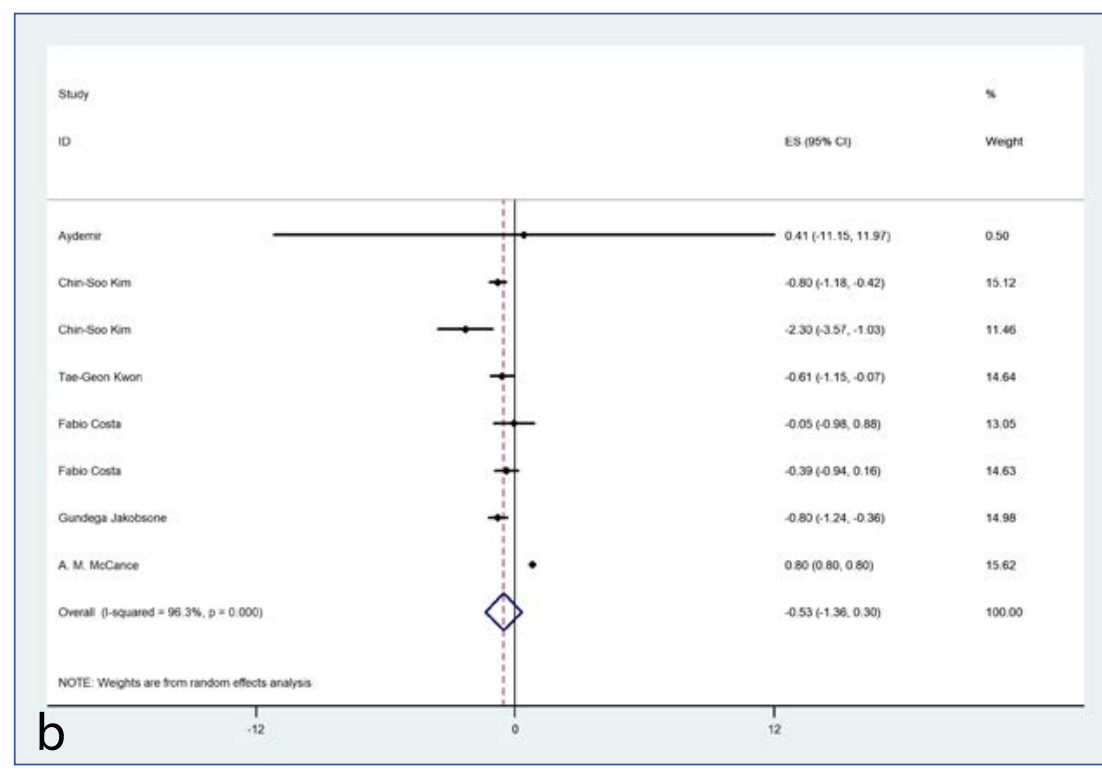

IFigure 5b. After surgery T2-Last follow-up T3, (T2-T3) Overjet.

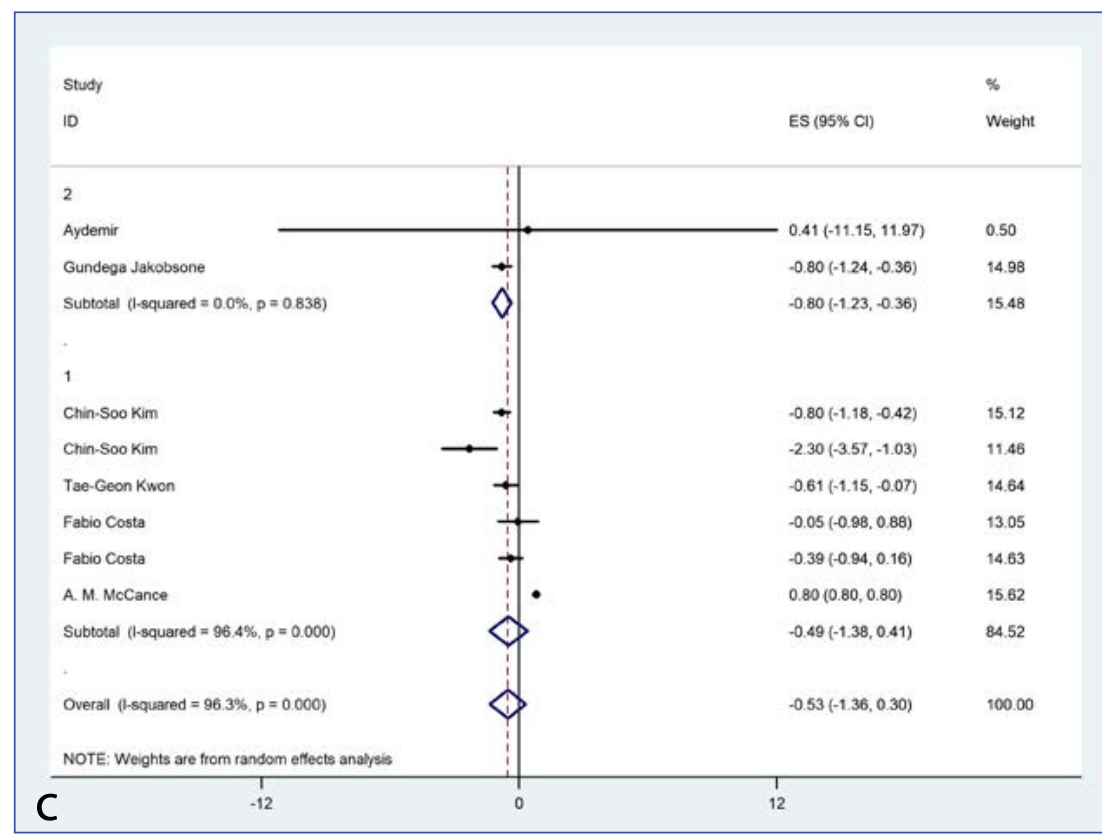

I Figure 5c. Subgroup analysis according to the follow-up period (Overjet).

1. Less than 2 years. ; 2 . More than 2 years. 
Table 1. Eligibility criteria used for the study selection.

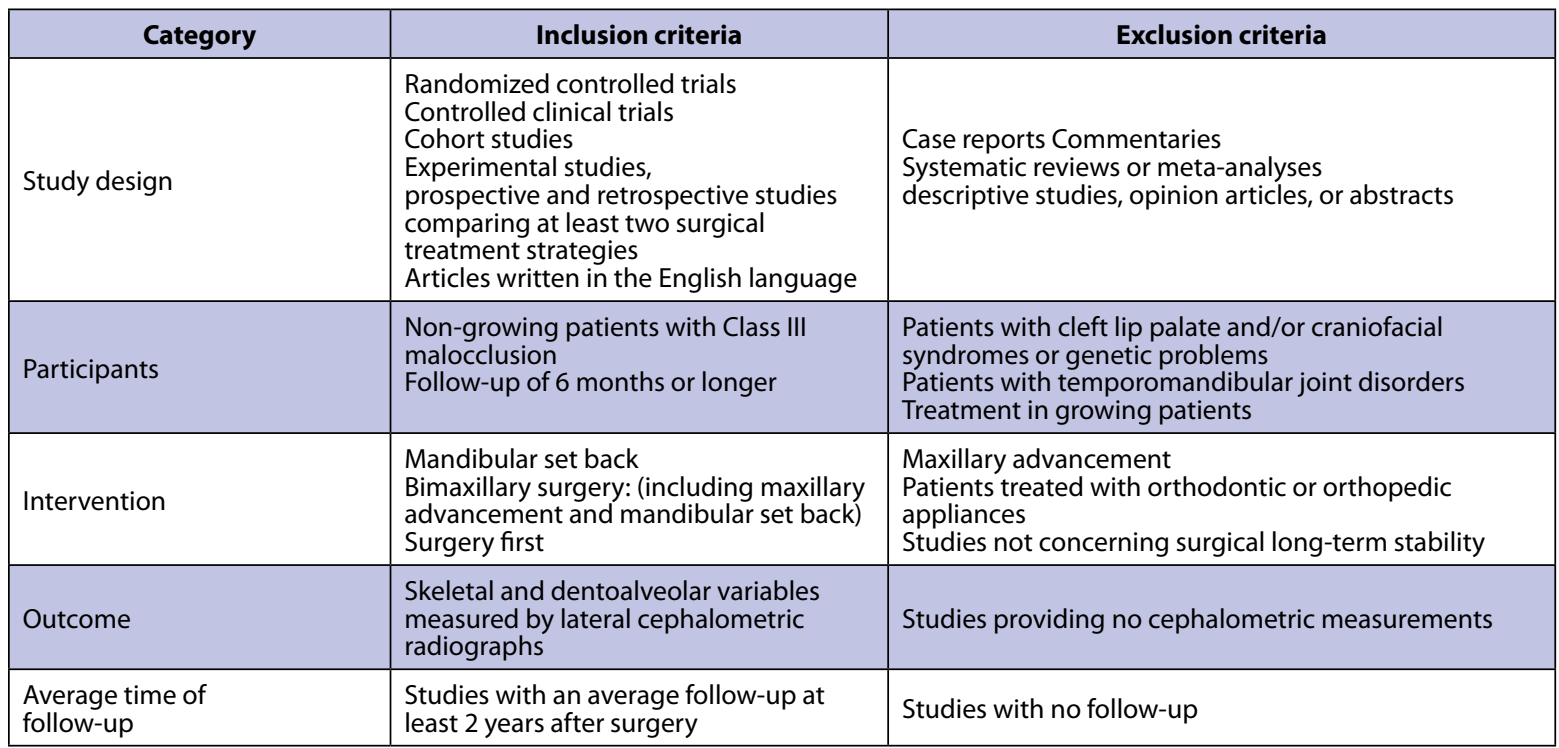

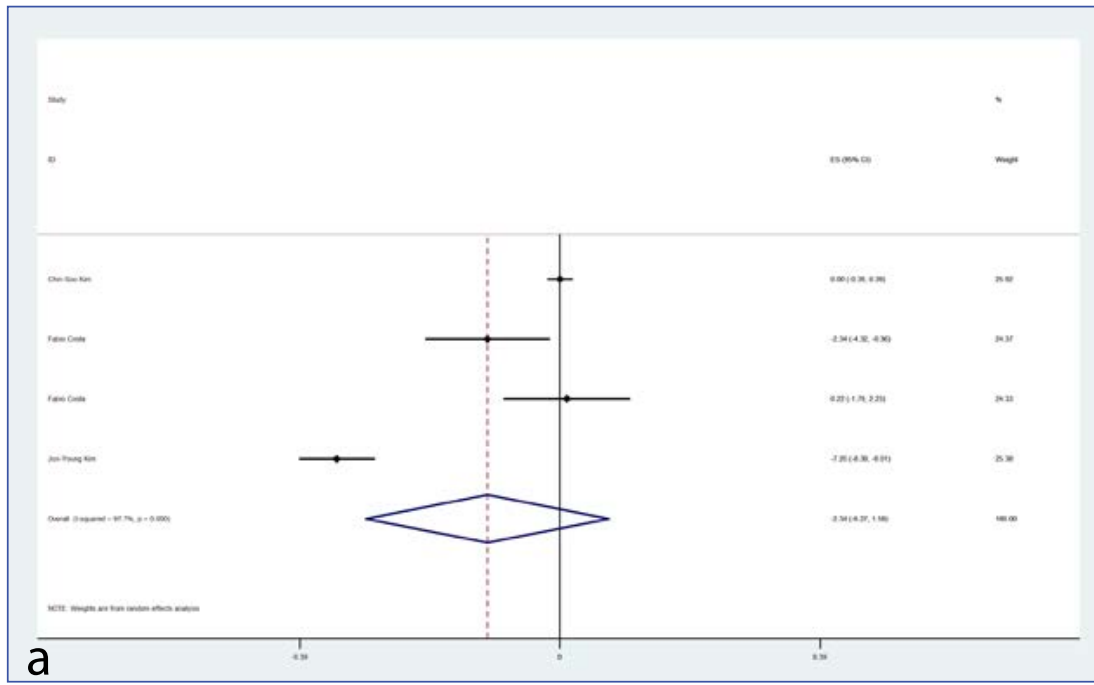

IFigure 7a. Before surgeryT1 - After

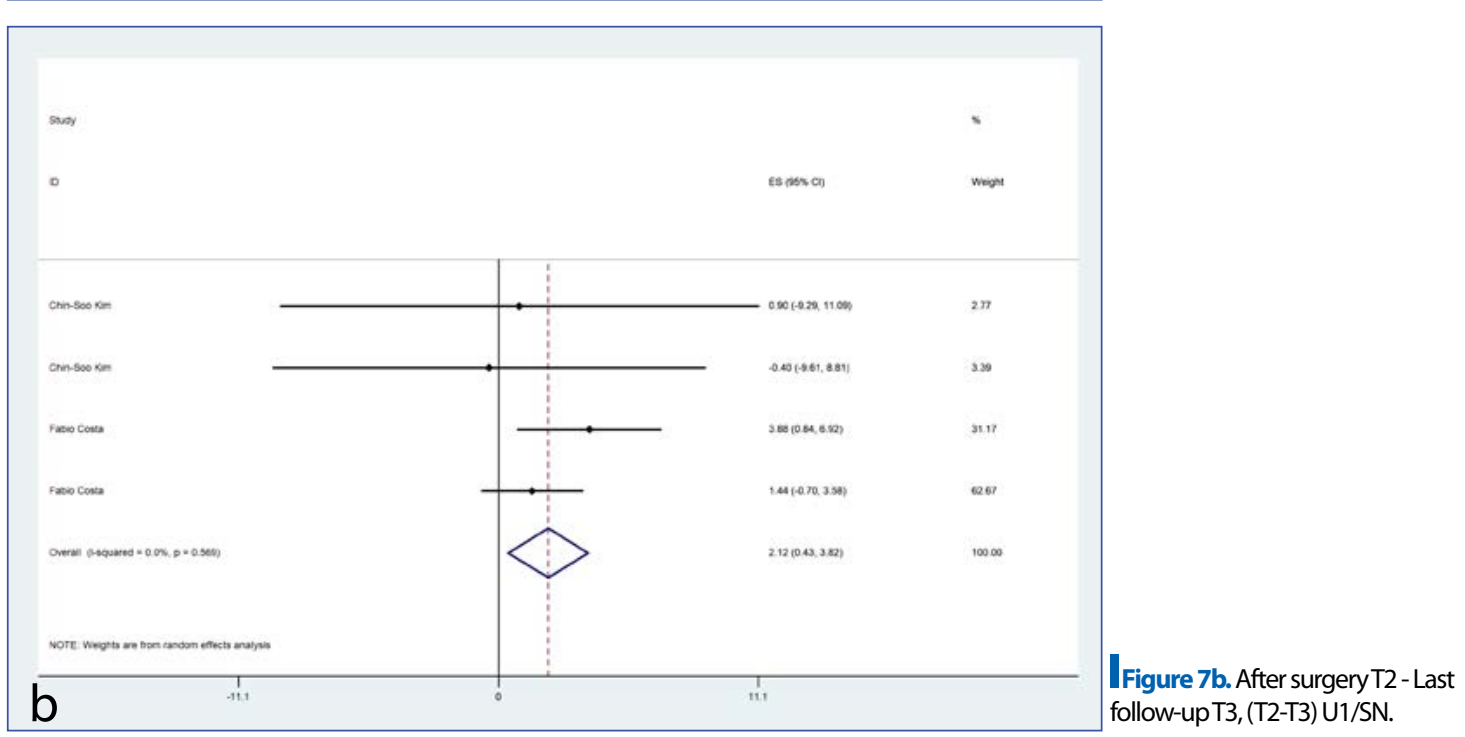
surgery 2 , (T1-T2) U1/SN. 


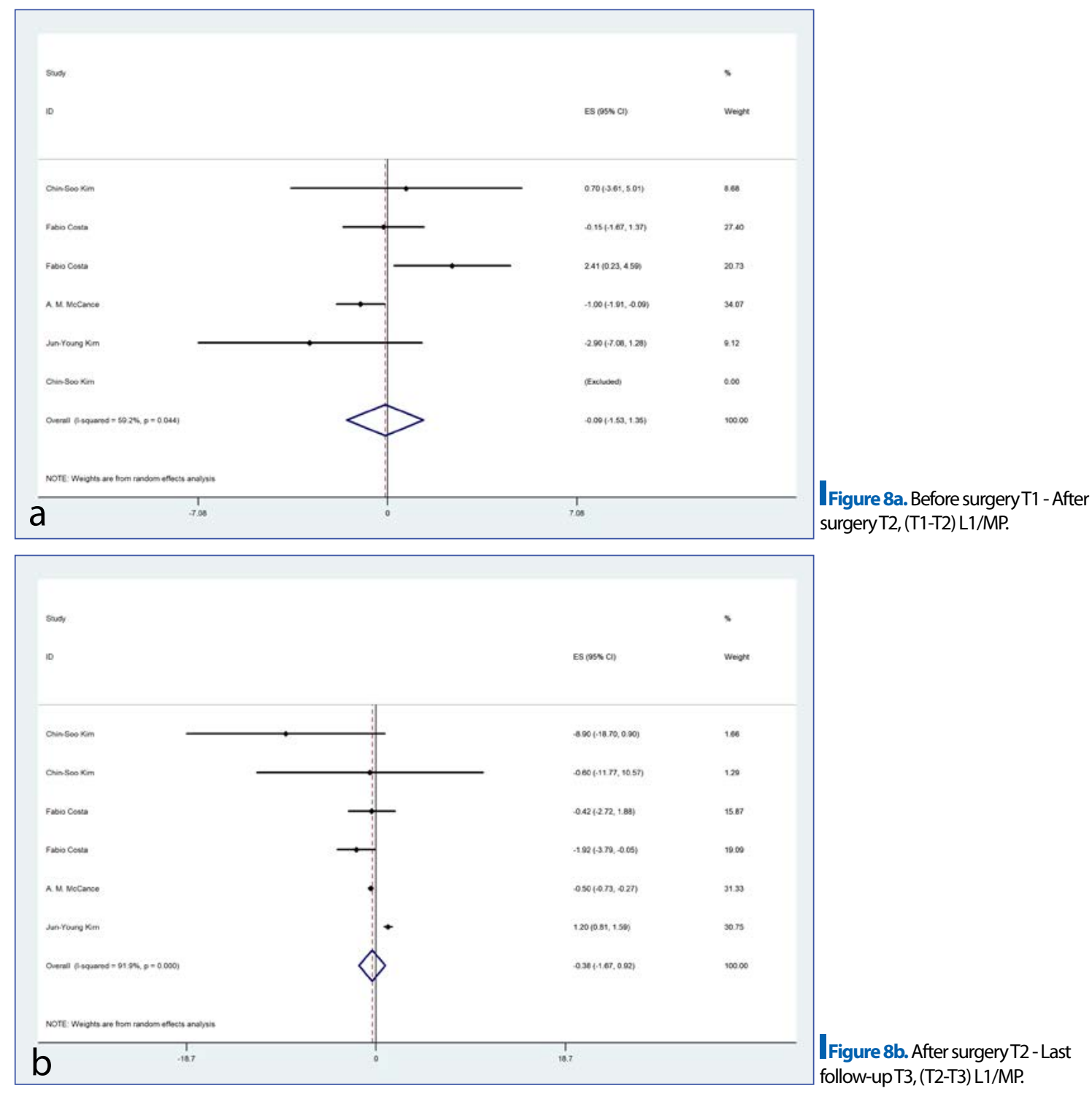

\subsection{Eligibility criteria}

The inclusion and exclusion criteria were established prior to the search according to Table 1.

Each keyword was carefully selected and revised for each database. All keywords used in the search are detailed in Table 2.

This systematic review and meta-analysis was conducted based on the PRISMA (Preferred Reporting Items for Systematic reviews and Meta-Analyses) guidelines [16]. Title-abstract-full text of each article was checked independently by two coauthors based on the PRISMA chart.

\subsection{Data collection and data items}

Two authors (AJ and AD) used pre-defined electronic sheets to extract study characteristics independently. Three time points were defined: T1 (before surgery), T2 (after surgery), and T3 (the end of the follow-up). The findings were obtained on the following items: Name of first author, year of publication, country, number and mean age of patients, gender, type of surgery (Mandibular setback including BSSO or vertical osteotomy) or (Bimaxillary surgery including Lefort $1+$ BSSO or Lefort $1+$ vertical), type of fixation including Rigid Internal Fixation (RIF) or Maxillomandibular Fixation (MMF), follow-up after surgery until 2 years, follow-up after surgery until 5 years, SNA, SNB, ANB, overjet, overbite, incisor mandibular plane angle (IMPA), upper incisor to SN (U1/SN) angle, during T1-T2 (surgical effects), T2-T3 (posttreatment changes) were recorded.

In order to identify the correlation between relapse and cephalometric landmarks, meta-analyses were conducted between cephalometric landmarks and different variables such as type of surgery (mandibular setback including BSSO or vertical osteotomy) or (bimaxillary surgery including Lefort $1+$ BSSO or Lefort $1+$ vertical), type of fixation including Rigid Internal Fixation (RIF) or Maxillomandibular Fixation (MMF), follow-up after surgery within 2 years, followup after surgery within 5 years.

The cut-off value of less than 2 years was chosen to separate short-term from long-term studies. 
Table 2. Keywords used for each data base search.

\begin{tabular}{|c|c|c|c|c|}
\hline Pubmed & Web of science & Scopus & Embase & Cochrane \\
\hline $\begin{array}{l}\text { (((((“"Malocclusion, } \\
\text { Angle Class III"[Mesh] OR } \\
\text { "class3"[Title/Abstract]) } \\
\text { OR "class III"[Title/ } \\
\text { Abstract]) OR "Maxillary } \\
\text { Deficiency"[Title } \\
\text { Abstract]) OR "mandibular } \\
\text { protrusion"[Title/ } \\
\text { Abstract]) OR "Maxillary } \\
\text { retrusion"[Title/Abstract]) } \\
\text { AND ((((Mandibular } \\
\text { Osteotomy"[Mesh] OR } \\
\text { "mandibular surgery } \\
\text { "[Title/Abstract]) } \\
\text { OR "bimaxillary } \\
\text { surgery"[Title/ } \\
\text { Abstract]) OR "surgical } \\
\text { orthodontics"[Title/ } \\
\text { Abstract]) OR "mandibular } \\
\text { set back"[Title/Abstract])) } \\
\text { AND (stability[Title/ } \\
\text { Abstract] OR } \\
\text { relapse[Title/Abstract]) }\end{array}$ & $\begin{array}{l}\text { TI=("Malocclusion, } \\
\text { Angle Class III" OR } \\
\text { "class3" OR "class III" OR } \\
\text { "Maxillary Deficiency" OR } \\
\text { "mandibular protrusion" } \\
\text { OR "Maxillary retrusion") } \\
\text { AND TI=("Mandibular } \\
\text { Osteotomy" OR } \\
\text { "mandibular surgery" OR } \\
\text { "bimaxillary surgery" OR } \\
\text { "surgical orthodontics" } \\
\text { OR "mandibular set } \\
\text { back") AND TI=(stability } \\
\text { OR relapse) }\end{array}$ & $\begin{array}{l}\text { ((TITLE-ABS- } \\
\text { KEY("Malocclusion, } \\
\text { Angle Class III") } \\
\text { ORTITLE-ABS-KEY } \\
\text { ("class3") OR TITLE- } \\
\text { ABS-KEY ("class III") } \\
\text { OR TITLE-ABS-KEY } \\
\text { ("Maxillary Deficiency") } \\
\text { OR TITLE-ABS- } \\
\text { KEY ("mandibular } \\
\text { protrusion") OR } \\
\text { TITLE-ABS-KEY } \\
\text { ("Maxillary retrusion"))) } \\
\text { AND ((TITLE-ABS- } \\
\text { KEY ("Mandibular } \\
\text { Osteotomy") OR TITLE- } \\
\text { ABS-KEY ("mandibular } \\
\text { surgery") OR TITLE- } \\
\text { ABS-KEY ("bimaxillary } \\
\text { surgery" OR TITLE- } \\
\text { ABS-KEY ("surgical } \\
\text { orthodontics") OR } \\
\text { TITLE-ABS-KEY } \\
\text { ("mandibular set } \\
\text { back"))) AND ((TITLE- } \\
\text { ABS-KEY (stability) } \\
\text { OR TITLE-ABS-KEY } \\
\text { (relapse))) }\end{array}$ & $\begin{array}{l}\text { 'malocclusion angle } \\
\text { class iii':ab,ti OR } \\
\text { 'class3':ab,ti OR 'class } \\
\text { iii':ab,ti OR 'maxillary } \\
\text { deficiency':ab,ti } \\
\text { OR'maxillary } \\
\text { retrusion':ab,ti } \\
\text { and 'mandibular } \\
\text { osteotomy':ab,ti } \\
\text { OR'mandibular } \\
\text { surgery':ab,ti } \\
\text { OR 'bimaxillary } \\
\text { surgery':ab,ti } \\
\text { OR'surgical } \\
\text { orthodontics':ab,ti } \\
\text { OR 'mandibular } \\
\text { set back':ab,ti and } \\
\text { 'stability':ab,ti OR } \\
\text { 'relapse':ab,ti }\end{array}$ & $\begin{array}{l}\text { ("Malocclusion, Angle } \\
\text { Class III" OR "class3" OR } \\
\text { "class III" OR "Maxillary } \\
\text { Deficiency" OR } \\
\text { "mandibular protrusion" } \\
\text { OR "Maxillary retrusion") } \\
\text { AND ("Mandibular } \\
\text { Osteotomy" OR } \\
\text { "mandibular surgery" OR } \\
\text { "bimaxillary surgery" OR } \\
\text { "surgical orthodontics" } \\
\text { OR "mandibular set } \\
\text { back") AND (stability OR } \\
\text { relapse) }\end{array}$ \\
\hline
\end{tabular}

\subsection{Statistical analysis}

All statistical tests were conducted using the STATA 14 (StataCorp LP, College Station, USA). The effects of bimaxillary surgery or mandibular setback on SNA, SNB, ANB, overjet, overbite, incisor mandibular plane angle (IMPA) and upper incisor to SN (U1/ SN) angle, before and after surgery as well as the last follow-up were measured by weighted mean difference (WMD) and the 95\% confidence intervals (CI). The standard error (SE) of the mean difference (MD) for non-reported studies was calculated by the following formula: $S D^{2}$ baseline $+S D^{2}$ final $-\left(2 R^{*} S D\right.$ baseline + SD final) and $S D=S E^{*} S q(n)$. Heterogeneity across studies was assessed using the I-squared and the alpha of 0.05 for statistical significance.

The subgroup analysis was based on the time of follow-up to identify the source of heterogeneities. To identify the source of clinical heterogeneity, susceptible variables including treatment plan, gender, country, treatment time, type of surgery, type of fixation, and follow-up time were introduced into a meta-regression model. WMD with $95 \% \mathrm{CI}$ was calculated for all variables. The publication bias was determined using Begg tests. The p-value of 0.05 was regarded for statistical significance. The changes in seven variables (SNA, SNB, ANB, IMPA, overjet, U1/SN, and L1/MP) during three time periods [Before surgery (T1), after surgery (T2) and last follow-up (T3)] were compared between the studies. The summarized data of included studies and cephalometric measurements of the included studies are seen in Tables 3 and 4 respectively. The results of the statistical analysis for heterogeneity and the funnel plots are displayed in Figures 2, 3, 4, $5,6,7$, and 8 .

\section{RESULTS}

\subsection{Study selection and characteristics}

Of the 165 records resulting from the search strategies, 73 studies were obtained once duplicated articles were excluded. Then, 40 papers were removed because of their titles and abstracts. In addition, 20 more were further excluded for not meeting the exclusion/inclusion criteria. Ultimately, 13 papers met the final selected criteria and were selected to conduct the systematic review and meta-analysis. The manual search did not yield any additional material. In case of disagreement, the authors discussed the controversy until an agreement was reached. Of the 13 studies, 2 of them did not provide us with enough data for the meta-analysis and were excluded from the study. Performing meta-analysis was only feasible for 11 studies, and these studies were included in our study. These studies include non-growing patients with Class III malocclusion with Follow-up of 6 months or longer. The level of inter-examiner agreement of data extraction was measured using kappa statistics. The level of agreement between the two examiners was assessed using the Cohen kappa scores. The kappa score for study selection was 0.978 , indicating an excellent level of agreement. The PRISMA flow diagram of study selection is outlined in Fig. 1.

Before surgery T1- After surgery T2, (T1-T2) Figures 2a, 3a, 4a, 5a, 6a, 7a, and 8a.

Short-term treatment effects included significant increase in SNA (WMD 1.78, 95\%Cl:1.42, 2.12), significant reduction in SNB (WMD -3.95, 95\%Cl:$4.50,-3.40$ ), significant rise in ANB (WMD 6.36, 


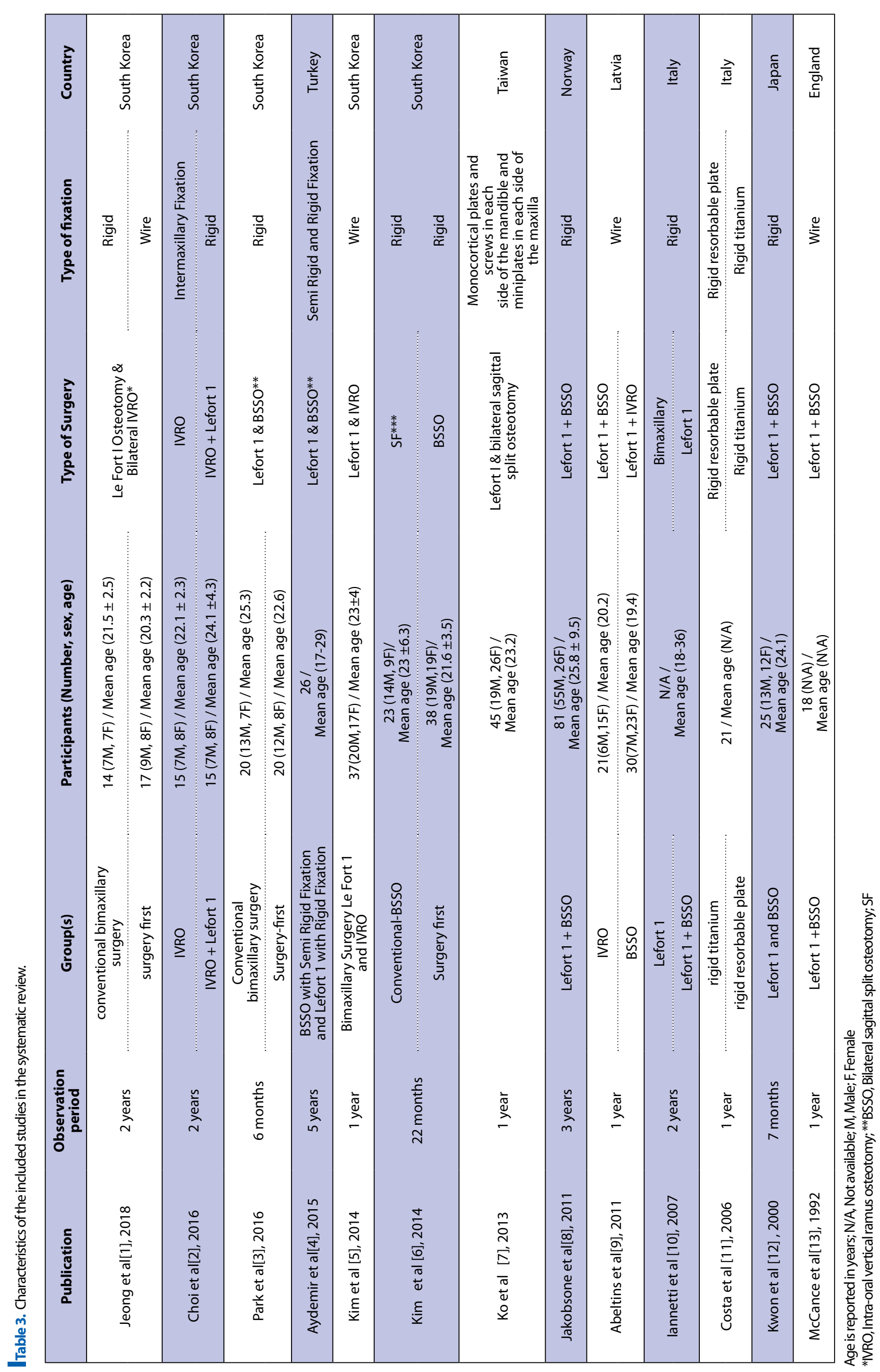


$95 \% \mathrm{Cl}: 5.59,7.13)$, significant growth in overjet (WMD 8.24, 95\%Cl: 6.56, 9.92), significant elevation in overbite (WMD 1.57, 95\%Cl: 0.30,2.84), while U1/ SN (WMD -2.34, 95\%Cl, -6.27, 1.58) and L1/MP (WMD $2.12,95 \% \mathrm{Cl}: 0.43,3.82)$ did not show any significant changes. After surgery T2- Last follow upT3, (T2-T3) Figures $2 b, 3 b, 4 b, 5 b, 6 b, 7 b$, and $8 b$.

The last follow-up showed no significant changes in SNA (WMD 0.06, 95\%Cl:-.05, 0.16), ANB (WMD $0.19,95 \% \mathrm{Cl}:-0.43,0.82)$, overjet (WMD $-0.53,95 \% \mathrm{Cl}$ : $-1.36,0.30$ ), overbite (WMD 0.20, 95\%Cl:-0.17, 0.57), L1/MP (WMD -0.38, 95\%Cl:-1.67, 0.92), while there was a significant change in SNB and U1/SN (WMD 0.38, 95\%Cl:0.24, 0.51) and (WMD 2.12, 95\%Cl:0.43, 3.82 ) respectively.

\subsection{Subgroup analysis}

A subgroup analysis based on the duration of followup: less than 2 years (group 1) and more than 2 years (group 2) was conducted to identify the source of the high heterogeneity and the influence of the follow-up duration.

SNA increased significantly after a 2 year-follow-up [WMD 0.07, 95\%Cl: 0.03, 0.11)] but no significant changes were noted in less than 2 year-follow-up [WMD -0.02, (95\%Cl: $-0.23,0.19)$ ].

SNB did not have any significant changes in more than 2 year-follow-up [WMD 0.03 (95\%Cl: -0.11 , $0.18)$ ]; however, it increased significantly in group 1 [WMD 0.76 (95\%Cl: 0.49, 1.03)].

There were no significant changes in ANB in both group 2 durations [WMD .047 (95\%Cl:-0.26,1.20)] or group 1 [WMD -0.49 (95\%Cl:-1.72, 0.74)] durations. For overjet, it decreased significantly after a 2 yearfollow-up [WMD $-0.80(95 \% \mathrm{Cl}:-1.23,-0.36)]$, but not in less than a 2 year-follow-up [WMD -0.49 (95\%Cl: $-1.38,0.41)]$. Overbite grew significantly in group 2 [WMD 0.50 (95\%Cl:0.01, 0.98)] and not in group 1 [WMD $0.03(95 \% \mathrm{Cl}:-0.36,0.41)]$. Only a few studies measured U1/SN and L1/MP; hence, the heterogeneity could not be measured due to the small sample size. The results of the statistical testing for heterogeneity and the corresponding funnel plots are given in Figures $2 c, 3 c, 4 c, 5 c$, and $6 c$.

\subsection{Risk of bias within studies /publication bias}

No publication bias was determined by using the Begg's test [in STATA 14 (StataCorp LP, College Station, USA)].

The results of the Begg's test for the analysis of small study effect (publication bias) for the measurements of SNA, SNB, ANB, overjet, overbite, U1/SN, and L1/ $\mathrm{MP}$ are as follows, respectively: $0.78,0.33,0.95,0.08$, $0.45,0.98$, and 0.34 .

\section{DISCUSSION}

\subsection{Summary of evidence}

This meta-analysis showed some significant relapse in skeletal and dental variables during the follow-up period. SNA and overbite increased significantly after a 2 year-follow-up. On the contrary, SNB increased significantly before a 2 year-follow-up. Overjet was significantly reduced after a 2 year-follow-up. To the best of our knowledge, this is the first metaanalysis reviewing the stability of skeletal class III malocclusion after bimaxillary surgery or mandibular setback. Data from this study revealed that the main relapse in SNA occurred after a 2 year-follow-up but not in less than 2 years. This suggested that SNA relapse often happened after a 2 year-follow-up and was largely associated with the growth of maxilla that is a common finding in class III malocclusion.

For SNB, a significant increase was noted before a 2 year-follow-up and not after a 2 year-follow-up. This relapse in the short-term is due to the growth of mandible which reportedly can continue even after 18 years of age [17]. Hence, it is important to consider the patient's age and their related growth pattern before bimaxillary surgery and/or mandibular setback treatment. Overjet was reduced significantly in more than a 2 year-follow-up; this relapse is due to an increase in SNB. However, the extent of overbite increased significantly after 2 years. Pre-surgical orthodontic treatment aims to decompensate incisor inclination toward normal values. Orthodontic decompensation allows a greater surgical correction, and this may be a more important factor in the relapse. We should keep in mind that skeletal relapse is masked frequently by compensatory changes in the axial inclination of the teeth [18-21].

Relapse varies considerably between patients and surgeons without any known reason. It is clear that good surgical training, profound experience in orthognathic surgery, and technical refinements by the surgeon are required to have perfect surgical outcomes with regards to esthetics and stability. The orthodontist should prepare the patient before surgery for a perfect coordination and leveling and alignment of both dental arches in transverse width, correct decompensation of the incisors, control of the surgical splint, and its newly defined occlusion to allow correct placement of the mandible during surgery.

The etiology of relapse is multifactorial, including, but not limited to: the proper seating of the condyles, the extent of mandibular setback and maxillary advancement, the soft tissue and muscles, the mandibular plane angle, the remaining growth and remodeling, the skill of the surgeon, and the pre-operative age of the patient [8].

Proffit et al [22] questioned the stability in orthognathic surgery since the stability of the surgical repositioning of the jaws varies considerably depending on the procedure.

In their view, the order of importance starts with the direction of movement, the type of fixation used, and in the end, the surgical technique that has been adopted. 


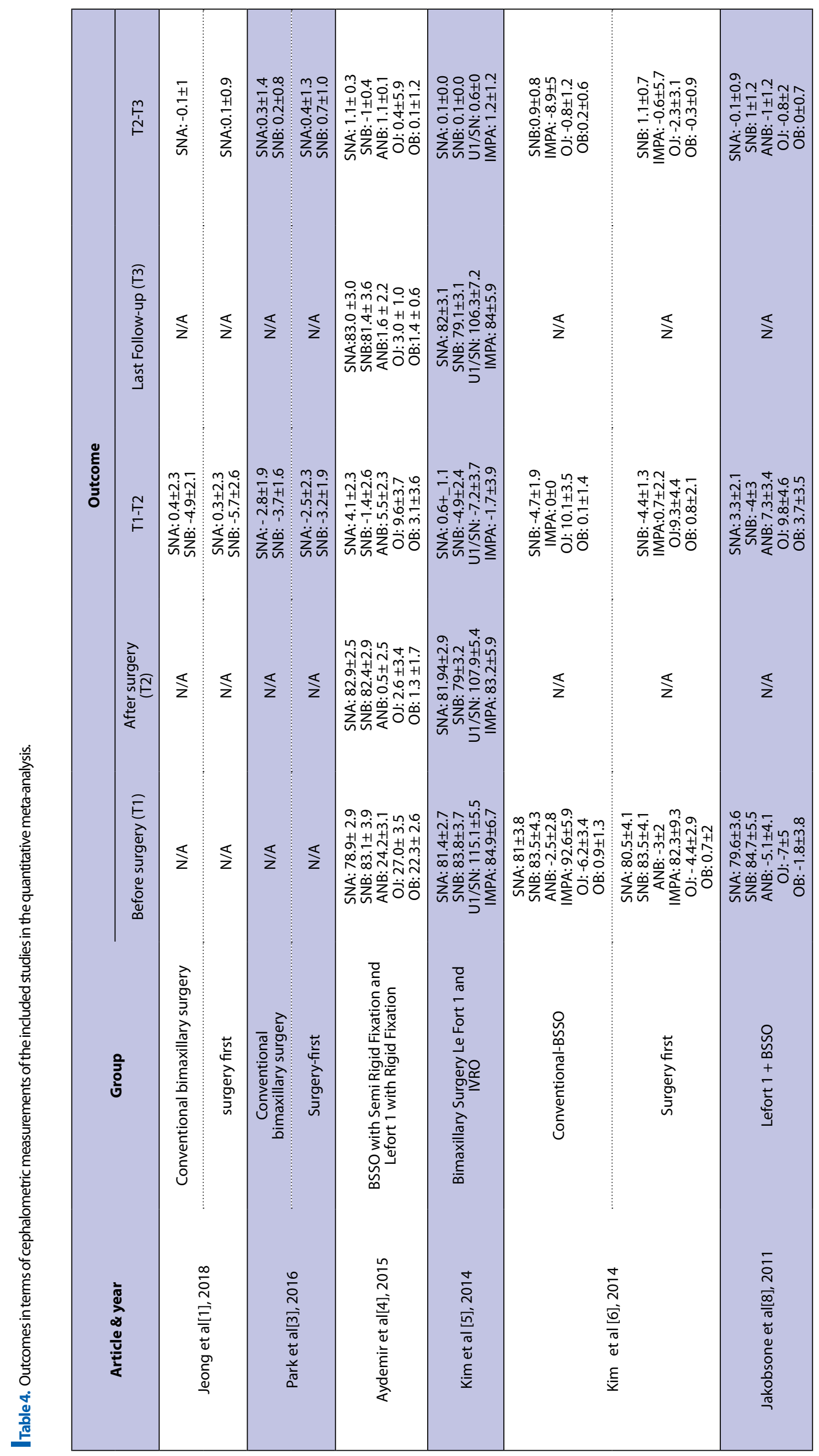




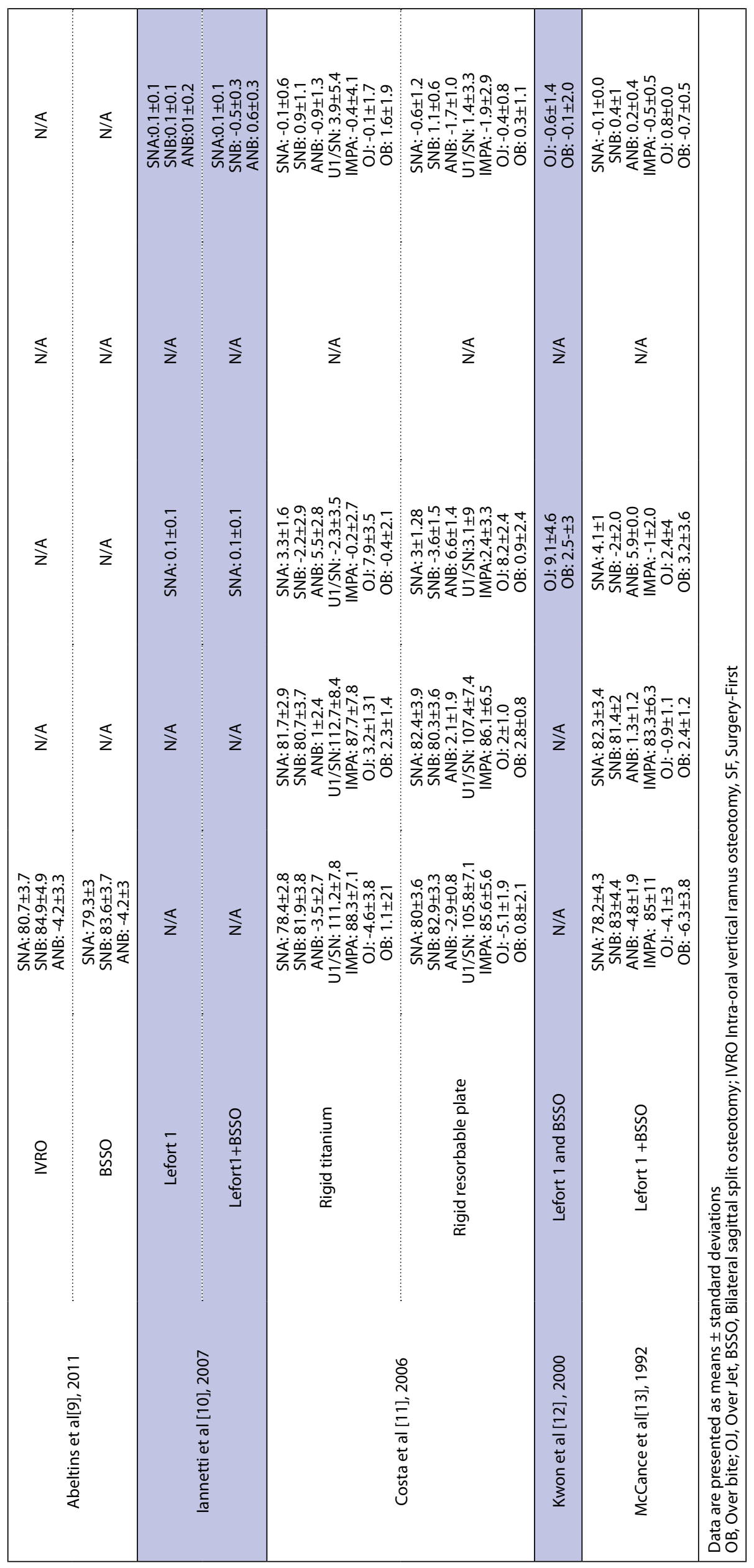




\subsection{Limitations}

This meta-analysis might be considered a first step in addressing the stability of skeletal class III malocclusion after bimaxillary surgery or mandibular setback. Although this study provided an overview of the topic, there were several limitations. One main limitation was the shortage of large and high-quality RCTs. The numbers of relevant research articles and patients included in the meta-analysis were not large enough. Furthermore, the sample sizes were diluted due to too many study variables included ( 7 cephalometric variables at 3 different time points). Hence, the quantitative analysis cannot accurately reflect real skeletal and dental changes. Additionally, not every study included looked at all variables further complicating the analysis. Eventually, some studies proposed surgery first which were deleted from the analysis; however, whether the treatment effects of surgery first can be stable remains unclear. Attention should also be paid to the stability of the treatment effects of surgery first. Therefore, future research in this area is warranted.

\section{CONCLUSIONS}

On the basis of this review, we concluded the following.

1. Surgical orthodontic improves sagittal skeletal and dental relationships but significant relapse during the follow-up period may happen.

2. SNA and overbite increased significantly after a 2 year follow-up.

3. SNB increased significantly before a 2 year followup with no significant changes after this follow-up.

4. Overjet diminished significantly after a 2 year follow-up.

\section{REFERENCES}

1. Chew MT, Sandham A, Wong HB. Evaluation of the linearity of soft to hard-tissue movement after orthognathic surgery. Am J Orthod Dentofacial Orthop. 2008;134(5):665-670.

[Full text links] [CrossRef] [PubMed] Google Scholar Scopus

2. Espeland L, Hogevold HE, Stenvik A. A 3-year patient-centred follow-up of 516 consecutively treated orthognathic surgery patients. Eur J Orthod. 2008;30(1):24-30.

[Full text links] [CrossRef] [PubMed] Google Scholar Scopus

3. Jakobsone G, Stenvik A, Sandvik L, Espeland L. Three-year follow-up of bimaxillary surgery to correct skeletal Class III malocclusion: stability and risk factors for relapse. Am J Orthod Dentofacial Orthop. 2011;139(1):80-89.

[Full text links] [CrossRef] [PubMed] Google Scholar Scopus

4. Jamilian A, Cannavale R, Piancino MG, et al. Methodological quality and outcome of systematic reviews reporting on orthopaedic treatment for class III malocclusion: overview of systematic reviews. J Orthod. 2016;43(2):102-120.

[Full text links] [CrossRef] [PubMed] Google Scholar Scopus

5. Johnston C, Burden D, Kennedy D, et al. Class III surgicalorthodontic treatment: a cephalometric study. Am J Orthod Dentofacial Orthop. 2006;130(3):300-309.

[Full text links] [CrossRef] [PubMed] Google Scholar Scopus

6. Jamilian A, Showkatbakhsh R, Behnaz M, et al. Tooth-borne distraction osteogenesis versus conventional Le Fort I in maxillary advancement of cleft lip and palate patients. Minerva Stomatol. 2018;67(3):117-124.

[Full text links] [PubMed] Google Scholar Scopus

\section{CONFLICT OF INTEREST}

The authors declare no conflict of interest.

\section{FOUNDING}

This manuscript was partially supported by the University of Michigan Graduate Research Fund.

\section{AUTHOR CONTRIBUTIONS}

AJ: conceptualization, study design, study concept, original writing and corresponding author. LN: drafting, data interpretation, drawings and editing. MT and AD: literature review, search design, data gathering. $A F$ and $M A$ : software programs and statistical analysis. CWW: drafting, data interpretation, critical revision and final approval.

\section{ACKNOWLEDGMENTS}

The authors report no commercial, proprietary, or financial interest in the products or companies described in this article.

\section{THE AUTHOR'S INSTITUTIONAL AFFILIATIONS} WHERE THE WORK WAS CONDUCTED

Department of orthodontics, Faculty of dentistry, Cranio maxillofacial Research center, Tehran medical sciences, Islamic Azad University, Tehran, Iran and Department of Periodontics and Oral Medicine, School of Dentistry, University of Michigan, Michigan, USA.

7. Eslami S, Faber J, Fateh A, et al. Treatment decision in adult patients with class III malocclusion: surgery versus orthodontics. Prog Orthod. 2018;19(1):28.

[Full text links] [CrossRef] [PubMed] Google Scholar Scopus 8. Joss CU, Vassalli IM. Stability after bilateral sagittal split osteotomy setback surgery with rigid internal fixation: a systematic review. J Oral Maxillofac Surg. 2008;66(8):1634-1643. [Full text links] [CrossRef] [PubMed] Google Scholar Scopus 9. lannetti G, Chimenti C, Di Paolo C. Five-year follow-up of Le Fort I osteotomies. J Craniomaxillofac Surg. 1987;15(5):238-243.

[Full text links] [CrossRef] [PubMed] Google Scholar Scopus 10. LaBanc JP, Turvey T, Epker BN. Results following simultaneous mobilization of the maxilla and mandible for the correction of dentofacial deformities: analysis of 100 consecutive patients. Oral Surg Oral Med Oral Pathol. 1982;54(6):607-612.

[CrossRef] [PubMed] Google Scholar Scopus

11. Proffit WR, Phillips C, Turvey TA. Stability after surgicalorthodontic corrective of skeletal Class III malocclusion. 3. Combined maxillary and mandibular procedures. Int J Adult Orthodon Orthognath Surg. 1991;6(4):211-225.

[PubMed] Google Scholar Scopus

12. de Haan IF, Ciesielski R, Nitsche T, Koos B. Evaluation of relapse after orthodontic therapy combined with orthognathic surgery in the treatment of skeletal class III. J Orofac Orthop. 2013;74(5):362-369.

[Full text links] [CrossRef] [PubMed] Google Scholar Scopus

13. Shamseer L, Moher D, Clarke $M$, et al. Preferred reporting items for systematic review and meta-analysis 
protocols (PRISMA-P) 2015: elaboration and explanation. BMJ. 2015;350:g7647.

[Full text links] [CrossRef] [PubMed] Google Scholar

14. Higgins JP, Altman DG, Gøtzsche PC, et al. The Cochrane Collaboration's tool for assessing risk of bias in randomised trials. BMJ. 2011;343:d5928.

[CrossRef] Google Scholar

15. Liberati A, Altman DG, Tetzlaff J, et al. The PRISMA statement for reporting systematic reviews and metaanalyses of studies that evaluate health care interventions: explanation and elaboration. J Clin Epidemiol. 2009;62(10):e1e34.

[Full text links] [CrossRef] [PubMed] Google Scholar Scopus

16. Moher D, Liberati A, Tetzlaff J, et al. Reprint--preferred reporting items for systematic reviews and meta-analyses: the PRISMA statement. Phys Ther. 2009;89(9):873-880. [CrossRef] [PubMed] Google Scholar Scopus

17. LoveRJ,MurrayJM,Mamandras AH.Facialgrowthinmales 16to 20years of age.Am JOrthodDentofacialOrthop. 1990;97(3):200-206. [CrossRef] Google Scholar

18. Schendel SA, Epker BN. Results after mandibular advancement surgery: an analysis of 87 cases. J Oral Surg. 1980;38(4):265-282

[PubMed] Google Scholar Scopus

19. Vasir NS, Thompson RT, Davies TM. Dental and skeletal changes following sagittal split osteotomy for correction of mandibular prognathism. Eur J Orthod. 199;13(2):134-142.

[Full text links] [CrossRef] [PubMed] Google Scholar Scopus

20. Grassia V, d'Apuzzo F, DiStasio D, et al. Upper and lower arch changes after mixed palatal expansion protocol. Eur J Paediatr Dent. 2014;15(4):375-380.

[PubMed] Google Scholar Scopus

21. Grassia V, D'Apuzzo F, Ferrulli VE, et al. Dento-skeletal effects of mixed palatal expansion evaluated by postero-anterior cephalometric analysis. Eur J Paediatr Dent. 2014;15(1):59-62.

[PubMed] Google Scholar Scopus

22. Proffit WR, Turvey TA, Phillips C. Orthognathic surgery: a hierarchy of stability. Int J Adult Orthodon Orthognath Surg. 1996;11(3):191-204

[CrossRef] [PubMed] Google Scholar Scopus

23. Jeong $\mathrm{JH}$, Choi $\mathrm{SH}$, Kim KD, et al. Long-term stability of preorthodontic orthognathic bimaxillary surgery using intraoral vertical ramus osteotomy versus conventional surgery. J Oral Maxillofac Surg. 2018;76(8):1753-1762.

[Full text links] [CrossRef] [PubMed] Google Scholar Scopus

24. Choi SH, Cha JY, Park HS, Hwang CJ. Intraoral vertical ramus osteotomy results in good long-term mandibular stability in patients with mandibular prognathism and anterior open bite. $J$ Oral Maxillofac Surg. 2016;74(4):804-810.

[Full text links] [CrossRef] [PubMed] Google Scholar Scopus
25. Park KH, Sandor GK, Kim YD. Skeletal stability of surgeryfirst bimaxillary orthognathic surgery for skeletal class III malocclusion, using standardized criteria. Int J Oral Maxillofac Surg. 2016:45(1):35-40.

[Full text links] [CrossRef] [PubMed] Google Scholar Scopus 26. Aydemir H, Efendiyeva R, Karasu H, Toygar-Memikoğlu U. Evaluation of long-term soft tissue changes after bimaxillary orthognathic surgery in Class III patients. Angle Orthod. 2015;85(4):631-637.

[Full text links] [CrossRef] [PubMed] Google Scholar Scopus

27. Kim JY, Jung HD, Kim SY, et al. Postoperative stability for surgery-first approach using intraoral vertical ramus osteotomy: 12 month follow-up. Br J Oral Maxillofac Surg. 2014;52(6):539-544. [Full text links] [CrossRef] [PubMed] Google Scholar Scopus

28. Kim CS, Lee SC, Kyung HM, et al. Stability of mandibular setback surgery with and without presurgical orthodontics. J Oral Maxillofac Surg. 2014;72(4):779-787.

[Full text links] [CrossRef] [PubMed] Google Scholar Scopus

29. Ko EW, Lin SC, Chen YR, Huang CS. Skeletal and dental variables related to the stability of orthognathic surgery in skeletal Class III malocclusion with a surgery-first approach. J Oral Maxillofac Surg. 2013;71(5):e215-e223.

[Full text links] [CrossRef] [PubMed] Google Scholar Scopus 30. Abeltins A, Jakobsone G, Urtane I, Bigestans A. The stability of bilateral sagittal ramus osteotomy and vertical ramus osteotomy after bimaxillary correction of class III malocclusion. $J$ Craniomaxillofac Surg. 2011;39(8):583-587.

[Full text links] [CrossRef] [PubMed] Google Scholar $\underline{\text { Scopus }}$

31. lannetti G, Fadda MT, Marianetti TM, et al. Long-term skeletal stability after surgical correction in class III open-bite patients: A retrospective study on 40 patients treated with mono- or bimaxillary surgery. J Craniofac Surg. 2007;18(2):350-354.

[CrossRef] Google Scholar Scopus

32. Costa F, Robiony M, Zorzan E, et al. Stability of skeletal Class III malocclusion after combined maxillary and mandibular procedures: titanium versus resorbable plates and screws for maxillary fixation. J Oral Maxillofac Surg. 2006;64(4):642-651.

[Full text links] [CrossRef] [PubMed] Google Scholar Scopus

33. Kwon TG, Mori Y, Minami K, et al. Stability of simultaneous maxillary and mandibular osteotomy for treatment of class III malocclusion: An analysis of three-dimensional cephalograms. J Craniomaxillofac Surg. 2000;28(5):272-277.

[Full text links] [CrossRef] [PubMed] Google Scholar Scopus 34. McCance AM, Moss JP, James DR. Stability of surgical correction of patients with Skeletal III and Skeletal II anterior open bite, with increased maxillary mandibular planes angle. Eur J Orthod. 1992;14(3):198-206.

[Full text links] [CrossRef] [PubMed] Google Scholar Scopus

\section{Abdolreza JAMILIAN DDS, PhD, Professor Department of Orthodontics Faculty of Dentistry \\ Cranio-Maxillofacial Research Center Tehran Medical Sciences Islamic Azad University \\ Tehran, Iran

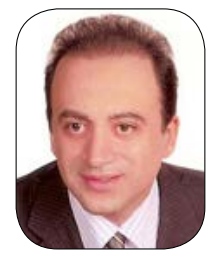

Professor Abdolreza Jamilian is a researcher and specialist in field of Orthodontics. He received his DDS (1991), MSc in Orthodontics (1998), and Fellowship of Orthognathic Surgery \& Craniofacial Syndroms (2010) from the Shahid Beheshti University in Tehran, Iran. He obtained his European Board of Orthodontics in 2013. Now he is a professor at the Islamic Azad University in Tehran. His practice is limited to Orthodontics. He has lectured in several international congresses and has been a consultant for various journals. He has published over 200 original, peer reviewed research and review articles, 15 book chapters and more than 300 scientific communications. He holds 3 patents with the United States Patent and Trademark Office. Research interests: (1) Class 3 malocclusion (2) Cleft lip and palate (3) Orthognathic surgery. 


\section{Ouestions}

\section{Which one is correct regarding stability after surgery.}

$\square$ a. Single jaw surgery has greater relapse than two jaw surgery;

$\square$ b. Two jaw surgery has greater relapse than single jaw surgery;

uc. There is a controversy regarding the stability of single and two jaw surgery;

ad. None of them.

\section{What are the causes of late relapse after orthognathic surgery?}

$\square$ a. Unstable occlusal relationships;

ab. Absence of myofunctional adaptation;

Dc. Persistent tongue or orofacial muscle habits;

口d. All of them.

\section{How much of the Class III malocclusions have true mandibular prognathism?}

口a. $5 \%$ to $10 \%$;

b. $20 \%$ to $25 \%$;

ac. $30 \%$ to $50 \%$;

ad. $50 \%$ to $70 \%$.

\section{How much of the of all class III malocclusions have some degree of maxillary retrusion?}
口a. $15 \%$;
口b. $25 \%$;
ac. $50 \%$;
ad. $75 \%$.

\section{1 ${ }^{\text {ST }}$ SIDO INTERNATIONAL CONGRESS}

( 10

ana di Ortodonzia

Accademia Italiana

$17^{\text {th }}$ AIDOR CONGRESS

November $12^{\text {th }}-13^{\text {th }}-14^{\text {th }}, 2020$

Firenze, Fortezza da Basso

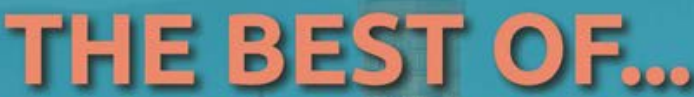

3D-DIGITAL TECHNOLOGY

SKELETAL ANCHORAGE

MANAGEMENT OF THE ESTHETIC ZONE

\section{DIGITAL PLAZA}

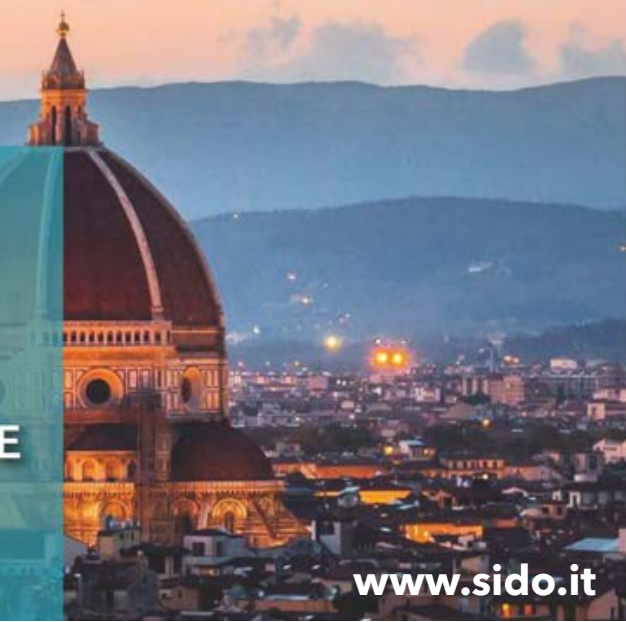



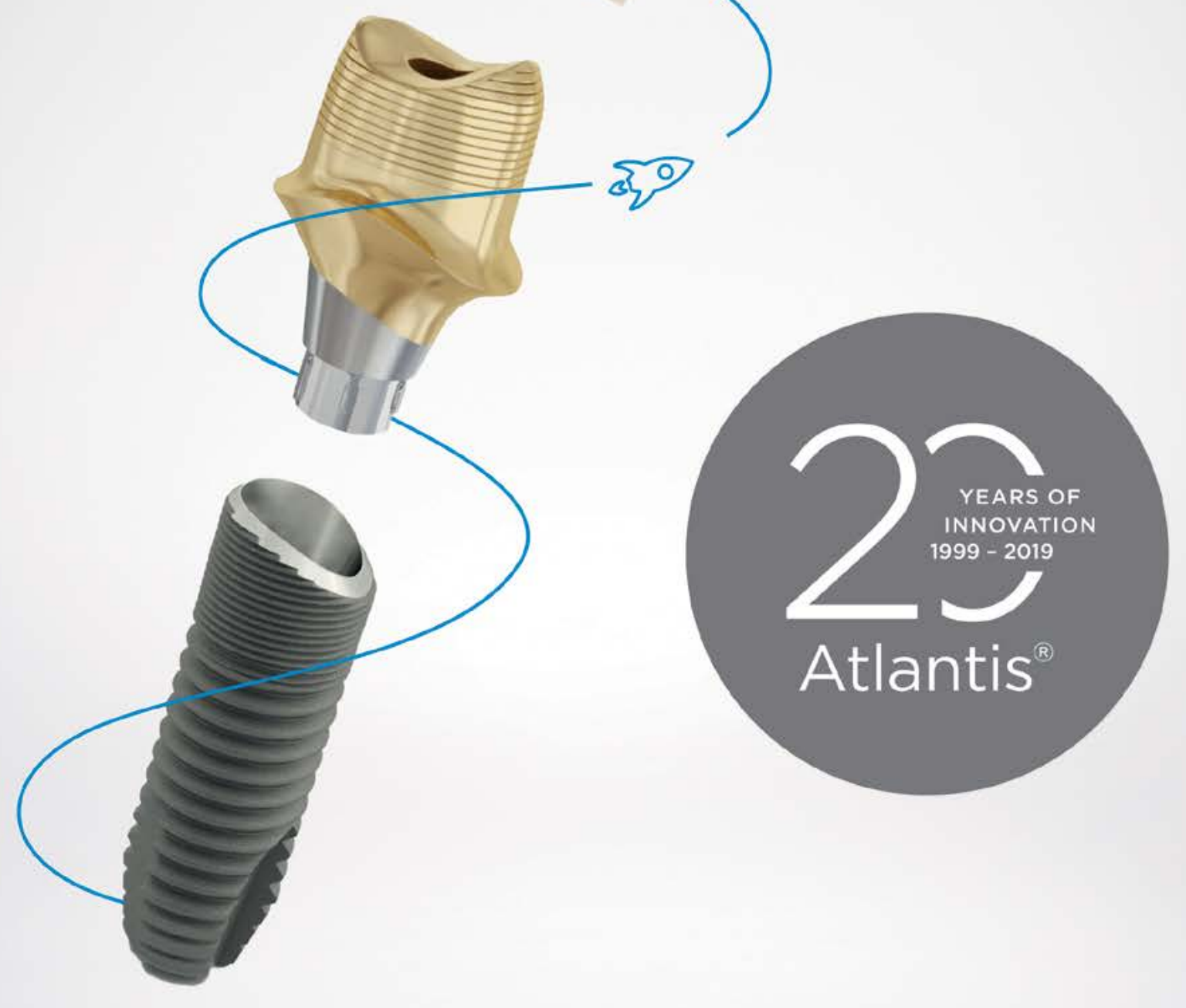

\section{Demand for dental implants is rising - are you ready?}

Changing eating habits, increasing life expectancy and the desire for a "perfect" smile, are causing the number of dental implant treatments to surge. By 2025 , the global dental implants market is expected to be $\$ 6.5 \mathrm{bn}$ *. Is your dental laboratory positioned to take advantage of the increasing demand? Outsourcing parts of your production could be the key to optimizing your dental laboratory business. 


\section{The gold standard for detecting buried dental implants - RomiPointer $^{\mathrm{TM}}$ Implant Detector of Romidan Ltd., Israel}

As I am a fan of complex oral rehabilitations, during the IDS dental exhibition in Cologne, I tried to identify the latest tools that help oral implantology. Thus, we came across some Israeli exhibitors who displayed a device for detecting implants buried beneath the gingival tissues in two-stage implantology. These dental implant detectors are manufactured by four companies, DSI Dental Solutions Israel Ltd., Edison Medical LTD., Forum Engineering Technologies (96) Ltd., and Romidan Ltd.

Later on, consulting the literature we noticed that the device for detecting dental implants is also manufactured in Belgium, Italy, Germany, UK, Turkey, Korea or USA.

The device detecting dental implants is a precise instrument that uses advanced technology, with an ergonomic design, easy to use and accessible, offering a non-invasive alternative to the exploratory mucoperiosteal flaps and retroalveolar radiographs, useful to qualified dental staff, implantologists and general practitioners working with dental implants. The dental implant detector acts as a vibration generator, the LC electronic Colpitts type of feedback system that uses the metal resonant circuit to verify the location of the implants.

To better understand the device detecting buried implants, I have chosen to present the RomiPointer ${ }^{\mathrm{TM}}$ Implant Detector of Romidan Ltd. The RomiPointer ${ }^{\mathrm{TM}}$ Implant Detector is not recommended for the use of patients or personnel who have a pacemaker or other implanted electrical devices.

When using the RomiPointer ${ }^{\mathrm{TM}}$ Implant Detector, the manufacturer recommends that we take some precautions: - the device is not to be used near devices emitting electromagnetic noise, such as fluorescent lamps, film viewers, ultrasound devices, etc., so these devices must be switched off.

- the device is to be protected against the occasional spillage of liquids.

- the device is not to be used in the presence of flammable anesthetic materials, mixtures with air, oxygen or nitrous oxide.

- the device should only be used with its original accessories.

- a new or sterilized sensor is to be used for each patient so as to prevent transmission of the infectious agent.

- avoid the presence of metal objects in the vicinity of the sensor during the operation of the device in order not to distort the location.

The standard package includes:

- RomiPointer ${ }^{\mathrm{TM}}$ Implant Detector - 1 pc.

- AA alkaline battery - 1 pc.

- Sensor holder - 2 pc.

- Sensor- 5 pc.

- User Manual - 1 pc.

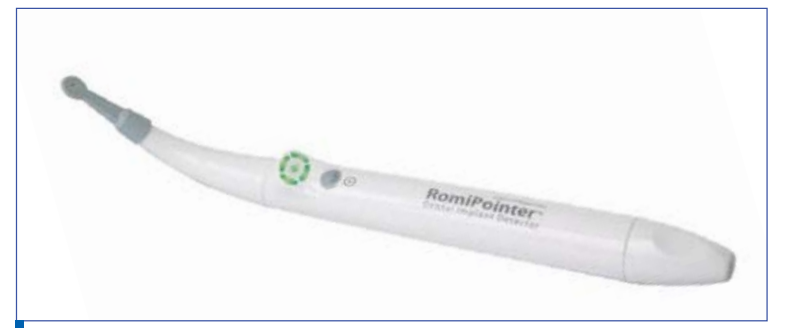

The device RomiPointer ${ }^{T M}$ Implant Detector.

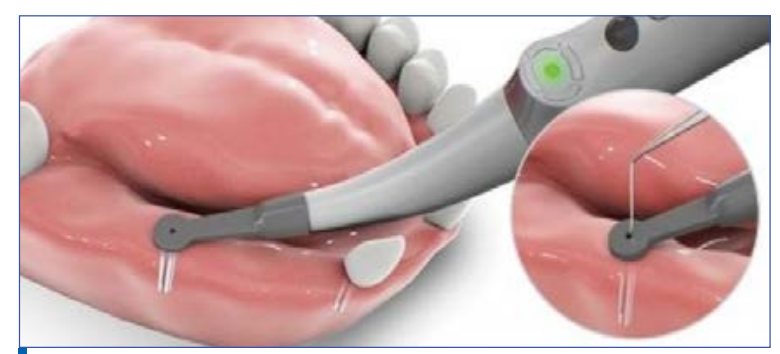

Detection of implant location.

The use of the RomiPointer ${ }^{\mathrm{TM}}$ Implant Detector is accessible and precise. When the sensor approaches the implant, four segments turn green constantly. Continue moving the sensor in the same direction, until the segments become orange, which indicates that the implant is out of position. The sensor turns back along the same path until the four green segments reappear. When the sensor returns to the implant position, the four segments go off and the center point turns green indicating the precise location of the implant, which is also accompanied by an audio signal. There follows the marking of the implant location with the help of the dental probe.

As a user of the RomiPointer ${ }^{\mathrm{TM}}$ Implant Detector device, allow me to recommend it to you and mention its main benefits:

- accurate and reliable detection of the dental implant center;

- saving time and money;

- does not require any suture after the implant is exposed; - reducing the dose of injection anesthesia;

- eliminates the need for gingival incision;

- significantly reduces the duration of the treatment time; - considerably less complications after treatment;

- obtaining accurate results with different systems of dental implants.

Romidan Ltd.

5 Simcha Holzberg St.

5502213 Kiryat Ono, Israel

Email: export@romidan.com

www.romidan.com 


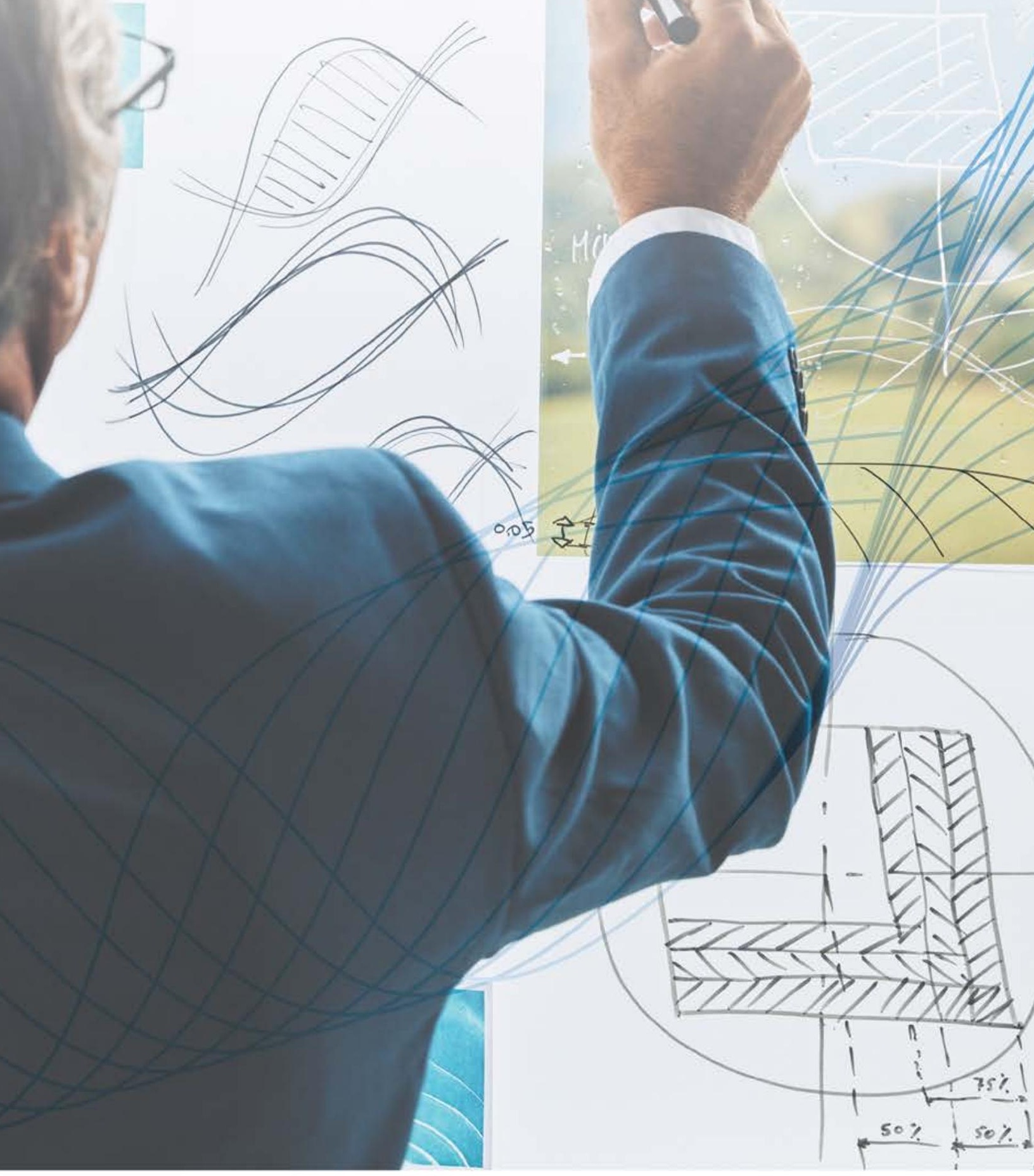

TruNatomy ${ }^{\text {TM }}$

Redefining our design process 


\section{Treating \\ the Complete \\ Denture Patient}

Editors: Carl F. Driscoll, William Glen Golden

Publisher:Wiley-Blackwell, Hoboken, NJ, USA

Language: English

ISBN: 978-1-119-56958-9

Edition: 1/e

Publish Year: 2020

Pages: 312, illustrated

Price: $€ 147.00$

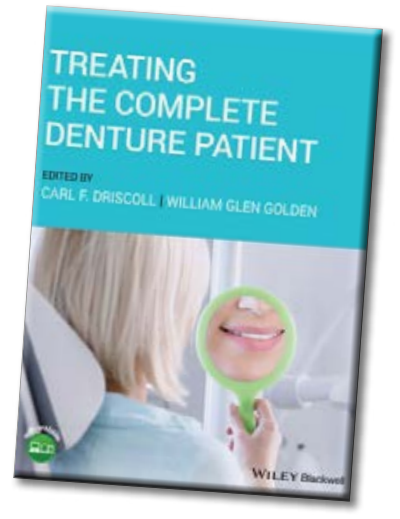

Marian-Vladimir

Constantinescu

$\mathrm{DDS}, \mathrm{MSc}, \mathrm{PhD}$

Holistic Dental \& Medical Institute

of Bucharest-ROPOSTURO

Bucharest, Romania

e-mail:

dr.vladimir.constantinescu@gmail.com

Even though the prevalence of edentulism is declining globally, the growth of the elderly population will be fueling the demand for complete prostheses for the coming decades. This tendency has led a number of authors to address the problem of treating toothless patients with the help of complete dentures.

Dr. William Glen Golden, DDS, initially a dental technician in the US Navy, along with well-known clinicians and professors Carl F. Driscoll, DMD, of the University of Maryland, Baltimore, MD, and Nadim Z. Baba, DDS, of Loma Linda University, Loma Linda, CA undertook to present their experience in the field of dental prosthetics in the book entitled Treating the Complete Denture Patient.

The book is divided into forty chapters and is accompanied by a list of captions, an index and a video material. It presents all the stages of achieving a complete denture in dental practice, descriptive material, techniques and methods used in current practice.

It explains all clinical and laboratory stages of complete dentures procedures. Emphasis is placed on the important clinical examination to identify anatomical landmarks in the maxillary and mandibular arch. From the initial appointment, preliminary and final impressions, centric relation records, mounting casts on an articulator, selecting and setting denture teeth, and processing complete dentures gets to explain how to repair a broken complete denture, how to use implants to stabilize a complete denture, immediate complete dentures, tissue conditioners and the fabrication of digital complete dentures.

This book clearly presents each clinical and laboratory steps in achieving complete dentures.

Each chapter is richly illustrated, more than 800 photographs illustrate the text, including access to a companion website offering video clips. It is a fundamental source for dental students, general practitioners and laboratory technicians, offering a practical approach to fabricating and fitting patients for complete dentures.

DOI: http://www.stomaeduj.com 10.25241/stomaeduj.2020.7(1).bookreview.1

The Books Review is drafted in the reviewer's sole wording and illustrates his opinions. 
Florin-Eugen

\section{Constantinescu}

DMD, PhD Student

Holistic Dental \& Medical Institute

of Bucharest-ROPOSTURO

Bucharest, Romania

e-mail:

dr.florin.constantinescu@gmail.com
Digital Restorative Dentistry

A Guide to Materials, Equipment, and Clinical Procedures

Digital Restorative

Editors: Faleh Tamimi, Hiroshi Hirayama

Publisher: Springer Nature, Switzerland

Language: English

ISBN: 978-3-030-15974-0

Edition: 1/e

Publish Year: 2019

Pages: 247, illustrated

Price: 106,99
Dentistry

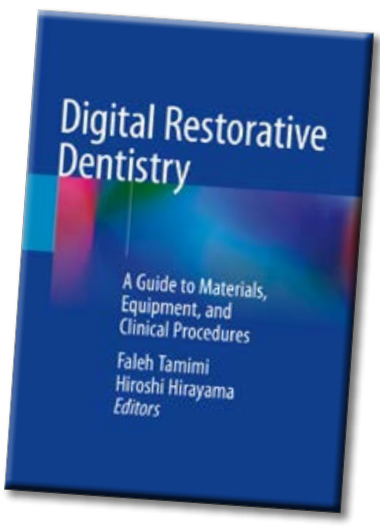

The industrial revolution introduced the daily dental technologies in the digital practice as well as the corresponding restoration materials.

Faleh Tamimi and Hiroshi Hirayama, editors of the Digital Restorative Dentistry aim to present it as a guide on this topic regarding the materials, equipment and clinical procedures used in restorative dentistry.

The book is divided into two parts, along eleven chapters.

After a first introductory chapter, the three chapters of the first part, Equipment, cover digitalization (dental photography, digital radiology, digital spectrophotometers, extra- and intra- oral scanners, digital stereophotogrammetry, jaw motion tracking, facial scanning, cone beam computerize tomography), computer-aid design (2D photography, 3D design, virtual tools and CAD software) and fabrication of digital dental restoration. The fabrication of dental restoration using digital technologies allows us to become acquainted with the techniques and materials necessary to perform the restorations, by means of subtractive or additive techniques. In turn, the seven chapters of the second part, Clinical procedures, describe a series of clinical procedures which use the digital technology: partially denture, complete denture, fixed restoration, CAD/CAM, digital implant surgery, digital implant prosthodontics, digital technologies in endodontics.

Each of these chapters contains an introductory part, and also the advantages and limitations of using digital processes.

All the chapters are accompanied by a rich iconography and up-to-date references.

The editors manage to fill a gap in the literature, presenting the latest digital restorative dentistry related attainments and technologies covering the dental technological revolution, for both dental practitioners and dental students.

DOI: http://www.stomaeduj.com 10.25241/stomaeduj.2020.7(1).bookreview.2

The Books Review is drafted in the reviewer's sole wording and illustrates his opinions. 


\section{Clinical Cases in Pediatric Dentistry}

Editor: Amr M. Moursi

Associate Editor: Amy L. Truesdale

Publisher:Wiley-Blackwell, Hoboken, NJ, USA

Language: English

ISBN: 978-1-119-29091-9

Edition: 2/e

Publish Year: 2020

Pages: 424, illustrated

Price: $€ 76.99$

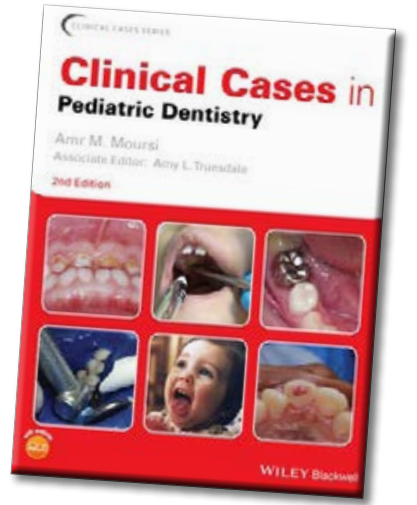

Iulia Ciolachi

DMD

Holistic Dental \& Medical Institute

of Bucharest-ROPOSTURO

Bucharest, Romania

e-mail:

driuliaciolachi@yahoo.ro

Clinical Cases in Pediatric Dentistry, $\mathbf{2}^{\text {nd }}$ Edition is aimed at pediatric dentists to help them have a holistic approach on treating infants. This book is also a source for dental teachers to expand their collection of clinical cases. The book is divided in nine chapters, accompanied by an index and a companion website.

The cases share the same structure, including medical and dental history, examination, assessment tools in infant oral cases, diagnosis, diagnostic tools, comprehensive treatment plan, prognosis, discussion, common complication and alternative treatment plans. Each case is accompanied by self-assessment questions with detailed answers and explanations.

Chapter 1, Early Childhood Oral Health, covers six cases and talks about: perinatal oral pathology, first dental visit, early childhood caries managed with silver diamine fluoride and interim therapeutic restorations and caries managed with general anesthesia.

Chapter 2, Restorative Dentistry, illustrates, in eight clinical cases, different classes of restorations either with glass ionomer or resin and strip crowns and zirconia crowns.

Chapter 3, Complex Pulp Therapy, approaches the complexed therapy in temporary and young permanent teeth through nine clinical cases.

Chapter 4, Orofacial Trauma, presents eight cases which exemplify the main dental trauma and how to treat it.

Chapter 5, Oral Medicine and Orofacial Pathology, illustrates seven different forms of oral pathology.

Chapter 6, Behavior Guidance and Medical Emergencies, presents seven cases which cover nonpharmacological and pharmacological behavior guidance, intraoperative pain management, nitrous oxide/oxygen sedation, airway management, allergic reactions and general anesthesia.

Chapter 7, Growth and Development, discusses, in seven cases, management of practical procedures.

Chapter 8, Medically Compromised Patients, presents the therapeutic approach for patients with general disorders such as congenital heart disease, cystic fibrosis, hemophilia A, acute lymphoblastic leukemia, liver transplant, type 1 diabetes, asthma, and Crohn's disease.

The last chapter, chapter 9, Patients with Disabilities, covers nine cases which explain the approach in Down syndrome, cerebral palsy, bronchopulmonary dysplasia, attention deficit hyperactivity disorder, seizure disorder, intellectual disability, autism spectrum disorder, sickle cell anemia, and intellectual disability.

This book is an essential working tool for dental students, postgraduate residents, and pediatric dentists preparing for board examinations and recertification. With a total of 66 cases, using a clear, concise, and consistent format, the book presents real-world cases that encompass all the important areas of pediatric dentistry.

DOI: http://www.stomaeduj.com 10.25241/stomaeduj.2020.7(1).bookreview.3

The Books Review is drafted in the reviewer's sole wording and illustrates his opinions. 
Alexandra Popa

Holistic Dental \& Medical Institute of Bucharest-ROPOSTURO, Bucharest, Romania

e-mail:

alesandra17popa@gmail.com

\section{Dental Digital Photography From Dental Clinical Photography to Digital Smile Design}

Editors: Feng Liu

Publisher: Springer Nature Singapore

Language: English

ISBN: 978-981-13-1622-7

Edition: $1 / \mathrm{e}$

Publish Year: 2019

Pages: 318, illustrated

Price: $160,49 €$

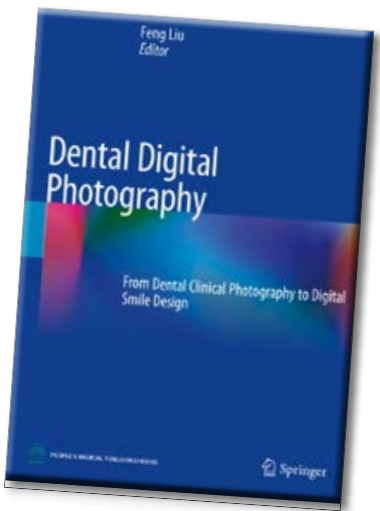

Medical photography in clinical practice has been widely used in oral medicine in recent years. Using clinical photography, a dentist can record a patient's case with greater medical accuracy and schedule appropriate treatment.

This revised third edition of Dental Digital Photography covers 9 topics.

The book begins with the presentation of The History and Significance of Dental Photography and explains the importance of photos in patient education, preserving the images for medical records, the doctor-patient, doctor-technician and doctor-doctor communications, doctor-technician and doctor-doctor as well as the legal basis. The next part tackles the Basic Concepts and Knowledge of the Photography. Prior to learning oral clinical photography, it is necessary for learners to understand the basic concepts and knowledge of photography. So, there are exhaustive explanations of notions such as photoelectric sensor, pixel and resolution, exposure, aperture, shutter speed, exposure control, ISO, depth of field, layout and white balance. The next topic addressed is Devices and Equipment of the Dental Photography. This part helps us to choose the appropriate equipment and devices to achieve ideal dental photography. Then the Basic Procedures of Dental Clinical Photography are presented. This part describes the dental photography protocol such as clinical image specification recommended, position and holding, placing retractors, composition and focus.

Basic Images of Dental Clinical Photography Considering is the next chapter. It summarizes 74 images usually used in clinical work. The shooting methods and applications of all these images are introduced in detail in this chapter, which describing both photographs taken with the camera and photos taken with the microscope. The next chapter, Standards for Common Aesthetic Oral Clinical Photography introduces the three main standards required by the: American Academy of Cosmetic Dentistry (AACD), European Society of Cosmetic Dentistry (ESCD) and Chinese Society of Aesthetic Dentistry (CSED). Clinical Still Life and Operation Photography is the following chapter. Besides clinical photographs there are also many other photos necessary in a clinic, such as photographs of clinical objects and photographs of clinical operations. Some examples are photographs of impressions, models and prostheses. Image Adjustment and Application is the next part. The chapter focuses on how to adjust images by some simple application of Photoshop, and the procedure of introducing acquired clinical images into the Digital Smile Design (DSD) process. The last part, Aesthetic Treatment Based on Clinical Image presents the basic protocol to establish aesthetic goals and it is explained by presenting many clinical cases.

The third edition of Dental Digital Photography is more comprehensiveand systematic providing a greater sense of knowledge. It will contribute to a clearer understanding of the scientific oral clinical photography concepts and methods, thus becoming for each dentist a working tool in the daily application of digital photography.

DOI: http://www.stomaeduj.com 10.25241/stomaeduj.2020.7(1).bookreview.4

The Books Review is drafted in the reviewer's sole wording and illustrates his opinions. 


\section{Practical Procedures in the Management of Tooth Wear}

Authors: Subir Banerji, Shamir B. Mehta,

Niek Opdam, Bas Loomans

Publisher:Wiley-Blackwell, Hoboken, NJ, USA

Language: English

ISBN: 978-1-119-38986-6

Edition: 1/e

Publish Year: 2020

Pages: 248, illustreted

Price: $€ 89.99$

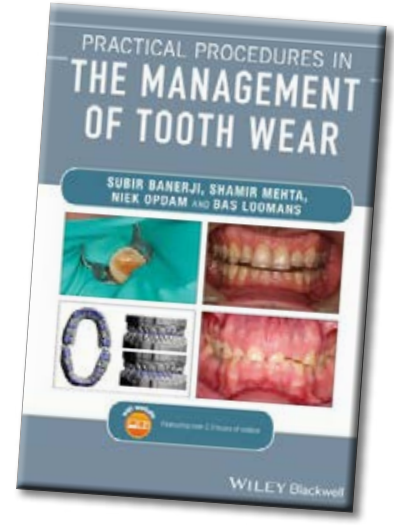

Marian-Vladimi

Constantinescu

DDS, MSc, PhD

Holistic Dental \& Medical Institute

of Bucharest-ROPOSTURO

Bucharest, Romania

e-mail:

dr.vladimir.constantinescu@gmail.com

Currently, in his daily practice, a dentist comes across more and more patients who have tooth wear due to the excessive consumption of carbonated drinks, bruxism and gastric regurgitation. Practical Procedures in the Management of Tooth Wear is a book drafted by a team of international clinical experts which describes a comprehensive number of examples of all practical procedures that address all cases of tooth wear from minimally invasive to invasive methods for treatment. The topics include patient assessment and diagnosis, treatment planning from localized to generalized tooth wear, monitoring, management, and maintenance of tooth wear.

The book has 14 chapters, an index and a companion website access of high-quality instructional videos. The first four chapters address the prevalence, the aetiology and presentation of tooth wear and the clinical assessment and diagnosis of the wear patient, including the use of common clinical indices.

Starting from the occlusion analysis in relation to tooth wear, the book establishes prevention strategies, the role of occlusal splints for patients with tooth wear and treatment planning as well as the application of diagnostic techniques.

The following chapters discuss concepts covering the restoration of worn dentition and present an overview of dental materials selection for the management of tooth wear.

The next three chapters tackle the principles and clinical management of localized anterior and posterior tooth wear, and generalized tooth wear.

The last chapter approaches the prognosis of the restored worn dentition: contingency planning, the importance of maintenance, and recall.

Practical Procedures in the Management of Tooth Wear is a clearly written book, very well illustrated, providing readers with a clinical guide to address dental tooth wear. It is a unique source of information for general dental practitioners, senior undergraduate dental students, and postgraduates which aim to treat this category of patients to high-quality standards.

DOI: http://www.stomaeduj.com 10.25241/stomaeduj.2020.7(1).bookreview.5

The Books Review is drafted in the reviewer's sole wording and illustrates his opinions. 
Florin-Eugen

\section{Constantinescu}

DMD, PhD Student

Holistic Dental \& Medical Institute

of Bucharest-ROPOSTURO

Bucharest, Romania

e-mail:

dr.florin.constantinescu@gmail.com

\section{Implants in the Aesthetic Zone}

A Guide for Treatment of the Partially

\section{Edentulous Patient}

Editors: Todd R. Schoenbaum

Publisher: Springer Nature, Switzerland

Language: English

ISBN: 978-3-319-72601-4

Edition: $1 / \mathrm{e}$

Publish Year: 2019

Pages: 334, illustrated

Price: $117,69 €$

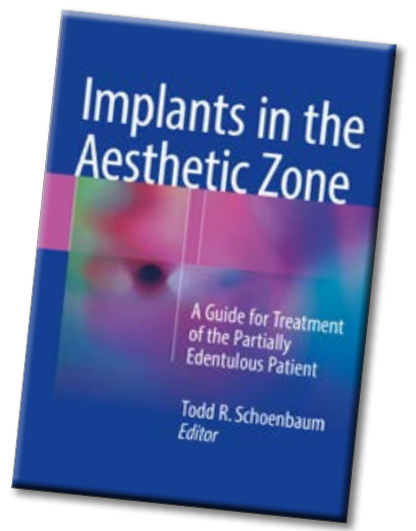

As science evolves, so too, the demands of patients are booming. Aesthetics and implant treatment are increasingly popular treatment options for patients and this book aims to present the protocols for implant treatment in the aesthetic zone.

The book entitled Digital Restorative Dentistry: A Guide for Treatment of the Partially Edentulous Patient is divided into 4 parts with 16 chapters.

The first part: Treatment Planning for Implants in the Aesthetic Zone along the two chapters, presents the proper interdisciplinary treatment planning and radiographic assessment. It shows what must be taken into account: the patient's medical conditions, dental and psychological assessment, functional and biological concerns. The second part: Site Preparation: Hard and Soft Tissue Augmentation has four chapters. It provides relevant information on indications for augmentation prior to / at implant placement, guided bone regeneration (GBR), soft tissue management and growth factors for site preparation.

The third part: Immediate Implant Placement and Immediate Provisional Restoration covers three chapters. Throughout these chapters, the reader receives information about advanced grafting techniques for implant placement in compromised sites, aesthetic risk assessment in compromised sites, management of horizontal and vertical defects, the implant-supported screw-retained provisional prosthesis: science, manufacturing and design, papilla management and development using provisional prosthesis.

The last part: Design, Fabrication and Delivery of the Definitive Implant Prosthesis has seven chapters. It tackles implant impression techniques to maximize accuracy, emergence profile of the implant abutment and its effects on the peri-implant tissues, cemented implant restorations in the aesthetic zone: biological, functional, and aesthetic considerations, screw-retained implant restorations in the aesthetic zone, delivery of the definitive abutment/ prosthesis: biologics, aesthetics and mechanical considerations, occlusal considerations and implant-abutment design to maximize the peri-implant tissue potential.

The purpose of this book is to make us aware of the importance of the interdisciplinary approach. Surgeons, restorative clinicians, and dental technicians must have a well-established protocol, adapted to the types of cases. This book supports those who want to improve their treatment technique by providing step by step protocols and many clinical cases. 


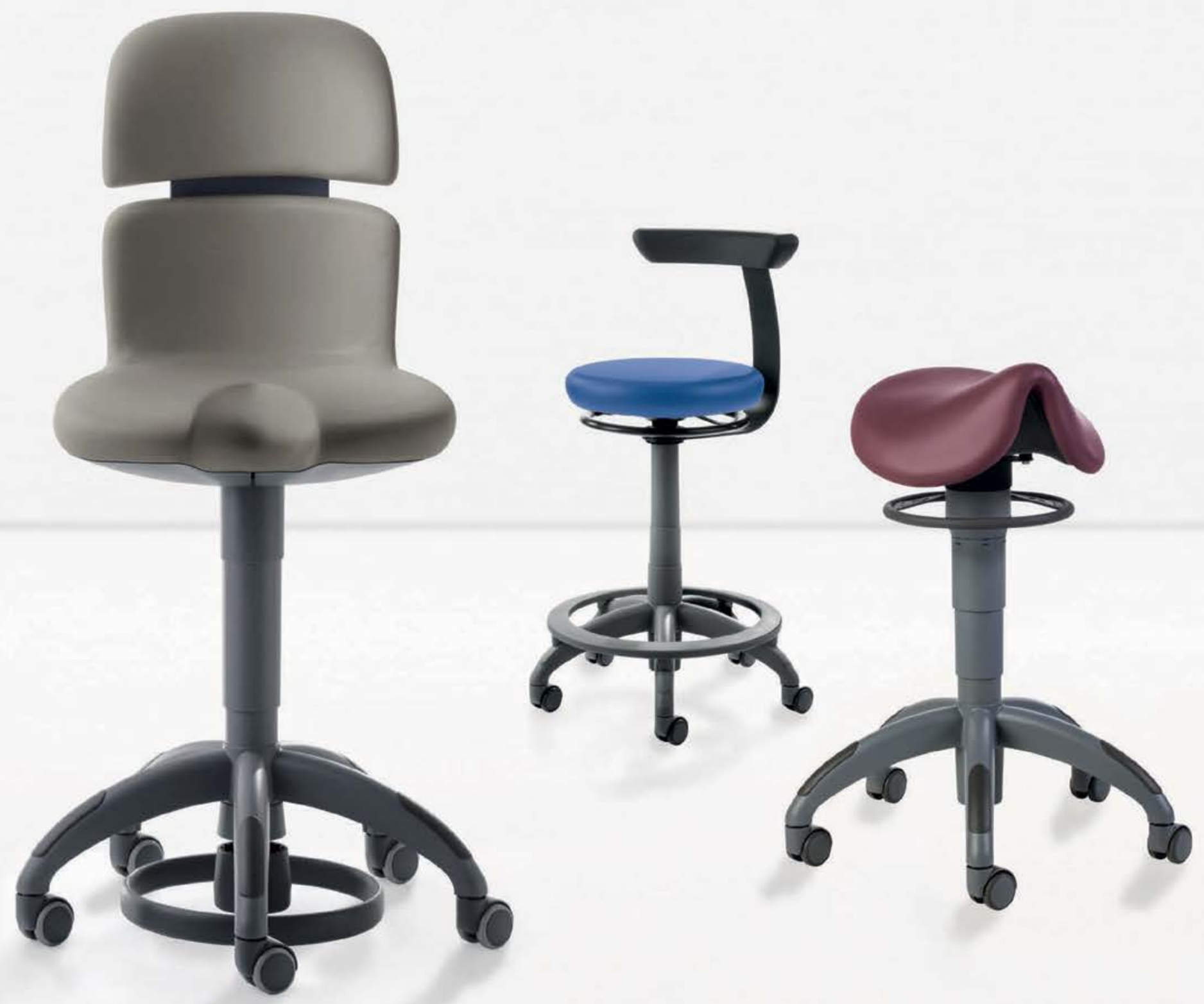

Hugo, Carl, Theo by Dentply Sirona Working Stools

It's all about keeping the balance 
The Stomatology Edu Journal (Stoma Edu J) is a quarterly international journal, double blind peer-reviewed, open access journal to be database indexed, which accepts original articles for publication in all aspects of dental development and research. It addresses those interested in oral and maxillofacia sciences including students, graduates, postgraduates, educators, researchers, dental practitioners, those involved in dental industry and policy-makers relevant to the practice of dentistry.

\section{Submission Instructions}

The Stomatology Edu Journal (Stoma Edu J) publishes articles written only in English. All articles will be accompanied by the signed copyright form which can be returned by e-mail, fax (as scanned documents). All the responsibility for the originality of the material sent belongs to the author(s) alone. Each article will be evaluated by the peer-review committee composed of two independent peer-reviewers, in a blinded fashion, according to the peer-review protocol. All manuscripts must be original and exclusive. The Stomatology Edu Journal Editor will consider only articles that are original, have not been published elsewhere and have been submitted exclusively to the Stomatology Edu Journal. The manuscripts should be submitted online at www. ManuscriptManager.net/stom

\section{Ethics in publishing}

The Stomatology Edu Journal (Stoma Edu J) and its editoria board fully adhere and comply to the policies and principles of Committee on Publication Ethics (COPE) (https:// publicationethics.org/files/2008 Code of Conduct.pdf). Your manuscript should not contain any information that has already been published. If you include already published figures or images, please obtain the necessary permission from the copyright holder to publish under the CC-BY license. Plagiarism, data fabrication and image manipulation are not tolerated. Plagiarism is not acceptable in the Stomatology Edu Journal (Stoma Edu J) submissions. Plagiarism includes copying text, ideas, images, or data from another source, even from your own publications, without giving any credit to the origina source. Reuse of text that is copied from another source must be between quotes and the original source must be cited. If a study's design or the manuscript's structure or language has been inspired by previous works, these works must be explicitly cited.

If plagiarism is detected during the peer review process, the manuscript may be rejected. If plagiarism is detected after publication, we may publish a correction or retract the paper. Image files must not be manipulated or adjusted in any way that could lead to misinterpretation of the information provided by the original image. To verify the originality of content submitted to our journals, we use iThenticate (www.ithenticate com) to check submissions against previous publications All submitted manuscripts will be checked for any possible duplication or plagiarism with iThenticate (www.ithenticate com). Nevertheless, corresponding authors are responsible for any fraud, intentional or unintentional malpractice.

\section{Articles sent for publishing}

The Stomatology Edu Journal (Stoma Edu J) publishes: origina articles; reviews; case reports; technical procedures; consensus declaration coming from an association or from a group of specialists; letters to the editor. All articles must be up to 3,000 and 5,000 words for meta- analysis (the word count is for the manuscript text only). Letters to the editor must not exceed 400 words of text and have no more than 3 authors. Letters to the editor can be related to an article already published in the journal or it can represent original scientific contributions or events news/presentations etc. of interest for the reader.

\section{Permissions and Ethics}

For citations, tables, figures etc. which are not original, these must be accompanied by the written permission for their use and the full reference must be provided. Photographs of identifiable persons must be sent alongside the written permission of the person(s) and all regions that may allow the identification of the subject must be covered. The author must have obtained, for all studies including human subjects, the permission of the subjects to be part of the study whilst keeping their anonymity. By sending the article, the author declares that he obtained this permission from all his subjects. All studies must respect the Helsinki Declaration (1975). For human and animal studies, the authors must have obtained the approval of the ethics committee from the University/Institute/etc. where the study was done. Consent for publication is required for studies involving human subjects - ALL case reports, letters that describe cases and some original articles. Cohort studies are exempt; instead evidence of IRB approval (name of IRB, date of approval and approval code/reference number) must be provided.

\section{Manuscript preparation}

The article must be written in conformity with the general recommendations of the International Committee of Medical Journal Editors. http://www.icmje.org/icmjerecommendations.pdf

The Stomatology Edu Journal (Stoma Edu J) uses double-blind review, which means that both the reviewer and author name(s) are not allowed to be revealed to one another for a manuscript under review. The identities of the authors are concealed from the reviewers, and vice versa. To facilitate this, please include the following separately:

Title page (with author details): This should include the title, authors' names and affiliations, and a complete address for the corresponding author including an e-mail address, Author Contributions, Acknowledgements and Curriculum Vitae.

Blinded manuscript (no author details): The main body of the paper (including the references, figures, and tables) should not include any identifying information, such as the authors' names or affiliations.

The articles must be sent either as a Microsoft Word 2000 document $\left({ }^{*}\right.$.doc) or as a Microsoft Word 2003 document (*.docx). The article will be written using Times New Roman font, size 12 for the characters with one and half (1 1/2) spaces between paragraphs. The manuscript must be sent in its final form. The pages will be numbered with the manuscript containing the following sections: title, authors, abstract, keywords, the text of article, contributions, acknowledgments, references, the figures and the tables legend.

A. The title of the manuscript will have a maximum of 100 characters without spaces, written in title case, centered capitals, and in 12 point bold Times New Roman font at the top of page. Abbreviations should be avoided within the title.

B. The author(s) will send their full name(s) and surname(s) the highest academic position, their full titles and their affiliations. All names are listed together and separated by commas. Provide exact and correct author names as these will be indexed in official archives. Affiliations should be keyed to the author's name with superscript numbers and be listed as follows: Laboratory, Department, Institute, Organization, City, State abbreviation (USA, Canada, Australia), and Country (without detailed address information such as city zip codes or street names)

The correspondent author will send his/her full name and surname, the highest academic position, his/her full title, his/ her affiliation, his/her institution address, his/ her telephone, fax and e-mail. The authors will send this information in the same format as that in the published articles.

\section{The Structured Abstract}

The abstract can have a maximum of 250 words. After the abstract, the author(s) must mention a maximum of 5 keywords Keywords must be selected from Medline Mesh. Abbreviations are not accepted in the title or the abstract.

The abstract for Original Scientific Articles should be no more than 250 words using the following structure: Introduction; Methodology; Results; Conclusion.

The abstract for Review Articles should be no more than 250 words with the authors covering all the following information regarding the subject presented under the following subheadings: Background, Objective, Data Sources, Study Selection, Data Extraction, Data Synthesis.

The abstract for Case Reports should be no more than 250 words using the following structure: Aim, Summary and Key learning points: provide up to 5 short statements of the report. The abstract for Clinical Articles should be no more than 250 words using the following structure: Aim, Methodology, Results and Conclusions. 


\section{The Article Text}

Headings and Sub-headings

Except for special names (e.g. GABAergic), capitalize only the first letter of headings and subheadings. Headings and subheadings need to be defined in Times New Roman, 12, bold. You may insert up to 5 heading levels into your manuscript (not more than for example: 3.2.2.1.2 Heading title).

For original articles:

1. Introduction - a presentation of the most important aspects in the studied domain without doing a review of the literature. The purpose of this part is to present and backup the hypothesis on which the study was based.

2. Material and Methods - this section will include all required information so that the reader can verify the validity of the study including, but not limited to, subjects, measurements, statistics and ethics. The methods used should be discussed (why the methods have been chosen, which the limitations/ advantages). A paragraph about the statistical analysis is required as well.

3. Results - the results of the study will be presented in a descending order of importance. An interpretation of the results will not be done in this section.

4. Discussion - the authors will present the way the results backup the original hypothesis, as well as the way in which the results are backed up or contradicted by the published literature. A paragraph must be dedicated to presenting the limitations of the study.

5. Conclusion - The conclusion presents the implications of this latest work. In addition, authors may consider discussing future plans or recommendations for future research etc. For all other types of articles, we recommend the use of a clear structure based on sections and sub-sections.

\section{E. Author Contributions}

The Author Contributions section is mandatory for all articles, including articles by sole authors. The Author Contributions statement must describe the contributions of individual authors and, in doing so, all authors agree to be accountable for the content of the work. Please list only 2 initials for each author, without periods, but separated by commas (e.g. AC, AS). In the case of two authors with the same initials, please use their middle initial to differentiate between them (e.g. AEC, ASC). Each author must be able to prove his active participation in the study by contributing to the concept, protocol, data gathering or analysis, their interpretation or by critically revising the manuscript.

\section{F. Acknowledgments}

Acknowledge persons who have made substantive contributions to the study. Specify grant or other financial support, citing the name of the supporting organization and grant number.

\section{G. References}

- The references will be written using the Vancouver style (https://www.imperial.ac.uk/media/imperial-college/ administration-and-support-services/library/public/vancouver. pdf). All references that are identified with DOI (Digital Object Identifier) must be mentioned.

- For each reference use active links to the full text (DOI link), free PMC article, PubMed, Google Scholar, and Scopus pages, were they exist:

- For all references identified with DOI the full-text link must be the CrossRef hyperlink

\section{Examples}

\section{Articles with DOI}

Singbartl G. Pre-operative autologous blood donation: clinical parameters and efficacy. Blood Transfus. 2011;9(1):10-18.

[CrossRef] [Free PMC Article] [PubMed] Google Scholar Scopus Articles without DOI

Mehta H, Shah S. Management of Buccal Gap and Resorption of Buccal Plate in Immediate Implant Placement: A Clinical Case Report. J Int Oral Health. 2015;7(Suppl 1):72-75.

\section{[Full text links] [PubMed] Google Scholar}

- The references will be numbered, in the order they appear in the text, in square brackets, as such: [3], [5,7-9].

- All sources found in the text must be present in the bibliography and all the papers mentioned in the bibliography must appear in the text.

- For references with more than 5 authors, list the first 3 authors followed by "et al."
- Full-page ranges should be given in expanded form (e.g., 426 429, not 426-9).

- If non-English-language titles are translated into English, bracketed indication of the original language should follow the title.

- All journals will be abbreviated and italicized names of journals according to the style in PubMed; refer to the National Library of Medicine (NLM) Journals Database (http://www.ncbi.nlm. nih.gov/nlmcatalog/journals) if needed. Journal names will be abbreviated according to the List of Title Word Abbreviations - Information obtained from sources which are not published yet, but accepted for publishing will include at the end of the reference the mention "in print" between round parentheses.

- If the cited results have not been published yet the mention will be "personal communication" written in the text of article between round parentheses.

- Only references read by the authors of the article will be cited.

- An original article will have at most 50 references, a review will have at most 100 references, a letter to the editor 5 references, whilst all other types of articles will have the minimum number of references required.

\section{Curriculum Vitae - Ultra Short version}

Please provide a brief presentation of the first author and his contribution in the field, of maximum 130 words (with a $3.5 \times 4.5$ cm color photo)

\section{Figures, Images, Tables}

All illustrations must be numbered and cited in the text in order of appearance.

Figures and Images will be drawn professionally and sent in separate file(s) as jpeg, tiff or png files. Illustrations should preferably fill single column width $(54 \mathrm{~mm})$ after reduction, although in some cases $113 \mathrm{~mm}$ (double column) and $171 \mathrm{~mm}$ (full page) widths will be accepted. See the Image quality specifications chart for details. Image files also must be cropped as close to the actual image as possible.

In the text, each figure must be represented by a number, a title and a description. The authors will indicate where should the figure be placed in the text. All images or figures must come from the author's personal collection or the author must have rights to publish the image or figure. All images must be at or above intended display size, with the following image resolutions: Line Art $800 \mathrm{dpi}$, Combination (Line Art + Halftone) 600 dpi, Halftone 300 dpi. We do not accept images or figures taken from the Internet.

The Tooth Identification System used in manuscripts must conform to the FDI International System. Units used in manuscripts must conform to the Système Internationale d'Unités (SI).

Tables will be included in the text and each table will have a number and a short description if required.

\section{Ownership Rights}

By sending the article for publication the author(s):

- take full responsibility for the scientific content of the text and for the accuracy of the send data;

- become (co)author(s) of the manuscript (all further plagiarism accusation are addressed solely to the author(s) who signed the manuscript);

- declare they are the rightful owners of the images, figures and/or information sent for publishing and that they have the permission to publish all the materials for which they do not own the intellectual property rights;

- declare that the message/content of the manuscript is not influenced in anyway by commercial interests/previous engagements/ any sort of relations with other people or companies;

- transfer all rights for the manuscript to the Editorial Council for the Stomatology Edu Journal.

\section{Other}

Previously mentioned limitations can be ignored in special cases with the agreement of the chief-editor and/or the publisher. All published materials cannot be returned.

Not taking into consideration the recommen-dations mentioned before can lead to delay in publishing the materials or may lead to not publishing the article.

The Stomatology Edu Journal (Stoma Edu J) also helps authors measure the impact of their research through specialist partnerships with Kudos and Altmetric. 


\section{I want to subscribe to tonqeduj}

- 1 year Subscription (4 issues of the journal) - 280 RON (72 Euro for foreign subscribers)

- 2 years Subscription (8 issues of the journal) - 540 RON (136 Euro for foreign subscribers)

- Single Issue - 80 RON (20 Euro for foreign subscribers)

Please send the filled subscription at the following e-mail: roposturo@gmail.com.

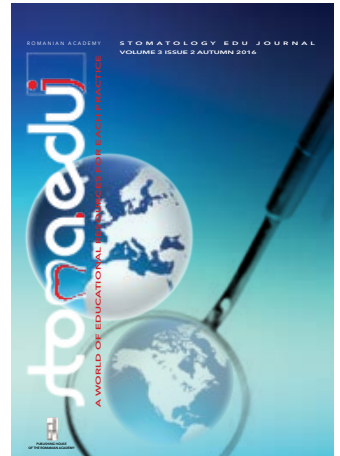

\section{PLEASE COMPLETE ALL THE SUBSCRIPTION FIELDS IN CAPITAL LETTERS!}

Name............................................ Surname

Mrs. $\square$ Mr. $\square$ Ms.

Home Address

City ..................................... Sector....

District.

Post office code.

Mobile phone.

Web

E-mail:

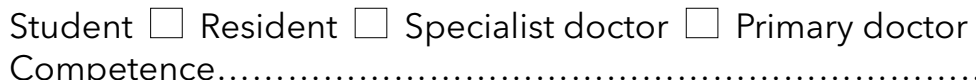

Institution

Activity domain: $\square$ Private $\square$ Public

Department.

Position

Specialty.

Institution address

City ...................................... Sector.

District.

Post office code.

Phone

E-mail:

Web.

CUI (Institution Unique Registration Code)

VAT Payer: $\square$ Yes $\square$ No

Invoice - please fill all the necessary details for invoice:

Name....

CNP (Personal Identification Number).

Or

Institution

CUI (Institution Unique Registration Code)...

Date.

Signature

After filling the subscription, please send it together with the proof of payment to:

\section{ROPOSTURO}

Romanian Association of Oral Rehabilitation and Posturotherapy

10, lonel Perlea St., $1^{\text {st }}$ District, RO-010209 Bucharest, Romania

Tel: +4021314 1062, Fax: +4021312 1357

e-mail: roposturo@gmail.com

www.roposturo.ro 


(BMar?

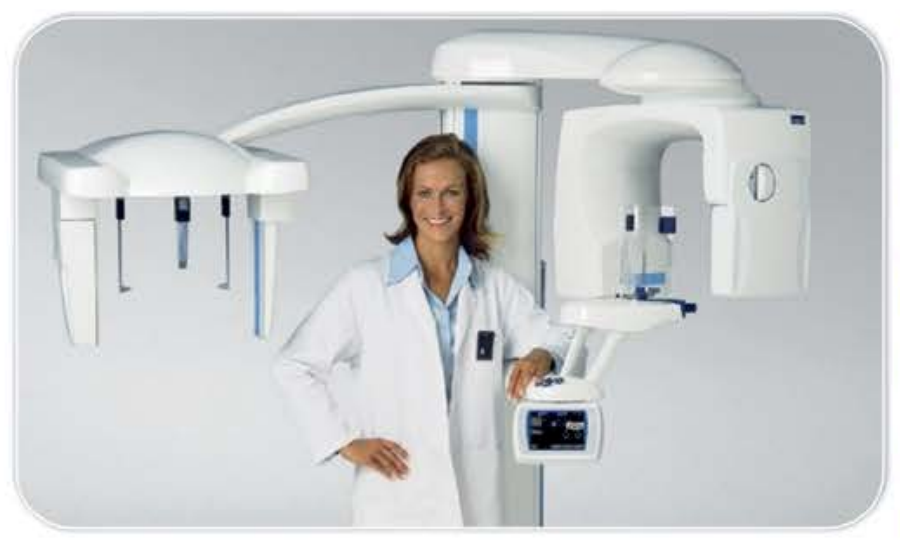

\section{ORTHODONTIC X-RAYS (RADIOGRAPHS)}

Profile (lateral) cephalometric views

Standard OPG (Orthopantomogram) for adults and children (magnification 1.3-1.6)

Orthodontic diagnostic photos

\section{X-RAYS (RADIOGRAPHS) FOR SPECIAL TREATMENTS} Standard OPG (Orthopantomogram) for adults and children (magnification 1.3-1.6)

Ortoradial orthopantogram for adults and

children (magnification 1.3-1.6)

Orthopantogram with reduced for adults and children

Combination for the same patient

(standard OPG +orthoradial+ reduced shadow)

Four-view TMJ-right to left joint

Anterior maxillary sinus panoramic radiographs

Posterior maxillary sinus panoramic radiographs

Salivary gland panoramic radiographs

Prophile (lateral) cephalometric radiographs

Orthodontic diagnostic photos

\section{D CT SCANS}

Full maxilla and mandible CT scan

Maxilla and maxillary sinus CT scan

Mandible and mandible

Mandible and mandibular canal CT scan

Partial maxillary and mandibular CT scan

TMJ CT scan

CT scan of included teeth

\section{MRI -CT}

Ortho-maxillofacial MRI

Ortho-maxillofacial CT

Examination of the throat using a special protocol for: cavum; oropharynx, oral cavity, tongue, soft palate, salivary glands, larynx and hypopharynx is conducted only at 79-91, Traian Popovici Street, $3^{\text {rd }}$ District,

RO-031422 Bucharest, ROMANIA

Tel: 021-323.00.00 | 0731-494.688
The Plevnei Gral Medical Dental Imaging Center provides dental imaging services dedicated to obtaining a quick and correct dental diagnostic in order to plan an adequate and efficient treatement.

Our state-of-the-art equipment provides dentists, implantologists or maxillofacial surgeons with accurate 2D and 3D images of the structures they will work upon, being of real service to the patients, by practically eliminating all major intervention-associated risks, both due to the use of very low radiation doses and the easy and comfortable positioning of the patient.
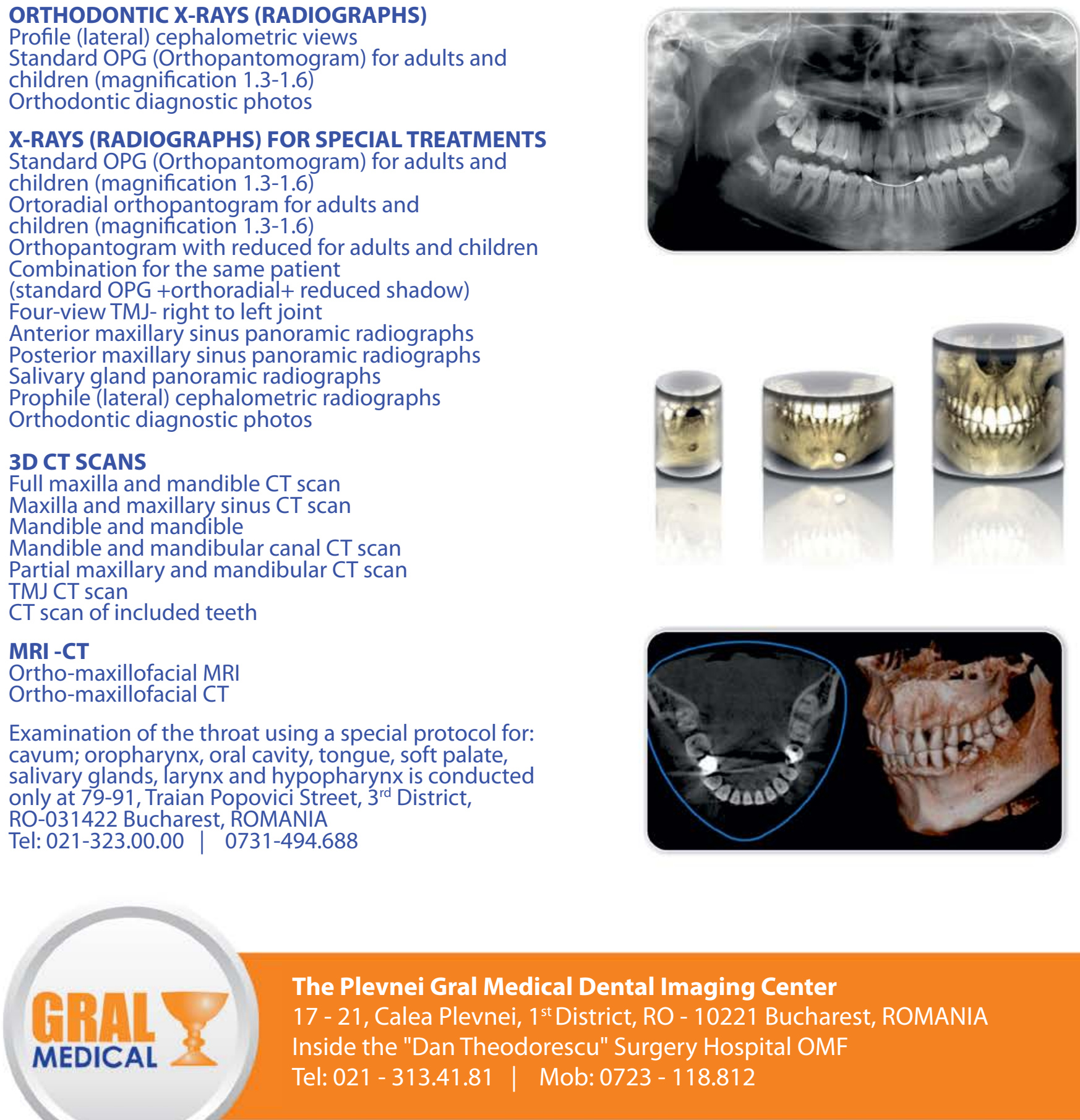


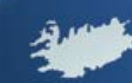

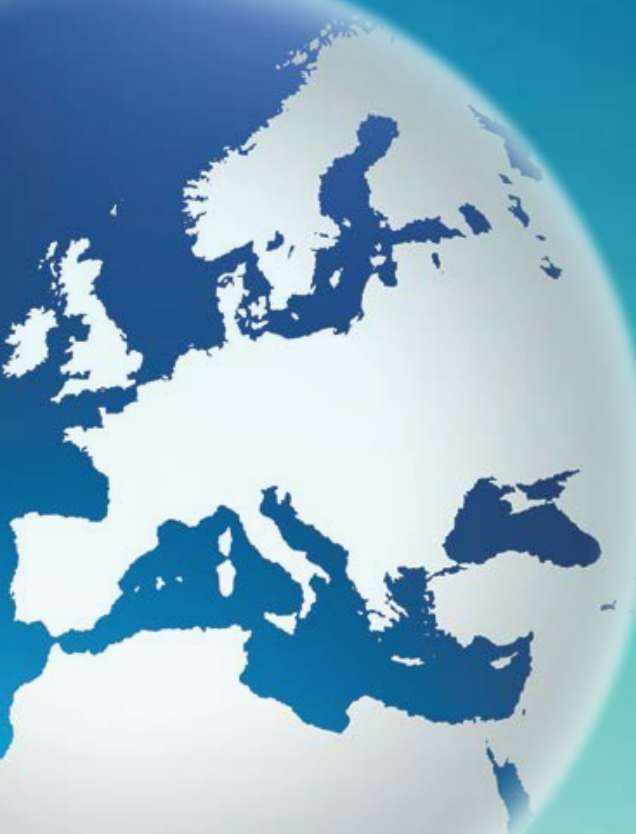

